THE EXPERIENCE OF HAPPINESS: A SOCIOLOGICAL INVESTIGATION 
THE EXPERIENCE OF HAPPINESS:

\section{A SOCIOLOGICAL INVESTIGATION}

By

JAMISS SCOTT KENNEY, B.A. (Hons), LLB.

\section{A Thesis}

Submitted to the school of Graduate Studies in Partial Fulfillment of the Requirements for the Degree

Master of Arts

$$
\text { McMaster University }
$$

(c) Copyright by James Scott Kenney, October 1992 
MASTER OF ARTS (1992)

(Sociology)
MCMASTER UNIVERSITY

Hamilton, Ontario

TITLE: The Experience of Happiness:

A Sociological Investigation

AUTHOR: James Scott Kenney, B.A. (Dalhousie University)

LLB. (Dalhousie University)

SUPERVISOR: Professor Richard A. Brymer

NUMBER OF PAGES: $\mathbf{x}, 220$ 


\section{Abstract:}

The following study attempts to investigate the emotion of happiness from a sociological perspective. By developing an interactional model integrating social definitions of the self, cognitive definitions of emotion and various cultural beliefs, this fundamental emotion is examined in detail.

of central concern in this endeavor is a fourfold typology of perceptual and evaluative beliefs that individuals hold in relation to the self that enable them to both passively experience and consciously manage happiness/ unhappiness. When these beliefs are looked at in light of the self, it becomes apparent that different typical beliefs may be more effective with respect to the different roles occupied by individuals. Moreover, individuals may move between different typical beliefs to adjust to present interactional circumstances.

This theoretical model is then operationalized by qualitatively examining the beliefs that a variety of single individuals exhibit regarding dating and relationships.

The results of this effort demonstrate a new, sociological approach to the study of human happiness, with a variety of research implications for philosophy, the sociology 
of emotion, the structure of the self, and role theory. 


\section{Acknowledgements:}

I would like to thank Professors Richard A. Brymer, Dorothy Pawluch, Charlene Miall, and William Shaffir for their many helpful comments in the preparation of this work.

I would also like to express my gratitude to the many individuals who gave of their time to participate in interviews and so help furnish data for this study. The final product is as much their work as mine.

Finally, I would like to express my profound thanks to my family for understanding and supporting my dream, to Katie for giving me the encouragement to begin it, and to the late Paul Chapman, with whom I spent many of my happiest times. 


\section{Table of Contents:}

Chapter 1: Emotion, Beliefs and the Self:

The Literature Outlined 4

(1) Theories of Emotion 4

(2) Beliefs and Emotion 13

(3) The Self, Identity and Emotion 18

(4) Conclusion 21

Chapter 2: A Model of Happiness 23

(1) General Interactional Model: 24

(a) Introductory Comments 24

(b) Definitions: 25

(i) Emotion 25

(ii) Belief 28

(iii) The Self 30

(iv) Happiness 31

(v) Conclusion 34

(c) Model: 35

(2) Typology of Beliefs: 43

(a) The Transcendental 44

(b) The Egocentric 47

(c) The Empathetic 50

(d) The Crusader 54

(3) Mechanisms of Change: 56

(4) Conclusion: 61

Chapter 3: Methodology and Research Design 63

(1) Rationale: Choice of the Single Role 63

(2) Hypotheses: 68

(a) General Interactional Model 68

(b) Typology 69 
(c) Mechanisms of Change

(3) Methodology 73

(i) Participant Observation $\quad 74$

(ii) Intensive Interviews $\quad 74$

(iii) Sampling $\quad 76$

(iv) Ethical Considerations 78

(v) Limitations $\quad 81$

Chapter 4: Data Analysis and Discussion 82

(1) General Interactional Model: 82

(a) Positive Interactions 82

(b) Negative Interactions 85

(c) Components of Evaluation 87

(i) Perceptual Beliefs 87

(ii) Evaluative Beliefs 92

(iii) Self-Interaction 94

(iv) Identity Maintenance

(v) Significance of Interaction 101

(vi) Social Support 105

(vii) Importance of Interactional 113

(d) Accumulation of Positive and
Negative Interactions

(e) Accumulation Across Roles 127

(2) Typology of Beliefs 135

(a) Transcendental Beliefs About
Happiness in the Single Role

(i) General Characteristics 138

(ii) Cultural Basis 140

(iii) Relationship to Self-Esteem 142

(iv) Management and Motivation 144

(v) Conclusion 146 
(b) Egocentric Beliefs About Happiness and the single Role

(i) General Characteristics

(5) The Downplayer

(c) Crusader Beliefs About Happiness and the Single Role

(i) General Characteristics

(ii) Cultural Basis

(iii) Relationship to Self-Esteem

(iv) Sensual Play/ Flirtation

(d) Empathetic Beliefs About Happiness and the Single Role

(i) General Characteristics

(ii) Cultural Basis

(iii) Relationship to Self-Esteem

(iv) Interactional vs. Relationship Conceptions

(v) Conclusion

(e) Problematic Beliefs

(3) Mechanisms of Change

(a) Disconfirmation

(b) Breakdown of Identity-

Maintenance Strategies

(c) Frequency

(d) Intensity

(e) Significance of Interaction Partner 206

(4) Conclusion 
(1) Summary 212

(2) Research Implications: 214 (a) Topics to Investigate 215

(b) Possible Sources of Data 217

(c) Theoretical Development 218

Notes to Chapter $1 \quad 221$

Notes to Chapter 2

Notes to Chapter $3 \quad 268$

Notes to Chapter $4 \quad 276$

Notes to Chapter 5

Appendix I: Interview Schedule 296

Appendix II: Demographic Profile 300

$\begin{array}{ll}\text { Bibliography } & 302\end{array}$ 


\section{List of Illustrations:}

$\begin{array}{ll}\text { Chart 1: Interactional Model } & 38\end{array}$

Chart 2: Positive vs. Negative Interactions 39

Chart 3: Typology: Beliefs Relating to Happiness 43 
"I think, therefore I am."1

-Descartes

This famous statement, so crucial in the development of modern philosophy, obscures as much as it answers. For in the synthesis, in true Hegelian fashion, can be seen the seeds of quite another problem: "I am what?" It is the response to this latter question that has engaged the attention of philosophers, scientists and everyday individuals for thousands of years. This study attempts to approach the problem in a different way - sociologically. Specifically, it will draw upon philosophy, symbolic interactionist theory and the sociology of emotion in relation to moral beliefs and the concept of self in an effort to explore the fundamental, defining emotion of happiness.

This study will be comprised of five chapters with several subsections apiece. The first chapter will consist of a brief literature review in the following format: subsection one will review various models and theories of emotion. Next, the relevance of socially constructed beliefs to emotion will be discussed. Last, the concept of self, so crucial in symbolic interactionist theory, will be briefly outlined in light of current disputes within the literature. The second chapter will represent a theoretical 
synthesis of much of the literature discussed above. First, definitions of emotion, belief, the self, and of happiness, from a social psychological perspective, will be given and elaborated into a descriptive model based in the interaction process. Second, beliefs about happiness - ancient and modern, philosophical and cultural, but always social - will be arranged into a fourfold typology representing different ways that individuals conceive of and experience the emotion. Lastly, a mechanism for change between types inter se will be postulated.

The third chapter will describe the operationalization of the above model. First, the rationale behind focusing on a particularly significant role - the single life/romantic relationships - will be reviewed in some detail. ${ }^{1}$ secondly,

${ }^{1}$ For a detailed discussion of the rationale behind choice of this role as the focus of research, see the first section of chapter three. There, it will be argued: (i) that studies show married people to be significantly happier than singles; (ii) that our society places overwhelming cultural emphasis on romantic relationships; (iii) this emphasis has grown over time, with uncertainty over increasingly uncertain relationships replacing earlier uncertainty over the natural world; (iv) this is reflected in powerful labelling institutions such as the medical profession and psychoanalysis; ( $v$ ) marital roles shape selves, particularly with reference to personal adequacy; (vi) individuals use personal relationships as a means of coping; and (vii) single individuals may acquire, especially as they age, a deviant "master status" such as "dirty old man." Under such circumstances, since singles, at any level of subcultural organization, likely share the meanings and behaviors outside of this role-identity with the surrounding culture, a researcher need concentrate only on identities central to the subculture itself to examine emotionality within the group. 
three clusters of hypotheses will be postulated, relating to (a) the general interactional model; (b) the presence of rolespecific varieties of the four fundamental types of belief about happiness; and (c) mechanisms of change between these types. Last, the nature and extent of qualitative fieldwork and intensive interviewing will be described, giving special attention to sampling and the limitations of this type of study.

The fourth chapter will discuss the data in relation to the above hypotheses, taking special care to point out instances that contradict their general thrust. In addition, other empirical studies relevant to this endeavor will be discussed at this time.

Finally, and in closing, the conclusions of this preliminary study will be set out with a view to future research.

Moreover, examining the experience of happiness with regard to such an important role/identity will likely go a long way in shedding light on its manifestation in other areas of an individual's life. 


\section{Chapter 1: Emotion, Beliefs and the Self: \\ The Literature outlined}

In this introductory chapter I will review current literature in both the philosophical and sociological treatment of emotions. The first section will review various models and theories of emotion within these disciplines. Next, the significance of socially constructed beliefs to emotionality will be covered. Finally, the concept of self, so crucial to any understanding of emotion, will be briefly outlined in light of current disputes within the literature.

\section{(1) Theories of Emotion:}

Emotion has been a controversial topic over the centuries. Some philosophers, such as Plato, have characterized it as essentially irrational and something to be controlled. ${ }^{2}$ Others, such as David Hume, have felt emotion necessary to any system of ethics. ${ }^{3}$ Yet, aside from this dispute over whether emotion is a good or a bad thing for us, some philosophers have attempted to figure out what emotions are.

Calhoun and solomon ${ }^{4}$ have identified five general types of emotion theories among philosophers:

"Sensation theories (Hume) and physiological theories (Descartes, James) both stress the actual "feel" of an emotion, although they disagree over whether it is primarily a psychological feeling (e.g. of being 
overwhelmed) or a feeling of actual physiological changes (e.g. the feeling of one's stomach churning, in disgust). In behavioral theories, as the name suggests, special attention is paid to the distinctive behaviors associated with different emotions. Emotions are analyzed either as the cause of such behaviors (Darwin) or as actually consisting solely or primarily of patterns of behavior (Dewey, Ryle). Evaluative theories (Brentano, Scheler) compare pro- and con- emotional attitudes (liking, disliking, loving, hating, etc.) and positive and negative value judgments. In this sort of analysis, the "object" of the emotion is important. Finally, cognitive theories, which cover a wide spectrum of particular theories, focus on the connection between emotions and our beliefs about the world, ourselves and others." 5 (emphasis added).

Because of the reductionistic tendency inherent in the first three categories, their extensive use of causal analysis, and their downplaying of cognition, belief, and the social self, ${ }^{6}$ these are problematic standing on their own. Therefore, it is the evaluative and cognitive theories that will be most prominently featured in this study. These theories envisage the actor's rational judgments about the world - past, present and future - coloring his/her experience of emotion: judgments that may be unfounded but that affect behavior and experience all the same. ${ }^{7}$

While not strictly sociological, such theories nonetheless leave open the door to the possibility of socialization and social interaction affecting the beliefs coloring one's emotions, while not logically precluding certain insights found in the other theories sketched above. Due to this compatibility, they are the most suited to the 
purpose at hand.

Among sociologists, there has been an explosion of interest in emotion in recent years. For the sake of brevity, I shall discuss these theorists under four broad headings.8

The first group will be termed "emotion management theorists." This is due to the fact that each of the three theorists follow the same "interactional" model of emotion suggested by Arlie Russell Hochschild, ${ }^{9}$ and agree, as well, upon the significance of emotion management in human social Iife. Hochschild states:

"I would define emotion as an awareness of four elements that we usually experience at the same time: (a) appraisals of a situation, (b) changes in bodily sensations, (c) the free or inhibited display of expressive gestures, and (d) a cultural label applied to specific constellations of the first three elements... Emotion functions like a sense. Indeed, it is a sense, and our most precious one... Like (the) other senses, emotion communicates information to the self." 10 (emphasis added).

As for management, Hochschild points to the importance of "feeling rules," culturally or situationally based norms whereby emotions are both shaped and managed. ${ }^{11}$ (e.g. one will feel sad and one is supposed to feel sad at a funeral). Where these two factors don't line up, however, we utilize, according to Hochschild, two management techniques to deal with our discordant emotions: "surface acting" and "deep acting."12 Essentially, the former involves changing our expression from the "outside in" so that we can change our 
feeling; the latter involves attempts at self-deception from the "inside out" in order to change our emotion. ${ }^{13}$

Other theorists in this group, following Hochschild, have elaborated the varieties of emotion management techniques. Peggy Thoits, ${ }^{14}$ much like Hochschild, defines emotion as a "subjective experience" made up of four interrelated components: (a) situational cues, (b) physiological changes, (c) expressive gestures and (d) an emotion label that serves to identify this specific configuration of components. ${ }^{15}$

Thoits, in her work on "emotional deviance," argues that a change in any of these four components can alter a subject's emotional experience. In addition, she argues that there are two principal modes that individuals can use to manage such changes in line with normative requirements: behavioral and cognitive. ${ }^{16}$ These may be taken to approximate Hochschild's "surface acting" and "deep acting" respectively. By crossing the four components with these two techniques, Thoits arrives at an eightfold and more elaborate classification of emotion management techniques than does Hochschild. Moreover, upon conducting a study of how students handled negative emotional experiences, she found, additionally, that:

"The ten most frequently mentioned techniques in handling a negative emotional experience were (in decreasing order of frequency): catharsis, taking direct 
action, seeking support, hiding feelings, seeing the situation differently, leaving the situation, thinking the situation through, thought stopping, distraction, and acceptance." 17

The last theorist in this category is Candace Clark. ${ }^{18}$ While following the four factor model of emotion, ${ }^{19}$ Clark further emphasizes that it is bound up with one's "sense of place" - an idea intricately related to self-concept. ${ }^{20}$ In her model, when self-concept and one's sense of place arising from an interaction coincide, positive emotions result; when they diverge, the opposite is the case. ${ }^{21}$ (e.g. The difference in emotional outcome following one's boss' compliment for "work well done," as opposed to that following his/her disapproval of one's performance).

The reason Clark has been included among emotion management theorists is her emphasis on human creativity, especially the manipulative potential in each individual to use emotions as interactional "place claims" to shape definitions of situations and self.22 Clark asserts that individuals can use their own emotions in a variety of "micropolitical strategies" to enhance place, and thereby manage their own emotions. ${ }^{23}$

Moving on to the second group of theorists, here one finds sociologists who attempt to forge an explicit link between social structure and individual emotionality. Randall Collins, ${ }^{24}$ for example, has developed a macro-linked theory 
based on Durkheimian solidarity and moral commitment at the micro level. His thesis is that in "interaction rituals," 25 "power rituals," 26 and "status rituals"27 individual cognitions become charged up with "emotional energy" through "emotional contagion," and common emotions are the result. ${ }^{28}$ Further, he contends that, over time and space, individual participation in these three types of rituals form "interaction ritual chains" in which individual emotional energy accumulates or decreases. ${ }^{29}$

A second theorist in this vein is Michael Hammond, ${ }^{30}$ who explores stratification systems and emotion from a micro perspective. He states that all individuals have an inbuilt need for long-term, positive emotional arousal. ${ }^{31}$ Yet, since humans exhibit the dual traits of "instinctual impoverishment" and "extensive cognitive capacity," he argues that, to gratify this need:

".. individuals will try to shape their worlds, consciously or unconsciously, to evoke a strong pattern of such arousal. "32

The key argument in Hammond's theory is that large scale social and idea structures are largely shaped by this need for "affective maximization." 33

The next major attempt at making the micro-macro Iink $J_{\text {is }}$ that of steven $L$. Gordon. ${ }^{34}$ He suggests that social structure is most influential on behavioral and motivational aspects of emotion; culture having more effect on the quality, 
intensity, object and setting thereof.35 At the micro level, he feels the central factor to be a person's definition of the situation, ${ }^{36}$ which he links in an "open system" to cultural definitions of human relationships, ${ }^{37}$ cumulative properties of given relationships, and a physiological substrate. ${ }^{38}$ overall, he stresses three interactional processes in which social structure effects individual emotional experience and behavior: differentiation, ${ }^{39}$ socialization ${ }^{40}$ and management. ${ }^{41}$ The last major theorist in this group is Thomas $\mathrm{J}$. Scheff..$^{42}$ He states that "society rests upon a foundation of pride and shame."43 Essentially, scheff argues that individuals are always unconsciously monitoring their levels of self esteem and their assessment of self in relation to others: ${ }^{44}$ pride and shame - be it "overt" or "bypassed" - being the chief factors therein. ${ }^{45}$ These steer individuals along a socially prescribed path, and:

"..cumulating this effect across the whole society provides a micro basis for a macro effect, namely, the general pattern of conformity that prevails in society. Social order is thus constructed by aggregating the total of individual cases of experience of pride and shame." 46

The third group of theorists to be discussed are those with a particularly positivist orientation. Exemplary of this group is Theodore D. Kemper. ${ }^{47}$ He argues that:

"There is evidence for a heuristic surmise about an important degree of integration between the social (expressed in power and status relations), the psychological (expressed in terms of specific emotions that are instigated in power and status relations...), 
and the neurophysiological and autonomic structures and processes that accompany emotions." 48

For Kemper, power and status interactions directly produce emotions, and emotional outcomes can be predicted on these dimensions. ${ }^{49}$ While he feels that culture and interpretation play a role, these can be ultimately reduced to the two above structural dimensions. ${ }^{50}$ Finally, Kemper asserts this theory to be valid, biologically, across all social and demographic groups. ${ }^{51}$

Another positivist variant can be found in the "affect control theory" of Lynn Smith-Lovin. ${ }^{52}$ Assuming that individuals perceive and create events to maintain the meanings evoked by their definition of the situation and their chosen identities, ${ }^{53}$ she then identifies three dimensions whereby we label self, others, and the meaning of social actions: "how good, how powerful and how lively such people and behaviors are." ${ }^{54}$ These dimensions are quantified in an "EPA profile" and run through "impression change equations" on a computer to predict the emotional outcome of interactions. ${ }^{55}$ Basically, this model states that interactional maintenance of positive identities in the types of roles a person usually occupies creates positive emotions, while maintenance of negative identities does the opposite. ${ }^{56}$

Moving now to the last group, which I shall term phenomenological theorists. ${ }^{57}$ Norman $K$. Denzin is the best 
example of such thinkers.s8 He defines emotion as "self feeling,"59 and has elaborated a descriptive, experiential model in which significant emotional symbols are mediated by two ongoing processes: the "phenomenological stream" (i.e. internal conversations) and the "interactional stream."60

Denzin views the body as the "point of reference" for our emotional experiences, ${ }^{61}$ and divides emotions in relation to the "lived body" into bodily sensations, the sense of the self experiencing the emotion, and the inner moral meaning of the emotion for the self. Translating all of this into processual terms, Denzin identifies four types of nlived emotion:"

(i) "Sensible feelings." (e.g. physical pain).62

(ii) "Feelings of the lived body" (e.g. anger, despair). ${ }^{63}$

(iii)"Intentional value feelings." (i.e. "feelings about feelings").64

(iv) "Feelings of the self and the moral person."

(i.e. one's moral identity). ${ }^{65}$

This exhausts the review of models of emotion per se. It is clear that any theory of emotion to be presented here must take into account both the philosophical and sociological insights presented above. Leaving aside the more problematic, and ultimately incorporated insights of philosophers from the physiological, sensation, and behavioral traditions, ${ }^{66}$ it may be asserted that the logical elements of the evaluative and cognitive theories outlined above have some merit. In tandem with these, however, the diverse and largely compatible 
elements of the four categories of sociological theory must be addressed. This is to say that there must be a place for emotion management, social structural effect, empirical illustration, and phenomenological experience in any subsequent theory. At the very least, any theory that seeks to do justice to this complex topic cannot deny their contribution.

\section{(2) Beliefs and Emotion:}

"If emotion is a joke, it is a joke that we

- Jean Paul Sartre

Sartre's evaluative comment graphically drives home the idea that beliefs play a major role in human emotion. Recent empirical studies have demonstrated the same in relation to individual happiness. ${ }^{68}$ Following these leads, this section will briefly review major philosophical and sociological theorists on this important topic. There will subsequently be a short discussion of the various dimensions of belief as relevant to emotion.

Among philosophers in the evaluative and cognitive traditions, beliefs are fundamental to emotionality. ${ }^{69}$ Among the former, positive and negative value judgments or beliefs are intricately related to individual emotionality. ${ }^{70}$ Central to this outlook is the idea that emotions are "intentionally" felt:

". of , about, or toward things in the world, they 
are not just brute "feels," like a twinge or pang; they are a way of being conscious or aware of the world. "71 (emphasis added).

As for the latter, cognitive theories go on to draw a logical or causal connection between emotions and evaluative beliefs, ${ }^{72}$ put more emphasis on thought as opposed to perception, and point to the rationality of emotions given certain beliefs. Robert solomon states:

"I must be in appropriate circumstances to pass judgement, have some evidence, know something of what the judgement is about. of course, one can make judgments rashly, with minimal evidence and with superficial knowledge of what the judgement is about. Emotions, we can now see, are rash judgments, something $I$ do, but in haste. Accordingly, the evidence upon which I become emotional is typically (but not necessarily) incomplete, and my knowledge of what I am emotional about is often (but again not necessarily) superficial. "73

Turning to sociologists, ${ }^{74}$ many of the authors in the last section incorporate beliefs, explicitly or implicitly, into their theories of emotion. For example, beliefs are important to cognitively "shaping the world" in Hammond's affective maximization model; ${ }^{75}$ the cognitive component of Collins" "emotional energy;"76 Denzin's "intentional value feelings" and "feelings of the moral person;" Hochschild's "feeling rules;"78 Gordon's "cultural definition;"79 Thoits" concept of disconfirming events; "18 and Smith-Lovin's theory of actors constructing events to confirm fundamental sentiments. ${ }^{81}$ It is further implied in scheff's model of continual self-evaluation ${ }^{82}$ and Clark's notion of self-esteem, 
place-claims and emotional micropolitics.83 Indeed, even Kemper does not rule out cultural beliefs entirely. ${ }^{84}$

From the above it would seem that beliefs are a central component to human emotional experience. ${ }^{85}$ Indeed, how can one assess one's self, place, status, self-concept, identity or moral person without reference to some form of criteria?

Yet, there has been one nagging problem with theories using belief as the basis of emotion: one can experience emotions that stand in direct contrast to one's intellectually held beliefs. Philosophers and sociologists have responded to this by noting that, without training to perceive the world in a particular way, all is confusion. ${ }^{86}$ This is perhaps best put by Calhoun, who writes:

". our cognitive life involves more than clear, fully conceptualized, articulated beliefs. Interpretive "seeings as.." and their background cognitive sets constitute a large portion of our cognitive life." 87 (emphasis added).

In other words, individuals may be socialized to involuntarily perceive events in a certain way that they may not be consciously aware of doing. ${ }^{88}$ Thus Smith-Lovin's comment that:

"..Those who hold the sentiments associated with a dominant ideology and culture experience the proper emotions without regard to feeling rules or norms." 89

This subtle point leads to the conclusion that beliefs are much more complex than previously thought, composed of 
both perceptual and evaluative dimensions, only one of which is necessarily conscious to the individual.

Given this division, it is now appropriate to discuss two further dimensions of belief that become relevant when applied to emotion: disconfirmability and extent.

The former refers to whether or not a particular belief or system of beliefs has an internal logical structure that enables it to be contradicted in an actor's perceptual experience, or whether, on the other hand, it is so constructed to protect:

". the world view as a whole from "facts," or better ways of looking at facts, which would disturb it. ${ }^{90}$

This idea is not a new one. It is implied in W.I. Thomas' concept of the "crisis;"91 Festinger, Riecken and Schachter's work on cognitive dissonance; ${ }^{22}$ Berger and Luckmann's concept of "routine vs. crisis maintenance;"93 and Garfinkel's ethnomethodological "breaching experiments."94 It is also suggested by recent theorists in the sociology of emotion such as Thoits ${ }^{95}$ and Smith-Lovin. ${ }^{96}$

The latter dimension - extent - refers to the degree of social support, commitment and determinativeness of beliefs in a given society. Interpreting Durkheim, ${ }^{97}$ it can be argued that in the traditional societies idealized in his structural concept of "mechanical solidarity," the simple division of labour, high social cohesion and relative similarity between 
individuals is reflected in belief. The degree to which similar beliefs are diffused throughout the population is high, as is commitment. The collective authority of these beliefs is close to absolute, often due to their highly religious and moral nature. Moreover, not only are they frequently impossible to disconfirm in experience, the high social support makes them powerful adjuncts to perception, and hence emotion.

However, in societies structurally approaching Durkheim's "organic solidarity," the situation differs regarding extent. In these "modern industrial societies" where social organization is premised on an extensive division of labour and the interdependence of dissimilar individuals and groups, the degree to which similar beliefs are general throughout the population is lower, as is overall commitment. There are usually more diverse ideologies and systems of belief floating around, thereby making the collective social influence of any one outlook on perception and emotion weaker compared to those in more traditional societies. Disconfirmability, both logical and social, is therefore much more likely in these settings. ${ }^{98}$

Keeping these four dimensions of perception, evaluation, disconfirmability, and extent in mind, as well as the general importance of belief to emotion, one must now turn to the final "building block" of the model: the concepts of 
self and identity.

\section{(3) The Self, Identity and Emotion:}

"Properly speaking, a man has as many social selves as there are individuals who recognize him and carry an image of him in their mind. To wound any one of these images of his, is to wound him. But as the individuals who carry the images fall naturally into classes, we may practically say that he has as many different social selves as there are distinct groups of persons about whose opinion he cares. " 99

-William James

This classic statement foreshadows the most influential theory of the self in sociology today - that of George Herbert Mead. Mead, like James, pointed to ongoing social and psychological processes in the development of the mind - particularly individuals' ability to turn experiences back on themselves: reflexiveness. ${ }^{100}$ In this process, perception mediates the person's relationship between him/herself and the social environment. ${ }^{101}$ Interacting through significant symbols, the developing individual takes on the:

". generalized attitude of a member of the group to which the self belongs, a group that widens until it takes in all rational individuals."102

Mead divided the self into two ongoing processes: the "I" and the "me," which interact during a partial, continual reconstruction of the social world, to generate a new "self" to meet each situation. ${ }^{103}$

Unfortunately, confusion has arisen over the "I," and two traditional interpretations have been made. Herbert Blumer viewed it as the impulsive, undifferentiated component of the 
self; ${ }^{104}$ while M.H. Kuhn fails to recognize either impulses or the I/me structure, in favor of a socially deterministic, "me" dominated self. ${ }^{105}$ Luckily, J. David Lewis has developed a third, "social behaviorist" interpretation,"106 whereby the "me" is seen as the social attitude, and the "I" the response to an internal conversation between both components of self in reasoning out future actions. ${ }^{107}$ Thus, when action is taken, by the "I," the observable activity is considered by both components of self and the other in interaction - leading to the formation of the next "me."108 Thus the "I" presupposes the "me," and allows conscious, rational control of the responses of self and other. ${ }^{109}$

In sum, this interpretation permits a degree of rational, individual creativity of self within a social context. Such a common sense viewpoint has long been reflected in diverse works such as Goffman's Presentation of self in Everyday Life, ${ }^{110}$ Scott and Lyman's Accounts, ${ }^{111}$ Hewitt and Stokes' Disclaimers, ${ }^{112}$ and, more recently, in Clark's work on emotional micropolitics, 113 to name but a few. It is the position adopted here as well.

Yet, in addition to this somewhat "lateral" view of the self must be considered the more "vertical" dimension of identity. Identity theory, ${ }^{114}$ which develops symbolic interactionism's affinities to role theory, states that:

"...identities are internalized role designations 
carrying the shared meanings and behavioral expectations associated with roles and group memberships; self is a hierarchical ordering of identities, organized into a structure of salience. The salience of identities is a consequence of commitment, ties to networks of social relationships. Choices among behavioral options are presumed to be consequences of the location of identities in the salience hierarchy, connecting cognition and conation." 115 (emphasis added).

Thus, the self may be viewed as a combination of various creative I/me components, organized in a hierarchy of various internalized role designations, ${ }^{116}$ based on commitment to various interactional relationships in the social structural network.

Finally, a third dimension must be added to complete the model of the self to be utilized here: morality. Denzin, asserting the self to be "consciousness conscious of itself,"117 states that in this process:

"The self entails inner moral feelings the person directs toward herself as a moral object in her own world and in the world of others. Feelings of the self cluster around these moral feelings, for the subject reveals herself through the feelings of these feelings." 118 (emphasis added).

It is this evaluative component of the self at the deep level ${ }^{119}$ that, according to Denzin, contains such things as dignity, self-respect, and an inner sense of moral worth. ${ }^{120}$ This, of course, relates back to beliefs, both socialized and emergent, that tell individuals who and what they are. Other emotion theorists have implied this dimension as well.121 
In conclusion, therefore, theorists present the self as a complex subject which may be analytically divided into three interlocking dimensions: (a) the "lateral" dimension of the "I" and the "me," with a recent emphasis on the creative "I"; (b) the "vertical" dimension of internalized and hierarchically arranged role-identities; and (c) the all pervasive evaluative dimension of morality which, of course, ties back into the socially-constructed beliefs of the individual in question.

\section{(4) Conclusion:}

This chapter has reviewed both philosophical and sociological theorists in relation to the complex subject of human emotion. It asserts, first of all, that evaluative and cognitive theories from the philosophical tradition must be integrated with current sociological theories, and that any adequate theory of emotion must not contradict prior theoretical and empirical insights regarding emotion management, social structural effects, empirical investigation, and phenomenological experience.

Secondly, it stresses the vital significance of perceptual and evaluative beliefs to emotion, and elaborates the additional analytic dimensions of "disconfirmability" and "extent," making four in all.

Finally; it has reviewed the theoretical work on the self, concluding that the individual self is extended along 
three dimensions: the "lateral" referring to particular creative "I/me" dyads; the "vertical" relating to hierarchically arranged internalized role identities; and the all-pervasive moral evaluation of self that permeates the others.

Reeping all of these matterg in mind, I now turn to consider the model itself. 


\section{Chapter 2: A Model of Happiness}

In this chapter the diverse factors reviewed in the previous chapter will be synthesized into a general theoretical system for understanding and interpreting the fundamental, defining human emotion of happiness, which, after all, subsumes, and is implicit, in varying degrees, in other emotional states. ${ }^{1}$

This system will be outlined in the following manner. First, following some general comments relating to previous philosophical treatments of the subject, explicit definitions of emotion, belief, the self and happiness will be made. These will then be traced through a simple model interaction, comprising, together, what will be termed the "general interactional model." Secondly, and within this broader framework, four general types of perceptual and evaluative belief relevant to the experience and management of happiness will be described in some detail. Finally, adaptive mechanisms of change between these typical beliefs will be outlined, with particular emphasis on interactional disconfirmation. Throughout, prior empirical studies will be cited in relation to this model, out of which will later be drawn the hypotheses to be outlined in chapter three and investigated in chapter four. 


\section{(1) General Interactional Model:}

\section{(a) Introductory Comments:}

"If happiness is activity in accordance with virtue, it is reasonable that it should be in accordance with the highest virtue; and this will be that of the best thing in us. Whether it be reason or something else that is this element which is thought to be our natural ruler and guide and to take thought of things noble and divine..., the activity of this in accordance with its proper virtue will be perfect happiness. That this activity is contemplative we have already said." ${ }^{2}$

- Aristotle

These words of Aristotle are perhaps the best known definition of happiness passed down over the centuries by philosophers. They are also the jumping off point for many modern philosophical treatments of the subject, still generating controversy and respect. ${ }^{3}$ By defining happiness in this way, but by also adding that it requires health, sufficient material means, a moderate degree of pleasure and the absence of great misfortunes, ${ }^{4}$ Aristotle not only devised a well balanced theory incorporating diverse elements; ${ }^{5}$ he also opened the way - too often neglected - to the processual interpretation of happiness flowing from some of the literature discussed in the previous chapter.

secondly, by including the term "virtue" in his definition, Aristotle points the way to moral belief as a component of happiness, since what virtue is has to be defined 
somewhere. ${ }^{6}$

Finally, Aristotle's comment, "whether it be reason or something else.." that "takes thought of things noble and divine.." tantalizingly points to the possibility that reason is not the only mental activity involved - in thought, emotion and happiness itself. ${ }^{7}$

The theory of happiness to be set forth herein does not claim to be exhaustive; $\underline{\text { i.e. }}$ while it rarely refers to factors such as health, material means, pleasure or "good fortune," these are nevertheless considered to be important concomitants thereof. ${ }^{8}$ Indeed, listings of similar conditions have been noted in Telfer, ${ }^{9}$ and Russell's ${ }^{10}$ treatment of the subject as well. Rather, this theory largely concerns those in a given society who experience the above conditions - even on a minimal level - and builds from there. Of course, those who do not experience these conditions are considered likely to have, at the very least, a much more difficult time in their attainment of the summum bonnum. ${ }^{11}$

\section{(b) Definitions}

I will begin with some definitions suggested by the literature in the preceding sections:

(i) Emotion:

In the following sections an emotion is defined as a perceptual judgement in relation to one's previously 
internalized moral and interpretive beliefs, one's selfidentity as a moral object occupying particular role(s), and the social context of the present interaction, which may be accompanied by pronounced physiological sensations in the subject. Defined in this way, emotionality is deemed to be a rational, active, self-reflective process based on the assumed truth or veracity not only of one's cognitively-shaped perceptions, but also of one's moral beliefs in social interaction.

It is the contention here that emotions are logically and rationally related to one's ongoing assessment of self in light of one's perceptions, i.e. definition of the situation, ${ }^{12}$ as well as one's moral beliefs. ${ }^{13}$ For example, if a woman in her self-perceived roles as mother and grocery shopper considers herself to be a morally sacrosanct individual who "respects private property," but is mistakenly apprehended as a shoplifter, then her perceptions in interaction challenge her past moral sense of self, and extreme emotion is the result. ${ }^{14}$

A number of things must be noted about this definition. First, credit must go where credit is due. This definition is clearly a combination of the evaluativecognitive theories of emotion discussed in the previous chapter. It incorporates Denzin's "feelings of the self and the moral person, "symbolic interaction's emphasis on the self 
and socially constructed reality, and the role-based hierarchy found in identity theory.

Second, this definition departs slightly from Hochschild, who defined emotion as a biologically given sense. ${ }^{15}$ This was done because it is here contended that emotion cannot be an independent sense as it must operate through the intervening medium of the five recognized senses in order to communicate information to the self. As such, if indeed a sense, emotion is at best a dependent one. This is not to say that Hochschild's work is in any way unworthy. Her concept that emotion carries information to the self - thereby "functioning like" a sense - is valid and central to this and much other work as well. It is here desired merely to avoid an unfortunate and misleading choice of words.

Third, the dyadic term "perceptual judgement" was chosen to emphasize the two ways that beliefs enter the emotional process. The first way, perceptually, relates back to the work of Thomas Kuhn, among others, and refers to the idea that one cannot see something as something unless one has been taught to perceive it in a certain way. For example, to a Roman, a cross is an instrument of execution, signifying death; to a Christian, it is a symbol of eternal life. In other words, one's beliefs colour one's perceptions of reality. The second point of entry for beliefs in the emotional process is morality: beliefs colour one's evaluative 
judgments - both of oneself and others. Of course, if one has no code of moral beliefs upon which to base one's evaluations, no sense of the generalized other; one will have difficulty logically passing judgement, and, correspondingly, difficulty in feeling specific emotions as such. ${ }^{16}$

Finally, this definition recognizes that emotions are experienced in relation to the "lived body," and as such may be, but are not necessarily accompanied by pronounced physiological sensations. ${ }^{17}$

\section{(ii)Belief}

Belief is here defined as that ongoing, symbolic combination of previously internalized, involuntary systems of perception, conscious rules of moral evaluation and those meanings generated by the present social interaction and structural setting. Several things must be noted here as well.

First, this definition obviously owes a great deal to George Herbert Mead's theory of the past. Mead, it will be remembered, defined reality in terms of an emergent present, the "seat of reality," in which the past and future are an integral component. ${ }^{18}$ Neither has any independent reality except insofar as it relates to the present. There are as many pasts as there are emergent presents; i.e., not only is the past redefined in terms of the present; the present and hypothesized future is structured, perceived and created in 
terms of past beliefs and experiences. This is both perceptual and evaluative, as noted above. Thus Mead's comment:

"The world that comes to us from the past processes and controls us. We process and control the world that we discover and invent...This is the world of the moral order." 19

Secondly, it follows that beliefs, in this model, are held to be cumulative - continually in a state of flux in relation to the self. This is in line with a long tradition of symbolic interactionist thought. Meltzer, Petras and Reynolds write:

"All of the early interactionists insisted that human behavior is accumulative and does not occur in isolated bits and pieces with no reference to the past or future happenings of our lives. It is cumulative and constructive; i.e. our acts, responses and perceptions are continually built upon those that are present in our social repertory at any one time. ${ }^{20}$ (emphasis added).

Moreover, recent theorists in the sociology of emotion such as Collins, ${ }^{21}$ Gordon, ${ }^{22}$ and $\mathrm{Clark}^{23}$, to name but a few, also point to the accumulative nature of beliefs in emotion.

Third, our beliefs are culturally derived through socialization, differentiation and the cumulative residue of various interactions up to the present. This can be seen in diverse authors in the sociology of emotion such as Hochschild ("feeling rules"; "gender ideologies");" Kemper ("cultural shaping of cognitive components"); ${ }^{25}$ Gordon ("emotional culture") $i^{26}$ Scheff ("socialization of emotions") $i^{27}$ and Denzin ("ideological state apparati") 
Fourth, the various dimensions of different systems of belief must be kept in mind. Central here are the factors of disconfirmability and extent of social support available for the maintenance of belief in a given type of social structure. Finally, this definition allows for the troublesome situation where a person's conscious, educated moral evaluation (e.g."there is nothing morally wrong or unnatural about homosexuality") conflicts with an involuntary perception of revulsion at a friend's "coming out" based on one's deeper, socially instilled "cognitive set."

\section{(iii)The Self}

The self will be defined as a combination of various creative I/me components or role-sets, organized in a hierarchy of various internalized role designations, that is related to commitment to various interactional relationships, beliefs, and values in the social structural network.

This definition obviously owes much to Mead's concept of the "I" and the "me" as interpreted by Lewis, those theorists such as Denzin who point to the self containing a moral element, and the hierarchical arrangement of identities in relation to social structure posited by identity theory. ${ }^{29}$ It is also fully compatible with the idea of active emotion management as proposed by various theorists. ${ }^{30}$ As such, all of the dimensions discussed in chapter one - the lateral, 
vertical, and moral - are represented here.

Also implicit in this definition is the idea that, by virtue of being sentient, reflexive beings with the ability to view ourselves as objects, humans are motivated to protect and enhance this self concept. ${ }^{31}$

\section{(iv) Happiness}

I will begin by noting that a number of authors in the sociology of emotion have either alluded to or made passing reference to the emotion of happiness, but haven't followed up on them. For example, Kemper identifies happiness with status enhancement, ${ }^{32}$ Collins relates it to high emotional energy, ${ }^{33}$ Denzin notes its relation to cultural ideology, ${ }^{34}$ Smith-Lovin to identity confirmation, ${ }^{35}$ and Clark notes that positive emotions occur when objective and subjective sense of place are aligned. ${ }^{36}$ These authors' suggestions, in concert with all of the above, have prompted the following tentative definition of happiness:

"That emotion that perceptually evaluates an individual's overall self past, present, and future, positively in relation to (a) his/her internalized moral beliefs; (b) the accumulation of past actions and interactions; and (c) current definitions of the situation, that (d) has not been disconfirmed in the present." 17 
short-term happiness, i.e. being "happy about" the result of an interaction, such as winning an important game, and longerterm, cumulative assessment of one's life from a moral perspective (e.g. as a "success"). ${ }^{38}$ One may have many of the former, but these do not necessarily add up to the latter (e.g. should one have a "deep dark secret" or "skeleton in the closet" that one keeps from others).

Similarly, by referring to one's "overall" self (and incorporating the above definition thereof) this definition recognizes the situation where there is long or short term happiness in one or several roles or areas of one's life, but not in others.

Taken together, this means that this definition incorporates at least three interrelated senses of what it means to be "happy": (i) short-term happiness in one role as a result of a positive interaction in relation thereto; (ii) long-term happiness in one role due to an accumulation of positive interactions in relation thereto; and (iii) varying degrees of (i) and (ii) across all of one's significant roles. It is thus only when there is some degree of happiness (i.e. perceived positive moral evaluation of self) in all of one's significant roles that it can be said that one's happiness is complete. ${ }^{39}$

Third, given that the earlier definition of emotion (which is also incorporated by reference) states that emotion 
may be accompanied by pronounced physiological responses, it is here to be noted that these are more likely to be prominent in the "short-term" happiness above described as opposed to the longer-term moral evaluations of self.

Fourth, as can be seen, this definition takes Denzin's feelings of the self and the moral person one step further and asserts that when, as the result of activity and interaction, these are positive in nature (and most likely when, it must be reiterated, the concomitant conditions stated by Aristotle are experienced); the individual feels happy. Of course, ultimate unhappiness, under this definition, will be the converse - the result of accumulated negative, unclear, or conflicting moral evaluations in all of the senses stated above.

Finally, it could be argued that this definition does not depart radically from those of Aristotle ("activity in accordance with virtue"), Robin Barrow, ("seeing the world as one would like it to be"), ${ }^{40}$ or Elizabeth Telfer ("a state of being pleased with one's life as a whole"). ${ }^{41}$

For example, since emotion and happiness are here defined in the active mental sense (and since individual "I" activity and social interaction are requirements for reflection in any sense), they clearly meet the species component of Aristotle's definition - and the differentia (virtue) is intricately linked with beliefs.

Similarly, with Barrow, there is reference to the 
individual's relationship to his/her environment. This presumably includes one's social environment and relative sense of self. ${ }^{42}$ As for the favourable attitude towards one's relationship to one's circumstances, this again brings in the necessity of perceptual and evaluative beliefs. ${ }^{43}$

As for Telfer, she defines happiness as "a state of being pleased," which she later clarifies as an "attitude of mind." ${ }^{44}$ Now clearly, an attitude is not static; i.e., it involves consideration, cognition and repetition over a period of time. If others are involved, as they inevitably are, add interaction to this. In short, an attitude requires mental activity, as does determining (or feeling) pleased. As for Telfer's latter component, "with one's life as a whole," it can be seen to parallel neatly the model presented here, including, it might be noted, the above observations as to concomitant conditions. ${ }^{45}$

\section{(v) Conclusion:}

This completes the definitions section of the model. As can be seen from the discussions of each, these definitions are not only based in much previous philosophical and sociological study, they are complexly interrelated in an overall theoretical system (i.e. the definition of emotion incorporates the definitions of belief and of self, while the definition of happiness involves a totalizing of all elements of the more interaction-focused definition of emotion). Due to 
the ultimate complexity of this model, it will be useful to illustrate its operation by an examination of the experience of happiness in the interaction process itself. It is to this task that I now turn.

\section{(c) Model}

The best way to illustrate the descriptive model of emotion presented here is through a simple model interaction. Let's take the example of Allison, an eager junior advertising executive with a strong desire to "move up the corporate ladder." Allison sees herself as an "up and comer" and dreams of the day when she will be sitting in the boss' office making deals and giving orders. One day, after working overtime long into the previous night on a marketing strategy to be presented to a potential client at "today's crucial board meeting", Allison's boss, Natalia, comes up to her, and, after discussing some details, tells her that her work was "brilliant." As it turns out Allison's work not only won the account, but also convinced the client to bring all of its subsidiaries "into the fold." Natalia tells Allison that she will be getting an immediate raise and "better surroundings" as the new "Executive Assistant to the Vice President of Marketing." Allison is elated.

This example can now be traced through the model. To begin with, Allison has certain role-specific pre-internalized beliefs, both accumulated and socialized, defining who she is 
and where she is going; e.g., "up and comer"; dreams of authority. These relate to certain past actions on her part (hard work) and her roles in the social structure (all of which form part of her "me"). Moreover, in keeping with our commercial, capitalistic culture, she feels positive about this identity morally, and thus about herself. Yet, she wants more.

Enter Natalia. In the interaction she first discusses details of Allison's work (which Allison is socialized to perceive in a certain way and understand as such), and then voices the good news and compliment. This all passes, via the interactional stream in word and gesture, to Allison. Entering Allison's inner phenomenological stream, she first examines her attitude toward herself (as found in her perceptual and moral beliefs), then takes the attitude of the other (which is here generally positive), and finally turns the imagined attitude of the other toward herself ("brilliant"). In the internal conversation that ensues between Allison's "I" and "me" with reference to her pre-internalized beliefs about her role-identity, this counts as a confirmation, so her response (the"I") takes the form of elation. ${ }^{46}$ For all intents and purposes this is an enhancement of a positive past selfidentity for her with potential for the future. This feeds back into her overall sense of self and accumulates as longterm happiness, even "after the glitter fades." 
Now, let us suppose, on the other hand, that Natalia appeared angry with Allison because her work "did not impress" the client, who then took his business elsewhere. Instead of complimenting her, Natalia says: "You'll have to do better on these proposals -God know's I'm paying you enough." Then, when Natalia is safely out of sight, Allison's co-worker, Andrea, says: "Oh, don't worry about her - she's not mad at you really. She's always like that when the firm loses a client for any reason. You know your work is good. Besides, she'll be all smiles tomorrow - and probably even apologize. It's happened to me." Allison recognizes this, having been through it herself, and resolves to be extra-friendly to Natalia for the rest of the day.

This variant of the above situation incorporates three additional components not found above. The first is an "escape route" in Allison's system of beliefs that enables her, in her inner phenomenological conversation between "I" and "me", to discount and manage the potential disconfirmation of her fundamental moral identity presented by Natalia's comments. ${ }^{47}$ The second component is the existence of social support for Allison's rationalization of Natalia's comment - in the person of Andrea. ${ }^{48}$ The third is Allison's conscious choice of a self-presenting "micropolitical strategy" for dealing with Natalia - being "extra friendly" to her in order to make her feel guilty and apologize as she has been known to do in the 
past. Should any or all of these factors fail given the same sort of disconfirmatory interaction, Allison would likely have a more difficult time maintaining her fundamental identity; i.e., this interaction would likely cumulate negatively in her overall assessment of self in light of beliefs, and reflect in reduced happiness - both present and future. ${ }^{49}$

Chart 1 illustrates the operation of this model. The starting point is always the pre-internalized system of beliefs that any individual brings to an interaction. These, which are intimately associated with the "me" component of any internalized role-set, arise partly as the result of ideological socialization, partly as a result of individual actions (or "I's"), and partly as an accumulation of positive and negative interactions throughout a person's lifetime. Fundamentally these beliefs define who and what an individual is within a social context. They perform three basic functions: (a) perceptual definition of reality; (b) moral definition of identity; and (c) identity maintenance strategies. ${ }^{50}$ In short, they provide the individual with the "who, what, where, when and why" of perception, moral identity and the maintenance thereof. Once an individual enters a social interaction these beliefs, as the "past" component of the present, play a major role in the shaping of his/her definition of the situation. The remainder are filled out by the contents of the interaction itself. 
Now, if the messages objectified in the interactional stream affirm one's positively defined moral beliefs about one's self and role-identity, the internal conversation in the phenomenological stream between the "I" and the "me" (i.e. the taking of one's attitude towards self, towards other, and turning the imagined attitude of other toward self) will be coherent - not only among these components of self, but also with reference to the beliefs themselves. Thus, the "I" response shows an overall positive emotional assessment of happiness, which is then tucked away as part of the "me" in the individual's emotional memory - ready to be brought to a future interaction. One's overall self, past, present and future takes on a brighter interpretation, and one is thus happier.

If, however, the messages objectified in the interactional stream disconfirm one's positively defined moral beliefs about oneself, the internal conversation in the phenomenological stream will be incoherent. (Chart 2). Specifically, one's pre-existing attitude toward self and imagined attitude of other toward oneself do not match the incoming message directed at self as soon as one takes the role of the other. Here, "Plan B" comes into play. The negatively assessed individual can do a number of creative things, such as: (a) searching his/her system of beliefs for an "escape route," past similar occurrence or label that enables 
the potential disconfirmation or perpetrator to be defined away $^{51}$ (b) seeking out social support for one's favored selfdefinition; (c)utilizing self-presentational emotional micropolitics, accounts or disclaimers in response to restore sense of self as a moral person; (d) resort to emotion management, feeling rules and intentional value feelings; ${ }^{52}$ or, as a last resort, (e) change one's self-definition into another morally acceptable one for that role. One, or a combination of these "Plan B alternatives" then forms the individual "I" response, and so on. Again, the result of this interaction feeds back into the individual's overall moral assessment of self, past, present and future, and is hence reflected in his/her happiness.

On this model, then, it could be suggested that the happiest individual could likely be characterized as one whose positive moral beliefs about him/herself in various roles are continually confirmed in interaction, but also are embedded in a system of beliefs that enables him/her to define away any potentially negative situation in a way that leaves him/her morally blameless; e.g., "everything is a result of God's will." Hence the greater cumulation of positive interactions in light of belief would show in a high degree of happiness. ${ }^{53}$ of course, it must always be remembered, social support and positive interactions for such a person will be greater in societies approximating Durkheim's "mechanical 
solidarity" where strong beliefs are current, the likelihood of encountering alternative beliefs and dissimilar individuals is comparatively slight, and where, when one "follows the rules," there is little prospect of seeing oneself - or reality - differently。

On the other hand, there are three possibilities for the least happy individual. The first would be the simple converse of the above; i.e., a self-perpetuating negative assessment of self cutting across roles that is continually reinforced in interaction and cannot be perceptually disconfirmed in present experience. ${ }^{54}$ Add to this the degree of negative social support outlined above and one paints a picture of a very unhappy fellow indeed. ${ }^{35}$

The second alternative would be an anomic individual without any firm self-concept, no significant belief about his/her moral identity, whose unidimensional attempts at self definition continually pass through series of disconfirming or negatively assessing social interactions such that a positive self-evaluation never has a chance to develop socially. ${ }^{56}$

The third possibility would be an individual with well-developed identities which are based on structural roles, beliefs and obligations that are in conflict with each other..$^{57}$ Here, it would be virtually impossible to gain positive assessments of self, either internally or interactionally, as to gain from one means to lose from the 
other. ${ }^{58}$

All of these unhappy types are more likely to be found in societies characterized by Durkheim's organic solidarity, division of labour, interdependence and conflicting beliefs (but by no means are they restricted to such societies). 59

Before moving on to the construction of the typology, let us pause for a moment to consider what have been characterized above as "concomitant conditions" for happiness. Namely, factors such as health, adequate material means, a degree of pleasure and the absence of personal tragedies. Certainly, removing any of these would seem to reduce the likelihood of an individual experiencing happiness. Note, however, that belief plays an important ameliorating role in such circumstances as well. There are certainly happy people who have poor health (e.q. those that feel that a good hereafter is awaiting them after living a long, fulfilling and "good" life), as there are among those with few material means (e.g. "I prefer to live a simple life"; "blessed are the needy"). As for pleasure, there are myriad ways of dismissing this (e.g. "it is for the wicked"; "pleasure does not necessarily bring happiness"; "the highest pleasures are accompanied by the highest activities"); and personal tragedies have their own mitigating beliefs (e.g. "she is free from pain now"; "you'll see her again").

It is not being suggested that the near total absence 
of these concomitant factors can be totally rationalized away through culturally prescribed perceptual judgments. Rather, there are both types of societal belief and individual cognitive strategies that are utilized, consciously and unconsciously, by individuals in difficult situations that enable them to reduce and manage the unhappiness resulting from such inadequacies and misfortunes, which closely parallel the above strategies for maintaining long-term moral self worth.

Given all this talk of "types of belief," it is now timely to turn an eye to this very subject: traditional beliefs about happiness itself.

\section{(2) Typology of Beliefs:}

In this section will be reviewed various historical and philosophical systems of belief in relation to human happiness, which add needed detail to the second definition in the above model. Upon a thorough review of this literature it became apparent that systems of perceptual and evaluative belief could be portrayed, for the sake of clearer understanding, in a table of four weberian ideal types. ${ }^{60}$ (Chart 3 ). It must be noted that these types are theoretical abstractions, and aspects of actual belief systems (e.g. Christianity) may fall into several categories (but this is by no means always the case). With this caveat, it is time to describe the typology. 
The two most important analytical dimensions that demarcate each type from the others are: (1) present vs. future temporal orientation, or "point of reference" ${ }^{61}$ and (2) "individual centered" focus on the pursuit of one's own happiness vs. "other-directed" activity and involvement. These dimensions, when arranged in a table, produce four categories or types of belief in relation to happiness. These have been labeled: (a) the "Transcendental," (b) the "Egocentric," (c) the "Empathetic," and (d) the "Crusader." Each of these types will now be reviewed in detail.

\section{(a) The Transcendental}

"Most people seem to believe that they are free, in as far as they may obey their lusts, and that they cede their rights, in so far as they are bound to live according to the commandments of the divine law. They therefore believe that piety, religion, and, generally, all things attributable to firmness of mind, are burdens, which, after death, they hope to lay aside, and to receive the reward for their bondage, that is, for their piety and religion; it is not only by this hope, but also, and chiefly, by the fear of being horribly punished after death, that they are induced to live according to the divine commandments, so far as their feeble and infirm spirit will carry them..." 62

-Spinoza

Spinoza's words could not more perfectly describe the most important of transcendental systems of belief for the western mind - messianic christianity. While there are other future-directed, "self-interested" sectarian outlooks (e.q. the marxist assertion that all will be well "after the 
revolution"), none can capture the tradition better than the above.

In transcendental beliefs about happiness, as the name suggests, future ends or perceived rewards that will "transcend" the present circumstances give both positive meaning and motivation to present activities and, as such, an individual's moral assessment of self (e.g. the former exemplified by "I'm a good revolutionary"; the latter by Augustine's "reward in heaven"). ${ }^{63}$ This outlook will be reflected in believers' accounts, disclaimers, and vocabularies of motive generally. ${ }^{64}$ Key to such beliefs is the observation of St. Thomas Aquinas that "..one is said to possess (happiness) already, when one hopes to possess it."165 This was also indirectly recognized by Mead, who saw the future, like the past, as an important component of the present, ${ }^{66}$ and an important variable in the motivation of behavior. ${ }^{67}$ That it may have a class-based structural component is suggested in Hammond's concept of "temporal differentiation. " 68

secondly, in transcendental beliefs about happiness, there are often individual-directed meanings telling one how to find happiness, and those individuals holding the beliefs frequently hold them as a means to this "state" (e.g. "I'm so happy that I'm born again"). As such there is a conscious awareness of happiness/unhappiness and a concern therewith in 
the individual. Fundamentally, when held in this way, these are individual-centered beliefs. ${ }^{69}$

Third, in the transcendental model, happiness is conceived of as a state of mind, a noun, something that can either be received or ultimately achieved once and for all at some given, but presently unknowable, point in time.

Fourth, transcendental systems of belief, more frequently, but not exclusively found in societies approximating "mechanical solidarity," (e.g. Valhalla, "the second coming", Muslim martyrdom), are usually not logically disconfirmable by reference to the present. This is because of such built in "conceptual escape routes" or motivational rhetoric such as: "the Lord will come someday," or "the revolution is inevitable - it just hasn't happened yet." Because of these, it is often easier for adherents of such beliefs to hold on to them and evaluate themselves with reference thereto even when the extent of social support is low. Yet, it cannot be denied that "interaction rituals" (e.g. meetings, war service, church services) with other believers help individual adherents maintain positive feelings about themselves and their beliefs. ${ }^{70}$

Fifth, due to the very nature of these beliefs (which are structured to put a positive future spin on present dissatisfactions), intentional value feelings and feeling rules are to be found in great abundance, (e.g. implicit in 
the biblical statement "it is easier for a camel to go through the eye of a needle than for a rich man to enter heaven," the beatitudes, etc). These, as well, circle back into the conceptual "escape routes" noted above - enabling the individual adherent to dismiss things they don't like by putting moral blame on others, while simultaneously maintaining and building their moral self-worth and eventual redemption.

Examples of beliefs with transcendental features range from those people are socialized to hold (e.g. exemplified by traditional Christianity and Weber's Calvinists); through those one encounters throughout life (e.g. Marxism's "perfect communist society after the revolution"); to those individually-generated in the internal conversation between the"I" and the "me" in a particular situation (e.g. "I'II be so happy when..." -and the "when" just keeps getting pushed further into the future).

\section{(b) The Egocentric}

"Of all existing things some are in our power, and others are not in our power. In our power are thought, impulse, will to get and will to avoid, and, in a word, everything which is our own doing. Things not in our power include the body, property, reputation, office, and, in a word, everything which is not our own doing. Things in our power are by nature free, unhindered, untrammeled; things not in our power are weak, servile, subject to hindrance, dependent on others. Remember then that if you imagine that what is naturally slavish is free, and what is naturally another's is your own, you 
will be hampered, you will mourn, you will be put to confusion, you will blame gods and men; but if you think that only your own belongs to you, and that what is another's is indeed another's, no one will ever put compulsion or hindrance on you, you will blame none, you will accuse none, you will do nothing against your will, no one will harm you, you will have no enemy, for no harm can touch you. " 71

-Epictetus

\begin{abstract}
"Eat, drink, and be merry for tomorrow you die." -popularized perversion of Epicurus
\end{abstract}

These two radically different outlooks on happiness share two common elements that firmly place them in the egocentric cell of the typology. The first is that, like the transcendental model outlined above, there are individualcentered meanings in these beliefs telling one how to find happiness, and individuals holding such beliefs often do so as a means of achieving same. In short, conscious awareness of one's happiness/unhappiness is at play here, so these beliefs can also be characterized as "individual-centered" in nature. Unlike the transcendental model, however, the temporal component here focuses on the present. In such beliefs, present ends give positive meaning and motivation to present activities and, as such, one's cumulative moral perception of oneself (e.g. the stoics prized virtuous activity solely for the virtuous state of mind it consciously produced; the epicureans pleasure). This would again be reflected in 
accounts, disclaimers and vocabularies of motive emergent in interaction with believers in such doctrines.

Third, in the egocentric model, like the transcendental, happiness is conceived as a state of mind, a noun, something that can be received, experienced or achieved. However, in this case the focus of attention is on the "here and now."

Fourth, these systems of belief are not necessarily disconfirmable logically, as they contain "escape routes" of their own (e.g. "if it is not in your power, it is nothing to you"; "the pleasant life does not consist of indulging every desire"). However, their emphasis on the present makes it more likely that events can arise challenging or making it hard to maintain one's cognitive perceptions, and hence, one's moral identity (e.g. the hedonistic epicurean with a hangover who wonders if there is more to life; the stoics were notorious for committing suicide when life got too hard under their rigorous system). Therefore, ironically, it is likely that social support and interaction with believers becomes more important in maintaining one's perceptual beliefs, cumulative moral identity and happiness when egocentric beliefs are the principal definer of self. ${ }^{72}$ of course, depending upon the type of Durkheimian solidarity one's society more closely approximates, this will be easier or harder, as the case may be. 
Fifth, due to the very nature of these egocentric beliefs, intentional value feelings predominate (e.g. "it is nothing to you"). There are lots of feeling rules (e.g. "you have it all, you should be happy") and a great deal of emotion management. These circle back into conceptual escape routes and rationalizations to help maintain perceptions, and hence long-term moral identity in interaction.

Examples of beliefs approximating this type include stoicism, hedonism, epicureanism, Benthamite utilitarianism, the "happiness through possessions" advocated by our consumer society with its media-driven desires, many of the "self-help" books found at supermarket checkouts, and the "happiness" of narcissistic or dependent lovers for whom their whole self concept seems caught up in the others' present opinion of themselves. For these latter unfortunates, hell is truly, to quote Sartre, "other people." 73

\section{(c) The Empathetic} itself. ${ }^{74}$

"Blessedness is not the reward of virtue, but virtue -Spinoza

"I have an opportunity to be twenty-four hours a day with Jesus." 75

-Mother Teresa

This latter statement, taken from a recent magazine interview, best exemplifies this third type of belief about happiness. Here, in contrast to the transcendental and 
egocentric types, the individual believer's attention is not focused on him/herself or how to find happiness. ${ }^{76}$ Indeed, if considered at all, happiness is an afterthought, because for such believers, there are more important tasks at hand than worrying about themselves. They are just too busy. These beliefs are truly "other directed" as they place more value on someone or something outside the individual; e.g., the missionary perception, based on scripture, equating the poor and needy with God. Here, individuals' evaluative beliefs about their moral self come into play less consciously and less often than in the other types discussed above - although they still function and accumulate reflexively "beneath the surface" in interactions. ${ }^{n}$

More needs to be said about this. Briefly, the "unselfishness" of these individuals has important ramifications in relation to the earlier discussion of the self as the "I" and the "me." Whereas in both the egocentric and the transcendental models the self is restricted by its beliefs, in the sense that there is conscious utilization of the "other" in interactions as a means to the happiness of the "person" inside the body; in the "other-directed" models to be considered here, the "other" is an end in itself. What is found in these latter models is a conscious expansion of the self outside the lived body to include others: a recognition that one's self does not reside solely beneath one's skin, but 
is part of the world of experience. ${ }^{78}$ In short, it is a realization, at some level, of one's true social psychological nature. Thus, the term "selfishness" has to be one of the greatest misnomers in the English language. ${ }^{79}$

A second component in the empathetic type of belief is its temporal orientation. Here, like in the egocentric type, the focus is on the present and current activities (e.g. feeding the hungry, caring for the sick, loving one's wife). Present ends give positive meaning and motivation to present activities and one's cumulative, moral evaluation of oneself in interaction. ${ }^{80}$ This meaning, again, would be reflected in accounts, disclaimers, and vocabularies of motive emergent in interaction with holders of such beliefs (e.g. Mother Teresa's comment that "We have only today to love Jesus").

Third, in the empathetic model, happiness, if considered by the believers at all, is thought of as an activity, a verb, something one does. As such it is epiphenomenal in nature, a by-product of the exercise of one's highest faculties by a complete self (Aristotle comes to mind here), and may show up in Denzin's feelings of the lived body. This type recognizes that a person can experience happiness without continually wondering about it.

Fourth, empathetic systems of belief are not necessarily disconfirmable in any logical sense, and conceptual escape routes exist when faced with difficult 
situations (e.g. "I'm being tested"; "he's unenlightened as to the truth"; seeing God in other people, etc). Yet, like the egocentric model, the present emphasis makes it more likely that events can arise challenging or making it hard to maintain such beliefs, and hence, one's positive moral identity (e.g. the priest who has a particularly disillusioning experience such as being used by someone he tries sincerely to help). Therefore, it is likely that the extent of social support and interaction with believers becomes important to maintaining one's perceptual beliefs, cumulative moral identity and happiness when such beliefs are the principal definer of self. Note, for example, that particularly ascetic adherents of such beliefs, such as monks and nuns live and work together, even in societies approaching "mechanical solidarity."

Fifth, there is a role for intentional value feelings and emotion management in this category, but to a lesser extent than the above. An individual who is truly involved in this sort of outlook will often be too preoccupied to worry about personal feelings, and feelings in this person will more likely be spontaneous than managed. It is only when these beliefs also impose great hardship on believers (e.g. abject poverty), or when one is faced with plausible conflicting viewpoints or lifestyles, that intentional value feelings and emotion management techniques, embedded in the beliefs, will 
be brought into play to maintain cognitive perception, moral belief, cumulative moral identity, and happiness.

Examples approximating such beliefs include the "golden rule" as exemplified in missionary Christianity, people with a passionate involvement in, and belief about their work as vitally important, noble and necessary (e.g. scientists, artists), and lovers who totally identify their lovers' well being with their self. ${ }^{82}$

\section{(d) The Crusader}

"Those only are happy... who have their minds fixed on some object other than their own happiness; on the happiness of others, on the improvement of mankind, even on some art or pursuit, followed not as a means, but as itself an ideal end. Aiming thus at something else, they find happiness by the way." ${ }^{83}$

-John Stuart Mill

This final category or type of belief shares much in common with the empathetic. Specifically, it shares the "other-directed" focus of attention, the epiphenomenal experience of the emotion, and the expansive conception of self. ${ }^{84}$ Thus, what was said above regarding the empathetic type applies with much the same force to these aspects here.

What makes this category distinct is its temporal orientation. Here, future ends or "pursuits" give meaning and motivation to one's present activities and moral sense of self (epiphenomenally, that is). Again, Mead's observation that the future is a key component of the present and an important 
source of motivation is key to an understanding of this type. ${ }^{85}$

Third, happiness is conceived of as an activity and a verb, but, as Mill's words above note, has reference to an ultimate goal. This goal is something one works toward; the prospect of its achievement resulting in positive cumulative evaluation of oneself (and vice versa).

Fourth, crusading beliefs regarding happiness usually are logically disconfirmable, but only ultimately so in the future. ${ }^{86}$ There are conceptual escape routes along the way (e.g. "we're doing better"), but, when the game is over and someone else has won the prize, it is time for some serious re-evaluation of identity as a disconfirmation has occurred. Here, extent of social support is not only significant on the way to the goal (e.g."knowing that one is doing something worthwhile"), but is absolutely crucial if a disconfirmation occurs (i.e. in emergent rationalizations - "we gave it our best"; "nice guys finish last"; "its all how you play the game"; "they played dirty politics"; "it wasn't the right time" ).

Fifth, intentional value feelings and emotion management come into play extensively here, not only motivating individuals to action and maintaining belief along the way (e.g. "if you show you really believe in the candidate , we're more likely to win"), but are applied even more 
intensively in the event of a disconfirmation. The very possibility of failure makes such safeguards most prevalent among this type.

Examples of beliefs approximating this type include those held by committed lobbyists for a political or moral cause ("moral entrepreneurs"), fundraisers raising money for a target figure, and those held by lovers in pursuit of their beloved.

This concludes the theoretical description of types of belief in relation to the experience and management of human happiness .

\section{(3) Mechanisms of change}

"We are entitled to believe anything at all if believing it is advantageous or helps us in life." 17

-paraphrase of William James

Now that a general model of experiencing the emotion of happiness has been constructed, and varieties of component belief that affect it have been typed, it is timely to briefly examine how individuals may change their views as to what makes them happy, and thereby move closer to one type or away from another. This exercise will be seen to be crucial to any final theoretical understanding of the emotion.

Central to this endeavor is the "adaptive" conception of mind so prominent among early interactionists. Dewey, for 
example, had proposed that the human mind be looked at as a "function," with "mind activity extrapolated from adaptive behavior in an ever changing environment. "88 Similarly, Mead felt the mind to be a tool which seeks an adjustive relationship between the individual and his/her environment. ${ }^{89}$ In addition, it would be well to keep in mind Hochschild's ideas on emotion management, Denzin's "intentional value feelings," and the above comments on the "extent" of beliefs in a given society, as these may all interact, internally and externally, in an interaction affecting moves between approximate types of belief.

Remaining cognizant of the above, then, it is here asserted that an individual will become disillusioned with his/her conception of happiness and seek a new outlook when (a) perceived disconfirmation ${ }^{90}$ occurs in interaction and (b) identity maintenance strategies for maintaining belief have broken down. ${ }^{91}$ In addition, it is important to keep in mind factors such as (c) frequency, ${ }^{92}$ (d) intensity, ${ }^{93}$ and (e) whether or not the disconfirmation occurred in interaction with significant others. ${ }^{24}$

This may be initiated by the following (or combinations of) the following situations (in addition, that is, to the strategically chosen example of single individuals experiencing disconfirmation in the midst of change to be discussed in the next chapter) $:{ }^{95}$ 
-failure of prediction; 96

- perceived hypocrisy; ${ }^{97}$

-loss of social support for beliefs; ${ }^{98}$

-indoctrination in new ways of perception; ${ }^{99}$

-exposure to new and persuasive ideas; ${ }^{100}$

- stress burnout; ${ }^{101}$

- personal tragedy $i^{102}$

-role conflict; ${ }^{10}$

-belief conflict; ${ }^{104}$

-accusation by significant other; ${ }^{105}$

- failure to achieve an important goal; 106

As can be seen, each of the above ultimately involve either a role-based reevaluation of one's beliefs (perceptual or moral) or of oneself in light of one's beliefs, both representing the past component of the present in interaction. Since, according to Mead, we are adaptive creatures, we may attempt at first to utilize emotion management, conceptual escape routes, emotional micropolitics, seek social support, and various other "identity maintenence strategies" to deal with such situations and maintain our sense of self.107 In addition, external social agents (e.q. psychiatrists, counsellors, in extreme cases) may come into play to help maintain our sense of emotional reality. If, however, both individual-initiated and externally applied strategies fail which they are more likely to do in the diverse societies characterized by organic solidarity - then one must ultimately adapt, take on a different perceptual and evaluative outlook and identity, and proceed from there. ${ }^{108}$

Keeping these concepts concerning disconfirmation in mind, as well as the role-based hierarchy of I/me identities 
comprising the social self, it becomes clear then that, aside from the ultimate disconfirmation of one's perceptual and evaluative beliefs about oneself with regard to a master $\underline{\text { role }}^{109}$ (i.e. one's identity as a moral person, which is embodied to some degree in all roles, and, more particularly, with reference to one's status relating to intimate relationships), ${ }^{110}$ most disconfirmations will be rolespecific: not affecting one's total identity. Flowing from this are several important additional considerations about the nature of happiness itself.

First, it is possible that, so long as one's cumulative beliefs regarding one's moral self are not inconsistent and not perceived as such by oneself or by one's interactants, one may entertain and adaptively move between different approximate types of belief about happiness with regard to the different social roles that one occupies. ${ }^{111}$ For example, one may be "empathetic" in one's role as spouse, stoic with regard to one's role as a financial failure, epicurean as a coffee lover, "crusading" with regard to whether or not one can meet this year's volunteer fund raising target, and "transcendental" regarding one's reward in heaven. So long as this mosaic of beliefs defining self do not conflict, perceptually or morally, in any fundamental way, and are not held up to one as such in interaction, then, keeping the basic model above in mind, one's happiness will consist. 
at bottom, in adapting the most favorable mix of the previously outlined types of belief to the roles one fills in order to maximize positive interactions, and, thereby, positive accumulative evaluations of oneself. ${ }^{112}$

Secondly, and this follows from the nature of these "ideal typical" beliefs themselves, since many actual systems of belief in the "real world" have diverse aspects that may fit into several of the above categories, to maintain happiness one can frequently merely make a change in emphasis within a given system rather than an outright change to another. (For example, an "empathetically" oriented Christian missionary may be struck by a great, unexpected personal tragedy, such as being diagnosed with cancer, and then turn his/her attention more to the "transcendental" side of the system). As such, it would appear that the most all-inclusive systems of belief, where disconfirmation is by definition rarest, are most conducive to the maintenance of perception, cumulative moral identity, and happiness itself.113 of course, this is even more so in societies approximating conditions of mechanical solidarity. ${ }^{114}$

Thus, even in the absence of outright disconfirmation, inconsistency of beliefs, or failure of emotion management, it is a very complex picture that has been painted here. One may have an overall, integrated system of beliefs about happiness that approximates one or several of the types outlined above 
for all or the majority of one's roles, or one may hold a variety of more diverse beliefs relating to happiness for different roles that, so long as they are perceived consistent, and not held up as inconsistent in interaction, can be maintained to achieve the most favorable mix of positive moral assessments of self in interaction.

In addition, without any disconfirmation of one's "root" moral belief about oneself, nor of those roles that one considers important to one's sense of self, it may be that, when pressed, one can sacrifice one of one's "less important" role identities to disconfirmation in order to maximize positive cumulative moral assessments of self and minimize negative ones.

In short, by remaining thus internally consistent and externally harmonious over time, one is happy. The endlessly creative process of the human mind guides one's way, and William James' pragmatic interpretation of belief, paraphrased above, bespeaks a profound understanding.

\section{(4) Conclusion}

The above theory of happiness, as can be seen, incorporates many components of previous philosophical thinking on the subject. By marrying the strengths of both philosophical rigor and sociological insight, a theory has been developed that not only has some grounding in previous 
scientific study of human experience, but also one that is capable of meeting the traditional criticism of purely cognitive theories: emotion-belief conflicts. Indeed; much of the foregoing has relevance not only to the emotion of happiness - but for the sociology of emotion in general.

At this point, however, it is appropriate to move from theory to a consideration of the research design, especially the choice of single respondents, the hypotheses to be deduced from the above, and the empirical data that will be brought to bear on this model. After all, no matter how well grounded a theory is in past research, a carefully selected methodological approach can often elicit data shedding new light on its fundamental precepts. 
Chapter 3: Methodology and Research Design.

In this brief chapter I will describe how. I have chosen to operationalize the model of emotion set out in Chapter 2. This outline will follow the following format. First, I will discuss the rationale for focusing on the study of one particular role/identity in relation to the experience of happiness. Secondly, the hypotheses to be tested will be explicitly stated. Finally, the nature and extent of qualitative fieldwork and intensive interviewing will be described in some detail, giving special consideration to sampling, ethical considerations, and the obvious limitations of this admittedly preliminary study.

\section{(1) Rationale: Choice of the Single Role:}

I have chosen to study the experience of happiness largely in relation to one of the few significant roles that all individuals experience at one point in their lives: being single. Specifically, I will largely consider those individuals who occupy the social structural position/roleidentity of being unmarried and/or not presently involved in a "relationship." 1

This decision is based on several considerations. First, there is Barrow's observation that, with regard to happiness, "sex, love, and relationships" are "problem areas 
for most people." ${ }^{2}$ He goes on to point to several studies indicating "married people to be significantly happier than unmarried people." ${ }^{3}$ Indeed, he asserts these to indicate that "marriage and family life are the most satisfying parts of most people's lives and being married is one of the most important determinants of being satisfied with life."4

Secondly, there is Couch's observation of the extensive cultural emphasis on romantic relationships in our society:

"Romantic relationships receive far more attention in the mass media than any other relationship. Several magazines are devoted to romantic problems, nearly every daily newspaper has a column that offers advice to the lovelorn, many publishing companies do a brisk business in sex manuals, and books are regularly published that are entitled some variant of "How to meet the Right Guy (Gal)." Despite all the attention romantic relationships receive, they are poorly understood." 5 (emphasis in original).

Third, storr, citing Gellner, contrasts this current overwhelming cultural emphasis on personal relationships with earlier times:

"The current emphasis upon intimate interpersonal relationships as the touchstone of health and happiness is a comparatively recent phenomenon. Earlier generations would not have rated human relationships so highly; believing, perhaps, that the daily round, the common task, should furnish all we need to ask; or, alternatively, being too preoccupied with merely keeping alive and earning a living to have much time to devote to the subtleties of personal relations. Some observers, like Ernest Gellner, suggest that our present preoccupation with, and anxiety about; human relationships has replaced former anxieties about the unpredictability and precariousness of the natural world. He argues that, in modern affluent societies, most 
of us are protected from disease, poverty, hunger, and natural catastrophes to an extent undreamed of by previous generations. But modern industrial societies are unstable and lacking in structure. Increased mobility has undermined the pillars of society. Because we have more choice as to where we live, what society we should join, and what we should make of our lives, our relations with the other people who constitute our environment are no longer defined by age-old rules and have therefore become matters of increasing concern and anxiety. As Gellner puts it, "Our environment is now made up basically of relationships with others." 6 (emphasis added).

Fourth, there is storr's observation that these shifts

in cultural emphasis are reflected in powerful labelling

institutions and professional opinion:

"The majority of osycho-analysts, social workers, and other members of the so-called "helping professions" consider that intimate personal relationships are the chief source of human happiness. Conversely, it is widely assumed that those who do not enjoy the satisfactions provided by such relationships are neurotic, immature, or in some other way abnormal. Today, the thrust of most forms of psychotherapy, whether with individuals or groups, is directed toward understanding what has gone wrong with the patient's relationships with significant persons in his or her past, in order that the patient can be helped toward making more fruitful and fulfilling human relationships in the future."7 (emphasis added).

Fifth, there is Blumstein's observation that marital roles (and, I would add, their absence) shape selves. These:

"Set important markers that are widely used to define traits or dispositions of role incumbents. The provider role, the homemaker roles, the parent role, the lover role, and so on, all have highly elaborated cultural standards that can be used to measure one's own and one's partner's adequacy as a person, as a man, as a woman, and so on." 8 (emphasis added).

Blumstein argues that as role relationships, intimate relationships provide common cultural scripts for their 
enactment which shape selves.9 The same self-shaping properties are also found in the internal processes of intimate personal interactions themselves. ${ }^{10}$

The argument I wish to reiterate is that the absence of such a culturally elaborated relationship with its attendant intimate interactions is also likely to involve cultural evaluation, and production of selves. Since, on our model, evaluation of oneself in relation to one's cultural beliefs about one's self in important roles is crucial to happiness, the absence of such a significant role should also involve cultural beliefs affecting this emotion.

Sixth, there is the suggestion that some individuals may use relationships as a culturally prescribed means of coping with life. Patrick Carnes, a well-known researcher on sex addiction, discussing what he calls our "addictive culture," writes that:

"When it comes to sexual issues, cultural influences are obvious. The glamorization of sex extends far beyond women's magazines in which a female's self-worth is contingent upon her looks and men's magazines in which a male's self-worth is contingent upon his ability to seduce good-looking women. It extends beyond commercials which use sexual turn-ons to sell, soap operas with unending sexual sagas, and gossip-oriented media with the latest tales to tell... Beyond being glamorous, sex becomes a solution, a way to cope with life's challenges."11 (emphasis added).

Of course, individual utilization of relationships to preserve promote, and manage self, within such a cultural context, is very likely to extend beyond such extreme sexual 
examples, but in more subtle ways.

Finally, since the valued norm in our society, past a particular age, is to have a relationship and/or marriage, it may be useful to characterize some associated single individuals as a deviant subculture sharing a "master status." 12 As Storr writes:

"If we call an adult dependent, we imply that he is immature. But if he has no intimate attachments, we conclude that there is something wrong with him. In Western society, extreme detachment from ties with others is usually equated with mental illness. Chronic schizophrenics sometimes lead lives in which relationships with others play virtually no part at all. The capacity to form attachments on equal terms is considered evidence of emotional maturity. It is the absence of this capacity which is pathological. Whether there may be other criteria of emotional maturity, like the capacity to be alone, is seldom taken into account." 13 (emphasis added)

If this is indeed the case, then Smith-Lovin's methodological comments become appropriate:

"For subcultures, it is reasonable to assume that the meanings of most behaviors and non-salient identities are shared with the encompassing culture. Therefore, a researcher need concentrate only on identities and behaviors that are central to the subculture... After a simple data collection task, one can examine the emotion norms within the group. "14 (emphasis added).

Thus, considering the overall cultural significance of the single role to an individual's happiness, its self-shaping qualities, and (in some cases) its possible deviant master status, focusing the bulk of one's efforts on such individuals promises to go a long way in examining the dynamics of this elusive emotion. 


\section{(2) Hypotheses:}

The hypotheses to be considered in this study are to be found in three clusters. The first derive from the general interactional model of happiness as set out in the previous chapter; ${ }^{15}$ the second refer to the typology of beliefs set out therein in relation to the single role; while the last describe the mechanisms of change between typical beliefs. Each of these will now be reviewed in turn.

\section{(a) General Interactional Model:}

With regard to the general interactional model of happiness, several hypotheses may be extracted. These are as follows:

(i) Positive, affirming social interactions will lead to positive self-assessment, consistency, and therefore happiness.

(ii) Negative, disconfirming social interactions will lead to negative self-assessment, inconsistency, and therefore unhappiness.

(iii) Whether or not interactions are seen as positive or negative will depend upon factors including: (a) perceptual beliefs;

(b) evaluative beliefs;

(c) self-interaction; utilization of "identity-maintenance strategies" significance of interaction partner; (f) social support; and 
(g) importance of one's interactional role.

(iv) Positive and negative interactions are additive over time, and will show up in an individual's general level of self-esteem and happiness.

(v) Happiness is also additive across roles, such that the more roles one is happy with, the happier one becomes. ${ }^{16}$

\section{(b) Typology:}

The second cluster of hypotheses are all based on the following logical format: By examining whether the attitudes and beliefs single individuals express in relation to their happiness/unhappiness correspond to role-specific varieties of those set out in the typology, I intend to illustrate how the perceptual and evaluative aspects of such beliefs both produce and manage happiness/unhappiness among these people. Should this be successful, it should lead the way to similar studies of the function of these beliefs in relation to other roles. ${ }^{17}$

I would hypothesize, therefore, that the attitudes and beliefs that single individuals express in relation to their happiness or unhappiness ${ }^{18}$ with the single role and personal relationships will be found, singly or in combination, in four categories:

\section{(i) Transcendental:}

These type of beliefs, one will recall, tend to emphasize (a) the positive, fulfilling aspects of the future 
(relative to the present), and (b) are characterized by a relatively individual-directed focus. When these two dimensions are translated into terms of the single role, which, by definition, involves the absence of a partner, then one should find individuals holding hopeful beliefs regarding their possibility of a personally fulfilling, happy relationship in the future and then "living happily ever after." A possible form of such a role-specific belief would be: "I'll be so happy once I meet my special someone."19

\section{(ii) Egocentric:}

Egocentric beliefs about happiness, in contrast, emphasize (a) the temporal present in relation to (b) individual-directed experience with, and management of, happiness/unhappiness. Since these beliefs do not locate one's happiness in the future like the transcendental type, one would expect, in translating their general characteristics into the single role, at least two varieties of egocentric beliefs corresponding to positive and negative present interactions: the "hedonistic" and the "stoic." The former should typically characterize positive, relatively enjoyable interactions such as those expressed by individuals seeking happiness in a series of successful "one night stands." (e.g. "Go out and have fun and don't worry about tomorrow"). ${ }^{20}$ The latter should typically be more of an unhappiness management device utilized by those experiencing negative interactions 
such as rejection in the singles scene (e.g. "take each day as it comes," "you don't need a relationship to be happy").

\section{(iii) Crusader:}

Crusader beliefs about happiness, in contrast, are characterized by (a) a relatively outward-looking, otherdirected focus of attention, ${ }^{21}$ while retaining (b) a predominantly future-directed temporal orientation. They put more of a premium on goal-directed, individual activity, as opposed to the more passive hoping found in the transcendental type; an adherent's level of happiness/unhappiness being a simple byproduct of striving towards these outside goals. When translated into terms of the single role, one should find individuals actively striving towards meeting "the right person" - deriving and managing their levels of happiness therefrom. (e.g. "The thrill of the chase" as opposed to, "At least I'm doing something").

\section{(iv) Empathetic}

Empathetic beliefs about happiness are defined by (a) their present temporal orientation and (b) their otherdirected focus of attention. Indeed, the striking thing about such beliefs is the further development of their otherdirected dimension to the point that they emphasize a conscious expansion of self to include others. In their pure form, activity directed towards these others is perceived as 
activity toward oneself.

There is some difficulty translating such beliefs into the single role as, by definition, this role lacks a specific other in the present with whom to empathize. However, the power of such beliefs should not be discounted out of hand. It is important to realize that cultural conditioning and past experiences lead individuals to hold such perceptual and evaluative beliefs in relation to both what relationships are and should be like. (e.g. "My better half," "soul mates," "he/she's part of me," "two shall be as one," etc.). As such, it is hypothesized that the lack of such a relationship will itself be an important factor related to an individual's happiness/unhappiness in the single role. ${ }^{22}$

These are, in their barest form, the types of perceptual and evaluative beliefs about happiness/ unhappiness that I hypothesize will be found among single individuals.

Before moving on, however, let it be noted that these ideal types were not constructed in a vacuum, nor are they the result of mere "armchair philosophizing." Rather, they originally arose out of the author's own experiences, both as a single individual, and with relationships, over a period of approximately twenty years. As such, they represent not so much an academic attempt at forcing square pegs into abstract, round holes, as they do a continuing dialectic between observation and experience, on the one hand; reading and 
reflection on the other.

\section{(c) Mechanisms of Change:}

The final cluster of hypotheses refer to the circumstances under which individuals are likely to change their role-specific perceptual and evaluative beliefs about happiness.

It is here hypothesized, following the theoretical discussion in chapter two, ${ }^{23}$ that an individual will become disillusioned with his/her conception of happiness and adopt another typical outlook when (a) perceived disconfirmation occurs in interaction and (b) identity-maintenance strategies have broken down. Also asserted to be relevant in this regard are factors such as (c) frequency, (d) intensity, and (e) whether or not disconfirmation takes place in interaction with significant others.

This concludes the list of hypotheses to be considered in this study. I will now move on to discuss the methods by which they will be investigated.

\section{(3) Methodology:}

Two complementary qualitative methodologies have been utilized in this preliminary study: (i) participant observation and (ii) intensive interviewing. In this section, I will first review how each of these methods were utilized. 
I will then go on to consider the issues of (iii) sampling and (iv) research ethics in relation to the data, before briefly remarking on $(v)$ the limitations of this type of study.

\section{(i) Participant Observation:}

In conducting observational field research on single individuals, the researcher simply continued involvement in his existing single role. This did not involve any deception or misrepresentation considering this existing status. Indeed, he was already much involved in the activities herein described.

In addition to meeting one respondent through a telephone personal-ad service, meeting old friends in bars, and attending a student house party, the researcher attended four advertised "singles dances" over a two-month period. Extensive field notes were taken on each of these occasions, all having been reduced to writing on the morning of the following day. Moreover, there were more frequent interactions between two respondents and the researcher, both on the telephone and in the form of dating. Carefully guarded notes have been taken on these interactions as well. ${ }^{24}$

\section{(ii) Intensive Interviews:}

Added to the above fieldwork are twelve intensive interviews of single individuals conducted over a three month period. These are based on a questionnaire consisting of fifty-two, largely open-ended questions developed by the 
researcher (Appendix I).

The researcher generally approached various single individuals about conducting an interview containing "life questions" about "emotion" and "the single life." Upon commencing the interview itself, at a time convenient for the subject, respondents were again advised of the topic of study, and of the researcher's background and interest therein. Each was advised that he or she would remain anonymous in any written reports. As to the questions themselves, respondents were told that they may find some of these far fetched, abstract, silly, or repetitive, but not to worry as there were no right or wrong answers, only opinions and experiences. Subjects were advised to feel free to interrupt, ask for clarification, decline, or comment on the questions - which they did. Finally, before proceeding, each respondent's permission was sought to record the interview. ${ }^{25}$ Each interview was then recorded and transcribed verbatim. ${ }^{26}$

The actual questions began with initial background indicators such as age, sex, occupation, education, marital status and class. Next came more detailed evaluative questions, questions about the respondent's beliefs, selfimage, responses to feedback, temporal/attentive orientation, and roles. Finally, the interview moved on to the subject's perceptions of the single life, and of happiness itself.

Interviews ranged in length from approximately forty- 
five minutes to an hour and a half, depending on how much subjects wished to elaborate on their opinions and experiences. The overlapping nature of many of the questions ensured complete and full treatment of particular subjects (e.g. self-esteem). In addition, the open-ended structure of most of the questions enabled the researcher to probe and ask additional questions if a respondent raised an interesting subject or experience that showed promise.

Taken together, the field notes and interview transcripts comprise 308 pages of rich, detailed data. Upon completion, these were numbered and critically reviewed in light of the above theoretical model, taking special care to note areas of difficulty. A system of coding and indexing based on topic and page number was then employed to facilitate understanding and retrieval of these data.

\section{(iii) Sampling:}

As a preliminary, qualitative study, the sample involved here is necessarily small. The participant observation field notes reveal interactions with, or observation of, only fourteen individuals - eight of these for very brief periods and thus holding more limited empirical value to the subject under study. When these are added to the twelve intensive interviews (conducted using the interview schedule), and to the experiences of the researcher himself ${ }^{27}$, 
the resulting sample comes to approximately 27 individuals, 19 of which exhibit more useful detail (See Appendix II). Still, the richness of most of this data may make up in quality what it sacrifices in quantity, especially given the preliminary nature of this study.

While, as in Kitsuse's well-known study of societal reactions to homosexual behavior, ${ }^{28}$ this sample was neither random nor clearly representative of any specified population, efforts have nevertheless been made to make the sample as diverse as possible for purposes of broad illustration. Among the more detailed subjects are included 2 bisexual males; several divorced women, of varying ages, with children; two individuals struggling with a serious illness; a young woman with children recently separated from her husband; a foreign student; an older divorced gentleman; several young employed individuals - some who live at home and some who do not; and a lonely, chaste woman in her late thirties. These have been added to the usual crop of young, single university students making up the remainder of the sample. ${ }^{29}$

In addition, these subjects represent a diverse range of beliefs - from traditional christianity, through "New Age," to secular humanism - and exhibit varying levels of selfesteem and happiness.

Finally, while females outnumber males in the total sample, ${ }^{30}$ when the more fleeting observations in some of the 
field notes are eliminated it comes out almost even: 10 females to 9 males. ${ }^{31} \mathrm{All}$ in all, for such a small sample, this is about as diverse as possible when approaching such a society-wide role.

\section{(iv) Ethical Considerations:}

The issue of ethics always arises whenever research involves the study of human subjects. In this section I will detail the considerations and decisions taken in carrying out this research with regard to three areas: data collection, confidentiality, and storage of data.

First, with regard to the collection of the data, it will be useful to discuss the two methodologies separately. With regard to the covert research involved in the participant observation, ${ }^{32}$ several comments must be made. It was felt, first of all, that to initially reveal oneself as a researcher studying the single life would have made several of the more extensive (and valuable) dating interactions impossible - the subjects reasoning that the researcher was only interested in their data. It may also have lead to greater bias and selectivity in the information they presented, because dating and relations between the sexes are a sensitive area for most people. ${ }^{33}$

Moreover, any assertion that the researcher was simply "using" these individuals must be rejected at the outset. The 
researcher is himself single, and would have been engaging in these same activities and dating these same individuals had he not been involved in this research. ${ }^{34}$

As for the intensive interviews, these data were collected from willing respondents who were informed in advance of the nature of the research. Just prior to conducting the interviews they were informed again that the questions would involve extensive questions about "life" and "being single." They were also advised that they should feel free to decline any questions they felt to be too personal. Finally, their permission was sought to tape record the interviews. By proceeding to complete the interviews in such manner the interviewees implicitly gave their consent to this procedure. ${ }^{35}$

Secondly, and inseparable from the ethical considerations involved in the collection of these data, is the issue of confidentiality in publication. It is essential, especially in areas as sensitive as relations between the sexes, to protect the identity and privacy of one's respondents. This has been accomplished in three ways. First, all of the names of respondents have been changed in this written report. Secondly, any details that may call attention to the identity of a subject are either left out, or, when necessary, discussed at a broad level of generality not permitting any clear identification. Lastly, and whenever 
possible, this study makes use of composite examples drawing traits from several similar individuals in the sample. This further protects subjects' anonymity. ${ }^{36}$

Finally, the issue of data storage must be addressed. In conducting this research, transcripted data has been kept in a locked briefcase behind a locked door at all times when not being utilized by the researcher. Similarly, all tape recordings have been stored in a locked drawer in a secure room since their transcription. At no time has this data been shared with any other individual except the researcher's supervisor, who is in possession of the only photocopy. Following completion of this study, the tape recordings will be destroyed, and all copies of the field notes, with any identifying marks blacked out, will be locked away in a secure location.

This completes the discussion of the ethical considerations going into this research. It is the researcher's opinion that, with the exception of the covert nature of the participant observation - which both follows a long sociological tradition, and was necessary to prevent bias - there are few ethical difficulties in this study. Moreover, the precautions that have been taken with regard to confidentiality and storage of data minimize, if not eliminate, any potential harm to the subjects. 


\section{(v) Limitations:}

Prior to moving on to discuss the data itself, it is necessary to reiterate that this is merely a preliminary study based on a small sample. As such, there is a legitimate methodological question as to how far its conclusions may be generalized beyond this particular group. Nevertheless, as the hypotheses herein have been generated out of both previous personal experience and the many empirical studies cited in the previous chapter, should these data fail to disconfirm the hypotheses in question, they will merit further investigation and attempts at replication.

I turn now to consideration of the data itself. 


\section{Chapter 4: Data Analysis and Discussion}

This chapter will extensively review the qualitative data from the field notes and interview transcripts in relation to the hypotheses set out previously. First, evidence relating to those hypotheses on the general interactional model of happiness will be discussed. Next, the hypothesis regarding the typology of beliefs in relation to the single role will be reviewed type by type. Finally, data relevant to the mechanisms of change between types will be discussed. Throughout, any data that does not support these hypotheses will be critically reviewed, before moving on to the concluding chapter.

\section{(1) General Interactional Model}

(a) Positive Interactions:

It will be recalled that the first hypothesis under the general interactional model of happiness stated as follows :

(i) Positive, affirming social interactions will lead to positive self-assessment, consistency, and therefore happiness.

It must be noted that this hypothesis has two components: evaluative and logical. The former refers to whether the interaction involves a positive assessment of the 
individual under study; the latter whether that assessment is consistent with, or affirms his/her valued self-image. It is the gist of this hypothesis that only when both of these elements are present will the individual experience happiness. ${ }^{1}$

With regard to situations where both of these components line up, there is considerable evidence in the data illustrating the hypothesis. For example, the following respondent's remarks are representative:

"..when somebody likes you, you definitely feel better about yourself - that's for sure. It reinforces any good feelings you have about yourself. Um, like when I was on vacation. I...being with the two guys that I hit it off with, uh, definitely boosted my ego because they enjoyed being with me as much as I enjoyed being with them." (female, age 28).

It is interesting to note the difference, however, when both the evaluative and the logical components of this hypothesis do not correspond. In such cases, while the individual is exposed to positive feedback such as a compliment in the course of interaction, these propositions do not correspond to the valued image they hold of themselves. ${ }^{2}$ The result can be seen as "cognitive dissonance" in the internal conversation between the "I" and the "me" in whatever roles are involved in the interaction, and consistency seems to prevail. ${ }^{3}$

For example, consider the comments of the following woman, whose self-esteem was "low" due to a bad marriage and 
an unfaithful, now departed husband. She notes that she felt she did not "deserve" compliments, and agrees that she would "filter out" good things. When asked whether this was to keep her in line with what she felt about herself, she answered:

"Yes! How can somebody give me something good about myself when... when I don't feel very good about myself? It's too confusing, so rather than to accept it I'd say "oh, well I don't.... d don't think that's necessary." Or, "well, you know, I...I did this wrong." You know, I'd try and find fault where I did something wrong, and it could be the...the (most) minute thing. It doesn't matter. I still did something wrong." (female, age 28).

Moreover, when asked whether this merely confirmed what she believed before, the same respondent emphatically answered "Oh yes! Yes."

A second, young bisexual respondent, who had been date-raped several years previously, had suffered from severe depression for several years before recovering. He notes that "at the moment" he has "fairly high self-esteem." However, when asked about his response to positive feedback, he stated:

"Sometimes I have difficulties in accepting it. Especially compliments. So it took me really, um, going to this assertiveness training, um, saying "thank-you." So, it's all a strange feeling for me to just say thankyou and smile. Um, I'm trying to do it. It's still a strange feeling. And sometimes I try to put it down, but this was more in times when I had this low self-esteem. So, because it didn't fit into my self-image of me. "How can you look at me like that when I'm...so... yeah." (laughter). (male, age 25).

Thus, these data illustrate the hypothesis that both the assessment given in interaction, and the self-image of the subject, must be consistently positive, or happiness is not 
the result. Indeed, the best statement of this principle is in the concise comment of one respondent that:

"I personally achieve happiness..by being who I am. And by letting me be me. By showing other people who I am. And, for them, when they see who I am, to smile." (female, age 36).

\section{(b) Negative Interactions:}

The second hypothesis listed under the general interactional model of happiness, referring to the emotional effect of negative interactions, read as follows:

(ii) Negative, disconfirming social interactions will lead to negative self-assessment, inconsistency, and therefore unhappiness.

Again, note that this hypothesis contains the two requirements that the interaction must not only be evaluatively negative, but also disconfirming in relation to any positive or desired role-identities involved. ${ }^{4}$ The following accounts necessarily and logically consist of interactions that contain both of these criteria.s

The vast majority of reported negative interactions revolved around the single role and personal relationships. Examples, ranged from minor, fleeting encounters to more intense, protracted matters of the heart. An example of the former would be the look of dejection witnessed by the researcher when an older woman approached a man to dance and was turned down. Similarly, consider the following comments:

"If you don't have somebody obviously you've had times when you feel a bit bummed out when you see your 
other friends with individuals." (female, age 26).

"Sometimes I kind of get down on myself, I think, you know, you go out to a bar and you get shot down left and right, you know, all over the place. And I guess you get down on yourself like that." (male, age 21).

"I've had some painful rejections... and they've been quite devastating. Um, I feel that the rejections have been a reflection of my own inadequacy." (male, age 33). More intense disconfirmations include the situations described in the following comments:

"It was a big blow to have someone that I trusted, and was devoted to and loyal to for eight years, just up and leave me for another woman." (female, age 28).

" (Divorce) is the death of a marriage and, uh, you have to go through a mourning experience." (female, age 36).

"When I was eighteen I was date-raped by a coworker." (this precipitated a) "personal crisis" (that) "put me down for...about four and a half years." (male, age 25).

Central to all of these examples is the negative evaluation of the emoting individual or of a highly valued component of his/her self. This may either originate with other individuals in the interaction, or occur in the subvocal conversation between the "I" and the "me" in light of an individual's beliefs. Essentially, the negative emotion, or unhappiness, expressed by these individuals reflects, in either case, role-specific inconsistency between one's evaluative perceptions of an event and one's previous or desired evaluative perception of oneself embedded in the generalized other. Thus, the preliminary evidence illustrates 
the second hypothesis as well. ${ }^{6}$

(c) Components of Evaluation:

The third hypothesis listed under the general interactional model of happiness discussed those components affecting whether or not an interaction is ultimately seen as positive or negative in relation to the self $\underline{i . e .}$ happy or unhappy. This reads:

(iii) Whether or not interactions are seen as positive or negative will depend upon factors including: (a) perceptual beliefs; (b) evaluative beliefs; (c) self-interaction; (d) utilization of "identity maintenance strategies" (e) significance of interaction partner; (f) social support; and (g) importance of one's interactional role.

Each of these factors will now be discussed in turn in relation to the qualitative data.

\section{(i) Perceptual Beliefs:}

The idea that perceptual beliefs affect one's experience of emotion is based on a simple logical premise: if one cannot perceive something as something significant in

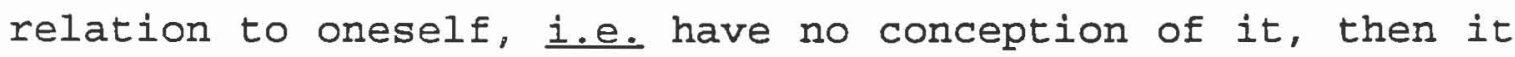
has little importance in relation to the emotions one actually experience. ${ }^{7}$

The data collected illustrate the significance of perceptual beliefs in three ways: (1) in comments suggesting less than conscious paradigms structuring the perception of interactions or social situations; (2) situations where emotions and conscious evaluative beliefs conflict; and (3) in 
conscious attempts by the individual to see the situation differently. Each will be dealt with in turn.

The underlying paradigms of perception are suggested by the following comments of respondents:

"Values and beliefs are not something that I ponder every...every moment of my life. It's...it's just more that they are there, uh, probably more subconsciously than any-thing else, um, making me react when I believe things the way I do." (female, age 26).

"I Eeel good if I help someone or something, or I feel shitty if I do something really stupid, and, you know, kick dirt in someone's face or whatever. Uh, so yeah I guess I use the Christian values quite a bit really. But it's sort of the underlying... I don't usually do it consciously." (male, age 21).

"My idealistic perception of people sort of clouded the...my, uh,...clouded the issues and clouded my...my true outlook of people." (female, age 36).

Each of these above comments belies the power of one's less than conscious perceptual beliefs in influencing one's emotional experience.

Moving on to the second situation, that where emotion and consciously-held evaluative beliefs conflict, consider the following comments by a young female university student. This individual states that she has had a "good life," and that she "likes herself" for a variety of substantive reasons. Yet, regarding her appearance:

"Every time you look on the stinking TV there's this beautiful woman and, I, you can't help like, I can't believe that someone can say that it's not 'cause it does, it really does affect you... I would love it not to be, but... I always...you know, you're sitting here all

the time, you look, and every time they look amazing. And 
every time...everyone's like getting fit... So like I, its so hard to not... every time I have a bulge here or get bigger I just go "ugh, I'm ugly!" (female, age 21).

It is important to note that similar experiences also occur among individuals specifically contemplating the single life. For example, consider the comments of the following subject, a 28-year-old female who has never had a boyfriend. This individual stresses how important it is to "have her act together" before she dates someone, and asserts her conscious position that:

"I would like to have one person important in my life - but, if that doesn't happen, I'm not going to (die)...I'll make the most of life."

Yet later, upon further questioning, this person reveals, in an unhappy and emotional tone of voice:

"I'd wonder about whether I'll be alone. 'Cause I think at this point I... I'm fairly realistic in that I've...I'm... I'm thinking I might very likely be alone, because I've been alone this far. So I don't hold out hope that I will be a couple..."

Finally, this respondent confesses to the extent of her inner conflict:

"I..I say if it happens, it happens...you know, whatever way it works out it will be fine, but that's not truthful. That's just me trying to convince myself of that. I definitely feel that if I go through life on my own I'll be missing out on a lot..."

"Lately, since I've met up with some guys that I hit it off with, now I feel like I really need that in my life. And yet, I don't want to... I'm mad at myself for wanting that because I feel that I'm setting myself up for a fall. Because, I don't know, it doesn't seem to work out for me so I... I don't want to rely on another person for my happiness. I...'cause I don't feel... I feel 
that the only person I can really rely on is myself." These comments clearly illustrate the emotional tension between consciously-held evaluative beliefs stressing self-reliance and stoic dignity, and deeply instilled perceptual beliefs stressing the value of being in a relationship. Even though this individual tries to consciously convince herself that there is nothing wrong with being alone, the deeply-instilled cultural beliefs, even when they become conscious, result in her negative self-perception, and the conflict results in the emotion of unhappiness.

Finally, perceptual beliefs are visible in great abundance in individuals' conscious attempts to see interactions or social situations differently with reference to themselves. Consider the following four comments by respondents as representative:

"I take (criticism) positively...I see it not as a personal attack on me, but as just an area of my life or a part of my personality that they are questioning or drawing attention to... It's not that they're knocking me down totally...you know, that they're totally condemning me. And I was unable to make that differentiation... I need to believe, as people have said to me when I go to them about talking about my rejections, and, it's just they aren't interested in me. It's not that they are condemning me. They're not personally criticizing me, it's just, for whatever reason, they're not interested at this point in their lives. They might not be interested in a relationship...or maybe just there's something about me that they don't feel comfortable with - and that's OK. It doesn't mean that they are judging me or condemning me.." (male, age 33).

"I'm going through counselling and she's helped 
me... see a lot of things. Um, I'm a very strong person, and I'm domineering, but I've learned that being a domineering person doesn't make you a bad person." (female, age 28).

"It was, um,...learning the concept of daterape...um, understanding the dynamics of, um, what a rapist is trying to do psychologically - especially this shifting of guilt... and in coping...having learned strategies of coping." (male, age 25).

"Well it's all relative isn't it? Um, you tend to every now and then get a little, uh, you know, full of self-pity because you don't have this or you don't have that. Um, and, of course, I mean, I've got... I've got friends who are more established than me. But, when you look at it on a more global level - I'm not starving and, uh, I have a lot of, uh, friends and family and things like that. So, in.. In the overall scheme of things, I...I don't come from a family of, uh, wife abuse, of child abuse, there's no alcoholics, there's, you know, no... nobody in any mental institutions or anything like that. So, I think, uh, as far as that goes, um, there isn't too much to write the soap operas about, you know." (female, age 26).

In all of the above comments runs the common thread that individuals are consciously utilizing beliefs to alter their perception of reality - a reality that would be more threatening to them were they not to do so.

Thus, the significance of perceptual beliefs to emotion - and happiness - is found in three ways, subconsciously, in relation to emotion-belief conflict, and in conscious management of unpleasant emotions in particular social situations. It would appear, therefore, that there is some preliminary evidence illustrating this component of the third hypothesis. 


\section{(ii) Evaluative Beliefs:}

Going hand in hand with one's perceptual beliefs are evaluative beliefs regarding one's self-image, and, therefore, one's happiness. Kept conceptually distinct, perceptual beliefs influence what we see in a particular interaction or social situation, while evaluative beliefs determine it's moral significance in relation to the self. Of course, this analytical distinction becomes blurred in the real world, as most perceptual beliefs contain evaluative elements, and viceversa.

Respondents most frequently noted self-evaluative beliefs in relation to situations involving the single role or personal relationships. Consider the following five comments:

"All through high school I never had a boyfriend. Most of my friends, a lot of us didn't. And, after a while you begin to wonder, you're like "Why? What is it about me that... why haven't I had a serious relationship? Why aren't people attracted to me? Why can't I... when I meet someone, maintain it? Or, why can't... Like it just makes you wonder about yourself." (female, age 19).

"I may not go out there and... and, uh, find a Robert Redford, but, I know that there are people out there that find me attractive and, uh, that's obviously a nice feather in your cap I suppose." (female, age 26).

"I guess when I do meet someone then, you know, then you've got some...you know, it makes you feel, it makes me feel better about myself. 'Cause like, you know, you say "Well, someone else sees something that, you know, someone else is attracted to me and all that." Yeah, that gives you some self respect and, you know, to know that someone else wants to be around you. So, I guess that, you know, it makes you feel better about yourself." (male, age 21). 
"You break up with a girl and it (self-esteem) goes really low if things don't work out right... When I was younger, I had gone out with girls for a long, long time and got really attached to them, and, uh, you know, it was really, really hard." (male, age 21).

"My morals... were brought right down to the ground. Um, I have always tried to perceive myself to be a lady. And I really felt, um, excuse the language, but I did feel like a slut." (female, age 36).

In addition, respondents themselves recognized the importance of positive self-evaluation for their overall happiness. 8 For example, one respondent states:

"If I go to do something, I..I think, "when I'm done this, how will it...how will it make me feel? will I know I've done a good job? Have I done the right thing? And that's how I look at everything. Like, anything major that I have to do, I do." (female, age 28).

Another respondent gives his opinion that:

"I would say happiness is being able to sort of...I think for me to be really happy I'd have to be able to fit my actions basically all the time... well not all...like, but more of the time to my beliefs." (male, age 21).

Finally, a 28-year old female respondent notes that she doesn't know how happiness couldn't be related to one's beliefs, as "you relate everything to what you believe." She adds:

"Happiness - what makes you happy from any one moment to the next changes - so I guess happiness is feeling...is feeling content. And that's based on your perspective at the time. Perspectives (are) always changing so, it's kind of what your current perspective is...meeting...meeting what you dec... whatever you decide is important to you at that time. I guess it's achieving that... um, living up to that. If I'm able to live up to what I think's important to me I quess I...then I'm pretty content." 
Thus, it would appear that there is some evidence illustrating this component of the third hypothesis as well.

\section{(iii) Self-Interaction:}

This third component of the third hypothesis is based in the classic Meadian tradition, asserting that the self of the "I" and the "me" interacts with itself in approaching and analyzing social situations and interactions. It is closely related to Denzin's concept of the subvocal phenomenological stream, which, of course, can be witnessed when made vocal by respondents expressing how they feel about and choose to approach these events.

The data demonstrate three main divisions in reported emotional self-interactions. Aside from the straightforward and expected split between positive and negative selfinteractions, there is a distinction to be made between (1) reported self-judgments vs. (2) judgments of others. As well, there are (3) consciously stated approaches that individuals espouse in relation to life or an event. 9 Each of these will be dealt with in turn, taking care to give positive and negative examples of each.

The data clearly show both positive and negative judgments being made by individuals in relation to themselves. Examples of these self-interactions are many and varied. Consider the following positive example:

"I'm proud of a lot of the things that I've done. 
I've...I've... I have taken some risks. Um, I've been very involved... in high school very involved. Um, and like I've done a lot of things to help other people, and... I've played a lot of sports and I did well at those, um, on the student's council and stuff... I helped out a lot there and, I just, I don't know, I feel like I've made an impact. I feel like, some of the people I've met I've made a good impact on them." (female, age 19).

Negative self-interactions are far more common in the data, however. A good general statement of self-interaction in this context comes from a 21-year-old male discussing his reaction to difficult and unpleasant events:

"I get really emotional myself. Like I get more emotional I think, than a lot of people see. Like, I think that when a personal problem arises in my life I think that I really...it messes me up for a while, and, uh, I think, uh, I reflect on it and I'm not myself for a few days or weeks or whatever - however long it takes, and, uh, you know. I mean, deep thought for me, like I need time alone, just to say hey, sit back and compute the situation." 10 (male, age 21 ).

Finally, consider the negative self-evaluations made by the following four respondents:

"I expend a lot of energy, you know, just not being happy being single." (male, age 33).

"I worry, like, if, um, I'm attractive enough to find another man. Like, to have another man look at me and think that way." (female, age 28).

"I also view myself as being a little bit unsatisfied with what I'm doing now... sort of, not really killing time, but not quite sure what I want to be doing, and sort of moving along and perhaps not, uh, being aggressive enough to change what I'm doing right now... The last 5 or 6 years of my life sort of falter and I'm not quite sure that I'm doing the right thing. I'm sort of waiting for something more. Which is, you know, I say I should be more aggressive and go out and try and find that something more." (male, age 21). 
"I compare myself to other people the same age - at what point they're at in their life, and, I'm definitely behind, in my opinion,... where I should be. You know, I'm not living on my own. I don't have a car. I'm not really, um, I'm not being independent enough. I'm not standing on my own two feet. I'm...I'm still kind of, uh, um, probably a lot relying on my mom in a lot of ways to, um, kind of cushion me from the real world." (female, age 28).

The second type of self-interaction reported in the data involves subvocal judgments of others in interaction. A good illustration of this is the following comment of a 26 year-old female in relation to the effect of male attention on her self-esteem:

"It really depends, I mean, if its somebody that I... I find attractive and... uh, in both, uh, in looks and the way that he, uh, um, presents himself and, uh, you know, as far as, uh, his personality is concerned, um, then I'm extremely, um, flattered, and it does a lot of things for my self-esteem. Um, conversely, if there's somebody that's a real idiot that comes up to me and thinks that they, you know; that they...they have a chance and they're complete, you know, goofs. Then I go "What kind of..." you know, "Jeez I put the wrong perfume on tonight" (laughter). Um, and that tends to lower selfesteem."

Finally, one comes to the third category of self interactions: consciously-stated, active approaches that individuals express in relation to life, or to a specific event. Consider the following comments as representative:

"I look forward to things like, say, you know, if I'm going on a camping trip in a week or something like that, you know. That week that's all I'Il think about, you know, its like doing that...I'll pack stuff and just have it... really look forward to it, you know, that sort of thing. Or, if I have, you know, a test on tuesday or a thursday night, thursday afternoon, you know, I'll look forward all, you know, the whole time saying "Oh yeah, at 
least I can go out on friday, I guess." (male, age 21).

"I think I take everything...I look at everything in a kind of a satirical way. Like, you know, politics I can't really get serious about because I see so much corruption and, I don't know... I guess I see things in a plainer view I think... Not so much criticizing them but, just laughing at the way you see things. You know, all the lies going around and stuff like that... You just got to throw your feet up and laugh sometimes." (male, age 21).

"I think when bad things happen, I think for me it ties into religion. I...I always try and think "Well, you know, maybe this is happening for a reason. I mean there's...maybe there's something good that can come out of it. Um, like, you know, Christianity says, you know, God only gives you what he knows you can handle." (female, age 19).

"I try not to think to the future or try not to stew on the past. I kind of just live for each moment - 'cause I have control over it now. I don't have control over the future or the past... The things I can change I'd probably work on, and the things that I can't change I'd try to tell myself that it doesn't matter. Like, it takes me a while to believe that. Uh, but yeah, if I can't change it I try not to think about it." (female, age 28).

"I find sometimes if I don't live up to my ideals that...that perhaps I...I will find myself beating myself up on it. And, uh, I just stop myself because I realize that I'm not perfect and I'm a human being, you know. And I think that...that you've got to realize that no... nobody can live up to their ideals... I'm no better or no worse than anybody else." (female, age 26).

All of the above examples illustrate the reflexiveness of the human individual, whether in judging oneself, others, or considering the best way to approach a situation. In all three of these types of self-interactions is implied the incipient "I" response, later objectified in word or deed, and the more general importance of self interaction as a component 
of the model above. It would appear, therefore, that there is also some preliminary evidence illustrating this component of the third hypothesis.

\section{(iv) Identity Maintenance Strategies:}

This component of the general interactional model of happiness is premised on the idea that rational, creative, reflexive individuals, in their interactions with others, and with themselves, do not have to accept negative feedback or social situations at face value. Rather, if their perceptual and beliefs enable them to initially see events as negative, they have options - both in assessment and in action. ${ }^{11}$

This component of the model promises to be one of the more difficult to discuss. To some extent these matters have already been reviewed, such as in the discussion of individuals consciously attempting to see things differently in the section on perceptual beliefs, and in the consciouslystated approaches to life expressed in the section on selfinteraction. Yet, a more thorough review of these matters is necessary.

It will also be remembered that the umbrella term "identity maintenance strategies" has been used to characterize a wide range of tactics utilized by individuals in protecting their self-esteem, and by extension, their happiness. ${ }^{12}$

It is not intended here to repetitively wade through 
the data seeking out specific examples of theoretical labels like "selectivity", "conceptual escape routes," "intentional value feelings," "emotion management," and "emotional micropolitics," to name but a few. Indeed, many of the terms lumped together are so closely related as to be interchangeable, or are subcategories of each other. ${ }^{13}$ Rather, upon a review of the available data, it has been determined that a more useful approach is to divide these strategies into two broad categories: (1) subjective, conceptual manipulation, and (2) active, interactional tactics. Each of these strategies will be reviewed in turn.

First, with regard to the subjective strategies, the data are rife with examples. Consider the following seven comments which demonstrate, respectively, the subjective strategies of shifting blame by labelling, comparing oneself favorably to others, asserting that "I'm doing my best," pointing to similar insecurities in others, medicalizing one's problems, focusing on the redemptive aspects of religion, and minimizing the significance of one's single status. ${ }^{14}$

"If you know a person is prone to saying those types of things, no matter how close they are to you, um, uh,...then it doesn't mean as much." (female, age 26).

"Well, part of the reason I'm happy I think is because I know how well off I am, like, I think its just ridiculous for me to be unhappy. I have so much compared to so many other people." (male, age 21).

"I take pride in what I do. And I was brought up with the fact that, when you put...you always put your 
best foot forward. And if you don't do well, know that you did your best. And, it doesn't make you any less a person. If you've done your best, and you can walk away saying "I did my best, " then, although I didn't do well, I did my best, and I can feel good about that." ffemale, age 28).

"I think I used to have less of an opinion of myself until. I, um, I came across a Murphy's law quote, and I started remembering it all the time... It was essentially: "Stop worrying about what other people are thinking about you, because they're walking around wondering what everybody's thinking about them. They're not really thinking about you." (female, age 26).

"I'd say for the majority of my life I didn't like myself because, um, well I always knew that I...I did things the hard way and...until I found out that I had O.C.D. (Obsessive Compulsive Disorder) I, um, I probably just thought I was.... person that didn't know how to get through life... in the proper fashion. Things seemed too hard for me and I... and I used to hate myself for that. Like, "Why can't you breeze through life like the other ...the way the rest of the world seems to?" But now that I realize, uh, that its a...a mental illness I...I'm not so hard on myself. And I... and I kind of, I probably am proud of myself that I've hung in there as long as I have." (female, age 28).

"I guess you can argue that I'm not living up to my ideals. But, if you're going to believe in the christian thing of forgiveness, again, you ask for forgiveness." (male, age 21).

"(The) downside (of being single is) watching, you know, certain news reports that say if you're a 34-yearold single, middle-class woman, your chances of getting married are 18 to 1 . Something like that. And, of course the two things I say to that is "Well, you know, first of all... what's...marriage isn't that great" and "You don't need a man or significant other in your life to, uh, um, to have self-esteem - 'cause if you didn't before you got involved with that person, then, uh, then its probably not going to work out properly anyways." (female, age 26).

In each of these examples the individual subjectively manipulates reality in the inner conversation between the "I" 
and the "me" in the phenomenological stream in order to avoid an otherwise negative self-evaluation.

Secondly, the data also show examples of: active, interactional strategies.15 For example, consider the following tactics utilized in response to negative feedback:

"I maybe even try and manipulate them a bit to sort of see..."Well, that didn't go right but, you know, this is why and now you can sort of see why it didn't go right," or something like that. Saying, "OK, these are the conditions I had to work under, and, considering that, you know, I can, you know, maybe..." You know, try and say that there was a reason for it, I guess... I just maybe try and worm my way out of it, I guess (laughter)." (male, age 21).

"I'm...I tend to veer towards the argumentative side. If, uh, somebody says something that...that's valid, um, I might challenge it at first, but then I'lI come around, um, because of, you know, just average human pride, I suppose. But, if somebody is...is saying or doing something that is...is absolutely ludicrous, then I will say to them "What you have just said is absolutely ludicrous." (female, age 26).

"I, um, use guilt because people want to be my friend. So I "Oh, OK, fine, if that's how you feel, "you know. And then they kind of go "Oh oh, Gee I..." (female, age 21).

Thus, with regard to both subjective, conceptual manipulation, and active, interactional tactics, there is some preliminary evidence illustrating the use of identitymaintenance strategies by respondents. This element of the third hypothesis also receives some backing. (v) Significance of Interaction Partner:

This component of the third hypothesis is based on the idea that the more significant an individual's interaction 
partner, the more weight their evaluative comments will carry in relation to that individual's self-esteem, and, therefore, happiness. Conversely, the less significant one's interaction partner, the easier their negative comments will be to dismiss.

Many respondents have commented on this issue. For example, consider the following:

"I would say that...friends and family...co-workers, I would take their negative feedback very seriously. strangers, not so much (laughter). Because they don't have experience with me, and they have to have experience with someone in order to be able to really assess." (female, age 22).

"It makes a very big difference, um, because people that are close to me are the people that really know me, and if they say something, uh, in a negative manner, uh, it...hurts." (female, age 36).

"Definitely. I mean, uh, um, if its someone you have a lot of respect for, um, obviously it hurts if they say something that's...that...that is, you know, is... is not friendly but of criticism, or any...you know, any type of criticism hurts more if it comes from a, um, a closer source." (female, age 26).

In all of these above comments can be seen the hypothesized idea that evaluative comments directed at self by others carry more weight when coming from significant or familiar others. Such comments coming from strangers generally evoke dismissal, or self-righteous anger at the other's lack of familiarity.

Two further matters need to be discussed, however. First of all, two respondents commented on the contradictory 
idea that strangers' evaluations may be more significant than those made by one's inner circle. ${ }^{16}$ These comments must be addressed.

One of these individuals, a 21-year-old male, was obviously referring to the supposedly objective, authoritative institutional evaluation of his highly-valued schoolwork rather than personal criticism by strangers. For example, this respondent referred to "putting a lot of work into" his schoolwork many times during his interview, and how important it was to him. Indeed, immediately prior to the comments cited above, he was questioned about his work, and stated:

"You know, if I put a lot of work into something and someone puts it down...that's just not going to go over that well."

Indeed, he later states that criticism by significant others is "just as bad:"

"You want your parents, your family and your friends to stick you up and put, you know, like, you know, sort of like back you up and stuff like this, so I guess when they do this - they put you down or something like that, I guess its just as bad."

A 28-year-old female, similarly, referred to this perceived objective authority as opposed to uninformed opinion. For example, this respondent tells of how being professionally diagnosed by a psychiatrist as having O.C.D. (obsessive compulsive disorder) helped her accept herself, but still discussed as highly upsetting situations involving family and friends. For example, this individual speaks of 
comparing herself to her siblings as a reason she evaluates herself as being "definitely behind" in life. She also tells of her upset that "People I thought would be my friends for Iife, um, just kind of disappeared from my life." Finally, she finds it hard living with her mother at the age of 28 because of the "perceptions of other people."

Thus, these comments can be interpreted as referring to perceived authority as merely another dimension of significance, instead of bluntly contradicting the general thrust of the above hypothesis.

The second matter to be discussed is the relation between this component and the single role. Again, consider the following comments:

"You break up with a girl... Now I don't know if my conscience is getting hardened or whatever. I find myself, I don't know, like I find, uh, sometimes I'm not as concerned. I don't know whether its because the girls I date I know I'm not going to be married to, whatever. But, uh, I know if I found the right girl I think I'd be really upset, you know, for the longest time." (male, age 21).

"Don't worry about it, have fun, that's the attitude I'm trying to have... You're not going to marry the person so why not just have fun?" (female, age 19).

"Its not so much...so much being with someone, its being with that someone." (female, age 36).

"You can't talk with anyone - especially the person that you want so much to listen, you want them to listen to... and you're afraid that, uh, they're going to turn their backs on you, and, that would hurt me even more." (female, age 36).

In all of these comments can be seen the common thread 
that the more significant the partner in the individual's life, the more important will be his/her interactions, comments, gain, and loss to that person.

Thus it would appear that there is again some evidence in the data to lend preliminary support to the hypothesized relationship between significance of one's interaction partner and the effect of the interaction on one's happiness. This significance appears on at least two dimensions: (1) personal closeness and (2) perceived authority. Finally, this is again directly seen in relation to the single role.

\section{(vi) Social Support:}

This component of the general interactional model is based on a very common sociological premise: human individuals, as social creatures, will be happier when there is social support for their positive self-assessments. ${ }^{17}$ This reinforces both self-evaluation and self-consistency. Moreover, they will frequently seek out social support as a means of managing negative experiences and interactions. ${ }^{18}$ As such, their behavior may also be classed among the active, interactional tactics utilized by individuals in the section on "identity maintenance strategies."19

The difference between this component and that discussed in the previous section is also important to keep in mind. Significance of interaction partner refers to the relative importance or authority of two or more individuals in 
interaction to one's interpretation of that interaction in relation to self - be it positive or negative. Social support, in contrast, refers to whether or not one actually has other individuals to turn to following difficult or disconfirming events in order to reinforce a positive self-identity, or, more generally, to help in constructing a positive interpretation of events in relation to the self.

Numerous respondents have made comments on this latter topic in three general ways: (1) by referring to their having loving friends and family as a source of their happiness; (2) by talking of seeking out the counsel of friends and family in difficult circumstances, or after a negative interaction; and (3) by referring to the significant effect of social support in relation to the single role - particularly in relation to interactions therein. Each of these will be dealt with in turn, giving special attention to give positive and negative examples where appropriate.

With regard to individuals' comments on their loving friends and family as a source of their happiness, consider the following representative examples:

"I would say that I've been really lucky. I was brought up in a really nice family... I've got good friends and, like, I get along well with my family on the whole..." (male, age 21).

"I find that my life is extremely enjoyable. Um, I have, you know, a wealth of friends..." (female, age 22).

"I have both my parents alive. I never had a...a 
relative really close to me that I was crazy about die .... I have a good... a normal amount of friends. Um, you know, I essentially am a very lucky person at this stage in my life. And, uh, so I guess those are things to be happy about." (female, age 26).

In contrast, respondents often speak of their relative unhappiness when these positively valued and reinforcing individuals are absent, or leave. For example, one 21-year-old male respondent notes the following "rough spot:"

"As a kid after my um... when my parents split up, we lived basically in a slum for, like, eight years..."

Others talk of divorce, the loss of friends, being left alone, death of loved ones, and failure of support for one's vocation:

"My friendships let me down so I was living more so for my family. And then when my parents split up, that foundation fell, and I couldn't... I think I always relied on my parents but I couldn't rely on my dad anymore. So I had to... I had to be the support for my mother... I think I've really clung to my mom for stability - I think vice versa for her." (female, age 28).

"I was overprotected by my folks because of my epilepsy. I was overprotected by my, uh, now ex-husband because he wanted to protect me from the cruel, cruel world... and then, uh, being thrust out into the cruel, cold world of, uh, you know, "OK, this is where...this is what its really like," you know, "You got to fight and scratch and do what you can." And, uh, when you're being, um...protected from that, and then, you know, thrust into it, its a rude awakening. Trust me, its a very rude awakening." (female, age 36 ).

"The first day when I heard about her death...it... it still hurts because she was like my second mom. She raised me (subject becoming emotional). And, um, I love her and I miss her..." (female, age 36).

"I felt very alone, and, uh, if you've ever had the feeling of being alone within a crowd, and, not being 
able to talk with anyone - especially your best friend, um, that...that makes you feel very lousy." (female, age 36).

"The only major tragedy was my mother's mother dying when I was 18. I was very close to her... And, uh, my husband leaving me. That would be the most traumatic. That's the worst... It was a big blow to have someone that I trusted, and was devoted to and loyal to for eight years, just up and leave me for another woman." (female, age 28).

"They don't really support me. And I have to live with the fact that I know that my parents and their relatives are thinking, you know, "This is some, you know, one of those professional 30-year-old...bums sitting around getting money off the government just to read books." And things like that. And, uh, that can get me down at times." (female, age 26).

Thus, it would appear that social support, in the first sense of having positively valued and reinforcing friends and family as part of one's life, shows some preliminary evidence of being an important element of personal happiness.

Turning now to the second aspect of social support: its ameliorating and management function in relation to life circumstances and individual happiness. There is no lack of evidence in the data on this topic. First, there are the comments of a 33-year-old male who positively states:

"Positive feedback is...is necessary for me to grow and to continue to prosper emotionally, and physicaliy, and spiritually, and materially as a human being. I mean I need that visible...that positive feedback. You know, and I seek it out. I ask people sometimes to say something good about me."

Aside from this general positive example, however, 
most respondents spoke of seeking out social support as a means of managing difficult life situations or negative interactions. Consider the following examples:

"I talk to some people sometimes when I've got something really bugging me... I really get along well with my family on the whole...they're always there to support me if I...if I need it. And so, if I'm feeling down I give them a call and, you know, feel better." (male, age 21).

"Yes, I have cancer, but I don't find it too much of a tragedy - because I've been very lucky in life, and because, like I said before, I have an awesome family and I have awesome friends and I have a great support system, and I still feel lucky... It also helps I live with somebody - we're just friends - but I see her, do you see what I mean? I go from this room, I see her face. I come to this room, I see her face. So I'm never by myself here. And that's another thing that's really important. I've never been by myself. I'm always around somebody. I've never been left alone, ever. My parents have always been with me. I'm always with my sister, my brother, I have lots of friends. I've never had to go anywhere by myself. So when I'm down, other people help bring me up, you know. It would be really scary to see myself by myself in my own apartment: by myself, isolated, not being able to have somebody. But then I would think I'd call someone on the phone, right? But with (my room-mate) being here all the time, you know it just...it does make a difference. It makes a difference, you know. When I'm up...even when I've been little, when I was little, I've always had somebody there to bring me, you know, or to look at them and go... (respondent gasps and makes a face). You know, or there's my mom to make me happy, and there's my sister, you know what I mean?" (female, age 21).

"When my husband left me, my mom and dad came and sat and talked with me... and they just said "Well you've always been that way... You've always been up front, straightforward, honest, what you see is what you get..." "Since this has gone on' I ask people, you know, "What do you think of me?" They say "You're responsible, you're mature, you're outgoing, you're kind, you're understanding..." And these - and I'm not fishing for compliments - $\underline{I}$ just want to know if what I'm feeling is 
what I should be feeling. Or, what my husband's telling me I should be believing... I just have to find the right people to give me that support." (female, age 28).

In all of these examples can be seen the common thread that individuals seek out social support when dealing with or managing difficult or disconfirming events. As such, social support has an ameliorating function when consciously used by individuals in relation to their unhappiness.

Finally, one must pause to consider the function of social support in relation to happiness and the single role. Specifically, this discussion will focus on the presence or absence of a significant other, as well as interactions related to that purpose. ${ }^{20}$

The following positive effects of social support for one's attractiveness have been noted by respondents:

"I guess when I do meet someone then, you know, then you've got some...you know, it makes you feel, it makes me feel better about myself. 'Cause, like, you know, you say "Well, someone sees something that..." you know, "Someone else is attracted to me" and all that. Yeah, that gives you some self respect and, you know, to know that someone else wants to be around you. So I guess that, you know it makes you feel better about yourself." (male, age 21).

"I know that there are people out there that find me attractive and, uh, that's obviously a nice feather in your cap I suppose. Um, and yeah, it does tend to lessen the, um, perhaps the...the desperation that some people may find themselves afflicted with, who are...have lower self-esteem." (female, age 26).

Similarly, several respondents noted that they were happier with the social support of a relationship. For 
example, consider the words of a 36-year-old woman speaking of a past relationship:

"I enjoy having the fine company, and I enjoy, immensely I enjoy being in love. It is the most wonderful and the most brutal feeling and all rolled up in one... Being with that special someone. The one that you know ...the one that you know knows everything about you. And you are willing to tell everything about yourself. And you are willing to listen while (he) opens up....and lets them...lets them, um, open up so that you're not only Iistening to them, you're hearing them, you're understanding them, you're knowing them... Yeah the, uh, the union with your soul mate, uh, there... its such a bond, its so strong. You can go through hell and back again and, uh, when you meet, its just like everything had not been there."

In contrast, several respondents found it disconcerting when others did not find them attractive. Consider the following comments of a 19 -year-old female as representative:

"Like, all through high school I never had a boyfriend. Most of my friends, a lot of us didn't. And, after a while you begin to wonder, you're like "Why, what is it about me that.. Why haven't I had a serious relationship? Why aren't people attracted to me..."

Similarly, many respondents expressed unhappiness at the lack of social support like that found in an intimate relationship, while others suggested that they would be happier in such a relationship. Consider the following:

"Some people are happy being single. I'm not. I accept it where I am right now but, um, its hard. I expend a lot of energy, you know, just not being happy being single. I mean I just dwell on it." (male, age 33).

"The hardest time is at night when I'm by myself and my kids are in my bed. And that's the worst time of 
night, because that's when your low self-esteem kind of sneaks up on you and, that's your quiet time, and of course what people do during quiet time: they think. And, um, that's when I bat my head against the wall...at night basically. So that's the worst time. And the loneliness and, just even to go out for a cup of coffee. Like just... and with a man. With the male companionship I miss." (female, age 28).

"Overall no, I didn't really like being single at all. I don't like being by myself as a rule - never did. Uh, even when I was married and my, uh, husband was out at sea, um, when I was by myself I didn't like it. Even though I was married I was by myself." (female, age 36). Thus, it can be asserted that there is some preliminary evidence in the data supporting the proposition that social support for one's attractiveness, and the positive reinforcing interaction of a relationship are also important to individual happiness.

In concluding this discussion, therefore, it can be reiterated that the preliminary importance of social support to individual happiness has been seen in three different ways in the data: (1) individuals pointing out that they have loving friends and family as an ingredient in their level of happiness (and vice versa); (2) individuals seeking out social support as a means to ameliorate or manage their life circumstances; and (3) the presence or absence of positive reinforcement - both as to one's attractiveness and one's degree of intimate involvement - in the single role. There is thus some tentative evidence in the data in favor of this component of the third hypothesis in the general interactional 
model of happiness.

(vii) Importance of Interactional Role:

This last component of the third hypothesis is based on the idea that the self is composed of "I" and "me" components arranged into a hierarchy of roles. These internalized structural components, a function of commitment to various networks of social and institutional relationships, affect the ultimate significance of an interaction or event to an individual's emotional state, and therefore, happiness. Essentially, the more important a particular role is to an individual, the more significant will be interactions which involve it.

Some introductory comments. First, while significance of interaction partner is discussed in this section as evidence of such a role hierarchy, this must be kept conceptually distinct as merely one component structuring such a hierarchy, chiefly within or across one's specific role sets. Indeed, subject matter, discussed herein, does as much to structure the role hierarchy as does significance of interaction partner. ${ }^{21}$

Secondly, in this section the self of the "I" and the "me" will not be given much attention. This is for two reasons: (a) it is implicit in much of the above discussion of positive and negative interactions, disconfirmation, selfinteraction, identity maintenance strategies, significance of 
interaction partner, and social support; (b) this has become such a widely accepted account of the self in sociology, both in theory and research, that to elaborate upon it further would appear to be redundant.

Rather, this section will take the "I" and the "me" as a given, and focus attention more squarely on the hierarchical organization of the self whereby some I/me dyads, (expressed in both role sets and roles) are considered by the individual to be more important, more central to his/her overall identity, than others.

In general, it would appear that this hierarchical ordering is expressed in three ways in the data: (1) perceived importance of interaction partner in one's social network (and, correspondingly, role-set) dictating degree of response to feedback; (2) importance of subject matter (i.e. role) determining level of response to positive and negative feedback; and (3) individual listings of the most important roles in their lives. Each of these will be dealt with in turn, following which there will be a short discussion of seemingly contradictory comments by several respondents.

First, with regard to importance of interaction partner in one's social network and internalized role-set, it would be prudent to review again the above section in this regard. (Infra, p.101-105). There, evidence was adduced suggesting that the less significant the person giving 
negative feedback is perceived and evaluated in one's social network, (and thereby role-set) the easier it was to dismiss, and the less concerned were individuals about hurting:feelings when doing so. The following comments on "I" responses to negative feedback from strangers further bear this out:

"If I don't know them very well I might... I'm very likely to say "Fuck off buddy.." (male, age 21).

"I think I discuss honestly with my friends. I... I encourage them to elaborate on their comments. Whereas a...a stranger I would defend myself... challenge them." (male, age 33).

"Well if a stranger told me something negative, I'Il tell him to stick it. Who is a stranger to tell me something?" (female, age 21).

In contrast, the emotional impact of such feedback from friends, family, and significant others within ones roleset is much greater. ${ }^{22}$ Consider the following:

"I take criticism from my family a lot harder than I probably do criticism from other people." (male, age 21).

"It makes a very big difference, um, because people that are close to me are the people that really know me, and if they say something, uh, in a negative manner, uh, it...it hurts." (female, age 36).

"If its someone you have a lot of respect for, um, obviously it hurts if they say something that's... that...that is, you know, is... is not friendly but of criticism. Or any... you know any type of criticism hurts more if it comes from a, um, a closer source." (female, age 26).

Finally, it is interesting to examine the difference in individual "I" response to positive feedback relative to the perceived significance of one's interaction partner within a particular role set ( $\underline{i . e}$ the single role). Consider the 
following comments of a 26 -year-old female:

"If its somebody that I... I find... if there's somebody that's, you know, completely attr(active)

...very, extremely attractive and... and... and, uh, in both, uh, in looks and the way that he, uh, um, presents himself and, uh, you know, as far as, uh, his personality is concerned, um, then I'm extremely, uh, flattered, and it does lots of things for my self-esteem. Um, conversely, if there's somebody that's a real idiot that comes up to me and thinks that they, you know, that they ...they have a chance and they're complete, you know, goofs, then I go "What kind of.." you know, "Jeez I put the wrong perfume on tonight" (laughter). Um, and that tends to lower self-esteem."

Thus, it would appear that significance of interaction partner in both an individual's specific social relationships and role-set affects his/her emotional response. If one makes the conceptual leap to the internalized aspects of these structural relationships, one can see suggested a hierarchical ordering of others in relation to one's significant roles.

Secondly, and in addition, the importance of the subject matter under discussion (i.e. in relation to one's roles) appears to affect the individual's degree of "I" response to both positive and negative feedback. Consider the following comments:

"When it is a compliment which is more connected, related to the values that I have, um, its easier then. Where someone is trying to make a compliment which is connected to areas where I don't put much polar energy. its just..."What?" (male, age 25).

"I don't think I'm as meek as I used to be. I try to be assertive on some things, like things I think are important. I can be aggressive I think if I really feel strongly about something. So its a mix I guess. It really depends when... whether I think whatever the discussion 
is... is important. If its important I'm much more likely to be assertive or aggressive: if its not important I don't really care. It would be like "Oh yeah, its cool" more than anything, so I'm a mix." (male, age 21).

"If I don't care about something, then I'm very passive about it. If I'm not very concerned about an issue, then I'll just let it pass." (male, age 21).

"Challenge people directly? I guess it would depend on the subject. Um... if it mattered or not to me."

(female, age 36 ).

In all of the above statements runs the common idea of a hierarchy of importance, a priority list of role-specific topics upon which degrees of response are determined. Again, this suggests a hierarchy of roles and associated beliefs that are central to an individual's self and identity. ${ }^{23}$

Third, upon being asked, individuals themselves describe hierarchical listings of more important roles in their lives. For example:

"My role as a mother is the most important one right now...'cause I worry for my kids... And they are my first priority. So, if a man were to come and say "Do you want to go out?" I'd say "Sure, but.." I 'd tell him "Look, I got two kids and...they come first before anything." (female, age 28).

"I guess (my role) as a student is important to me ' cause like basically that's what I'm doing right now, but I think even that takes a back seat, like, to certain things like...being one of the guys... Like, to have a lot of friends that you can associate with yourself. I think that's almost the most important..." (male, age 21).

"Being a top athlete in my age category...I feel I have a role as an athlete... I write well. I want to be a writer. I...I'm not just... I don't just have athletic goals, I also have literary goals...I don't know about other roles in my life. A role as a spouse - that's not appropriate, its N/A. Role as a lover: N/A. There's a lot 
of roles that people have which just don't apply to me even though I can imagine myself in those roles. Role as a breadwinner, role as a money....as a contributing member of society. I still, you know, I work. I make an honest dollar, but I'm not... I don't feel that as a role as a contributing member of society describes me." (male, age 33).

"Probably what has been my most important role has been daughter because, um, because there's been nobody really special as far as men go, there hasn't...since there's never been any special man in my life, I've never had that to rely on, so... Um, family... Friends were always my number one thing. That was what I was dedicated to. I've always had good friends and, family was important, but I still think I lived for my friendships. And then my friendships let me down so I was living more so for my family. And then when my parents split up that foundation fell and I couldn't... I think I always relied on my parents, but I couldn't rely on my dad anymore. So I had to... I had to be the support for my mother. And my mom's really been my own immediate family through the years since... So I would say that my most important role is daughter because, um, I think I've really clung to my mom for stability." (female, age 28).

"Role? Right now, being a student... Um, role in relating to other people, so, relating to friends and fellow students...Role of the...the activist, um, I'm getting into it... Role of the son I'm rejecting very much." (male, age 25).

In all of these comments can be seen at least the partial hierarchical arrangement of some roles as more important than others to the individuals in question.

Lastly, it must be pointed out that some respondents were either not clear on this latter point, or made objection to a role perspective based on priority. The following comments serve to point this out:

$$
\begin{aligned}
& \text { "I don't play roles." (female, age 21). } \\
& \text { "I'm a little bit confused 'cause I don't really }
\end{aligned}
$$


have a role I see as being super important...I don't have anything that dominates just now." (male, age 21).

"A lot of the roles blend in together. Because being a student means that I have this wide circle of, you know, peers. Um, my role as, um, as a, you know my role in student politics also blends into my friendship, and also blends into the student role. So I guess that, um, just, you know, the role that I'm taking on now at university, so a wider role - including the friends, the circles, the student organizations that I'm involved in. I guess the academics is a real part too - I enjoy that the academics. So I guess that larger role is probably the biggest role to me right now." (female, age 22).

"I think everything is... is very important to me. Um, I really can't separate myself, I can't compartmentalize myself like that." (female, age 26).

Each of these comments must be dealt with before concluding this section.

The first comment is easy enough to address. This individual is referring to "playing" roles as in deceiving others and not being true to herself. This can be seen in her following words that "I play me. I don't change me." When told that roles are not necessarily something that one puts on, she understands. She then goes on to state that "friends and parents mean a lot to me" and agrees that they are the most important things in her life. In contrast, of her studies she states: "No, I'm not a student." It would thus appear that, with respect to this respondent, it was a simple misunderstanding of the question. Moreover, a partial prioritization of roles appear in her ensuing comments.

The second comment is more difficult to address. While 
this individual's later comments show that he recognizes the various roles that he occupies - such as student, coach, understanding friend, worker, and single individual = he does not find that any one dominates. This may in part be due to the question, which asked him to state the "most important" role in his life. However, it may also be due to this individual's present view of his life that:

"The last five or six years of my life sort of falter and I'm not quite sure that I'm doing the right thing. I'm sort of waiting for something more... I view myself as being a little bit unsatisfied with what I'm doing now...sort of, not really killing time, but not quite sure what I want to be doing, and sort of moving along and perhaps not, uh, being aggressive enough to change what I'm doing right now." (male, age 21).

Indeed, this appears to be an example of the concept of "anomie," or, in relation to roles, Goffman's concept of "role-distance" whereby this individual occupies but does not "embrace" his present roles as central to his identity (Goffman, 1961:106). That this individual lacks central meaning in his life is shown by the fact that he has returned to attending church recently "Trying to answer a few questions...trying to make myself a little bit more sure of myself."

However, beneath the surface a list of priorities does emerge for this individual. Consider the following comments:

"I'm...not particularly worried about money so its not really a criteria."

"I would like to be seeing someone I guess. But... I 
do OK. I mean, I'm not too uptight about it."

"I'd like to be more outgoing. About that sort of thing I...you know, I don't like myself quite as much ' cause I think... I should get out, should get out more and, you know, try to make more friends."

"Happiness is definitely up there, and" being happy with myself, like self-worth...has got to be probably the most important." (male, age 21).

Thus, with regard to this individual it may be concluded that the lack of meaning in the roles in which he is presently engaged does not disprove the hypothesis that a prioritization of roles exists. These latter comments in particular show a hierarchy of importance, a partial list of roles that this individual would like to embrace in order to improve his self-worth, and, therefore, happiness.

The third set of comments are relatively easy to deal with. This respondent is clearly confusing the idea of roleset with the concept of role itself. She refers to a "wider role" which includes all of her activities at university such as "academics," "friends," and "student organizations." She says that these all "blend in together" into what is "probably the biggest role to me right now." Clearly, this individual is setting a present priority on her involvement in student life. This is in contrast, for example, to the priority she places on romantic involvement:

"I like being independent and I don't...think "Oh gosh I've got to get myself a boyfriend." (female, age 22). 
Finally, the last set of comments must be examined. While this individual states that she does not "look at" herself in terms of specific roles, it is important to note that she is quite willing to make comments prioritizing some aspects of her life over others. Consider the following:

"I'd prefer better material possessions, but I don't think that's all there is to life anyways."

"I used to evaluate (my life) by, um, by things like money and what I was doing as a career. Um, and if I was to evaluate it on that basis, I obviously wouldn't think too much of my life."

"Family...um, yes definitely... I mean I'm not too sure if I'm friends with them despite the fact that I love them! Um, you know how that goes."

"I tend to find friendship a very important part of my life. Um, I guess that would probably be, if I had to (choose) any....any particular role, um, I think its what it comes down to at the end of the day. Things like academics and career...uh, they're...they're not as important." (female, age 26).

Thus, despite this respondent's disclaimer, she makes statements in support of a hierarchical ordering of role identities in her self. Indeed, several of these statements were made in response to earlier questions, and so cannot be confused with her disclaimer. In short, all of these may indeed be "very important" to her, but some are more important than others.

Hence, none of the respondents seemingly contradictory statements clearly disprove the hypothesized hierarchical 
ordering of role-identities in the self.

In conclusion, preliminary evidence has been adduced suggesting that the individual self consists not only of the "I" and the "me," but also of a hierarchical ordering of these dyads in role-identities comprised of role-sets and associated prioritization of topics. ${ }^{24}$ This has been shown in three ways: (1) significance of interaction partner in one's social network and role-set affecting degree and nature of emotional "I" response; (2) significance of subject-matter in relation to one's extant roles affecting emotional "I" response; and (3) partial listings by respondents of roles which are more significant to them than others. Thus, there is also some evidence illustrating the last component of the third hypothesis.

In brief, the data provide suggestive preliminary evidence illustrating all the components of the third hypothesis.

(d) Accumulation of Positive and Negative Interactions:

The fourth hypothesis refers to the long-term impact of positive and negative interactions. It reads:

"Positive and negative interactions are additive over time, and will show up in an individual's general level of self-esteem and happiness."

Essentially, this hypothesis states the idea that if individuals are involved in numerous positively enhancing 
interactions over time, their self-image, and, therefore, degree of happiness will be greater. Conversely, if individuals are involved in many negative, discónfirming interactions over time, their self-image will suffer, and overall happiness will be reduced.

Many respondents have made comments on this topic. The following will review subjects' comments with regard to first positive and then negative interactions, before concluding the discussion of this hypothesis.

With regard to the additive effect of positive interactions, consider the following comments:

"Well, you know, I think if someone's giving you positive feedback constantly you're going to feel "Hey, I'm the cat's ass,...I'm the..." You know, and you're going to feel good about what you do. And, I think that's really healthy... And I think it does build up over time." (male, age 21).

"Oh, it builds you up. If you're getting a lot of positive (feedback) I'd be flying high, I'd be the greatest person, and I would be so conceited...Look out! (laughter). What do you mean if I was getting (laughter) I'd be like "I am great!" (female, age 21).

"If you get positive feedback you... you feel good about yourself because other people are admiring what you do and they think you're doing a good job and they, you know. You're in the right line of work or whatever you're doing. If you're the best laundry-presser in the entire city, and everybody brings their laundry to you, aren't you going to feel proud?" (female, age 28).

"I think, um, adequate positive and negative feedback, um, helps me, um, to more and more realistically analyze, um, how well formed the certain situation is... I would say, um, this making it more realistic, um, in the end, um, builds about, um, towards more self-esteem." (male, age 25). 
"Probably the positive feedback doesn't stay with you as long as the negative does." (female, age 28).

It will be observed that the majority of these comments strongly support the hypothesis that perceived positive interactions accumulate in one's sense of self-worth and level of happiness. The latter are either more modest, limit their assessments of the length of time that positive feedback lingers, or note the interesting prospect that "adequate" (i.e. constructive) negative feedback may improve self-esteem, but say nothing to blatantly contradict the positive half of the above hypothesis. ${ }^{25}$

Moving on now to consider the accumulative effects of negative interactions, consider the following subjects' comments :

"I think it does build up over time. I mean, if you're constantly criticized for what you do you're going to feel like you're a ball of shit. Really, you're going to feel like you're useless and you can't do anything. Like, when I was in high school, grade 12, I had an English teacher who said that I would never pass university, I would do well in university, I would never pass university English. And, I mean, I felt like in university I was useless, I thought I was as useless as two tits on a bull, you know, I thought I couldn't do anything..." (male, age 21).

"If you get a lot of negative (feedback) of course you're going to feel like a piece of shit... isn't that proven psychology? Like a kid who's constantly said to "You're a loser..you're a loser..you're a loser" eventually you're going to think you're a loser... And I've seen it when you go to their home: "No wonder you're like that!" Well, of course it does!" (female, age 21).

"The life I had been leading was bound... was going to destroy me. Um, it was the result of my family 
upbringing. I carried over a lot of my father's misogynist, racist, narrow-minded thinking into my own life...There wasn't that many instances where I did get positive feedback and I suppose I...I deliberately sort of set up my life so that I wouldn't. That's why=I said nasty things to people, like, make derogatory comments ... You know I didn't want positive feedback because I knew I believed fundamentally that I was...evil or something." (male, age 33).

"People's opinions have in the past, um, nearly destroyed me. In a, destroyed not me so much, but destroyed the relationship that I had with the man that I love...Well, uh, his folks, um, don't like me, um, they.... and, I guess its because I'm older, divorced, with a child. Uh, and there is animosity there. Um, uh, I can understand them as being parents, uh, they want the best for their child, because I have a child of my own, and uh...But, uh, it did, you know, come between (us)." (female, age 36).

"I had very low self-esteem. I let myself go. Um, you have a person who says "Where the hell am I going to take you?" You know, like I say "Come on, lets go." Well "Where am I going to take you... Why would I want to take you out?" Then you start to...you start to lose all that. You start to question: "Well maybe I'm not the person that I think I am." You think that maybe you're living a lie." (female, age 28).

In all of these comments, conversely, one sees that the cumulative effect over time of repeated, negatively assessing interactions is an increase in individual unhappiness, whether in one role or across several at once. ${ }^{26}$ Thus, it can be asserted that there is some preliminary evidence in the data illustrating the fourth hypothesis that perceived positively and negatively assessing interactions accumulate over time in one's general level of self-worth and, therefore, happiness. As one respondent has so perceptively stated: 
"In the long run I think you can achieve happiness over... about a particular thing, OK,... and it may take a long, long time to achieve happiness. But I think there's also short-run happiness. Its kind of like economic theory. You've got long-run happiness and short-run happiness..." (male, age 21).

\section{(e) Accumulation Across Roles:}

The fifth and final hypothesis is a variation on the accumulation of happiness over time as discussed above. It states that:

(v) Happiness is also additive across roles, such that the more roles one is happy with, the happier one becomes."

This hypothesis shifts the emphasis of accumulation by focusing on an individual's reasons for happiness at a particular time. While not strictly scientific in an experimental sense, it is nonetheless felt that by holding the time variable constant in this fashion (i.e. in the questions asked), individuals will not only refer to one, but several role-related reasons for their level of happiness/unhappiness. Essentially, the more roles in which the individual feels happy, the more happy should be that person. Conversely, the more roles in which the individual is unhappy, the less happy he/she should be. ${ }^{27}$

This section examines this hypothesis in relation to the data in three ways: (1) it reviews individual accounts of why they are happy/unhappy to see whether they discuss several 
roles in their stated reasons; (2) it considers individuals' statements as to what circumstances would make them happy; and (3) it examines individual responses to a question regarding their general, background level of happiness in relation to the experience of negative events. Essentially, this latter question inquires whether "other eggs in the basket" help individuals to put negative events in perspective. A multifaceted response to these questions will be suggestive of happiness accumulation across roles in the present, real or hypothetical, in addition to its already discussed accumulation over time.

First, it is clear from the data that respondents' comments about happiness are rife with discussion of more than one role. For example, consider the following:

"I think I'm pretty happy... There's a lot of things in my life that I'm not happy with, but generally, if you had to rate me on a scale of 1 to 10 on being happy, I think I'd be around 7,6 or 7 ... I mean, I don't think I could have got a better set of parents anywhere... and I'm happy that I can get up on a November afternoon and go deer hunting and stuff like that...I'm happy with those kind of things in life. There's other things I'm not happy with, like relationships, because you never get what you want..." (male, age 21). ${ }^{28}$

Another 21-year-old male gives various role specific

factors impinging on his happiness:

"I'd say I'm... a pretty cool guy. Like, I mean, you know, I've got my shit together, like I'm pretty, you know, I've got.. I'm smart, I'm intelligent, you know, reasonably good looking, I guess. You know, I get along well with people for the most part...So, you know, I think, overall I'm...I'm pretty damn good..." 
"I've developed a lot in the last little while I'd say. 'Cause saying just, you know... four years ago I was just some, you know, Joe Blow in high school, you know, really didn't have a lot going... Now like I'm, you know, third year university. I've got, you know, I havé a good education, you know. I've got. you know, a lot of my talents and stuff like, you know, I've gotten better at..."

"You know, you get back an "A" or something like that and, you know, there's something on it that says "Good work, excellent job,"...that comes over good... And even with, you know, playing with the guitar, like, you know, someone says "Oh, that sounds really good," you know, and you put a lot of work into it, you know, and now its paying off, you know, people are...other people are impressed by it, you know, that's...that's good."

"If you have guy friends that you sort of hang around with, and if you have a lot of them and you have a good time with them and you go out and you have fun... that helps a lot too I guess."

However, this same individual goes on to describe several recent role-specific reasons taking away from his happiness:

"Last week, pretty well unhappy, I guess... You know, combination of events, you know, a couple of weeks really hard at school, breaking up with a girlfriend, you know, that was, you know, pretty bad."

These listings of role-specific reasons for happiness/ unhappiness continue. Consider the following comments, which are arranged in two numbered groups of comments amounting to partial "role mosaics" of individual respondents, one relatively happy: the other unhappy:

(1)"I just had it. I had good clothes. I never had to really, you know, I never went without anything. I've gotten mostly what I wanted at christmas. I've been relatively healthy throughout my Iife. I have a dog that I love. I have lots of friends that I can count on. 
I've...I've gotten, like, with um, growing up I've always had these expectations that I've wanted to have and I've always gotten it, you know. I've always wanted to make the basketball team and I was on, you know, I wanted to be on student council, I wanted to go to university Yes, I've been very lucky."

"I'm not poor...I have things that I want... I have a nice family life, I have lots of friends. I'm going to school. I'm passing (laughter). You know I'm just...I'm just I'm doing... I'm happy with my life... You know, I have an opportunity to not... You know, I'm not on the streets, I'm not broke, I'm not from a broken family, I don't have a dysfunctional family, I..you know. So I see, you know, like I see what else you could have so that makes me very happy. I'm in school - most of my friends are not in school. What are they going to do? They're working at 9 to 5 jobs that they hate making $\$ 5.00$ an hour where I have the opportunity to do something, and become more, so that makes me happy. That make sense?"

"I could do a lot better than what I'm doing but.. I'm so goddamn lazy.."

"I think I'm ugly, so there's no way I would think...Right now I think there's no way no-one's going to like me..." (female, age 21).

(2)"Not health-wise, but emotionally I've had, uh, you know with, um, bad job choices I... and not choosing a very...not making a good choice as far as what I took at college. You know, choosing advertising, it is a field that is so hard to get into and I wasn't aggressive enough. So, with all the unemployment I've had since I graduated. That, as well as the O.C.D., have been two things that have really dragged me down."

"Well, with the O.C.D. that I have...it held me back from the time...from as far back as I can remember. Um, I had difficulty with school and, um, taking on new challenges. And it definitely prevented me from, in later years, dating..." life."

"I would like to have one person important in my

"I'm definitely behind, in my opinion... where I should be. You know, I'm not living on my own. I don't have a car. I'm not really, um, I'm not being independent 
enough."

"My friendships let me down so I was living more so for my family. And then when my parents split up, that foundation fell... So I would say that my most important role is daughter because, um, I've really clung to my mom for stability. I think vice versa for her." (female, age 28).

In all of these comments, which combine both listings of role-specific reasons for the individuals' happiness/ unhappiness and their attitudes toward specific roles, one can see not only that many individuals imply that happiness is additive across roles, but also that they are happy with some roles and unhappy with others. This suggests that happiness/ unhappiness is additive across roles in forming one's overall self-image.

Moving on, secondly, to consider individuals' statements as to what circumstances would make them happy, again multiple conditions are evident in their responses suggesting the cumulative nature of happiness across roles. Consider the following statements:

"Well, OK, if I could have anything in the world I'd have a big farm in Montana with tons of corn and a huge deer population on it so I could go hunting every day. Have a really great wife and be financially secure, and live a nice quiet, pleasant life, and that would be happy for me." (male, age 21).

"In my opinion, what I think is happiness. To be healthy, to have an awesome family, to have awesome friends, to be...to live in a nice house with food on the table. You don't have to worry about your food all the time. Have healthy kids. Have a husband that treats you with respect. He's trustworthy, you know that all marriages, you know, should be trustworthy. Yep, there 
you go. And a happy job. And a dog named Rover." (female, age 21).

In these comments is implicit individuals' desire to be satisfied with several areas of their lives at once. These desires suggest that individuals themselves recognize that happiness is additive across roles.

The third and final evidence to be brought to bear on this issue of accumulation relates to the idea that existing happiness in several roles enables individuals, who experience positive or negative events, to put these matters into perspective against the "base line happiness" of the "other eggs in the basket." Consider the following widely-varied comments :

"I get home and I see that the Simpsons is on (TV) or something - that's short-run happiness, it lasts half an hour. But there's other things that last for a long time. Like, you have your parents. That's continual... that's a lifetime of happiness right there. You may have your ups and downs but its generally a lifetime of happiness." (male, age 21).

"Yes, I have cancer, but I don't find it as too much of a tragedy because I've been very lucky in life, and because, like I said before, I have an awesome family and I have awesome friends and I have a great support system, and I still feel lucky." (female, age 21).

"I take it positively. I see it not as a personal attack on me, but as a...as a criticism of a...you know, for instance of a paper that I'm doing, you know, some part of my work. Its just not... its not a personal criticism....its just an area of my life or a part of my personality that they are questioning or drawing attention to... Its not that they're knocking me down totally." (male, age 33).

"I think there's a definite base-line for me. Um, 
I'm a fairly stable person in terms of emotionality. So, um, I think there would be a base line. If something bad happens go down (respondent motions with hand); if something good happens, go up. There's fluctuations but I think there probably would be some line in between that would, you know, kind of be the average of the fluctuations. And that's where I'd probably be most of the time. I'd be at the line." (female, age 22).

"I tend to go way down or way up and then settle somewhere in between. I'm, you know, something bad happens, I'll...I'll get really down and then I will, um, look at it in perspective and, um, build myself back up again." (female, age 26).

In the above comments are found the complementary ideas that happiness/unhappiness in one role is not total, and, that it is possible to have a broader base line of happiness against which role-specific unpleasant events stretch, but do not permanently cut. ${ }^{29}$

However, it must be noted that several respondents comments appear to diverge from this latter point by referring to themselves as "emotional rollercoasters" who are "all over the board." These must be dealt with. Fortunately, upon closer examination it appears that it is not so much the concept of a base-line accumulation across roles that is in question as it is the broadly unpleasant life situation of the particular respondent. First, consider their following comments:

"There is a base-line, yes. Its just that every now and then I'd lose track of what that base-line was, and that's where the roller-coaster would, uh, start up. And then I'd try to find it again and, uh, I guess in the process of trying to find that base-line, it was also a process of finding myself." (female, age 36 ).

"Right now its all over the board...with everything 
that's happening in my personal life...I don't think that happiness is something that's constant in anyone's

life... if too many eggs fall out.." (female, age 28).

Both of these comments are made by relatively unhappy separated or divorced women in difficult financial circumstances. One, who is unemployed, does not have custody of her daughter, while the other is struggling to provide for two small children on a limited income. In addition, one is suffering rejection by her husband, while the other recently suffered death of two loved ones, was rejected by a boyfriend, and was on shaky ground with an old flame. In such circumstances, both limited role involvement and accumulative negative evaluation in ones extant roles have these individuals" base-line of happiness/unhappiness scraping bottom, and, therefore, they become highly sensitive to more immediate events.

More interestingly, the former respondents who reported base-lines of happiness are, as a group, much more involved in outside activities, interests, and therefore roles than are the latter. ${ }^{30}$ As such, they have both more areas of their life from which to glean positive self-assessments, and more positive sources upon which to rely in difficult situations.

In conclusion, therefore, it would appear that there is some preliminary evidence illustrating the fifth and final hypothesis regarding the accumulation of happiness across 
roles. This has been shown by reference to individuals' reasons for present happiness, their listings of factors that would male them happy, and by their referral to "other eggs in the basket" and "base-lines" of happiness in relation to life's largely role-specific ups and downs.

This concludes the discussion of the data in relation to the five general hypotheses in the general interactional model of happiness. Reviewing the above pages it is clear that there is some preliminary evidence in the data illustrating each of these propositions: none of it blatantly contradictory. While based on a small qualitative sample, these results are suggestive of further investigation.

It is now time to turn to the core of this study - the typology of beliefs in relation to happiness in the single role.

\section{(2) Typology of Beliefs}

\section{(i) Introduction:}

This section will review the second cluster of hypotheses described in chapter 3 relating to the typology of beliefs about happiness in relation to the single role and personal relationships. It will examine whether individuals experiencing this highly significant and strategic role (the rationale for which is discussed Infra, p.62-66) exhibit rolespecific beliefs in relation to their happiness/ unhappiness therewith that correspond to the typology set out in chapters 
2 and 3. Specifically, if single individuals are found to express beliefs that may be characterized as "transcendental," "egocentric," "crusader," and "empathetic" in nature, then this wili go a long way to explain happiness in this, and in other roles.

Several things must be addressed before proceeding. First, it must be noted that this section is highly illustrative, and that any negative cases that may not be so easily classified will be dealt with in the final section before concluding.

Secondly, it must be pointed out that many individuals in the sample expressed these various types of belief in relation to numerous other roles. However, the majority of comments were in relation to the single role, which was, after all, the object of study.

Third, throughout this discussion it will become apparent that the same individuals sometimes express different types of beliefs at different times. This attests to human adaptability in emotion management. Indeed, individuals appear to select different types to address different aspects of the single role, whether on the temporal or interpersonal dimensions, while still allowing one to predominate overall. Individuals expressing only one type of belief in relation to happiness in the single role are more rare.

Fourth, it must be noted that the largely deductive 
typology, with its broad analytical dimensions of self/other focus and present/future temporal orientation, allow for classification of diverse outlooks into larger cultural "prototypes" a" la' Ruth Benedict. ${ }^{31}$ Nowhere is this more apparent than in the foregoing discussion of egocentric beliefs in relation to the single role. While the prior theory suggested at least two of the extant subtypes, namely, hedonism and stoicism, the data have forced a further expansion to include four more. This does not imply a change in analytic categories. Rather, it illustrates both the inductive flexibility of the model, and the relative cultural importance of egocentric beliefs, with their total present focus on the individual, to the "me generation."

Finally, it must be noted that in addition to discussing the general characteristics of each type, its cultural basis, and its relation to self-esteem, the data have demonstrated that each type has certain significant characteristics that necessitate separate comment (e.g. management and motivation for transcendental; the variety of sub-types for egocentrics; sensual play/flirtation for crusaders; interactional vs. relationship conceptions for empathetics;). Accordingly, each of these will be dealt with in the following discussion of each type following comment on their common characteristics.

Let us now turn to the data. 
(a) Transcendental Beliefs About Happiness in the single Role

In this section will be examined, through thie use of composite examples, the basic dimensions of transcendental beliefs about happiness as expressed by individuals experiencing the single role.

Transcendental beliefs regarding happiness, it will be remembered, tend to emphasize the positive aspects of the future and the individual's focus on self. They provide hope for the future and meaning for the present. When translated into terms of the single role, such beliefs usually tell the individual that they will not always be single, but that the "right person" will come along. As such, these beliefs help both create and manage the level of happiness/unhappiness experienced by their proponents. ${ }^{32}$

Several things must be noted about such beliefs: (i) their general characteristics; (ii) their cultural basis; (iii) their relation to self-esteem; and (iv) their specific management and motivating functions. Each of these will be dealt with in turn.

\section{(i) General Characteristics}

The general theme of transcendental beliefs in relation to the single role is expressed well by "Fred," a 21 year old university student studying to be an engineer. Fred is unsure whether he is pursuing the right career path, does 
not have "super high" self esteem, and is "waiting for something more" - although he stresses, and berates himself, that "I don't really actively go after it." Fred looks at happiness more in the long-term. As he has never had a serious relationship, he considers this one of the things he would like to change. He states:

"I think I, I mean, if I could find the right person I think that would be great and I'd love to, love to be with them all the time."

While stating that he is "not in a great rush", Fred immediately adds:

"I say, when... if I find, if and when... when, not if, I find the right person, I'll be really happy."

Similarly, another young student, who stresses that he has low self-esteem "as far as the opposite sex goes," notes that one thing that would make him happy would be to "have a really great wife." He states that:

"I think I have a big hope that one day I'm going to meet that... I'd like to meet that perfect girl. I'd like to think she's out there... I don't know...its kind of like my dream to get...serious." (male, age 21).

An important thing to note about such beliefs is that they can refer to the future in either a short-term or a longterm manner. For example, a 21-year-old male respondent who had been dating a woman for a short time stresses how much he looked forward to seeing her again. A 28 -year-old female notes that she used to say "I can't wait 'till such and such a date comes." This is to be contrasted with the more general, long- 
term variety of transcendental belief outlined above.

In addition, such beliefs, in their longer-term variety, are more difficult to empirically disconfirm in experience. The future-directed orientation provides the convenient conceptual escape-route that "maybe you haven't met the right person yet." However, over longer periods with little social support, such beliefs may wear increasingly thin (e.g. the female referred to above expressed despair over this rationalization).

Finally, it is to be noted that holding such hopeful beliefs can actually produce a degree of happiness in the subject. Thus, a young man out camping with friends is happy at the prospect of seeing his new girlfriend soon. A 28-yearold separated woman with two children states that she "feels it", stating that "I know in my heart there is someone out there for me." Indeed, one 33-year-old bisexual man, while stating that he does not live in such a "fantasy world" anymore, notes that "its very comforting. Its like...a narcotic effect."

\section{(ii) Cultural Basis}

It is clear that transcendental beliefs about happiness are central to western culture. (e.g. messianic religion). With regard to the single role, such beliefs center around concepts like meeting "Mr/Miss Right" and "living happily ever after." Acting in concert with this are social 
norms and attitudes devaluing the single life - especially beyond a certain age. For example, one young student has stated:

"I think that once you're really much older...like when you get up there in age, I think that a lot of people expect you to get married and... I think a lot of people should get married. I think that's just the way it should be." (male, age 21).

Similarly, a bisexual male notes that "I unfortunately buy into a lot of the social nits and the strong social pressure, you know, to be married." Referring to the older cultural value that saw the single life as a sign of status, at least among men, to be able to devote one's life to one's work, he notes:

"I think that...that's gone... I mean a single person today is a dirty old man that lives in skid row, or else he's a...he's a hermit in some, um, you know, religious, uh, monastery or something." (male, age 33).

These "carrot and stick" values are socialized through the media and our parents. For example, one Italian lady noted that her dad wanted her "to meet a nice Italian man and settle down." A young student referred to meeting the "perfect girl" as "kind of like the American dream." Indeed, even two divorced women with children spoke of wanting the "fairy tale ending" of marriage - one with regard to a relationship recently resumed; the other still waiting for her "prince charming." 


\section{(iii) Relationship to Self-Esteem}

Implicit in several of the examples above is an apparent relationship between transcendental beliefs and selfesteem. While these types of cultural belief appear among respondents of most esteem levels, they receive their greatest emphasis among those with low role-specific self-esteem, or those who are managing an emotional blow.

In an extreme example, "Teresa," a suicidal, a 36year-old divorced woman with children, had always conceived of being single as being "alone." After stating that she doesn't like being by herself as a rule, she adds that "I thought that there was someone that was saving me from being single."

Similarly, "Dick," a young science student who tends to "look forward" to meeting someone and "get down on (him)self when it doesn't happen" notes that:

". .when I do meet someone then, you know, then you've got some... you know it makes you feel, it makes me feel better about myself. 'Cause like, you know...someone sees something that...someone else is attracted to me and all that, yeah. That gives you some self-respect and, you know, to know that someone else wants to be around you. So I guess that...it makes you feel better about yourself." (male, age 21).

Contrasting sharply with this is "Jessica," a busy senior student, and "Sam," a successful professional. Both express nominally transcendental views in relation to the single role, ${ }^{33}$ but do not make a relationship a priority in their lives. They prefer to concentrate on their careers and 
have fun. Says Jessica:

\begin{abstract}
"I would like to think that, uh, that one day there...I will, uh, meet the person who I'm going to spend the rest of my life with... I'm not sure if 'I'll get it because I'm very picky as, uh, as to who that person is... I'm looking for a kindred spirit... I'm not too sure whether or not there is one of those out there for everybody.... I think, in the end, if it comes down to a choice between, um, settling for somebody who I probably, uh, wouldn't really want to settle for...to be honest, and being on my own, I would prefer the latter." ${ }^{34}$

(female, age 26).
\end{abstract}

Sam, as well, is very involved in his career and extracurricular activities. He does not make a relationship a priority right now, preferring to have fun. However, when pressed on this issue, he adds:

"You've got me all wrong. It's not that I want to spend the rest of my life in the singles scene. I believe that there is the right woman out there for me but that I just haven't found her yet - although I did come close with (my ex-girlfriend). But, it makes no sense to dwell on the future or what might be because we have to make do with the here and now. Right now I prefer to play the field and see what happens. Besides, until the right one comes along, its not the having, its the getting where the sport is." (male, age 27).

Of further support in this regard is that both of these respondents have had no trouble in meeting interested members of the opposite sex. Sam has been characterized as a "gigolo" by his friends; Jessica notes, in her case, that:

"I know that there are people out there that find me attractive and, uh, that's obviously a nice feather in your cap, I suppose. Um, and yeah, it does tend to lessen the, um, perhaps the ...the desperation that some people may find themselves afflicted with, who are...have lower self-esteem." (female, age 26).

Indeed, another respondent, an active, self-directed, 
22 -year-old female very heavily involved in student politics, with perhaps the highest self-esteem in the sample, failed to express any transcendental beliefs about the single role at all .

Thus there would appear to be some relationship in the sample between emphasis on transcendental beliefs and low self-esteem in the single role.

\section{(iv) Management and Motivation}

It is also clear that transcendental beliefs, when applied to the single role, not only play a large part in managing unhappy feelings, ${ }^{35}$ there is more evidence in the data of how they generally motivate behavior, in addition to that in the single role, compared to other types. This, of course, does not deny that other types of belief perform such a motivating function. It merely points out the broader nature of the evidence in the data with regard to this type.

The management function is brought out well by the initial tactic utilized by two respondents in response to the breakup of their relationships. One, "Nicola," an unmarried, 37-year-old immigrant woman, noted that she spent her time "hoping against hope" that she would regain in future someone from her past. Another, a young science student, stated:

"(My ex-girlfriend) sort of had things to work out 
and, you know, I think maybe possibly when she gets 'em, you know, figures things out for herself, you know, I think the possibility, you know, things might get back together again... I guess for the last week since I broke up with her I've been kind of holding my breath hoping that, you know, that would happen..." (male, age 21).

It is also brought out in the management tactic expressed by Teresa - an older divorced woman who had just left an unhappy relationship. During that relationship, she states:

"I found myself being pushed under... and under, and, uh, thinking "It'll get better...it'll get better - and it wasn't. And I found myself still thinking "it'll get better..it'll get better." But it didn't until, um, I just couldn't handle it anymore." (female, age 36 ).

Closely associated with this management function is the broad motivating property of such transcendental beliefs. For example, a 30-year-old graduate student noted that for years he "instilled" in himself "hopes" of a relationship, sometimes even "putting a face on it"..."in order to get through the daily routine." Similarly, a younger male undergraduate, when asked what makes him "want to get out of bed in the morning," replied:

"I don't really have a steady, steady girlfriend, so that's not a really big reason to get out of bed. I think that getting out of bed is just...just for the search to find that perfect girl and that perfect life...I think that's part of it."

These comments imply that transcendental hope in the single role encourages activity in other areas of an individual's life, and vice-versa. Indeed, this may also 
reflect on the idea of being single as a master status.

(v) Conclusion

Summing up, it would appear then that transcendental beliefs regarding the single role are common cultural symbols affecting our perception and management of happiness/ unhappiness. They also appear to have an important relationship to self-esteem ${ }^{36}$ - which is not surprising since this is, in itself, a fundamental component of the experience of happiness. Finally, they appear to have broad management and motivating functions in relation to emotionality and action.

(b) "Egocentric" Beliefs About Happiness and the Single Life

In this section will be reviewed, through composite examples, the variety of beliefs relating to the single role that can be characterized as approximating the "egocentric" type.

Several things must be noted about these type of beliefs: (i) their general characteristics; (ii) their cultural basis; (iii) their relationship to self-esteem; and (combined therewith) their overwhelming variety of subtypes. Each will be dealt with in turn.

(i) General Characteristics:

"Egocentric" beliefs about happiness, it will be remembered, focus on the present as opposed to the future, 
putting experience over hope or goals. As well, the individual holding such beliefs tends to put more emphasis on him/herself as opposed to other individuals. When these broad general parameters are translated into how single individuals conceive of, or manage, their level of happiness/unhappiness in respect of that role, very little can be said. Egocentrism, quite simply, involves the individual's focus on him/herself in a variety of culturally prescribed ways in relation to the single role, with minimum focus of concern on others.

\section{(ii) Cultural Basis:}

We, as North Americans, live in a time and in a culture in which there have arisen both an increased tendency to focus on the present, as well as a continued, if not increased, tendency for individuals to focus on themselves. Each of these cultural influences will be reviewed in turn.

First, with regard to the increased tendency to focus on the present. We live in a culture in which the traditional values of patience, "a better world to come," and hard work are in relative decline, and in which social structural instability and normlessness have shown relative growth. ${ }^{37}$ In addition, the economic downturns and dislocations of the last twenty years have, to some extent, battered individuals' hope and faith in their future "progress."

Acting in tandem with this, we also live in a consumer culture which increasingly promotes quick-fixes and instant 
gratification. As Carnes ${ }^{38}$ has written:

"Ours is a convenience-oriented culture dedicated to removing obstacles to satisfaction. Everything from oil changes to food preparation can be done with little effort." (1991:75).

Thus, it may be asserted that, to some extent, individuals' focus of attention has been shifted to the present.

Secondly, it is clear that we live in a society in which individualism is the prevailing ideology. Individual political freedom, individual rights, individual choice in the "free market," individual civil and criminal responsibility, individual salvation, and, yes, the individual "pursuit of happiness" are all sacred cows in North American (and, to a lesser extent, Western) popular culture.

Backing these up are several cultural factors. First, there is the traditional (and still influential) liberal political ideology, borne out of the enlightenment and the French revolution, which stresses atomistic individual autonomy, dignity, and the social contract (e.g. Rousseau, Locke, Bentham, Mill, and Spencer).

Second, there are culturally legitimated liberal economic theories of a free market composed of autonomous, rational, self-interested individuals who act in their own selfish interests to maximize profits - leaving the rest to the "invisible hand" of the market (e.g. Adam Smith; Wall 
Street traders).

Third, there is the common law tradition, tempered by individualistic constitutional guarantees, which stress individual liability for civil or criminal wrongs, while simultaneously providing a duty to protect individuals from arbitrary or unfair infringement of their rights (e.g. the U.S. Bill of Rights; the Canadian Charter of Rights and Freedoms).

Fourth, there is the Christian religious tradition which promises individual salvation as well as individual responsibility for one's sins. ${ }^{39}$ Moreover, as traditional religion declines in influence, its individual-centered mindset appears to have continued.

Last, there is the traditional idea that the individual has a right to pursue happiness. This is evident in utilitarianism, and was even enshrined in an article of the U.S. Declaration of Independence. Indeed, it may be argued that as Western society becomes ever more diverse, complex, and interdependent (a'la' Durkheim's concept of "organic solidarity") individualism has not waned, but has become correspondingly multifaceted. This may be especially true after the decline of traditional religion, the upheavals of the 1960's, mass immigration, and the "me decades" of the 1970's and 1980's.

This last point is important. As society becomes more 
complex and interdependent, it is likely that a multiplicity of egocentric beliefs, some old and some new, will exist side by side. Translating this to the single role, again, it is likely that individuals will, within these two broad analytical dimensions, utilize diverse types of egocentric beliefs to experience and manage their present level of happiness with their relationships (or lack thereof).

This is exactly what is shown by the data. In analyzing individuals' egocentric beliefs in relation to the single role, six distinct varieties have been identified. These have been termed: (1) the "hedonistic"; (2) the "selfworth"; (3) the "stoic"; (4) the "free"; (5) the "downplayer"; and (6) the "lonely." These will be illustrated within the ensuing comments regarding self-esteem.

\section{(iii) Relationship to Self-Esteem:}

It would appear that there is a difference in both the variety of egocentric belief chosen, and in the emphasis to place on a particular variety, depending upon the self-esteem of the individual. For example, those expressing the stoic variety often were dealing with a blow to, or ongoing problem with, their self-esteem; while the emphasis put on the hedonistic variety varied widely between respondents: those with high esteem considering pleasure one reason for their happiness; those with low opinions of themselves utilizing pleasure to manage their unhappiness. These differences will 
be brought out in relation to each sub-type of egocentric belief set out below.

\section{(1) The Hedonistic}

This is perhaps the most clear-cut variety of egocentric belief among the respondents - and the most common. Likely a by-product of our convenience-oriented culture, it is characterized by the desire to enjoy oneself, often sexually, in the present and not worry about the future or a possible relationship. ${ }^{40}$ Furthermore, there is frequently a reason limiting the individual in taking a longer-term outlook. (e.g. being "too young to commit"; uncertainty over health; having too busy a life to put time into a relationship; a string of unsuccessful relationships reducing expectations; or, interest in sex, but not a relationship, with a particular person). The following four composite examples illustrate this type.

Sam is a busy young professional. He is well-educated, attractive, ambitious, and works very hard to move up the corporate ladder. He often puts in long hours, nights and weekends, at the office. He is also involved in many outside activities that take up much of his time, such as writing articles, appearing on a radio talk show, volunteering for a support group, and playing hockey and other sports several days a week. With this hectic schedule, Sam finds it difficult to find time for a serious relationship. Moreover, he does not make it a priority as he has never had difficulty in "picking 
up" women. Characterized as a "gigolo" by his friends, and exhibiting high self-esteem, Sam has been quoted as saying that one should:

"Go out and have fun, get laid, and not worry about the serious stuff, because if it happens, it happens, and if not, you're still having a good time." (male, age 27).

Jessica is a senior student involved in writing a thesis, political causes and volunteer activities. She has high self-esteem, several men interested in her, but no time for a relationship in the present. She states:

"Perhaps we're also a bit too serious in this life. It's only life. You know..these people I tend to hang around with get worked up about so much - and I'm guilty of that myself - but, I think that..we should go out and... and just, you know, dance our faces off every weekend, and have a few drinks..." (female, age 26).

Danny is a young student in his first year in university. He has spent his teenage years in a secure family environment that enabled him to enjoy himself a great deal. While stressing that his self-esteem is "not super high as far as the opposite sex goes," he nevertheless states that he:

"like(s) to go out there... and, just like, drink beer and chase babes and, you know, not have a worry about anything...play cards and stay out all night, stuff like that...just hang out with the boys and go hunting." (male, age 21).

He is a long way from worrying about the future, and this shows as well in his attitude towards relationships. He says: "don't worry about it, have fun, that's the attitude I'm trying to have...Y You know, you're not going to marry the 
person, so why not just have fun?" Adding: "at 21 most of the times you cannot find somebody who is serious enough for you", Danny describes happiness as follows:

"I guess it's kind of having fun. Just going out and having fun like, going out and sort of like partying and having a good time and things are working out, you know, when your whole, when life's working, you're getting.... you know when things are paying off... you're having a good time and, I guess feeling good about myself... I guess that's basically what it's all about... Yeah, just feeling good about yourself, having fun, I guess that's what counts." (male, age 21).

Finally, and in the sharpest contrast regarding selfesteem, one finds Louisa, an immigrant woman in her early thirties who has recently lost her job. She was married at one time, but, several years and children later, there was an unpleasant breakup. Since that time, four years ago, Louisa has had many boyfriends. However, it seems that these relationships never last, and she has been hurt quite badly every time she grows attached to a man. Some didn't like her kids, others found her too aggressive, while still others felt they couldn't trust her. On top of this, several months ago she was diagnosed with cancer. Louisa has long given up hope for the future. Now, she asserts:

"I'm just out to have fun and good sex (because) every time I hope or let myself believe any more I just get hurt." (female, age 34 ).

These, then, illustrate the "hedonistic" variant of egocentric beliefs about happiness in the single life. Note, especially, the increasing belief in pleasure as a management 
technique among those with lower self-esteem. ${ }^{41}$

\section{(2) The "Self-Worth"}

This variety of egocentric belief stresses the cultural value of self-sufficiency in advocating working on oneself in the present as a prerequisite to any form of healthy relationship. It has been stated succinctly by one respondent who stated: "a person cannot go out with somebody to feel good about themself, they have to feel good about themself before going out with someone." (male, age 30).

A good composite example of such a belief is provided by Josie. This subject had spent many years struggling with a compulsive disorder and low self-esteem. Because of this, she never had a boyfriend. She says that she never considered dating because "I always told myself I'm not going to date somebody until I have my act together." (female, age 28).

Another respondent, a young female university student with an outgoing personality and a wide variety of interests, put it this way: "I think its really important to feel good on your own...to feel good about your independence and then you can feel good with someone else..." (female, age 22).

Note the difference in emphasis between these last two respondents. The former utilizes it as a shield, a justification as much to herself as to the listener; the latter makes a confident statement in light of her already high self-esteem. ${ }^{42}$ 


\section{(3) The "Stoic"}

This culture-bound variety of egocentric belief tends to be utilized by single individuals who are enduring difficult circumstances in their personal lives. It tends to stress the limitations of what one can do in a particular situation, and acceptance of one's lot. (e.g. "Take each day as it comes"). ${ }^{43}$

A good example of this variety is given by Dick, a young college student who had been "dumped" by his girlfriend. Very upset by this turn of events, he states:

"you don't have any control over it and you can't change the fact, you know..". (male, age 21).

Another example is provided by Josie, who states:

". lately since I've met up with some guys that I hit it off with, now I...I feel like I realiy need that in my life. And yet, I don't want to...I'm mad at myself for wanting that because I feel like I'm setting myself up for a fall. Because, I don't know, it doesn't seem to work out for me so I...I don't want to rely on another person for my happiness. I...'cause I don't feel... I feel that the only person I can really rely on is myself." (female, age 28).

Josie later adds, in an emotional tone of voice:

"I'd wonder about whether I'Il be alone, 'cause I think at this point I...I...I'm fairly realistic in that I've... I'm thinking I might very likely be alone, because I've been alone this far. So I..I don't hold out hope that I will be a couple."

This illustrates not only that this sub-type receives overwhelming emphasis among those experiencing emotional blows, it also shows that it is almost totally geared toward 
management of unhappiness.

\section{(4) The "Free"}

This common variety of egocentric belief tends to stress the positive side of the single life in our culture: the freedom and independence to make one's own choices and pursue one's pastimes without interference. It is a common face-saving comment of individuals attempting to manage their unhappiness being single. However, it is also emphasized by those single individuals who enjoy many aspects of their life. Two examples will serve to illustrate here.

Jessica is a busy university student in her final year of study. Characterized by high self-esteem, she puts a great deal of time into her work and extracurricular activities, and is "single by choice." When asked about the single life, Jessica noted the difference between the present and her past relationship:

"With the last person that I was involved with, I...found it more of an obligation to spend time with that person on the weekends because I had other things - and that wasn't fair to that individual...Um, I'm much happier. I'm...I'm very independent and I can do what I want when I want." (female, age 26).

A similar sentiment is echoed by Rose, a recently separated woman with several children. Referring to her husband's leaving as a "burden being lifted," Rose states that she "likes" being single:

"I don't have to worry about anybody else besides myself and my kids. I can come and go as I please. I 
don't have to feel guilty about going to a house just for a cup of coffee. I don't have to ask permission for anything. And those things, when you have someone saying that "you can't, because I want to do this", and your life is being put on the back burner, and you're'doing everything for everybody else, its nice to do something for myself for a change." (female, age 28).

Yet, Rose is not as confident or as happy in these views as Jessica. Unlike Jessica, Rose talks at other points in the interview of her doubts about her continued attractiveness to men, and of how she "bats her head against the wall" at night when she is lonely and her "low self-esteem catches up with her." It would appear that she is predominantly utilizing this variety of egocentric belief to emphasize the positive aspects of her situation and thereby manage her unhappiness, while Jessica is predominantly experiencing happiness through this belief.

\section{(5) The "Downplayer"}

This variety of egocentric belief has also been seen frequently in the data. It de-emphasises the importance of a relationship to the individual in question, often serving as a springboard to discussion of other positive aspects of the person's life. For example, several respondents used the words: "if I meet someone, I meet someone - if I don't, I don't." (female, age 28). In cases such as these, one sees low self-esteem utilizing such comments as a management tool.

In contrast, another respondent, who is heavily involved in student politics, said of being single: "It's not 
that different than not being single." (female, age 22). Here, the individual has a diverse, busy, and well-rounded life such that her obviously high self-esteem is influenced by multiple factors and is not nearly so susceptible to the blows of being alone.

Again, the focus is on the self as object dealing with the single role in the present.

\section{6) The "Lonely"}

This final type of belief about being single shows the individual focusing solely on the most unhappy aspect of the single experience as emphasized by our culture: loneliness. ${ }^{44}$ It is a belief that arises when other ameliorating beliefs and social support have broken down, and the self sees itself naked in the present. This was hinted at above in Josie's emotional comment about being alone. It is perhaps better expressed by Teresa, an older, divorced woman who has gone through several unsuccessful relationships. Referring to being single, she states:

"It sucks...being by yourself, being alone, sleeping in a bed... a big empty bed all by yourself. It sucks!" (female, age 36).

Teresa adds:

"When I was single I conceived myself to be alone ... d didn't really like being single at all. I don't like being by myself as a rule - never did. Uh, even when I was married and my husband was out at sea, um, when I was by myself I didn't like it. Even though I was married I was by myself." 


\section{(iv) Conclusion}

This completes the review of egocentric beliefs about happiness/unhappiness. As noted, each of these varieties, a product of our increasingly diverse, individualistic, and present-oriented culture, exhibits a predominantly present temporal focus and an individual centred priority of emphasis. As well, the perceptual and evaluative dimensions are active in all of these, whether in producing or managing the emotional state in question.

It would also appear from the foregoing that there is a difference in both the variety of egocentric belief chosen, and in the emphasis to place on a particular sub-type, depending on the self-esteem of the individual. Those with low self-esteem tend to emphasize the "stoic" and the "lonely" types, while emphasizing the management or face-saving qualities of the rest. Those with the highest self-esteem do not strongly emphasize the "stoic" or the "lonely," if they mention them at all, and focus on the experience of happiness through the other types.

\section{(c) Crusader Beliefs About Happiness and the Single Role}

In this section, through the use of composites examples from the data and other empirical work, the general features of crusader beliefs about happiness as related to the single role will be reviewed. 
Crusader beliefs about happiness, it will be recalled, exhibit a predominantly future-directed temporal orientation along with a largely outward-looking focus of attention. They put more of a premium on goal-directed individual activity as opposed to the more passive hoping found in the transcendental type. One's level of happiness/unhappiness will thereby be seen as a byproduct of striving towards these other goals. ${ }^{45}$ This section will examine several interrelated factors regarding crusader beliefs: (i) general characteristics; cultural basis; (iii) relationship to self-esteem; and (iv) sensual play/flirtation.

\section{(i) General Characteristics:}

When crusader beliefs about happiness are translated to the single role, one would expect to see an individual focused on actively striving towards the long-term goal of meeting someone, while gaining a measure of meaning from the present exercise of one's talents (i.e. the "thrill of the chase").

Just such an outlook is found in "Sam," a 27-year-old male professional whose views on life, and relationships, are intricately involved with his extensive and lifelong involvement in sports (e.g. "it's how you play the game"). While sam appears to be egocentric when experiencing his own pleasure in the present, and minimally transcendental with regard to his ultimate fate, he is largely a crusader when it 
comes to the other-directed "playing the game" of conquest, as well as in his lower priority of "finding" the "right woman. " 46

While very busy with his career and outside activities, Sam admits that he "believe(s) the right woman is out there" for him, but that "he hasn't found her yet." ("You never get what you want.") Meanwhile, he is quite successful at the singles scene, enjoying the strategies, tactics and positive interactions of "the game." As he states: "until the right one comes along, its not the having, its the getting where the sport is."

A different example of such an outlook is given by a 33-year-old male bisexual who states:

"Life is what you make it...I say good things about people because that's a reflection of how good I feel about myself. And then, saying good things about people will make them do things that will make me feel better about myself. They'll want to spend more time with me, they'll give me things, they'll want to be in a relationship with me - and it will make me feel better about myself. So its a very reciprocal, positively enhancing relationship."

Again, note the future goal of a relationship, the experience of meaning from activity in striving toward it, and the predominantly other-directed search for happiness. These examples, therefore, set out the general parameters of crusader beliefs in the single role.

\section{(ii) Cultural Basis:}

The cultural basis of crusader beliefs in relation to 
the single role is set out well by Carnes, who writes:

"When it comes to sexual issues, cultural influences are obvious. The glamorization of sex extends far beyond women's magazines in which a female's self-worth is contingent on her looks and men's magazines in which a male's self-worth is contingent upon his ability to seduce good-looking women.... It extends beyond commercials which use sexual turn-ons to sell, soap operas with unending sexual sagas, and gossip-oriented media with the latest tales to tell... (movies and) TV series that portray the good life as the pursuit of excitement typically use sexual excitement as a counterpoint to the adventure." (Carnes 1991:77-78).

Of course, this self-worth and excitement obtains whether one is striving for the short-term goal of a "conquest" or the longer-term goal of a relationship. The emotional mechanics of pursuit are the same.

\section{(iii) Relationship to Self-Esteem:}

The relationship of crusader beliefs to self-esteem brings us back to consider the difference between sam and our bisexual respondent discussed earlier. Compared to Sam, the bisexual individual has not been successful at the singles scene - never having had a relationship or sexual experience until he was 28 . Rather than enjoying the positive feedback of successful interactions in "the game" then, this individual actively "seek(s) out" positive feedback, gaining meaning from his ongoing efforts.

This issue of self-esteem with relation to crusader beliefs about happiness in the single role is also brought out well by another young man. This respondent freely admits that 
his self-esteem is "low" in relation to dealings with the opposite sex, that he feels "self-respect" when he meets someone, and that he "gets down on himself when it doesn't happen." stating that he is motivated by "the search to find that perfect girl", ${ }^{47}$ he adds, in relation to his happiness:

"I'd say you definitely have to go out and get it...go out and work for it. If you sit around your room all day, you know, I don't care, it's not like it's going to come by and say, you know, you're happy...that's not going to work. I think you have to go out and get it. You know, you got to put a lot of effort into it. I think then it's even more rewarding when it does work."

Again, here is seen the emphasis on active seeking of a relationship as the individual's goal, and the outwardlooking, largely other-directed nature of one's search for happiness. The degree of happiness/unhappiness is again relative to the striving for attainment of the outside goal. Yet, like the young bisexual above, the low selfesteem of this individual in the single role propels his search more than the positive, successful interactions stated by sam. It would indeed appear that crusading beliefs perceptually and interactionally produce happiness more among those successful individuals with higher self-esteem, while acting to manage unhappiness among the rest with the rationalization that "I'm doing something."

Indeed, it may be useful to distinguish two varieties of crusader beliefs in relation to happiness/unhappiness in the single role. The former would reflect a well-rounded 
individual with multiple interests and relatively successful past involvement with the opposite sex. Such an individual exhibits high self-esteem as he/she does not doubt his/her attractiveness nor efficacy in the "game", and is free to concentrate on enjoying the give and take while working towards the ultimate goal.

The latter would tend to reflect lower self-esteem due to fewer outside involvements and sporadic success, at best, with the opposite sex. An individual exhibiting this latter variety of crusader beliefs retains the long-term goal of a relationship, and his/her happiness/unhappiness fluctuates upon the relative success of interactions in relation to striving for that goal. Yet, with a lower level of self-esteem and a less diverse self-concept, here the individual tends to use these beliefs more as a management tool to reduce unhappiness.

\section{(iv) Sensual Play/Flirtation:}

The emphasis on sensual play and flirtation is uniquely high amongst crusading individuals "playing the game" on their way to their goal - whether this be the short-term goal of conquest or the longer term desire for a relationship. As Kasl writes: "Flirting is basic to the hunt." (1989: 120). Carl Couch also expresses this aspect of crusader beliefs in action well in his statement:

"Sometimes the one who initiates sensual play...may 
be looking for a little excitement if the right person comes along or if the right mood happens to develop. In the words of one woman, "Oh, sometimes I just throw out a flirt to see what will happen." Some people participate in it, not with the intention of finding a sex partner or establishing a relationship, but for the excitement generated by the activity itself." (1989:180). ${ }^{48}$

Kasl describes the flirtation between two couples she had observed in therapy, referred to by the codenames Arlene and Barry, Mary and Jack. She notes, for example, how Arlene, who "was looking for a mate," was delighted when Barry came to work in her office. She immediately began to dress more provocatively and become very helpful in order to enable him to "learn the territory." Then, one day after a joint business excursion, she mentioned she was hungry. He, picking up on the cue, suggested that they have supper. During this encounter she casually brushed his hand, made a passing reference to previous sexual behavior, talked of "relationships," smiled a lot, and let her gaze linger longer than usual during conversation. They were involved in a sexual relationship within two days. (Kasl 1989:124).

Similarly, flirtation played a role in the establishment of a relationship between Mary, and Jack, her supervisor. "Obsessed" with Jack "from her first day on the job, " Mary:

"Talked to him sweetly and flattered him by listening intently to his every word. She was exquisitely tuned in to his every move, often anticipating his wants. Her clothes were subtly sexy, innocent and pretty, but also sheer and close-fitting. When there was extra work 
at the office she offered to stay late and help Jack. "Oh, its no trouble," she would say sweetly. "I don't mind." (Kasl 1989:125).

of course, when Jack eventually suggested that they have dinner, a relationship began soon afterwards. (1989:126; $131-32)$.

The happiness-evoking and management functions of crusader beliefs in these contexts of sensual play/flirtation are self-evident..$^{49}$

(vi) Conclusion:

The foregoing has described the general characteristics of crusader beliefs about happiness in the single role, noted their cultural basis, and differentiated the different ways they may be utilized by individuals of low or high self-esteem in this role. As well, the emphasis on sensual play/flirtation by adherents of these beliefs has been noted. This concludes the discussion of crusader beliefs.

\section{(d) Empathetic Beliefs About Happiness and the Single Role}

In this section will be reviewed, through the use of composite examples drawn from the data and other empirical work, the characteristics of empathetic beliefs relating to happiness and the single role.

Empathetic beliefs about happiness, it will be recalled, are defined by their largely present temporal orientation ${ }^{50}$ and their other-directed focus of attention. 
Indeed, the striking thing about such beliefs, relative to those of the crusader variety, is the more conscious expansion of self to include others. Activity directed towards these others is often seen as activity toward self. (e.g. the biblical exhortation to "love thy neighbor as thyself"). 51

When such beliefs are translated to the single role, one must examine four aspects: (i) their general characteristics; (ii) their cultural basis; (iii) their relationship to self-esteem; and (iv) interactional vs. relationship conceptions.

\section{(i) General Characteristics}

The general thrust of empathetic beliefs when viewed from the single role is to see another person positively as very much like oneself, either in a particular interaction or in general. The emphasis is on the activities of "good communication", "understanding" the other person's feelings, "sharing" common emotions in a particular setting, and "sensing" the other's thoughts and feelings. There may also be reference to "losing oneself" in the ongoing experience of an "emotional union" with another person, referred to by terms such as one's "soul mate". 52

Such beliefs are exemplified by "Rose," a 28-year-old woman with small children presently separated from her husband. Rose states that one problem in the relationship with her husband was that they did not share the same religious 
beliefs and put the same value on family. Now, she says she wants a "good man who has the same morals, same beliefs." someone with whom the "emotional bond" can "click" such that she can "know what (he's) feeling." As she states:

"I like an emotional man.. who can try and understand... Instead of me doing for him, I want him to do for me without being asked. Without being subtly hinted at...An emotional bond...click... and he can finish a sentence for me...know exactly. You know what I mean?"

\section{(ii) The Cultural Context}

The theme of love as merger runs deep in our culture. Blumstein ${ }^{53}$ notes a study he conducted on the social construction of sameness, and recounts how the accounts given by couples "key into" this theme and "thereby multiply the symbolic solidarity and perfect taken-for-grantedness of the happily ever after scenario for their relationship." (1991:318). One example he gives is that of a lesbian couple who arrived for their interview with the "same hairstyle " and "virtually identical clothes." Blumstein notes that the words of one of these partners "exemplified couple identity work directed at sameness."

"I could honestly believe in reincarnation. We think so much alike and we have so much in common and we do these dumb things like get the same clothes on. We buy the same things. We bought each other the same valentine at different stores at different times...we go out and buy the same groceries, not having discussed what we wanted ahead of time...We'll shop at the same place and drift into each other. We drive up nose to nose in the same parking lots at the same moments." (1991:318).

Indeed, the idea of love as union or reunion of the 
estranged has been discussed by philosophers from Plato ${ }^{55}$ to Tillich. ${ }^{56}$ It is also implicit in the biblical statement that the "two shall become as one flesh", and in our traditional wedding vows ("two shall be as one"). It is thus not surprising that this view is echoed in the present desires of those experiencing the single life.

\section{(iii) Relationship to Self-Esteem}

As with the other types of belief about happiness, there appears to be a difference in how empathetic beliefs function in relation to the self-esteem of the subject. In the case of those individuals characterized by high self-esteem, such beliefs are discussed in the context of a sharing of strengths and a lower priority on relationships. Those with a lower self-conception tend to put more emphasis on the relationship "bond" in relation to themselves.

For example, "Jessica," a senior student involved with writing a thesis, volunteering in support groups, and political causes states that she is "single by choice." She ended the last relationship she was involved in. She explains that she "values that kind of relationship so strongly", and wants to be able to "give everything to it" (but) "at this point I can't" as she has other commitments. She says that, ultimately, she wants a relationship of "strong, independent persons interacting with each other...in the sense of developing the growth of both partners and of the people they 
interact with." Yet, she would rather be on her own than "settle" for someone she does not want to be with. Her selfesteem not highly dependent on her single status, shè is very "picky" about what she wants. Jessica states:

"The whole point of being in a personal relationship is that...you worry about the other person. That you..you become more of one entity than two entities, I would think... I'm looking for a kindred spirit... I want somebody who..will go to bat for me... who cares a lot about me, obviously. And I want to.. feel that I, you know, love that person enough that that's what I want to do. Uh, giving up your ego is one of the hardest things, I think, that is ever required of an individual. And.. I would want that... that kind of a union, definitely. Which is why I say that, uh, you know, that it may not happen." (female, age 26).

This viewpoint contrasts sharply with that of "Teresa" and "Rose," both divorced or separated women with children. Teresa, who describes herself as being "very depressed" recently over the breakup of an unhealthy relationship, with "very low" self-esteem...almost to non-existent", expresses her empathetic beliefs in the context of an old boyfriend coming to her aid:

"I thought that, um, there was someone that was saving me from being single, and, um, found out over the period of time that, um, my soul mate was the one that had to save me from that relationship." (female, age 36).

"Rose," as well, has expressed empathetic beliefs when discussing the man she wants. Yet, her husband's leaving her for another woman has damaged her self-esteem, and the underlying motive for her desire for an emotional union may reside in the following words: 
"I want to be in control. I want to know what's going ${ }_{57}$ on. I want to know why it's going on." (female, age Indeed, this relationship is also shown by a 33 -yearold bisexual male respondent who has "instances" of low selfesteem", used to "fantasize" about death, "dwells on" being single, and has "had some painful rejections." Committed now to "new age" thinking and attending twelve step programs, this man stresses that his self-esteem is much higher now than it used to be. Yet, after expressing empathetic beliefs, linked to astrology, about the union of two people, he states:

"I think..the way I look at it is that meeting someone...getting into a relationship, getting married... would be confirmation to me that I've really done a lot of work in my...in my program of selfimprovement... in my new life..you know?" (male, age 33).

Last, but not least in this regard is the comment of Melody Beattie, ${ }^{58}$ a family therapist who has dealt with and written extensively on that unhealthy manifestation of low self-esteem and empathetic beliefs known as "codependency." She has written:

"Most of the people I've worked with in family groups have been. obsessed with people they care about. When I asked them what they were feeling, they told me what the other person was feeling. When I asked what they did, they told me what the other person had done. Their entire focus was on someone or something other than themselves. Some of them had spent years of their lives doing this - worrying about, reacting to, and trying to control other human beings. They were shells, sometimes almost invisible shells of people. Their energy was depleted - directed at someone else. They couldn't tell me what they were feeling and thinking because they 
didn't know. Their focus was not on themselves." (1987:53).

From the above the conclusion is likely that there are two different ways that empathetic beliefs manifests themselves depending on the self-esteem of the individual. In the case of those with low self-esteem, it would appear that there is a desire to fill a void.by a merger with a greater whole that will provide positive meaning to one's life. ${ }^{59}$ In those with high self-esteem, on the other hand, it would appear that there is little, if any, void to fill as here we are dealing with relatively complete, diverse individuals with multiple determinants of their self-image. As such, these individuals focus on a merger of existing strengths, but only when these are seen as compatible. ${ }^{60}$

\section{(iv) Interactional vs. Relationship Conceptions}

An interesting aspect of empathetic beliefs about happiness is that they exist on a continuum of wider to narrower scope in interactional experience. ${ }^{61}$ They may refer, for example, to the narrow but pleasant empathy that two people on a date enjoy in sly glances over a joke, or experiencing the same emotions while holding hands at a movie. Somewhere in the middle would be comments like those made by a 19-year-old female that:

"I find I feel really good when I'm with people that I feel close to and that I can be open with and honest 
with. Then I feel...it's like "Wow, this is really great."...I've experienced things like that at camps and things where all of a sudden you become very close to people, and you just, you're so honest and you share..."

At the other extreme, there may be the profound joy of deeply understanding many, if not all facets of the other person on an intimate level, as in making love to one's "soul mate."62 Of other interactions at this intimate end of the continuum Couch writes:

"Robust romantic relationships come closer to transforming two people into a single unit than any other relationship. In the extreme case, the two selves that compose the relationship almost become merged into a single self. The partners in such relationships sometimes literally find it impossible to live without each other." (1989:191). ${ }^{63}$

As suggested, this same multifaceted or "relationship" empathy may produce the deepest unhappiness as well. For example, one 30-year-old male, whose longtime girlfriend had left him, stated that he "felt like a part of me (is) gone", and noted how he had become "very emotional" and cried upon hearing her voice on the phone, just "catching up on the gossip" like nothing had happened.

\section{(v) Conclusion:}

Summing up, the foregoing has reviewed the general characteristics of empathetic beliefs in relation to the single role, noted their deep cultural basis, and explored the different ways in which they may be utilized by individuals of various self-esteem levels. In addition, various degrees of 
emphasis on such beliefs have been noted, chiefly with regard to familiarity in interaction and intimacy of relationship.

This also concludes the preliminary discussion of the four ideal types of belief about happiness in relation to the single role. As can be seen, there is significant material available to illustrate the variety of evocative and management functions of these beliefs in relation to the single role. However, some problematic statements in the data must be addressed before reaching a final conclusion on this hypothesis. It is to these that the discussion now turns.

\section{(e) Problematic Beliefs:}

It is clear that the above system of ideal types is not perfect in classifying beliefs about happiness. ${ }^{64}$ While an examination of the data has shown rich and diverse illustrations of these four types, it must be remembered that they are, after all, analytic ideals which may sometimes become blurred in the real world of experience. This blurring appears in two ways: (1) there are a relatively few statements of beliefs or outlooks that appear difficult to classify according to the schema of types as set out; (2) individuals frequently seem to discuss several identifiably typical beliefs with regard to a single role. ${ }^{65}$ Each of these interrelated matters will now be addressed in turn.

First, with regard to difficult to classify statements 
in the data, consider the following, which have been numbered for convenience:

(1) "Everything happens for a reason." (female, age 37).

(2) "What goes around comes around." (female, age 36).

(3) "Life is what you make it." (male, age 21).

(4) "I want to try it all." (female, age 19).

(5) "If you don't take risks you'll never know." (female, age 19).

(6) "(I have) beliefs about...a person's ability to develop, a person's ability to grow." (male, age 25).

(7) "You...try to improve things so that, you know, maybe things will get better. You know, kind of like ride the wave, I guess." (male, age 21).

(8) "I try to live... Iive in the present for the future, I guess." (male, age 21).

(9) "(Happiness is) something that you achieve ...something that you have to work at... a lot of shit gets thrown your way and, uh, you have to know how to deal with that and accept it. Uh, or change it." (female, age 26).

(10) "When you accept yourself, um, it brings an aura about you so that you...you're sharing the wealth. You're sharing your own personal wealth. Um, and...you're sharing that type of personal wealth, of...that giving, that happiness..." (female, age 36).

(11) "Happiness in general, if you are happy with what you are doing, and, I think, if you know what you are doing is right - you're doing good things - that makes you happy." (female, age 28).

It is not intended to extensively analyze each one of these statements one by one to glean exactly where it fits or 
does not fit on the typology. Rather, it becomes abundantly clear that these statements, when looked at in context, fall into one of two somewhat overlapping categories: (i) beliefs whose classification depends on the meaning of a key word in the phrase, and (ii) hybrid or combination beliefs differentiated on the temporal and/or self/other focus intended by the respondent.

For example, it is clear that the specific classification of statements number $3,4,6,9$, and 11 turn on the exact interpretation to be placed on the words "make," "try," "develop," "achieve," and "doing," respectively. Specifically, does "make" in statement 2 refer to present altering of perceptions and management of ones own emotions, or does it refer to a future-oriented external goal. Whether this statement can be interpreted as an egocentric or a crusader belief depends on this determination. Similarly, statement 4 could be egocentric or crusader in nature depending upon the time/self-other meaning given to "try;" statement 6, and others referring to personal "development," may be either egocentric, or transcendental depending on whether past or future development is the focus; ${ }^{66}$ statement $^{-1}$ 9 may be either egocentric or crusader in nature, depending on the temporal orientation intended; and statement 11 may be either egocentric or crusader depending upon whether the individual intended "doing" good things to refer to present 
activities undertaken to make her feel better about herself, or whether she was referring to external, more future-directed goals.

Of course, to the extent that respondents intended both or multiple meanings in the above statements, it is evident that they also fall into the second category above: hybrid beliefs. These are beliefs about happiness that combine elements of two or more typical beliefs in relation to recognition of two different temporal situations and/or self/other orientations. Perhaps the best example is in statement 2 - the "philosophy of life" of a 36-year-old woman that "what goes around comes around." When this is broken into its component parts, one sees a predominantly active, other directed, crusader statement in "what goes around," and a largely passive, individualistic, future-directed, transcendental statement in "what comes around."67 Similarly, statement 5 states that if the individual does not take present risks (egocentric), then the future goal of externally located happiness (crusader) cannot be obtained; statement 1 , closely associated with transcendental religious beliefs, moves their future-directed nature to the present, forming a predominantly egocentric interpretive belief to help deal with personal problems; ${ }^{68}$ statement 7 talks of the external, future-directed goal of trying to "improve things" (crusader) in concert with the present, individual-oriented experience of 
"riding the wave;" statement 8 differentiates a 21 -year-old male's philosophy by referring to a combination of egocentric, individual-focused beliefs for the present and crusader, goaldirected beliefs for the future; ${ }^{69}$ and, finally, statement 10, while retaining a present temporal orientation throughout, splits the self/other dimension in its recognition that in accepting oneself (egocentric), the "aura" one exhibits is infectious, enabling one to "share the wealth" with others (stressing the empathetic aspect).$^{70}$

From the above, it becomes clear that, occasionally unclear statements aside, individuals do not necessarily express only one typical belief about their happiness at the same time. Rather, they entertain hypothetical situations and focus on different aspects of the temporal and self/other dimensions in order to give broader statements, incorporating several types, and covering as much ground as possible. As such, this does not so much disconfirm the typology as it does demonstrate its flexibility in light of human ingenuity.

This leads to consideration of the second matter stated at the outset: individuals stating several identifiably distinct types of belief with regard to the same role. This is also common in the data, and must be addressed. In the discussion that follows, emphasis will be on the single role as this is the area in which the most data is available.

It is quite apparent that individuals in the sample 
were not so unidimensional as to express only one type of belief with regard to the single role. Indeed, this would be the exception rather than the rule. Rather, it is ckear that individuals usually express a variety of clearly identifiable beliefs, both over time and simultaneously in relation to different aspects of the same role. Each of these matters will be dealt with in turn.

With regard to individuals holding different typical beliefs over time with regard to the single role, consider the extensive and representative comments of a 21-year-old male relating to his emotional experiences. At times when he is single, he states, in typical transcendental form, that he would "rather have someone around" and "looked forward to it."

The management function of these transcendental beliefs is shifted to the crusader, however, in the next selfinteractional context expressed by this respondent. When attempting to meet someone at a bar he expresses a more active, other-directed outlook, which can be seen in his statement that:

"Like, its the weekend, you're going through the whole singles grind again, you know, its like, you know,
going to a bar trying to meet someone..." ${ }^{71}$

At this point the management function of the crusader beliefs consists of the idea that he is at least "doing something" about being single. As he states:

"I'd say you definitely have to go out and get it. 
You know, you can't sit there and wait for it...it'll take you forever. It may eventually show up, who knows, it might work. But I think for the most part you have to go out and work for it."

Upon actually meeting someone, however, this respondent suddenly shifts gears to a more immediate and egocentric subjective outlook, stating "Its a chance, you know, you never know, so lets see how it works." This is also reflected in his remarks as to the immediate effects of interaction with the other person on his happiness:

"I guess when I do meet someone then, you know, then you've got some... you know, it makes you feel, it makes me feel better about myself. "Cause like, you know, you say "Well, someone sees something that..., you know, someone else is attracted to me" and all that. Yeah, that gives you some self-respect and, you know, to know that someone else wants to be around you. So I guess that, you know, makes you feel better about yourself."

This egocentric outlook continues throughout most of this individual's relationships. He states that:

"When you first start going out with someone you really want to spend a lot of time with them, you know, its...being with someone else is a lot better. A lot of relationships I've been in, after a couple of months that wears off and its like "God, I wish I was by myself again, I need some time for myself." You know, its like "Well, see you later honey, that's it."

However, this respondent was recently involved in a relationship that meant more to him than these others. Indeed, he states that he "fell for her," and noted the passing transcendental comment that he was "looking forward to seeing her" while away hunting several weeks before.

Yet, the brief relationship in question did not 
persist. Both the relative ensuing level of his upset, and the following comments, suggest that minority empathetic elements were creeping into his thoughts:

"Like now there's nothing...Yeah, you know, you got nothing really...Especially, you know, especially when...this girl I was going out with, you know, we had things... it was going really good, like, you know, I would find, you know, she was...she was like, she was a keeper, OK, like she had a lot going for her. You know, so that really screwed it up..." "72

Interestingly, this unhappy turn of events is again reflected in his typical beliefs relative to the single role. In a very real sense he has come full circle, as now he utters transcendental beliefs to manage his unhappiness - albeit largely in relation to their chances of getting back together:

"She sort of had things to work out and, you know, I think maybe possibly when she gets 'em, you know, figures things out for herself, you know, I think the possibility (is), you know, (that) things might get back together again. You know, I'm...I guess for the last week since I broke up with her I've been kind of holding my breath hoping that, you know, that would happen..."

Thus, taking this example as representative, it is clear that individuals express different typical beliefs over time in relation to the same role.

Moving on, however, to the second, more controversial matter, it is also the case that individuals hold different typical beliefs with regard to different aspects of their present circumstances with regard to the single role. For example, consider the various comments of a recently separated 
woman as representative. First, regarding the freedom of being single again, this respondent expresses a shift from empathetic ${ }^{73}$ to egocentric beliefs:

"My marriage wasn't a healthy one, and its...its like a burden being relieved. I'm almost starting over again and I'm enjoying doing that... I don't have to worry about anybody else besides myself and my kids. I can come and go as I please. I don't have to feel guilty about going to a house just for a cup of coffee. I don't have to ask permission for anything. And those things, when you have someone saying that "you can't, because I want to do this," and your life is being put on the back burner, and you're doing everything for everybody else, its nice to do something for myself for a change." (female, age 28).

However, the degree to which this respondent is utilizing these beliefs as a management technique is shown by the following two comments - the first regarding a disconfirmation of her prior crusader beliefs about working through marital problems; the other a different and unhappy variety of egocentric belief: the alone.

"If something goes wrong I like to try to make it work, and I think that the thing that bothers me the most is, I want to try. I'm willing to forgive. But he doesn't want...he doesn't want nothing to do with that. Nothing. He just slammed the door and that's it. Its done."

"The hardest time is at night when I'm by myself and my kids are in my bed. And that's the worst time of night because that's when your low self-esteem kind of sneaks up on you and, that's your quiet time, and of course what people do during quiet time - they think. And um, that's when I bat my head against the wall...at night basically. So that's the worst time. And the loneliness and, uh, just even to go out for a cup of coffee. Like just... and with a man. With the male companionship that I miss." Yet, this respondent has other typical beliefs to help 
her get through her present unhappiness: transcendental ones. By hypothesizing a better marital future for herself, she simultaneously alleviates her unpleasant experience of the present. Consider her following comments where she expresses hope :

"That I will someday meet my prince charming. Basically. And that's a lot of...Um, I think there is someone out there for me, and I think he'll be a very good man. Uh, I think that the next man that I plan to... or have a chance to marry will treat me like a queen - like I treated my husband like a king. I know that in my heart. I feel it in my heart. And when I meet him. I'll know. I'll just know. I don't worry about it because I know in my heart that there is someone out there for me -even though, at times from this conversation, it feels like I don't..."

Also in her hypothesized future, this respondent expresses empathetic beliefs with regard to how her relationship with this "prince charming" will operate:

"I like an emotional man... who can try and understand. Because I've been with men who... who don't care. Their only care is about... for themselves. I'd like to find someone who would care about me for a change. Instead of me doing for him, I want him to do for me without being asked. Without being subtly hinted at. (An emotional bond, like a) "click" Yeah, and he can finish a sentence for me... know exactly. You know what I mean? Like, that relationship may never happen, but I'd like one to gear that way."

Finally, she brings herself back to the present by expressing both the "self-worth" and the "downplayer" variety of egocentric beliefs:

"People say "How come you...you don't have a man?" I mean, they say "You know, you're a good looking girl, you're...you're wonderful. Why don't you...?" I say "Because that's not fair to other people. I'm not ready 
to start that. I have too much to sort out for myself... I'm just not ready. And that's not fair to anybody else...to be included in this." 74

"Its not important to me right now to find that Mr. Right. When it happens, it will happen. And I know, I've... I'm not putting a time limit on it...It's important...its important for me to think that there's somebody in the future, but its not important to happen right now. It doesn't matter if I'm 40 or 50 . It doesn't matter if it happened tomorrow - that would be great. What I'm saying is, um, I don't want to spend old age by myself. That I do know. But I'm not going to find a guy just...so I don't have to spend old age by myself. I would rather spend old age by myself being happy, and at times feel lonely, than I would living a miserable life." 75

From this woman's comments it is clear that she does not merely hold one typical belief per role. Rather, she holds a variety of typical beliefs with regard to different aspects of her role as a recently separated, single woman. Specifically, she expresses the "free," the "self-worth, " and the "downplayer" variety of egocentric beliefs in relation to her underlying unhappy perceptual and evaluative view of herself as "alone." Moreover, she buttresses the management function of these egocentric varieties by hypothesizing a better future in which transcendental and empathetic images bring meaning and hope to her present experience.

Another example of this is provided by one of the observed subjects. This man, a successful professional heavily involved in sports and his many extracurricular activities, has been characterized as a "gigolo" by his friends. In a conversation consoling one of his friends over the breakup of 
a relationship, he advises his friend to:

"Live for today...Go out and have fun, get laid, and not worry about the serious stuff, because if it happens, it happens, and if not, you're still having a good time." (male, age 27).

This combination of the "hedonistic" and "downplayer" varieties of egocentric beliefs is modified, however, when his friend challenges him by asking whether he simply wanted to have fun for the rest of his life. He introduces transcendental and crusader elements in his rebuttal that:

"You've got me all wrong. Its not that I want to spend the rest of my life in the singles scene. I believe that there is the right woman out there for me, but that I just haven't found her yet - although I did come close with what happens. its not the having, its the getting where the sport is."

Note that this individual also combines several types of belief to refer to and manage his experience of happiness/unhappiness in the single role. He utilizes the "hedonistic" variety of the egocentric type with regard to his present sexual enjoyment, and the "downplayer" with regard to the immediate chances, or his wishes, of these turning into a meaningful and lasting relationship. ${ }^{76}$ However, he also looks forward in a transcendental way to the "right woman" "coming along," and expresses his happiness in the search by the quintessentially crusader comment that "Its not the having, its the getting."

However, it must also be noted that occasionally this 
multiplicity of typical beliefs can conflict with the present life experiences of an individual when referring to the same conceptualized aspect of the same role at the same time. A good example of this is the unhappy inner conflict over who she can "rely" on expressed by a 28-year-old female who has never had a serious relationship:

"It wasn't bothering me for a good year or so. But like, lately since I've met up with some guys that I hit it off with, now I... I feel like I really need that in my life. And yet, I don't want to... I'm mad at myself for wanting that because I feel like I'm setting myself up for a fall. Because, I don't know, it doesn't seem to work out for me so I...I don't want to rely on another person for my happiness. I...'cause I don't feel... I feel that the only person I can really rely on is myself."

What becomes clear from all of this analysis is that, in addition to the multiple-type statements discussed earlier, individuals do not necessarily hold merely one typical belief about happiness per role. Matters are much more complicated than originally thought. Instead, it is readily apparent that individuals not only draw on each of these four typical beliefs at different times with regard to the same role, they also do so at the same time with regard to different conceptualized aspects of the same role. They do not, however, unless undergoing unhappy internal discord, express more then one typical belief with regard to the same conceptualized aspect of the same role at the same time.

This concludes the section on problematic beliefs relative to the hypothesis on the typology. As has been shown, 
matters are considerably more complex than originally thought. While there is ample evidence in the data demonstrating the existence of all four types of belief about happiness, there is also evidence showing: (i) hybrid beliefs that incorporate elements of several distinct types to address different temporal and/or self/other situations; and (ii) that, depending on the aspect focused on, individuals may utilize more than one belief per role in the experience or management of their happiness/unhappiness, whether over time or simultaneously. As such, these refinements of the theoretical model do not disconfirm the hypothesis regarding the typology. Rather, they point to the amazing adaptability of human beings in synthesizing beliefs to maximize their happiness.

\section{(3) Mechanisms of Change:}

In this final section the data in relation to the final group of hypotheses regarding mechanisms of change between types will be discussed. As will be recalled, this states that:

"An individual will become disillusioned with his/her conception of happiness and seek a new typical outlook when (a) perceived disconfirmation occurs in interaction, and (b) identity-maintenance strategies for maintaining belief have broken down."

Also relevant to this shift are the hypothesized contributing factors (c) frequency, (d) intensity, and (e) whether or not the disconfirmation takes place in interaction 
with significant others.

As will be appreciated, many of these matters have already been extensively discussed in earlier sections of this chapter. As such, considerations of economy dictate that they do not need so much a full review as elaboration where warranted. Other matters may need more extensive review.

This hypothesis will be dealt with by examining disconfirmations in relation to the social role/identity upon which the most data are readily available: the single role and personal relationships. It is hoped that this will be suggestive of the dynamics of change relative to other roleidentities.

\section{(a) Disconfirmation:}

This is the core of the hypothesis regarding mechanisms of change between types of belief about an individual's happiness/unhappiness. It asserts that when an individual's typical perceptual and evaluative belief about self in a particular role-identity is seen by that individual to be inconsistent with the contents of interaction, that individual will adopt a different typical belief. $\pi$

In the single role, the variety and types of disconfirmation have already been discussed in the section on negative interactions (Infra, p.85-87). In each of these contexts, ranging from minor matters such as being turned down for a dance to more major situations such as breakups, 
separation, and divorce, a root perceptual and evaluative belief was challenged in interaction: the individual's perception of self as evaluatively desirable and worthy of interaction with a member of the opposite sex. That such a perception corresponds, in different situations, to the four types of belief about happiness, has already been discussed. ${ }^{78}$ Perhaps the best example given for the change between types upon disconfirmation is that of the separated woman in the previous section (Infra, p.181-84). ${ }^{79}$ Upon her husband leaving her for another woman after an eight year marriage, she is very upset. She cannot deny what has occurred, ${ }^{80}$ and her previous impliedly empathetic image of their marriage ${ }^{81}$ is destroyed. In addition, her crusader beliefs about working through marital problems are dashed when he slams the door in her face in response to her overtures.

Afterwards, at the time of the interview, this respondent expresses a variety of egocentric beliefs in relation to the present, and very strong transcendental beliefs with regard to her hypothesized future. These conceptual changes between types help her manage the level of unhappiness she feels in the present.

Interestingly, however, the data show that it is not only disconfirmation that precipitates a change between types. Perhaps the best illustration of this is that of the 21-yearold male student in the section immediately prior to this 
(Infra, p.179-81). As will be recalled, this individual initially exhibited transcendental and crusader beliefs to manage his happiness in the single role. Upon a: present confirmation of these future-directed beliefs about his desirability and ability to find a woman, in a bar, the respondent shifts to egocentric beliefs to experience happiness in the present. As well, he notes the difference between most of his relationships and that with his recent girlfriend by noting that he "fell for her," and suggests that an incipient empathetic outlook was developing in his comments and his level of upset over their breakup.

Of course, upon her breaking up with him, this respondent immediately shifts his attention to transcendental beliefs about her coming back to him in order to manage the level of unhappiness in the present.

This example forces a revision in the original hypothesis to include present confirmation of the hope or goal of one's future-directed typical beliefs as a trigger for the individual making changes between types of perceptual and evaluative beliefs regarding happiness.

At this point, however, it is timely to turn to the second major element of the hypothesis: identity-maintenance strategies.

\section{(b) Breakdown of Identity-Maintenance Strategies:}

This component of the third hypothesis is based on the 
logical premise that where an individual has well established means to effectively deal with potentially disconfirming interactions, this event will not be perceived as disconfirming. If, however, these are not in place, the full force of the disconfirmation will result in the individual making a change between types.

The variety and types of identity-maintenance strategies have, of course, already been discussed at some length (Infra, p.98-101). It is not intended here to review these matters much further. Rather, the present section will address those representative situations in the data regarding the single role where these strategies are breaking down in response to a potential interactional disconfirmation of a particular typical belief. Of course, it must always be remembered that shifting to another typical belief is in itself a way of maintaining a positive identity in a particular role. ${ }^{82}$

Again, the emphasis will be on events such as rejection, breakups and divorce. The intention is to contrast three representative respondents, both with regard to the degree to which their identity-maintenance strategies enable them to deal with such disconfirming events, and relative to their ultimate change to another typical belief.

The first example is that of a 33-year-old male. While he is not totally happy with being single, he is satisfied 
with his life in general. He states that he has high selfesteem, and this is expressed in his involvement in many activities such as work, university, support - groups, athletics, and writing. In general, he confidently expresses a combination of crusader and transcendental beliefs with regard to his chances of finding, or being found by, another person:

"Saying good things about people will make them do things that will make me feel better about myself.

They'll want to spend more time with me, they'll give me things, they'll want to be in a relationship with me..."

"I think for me its having faith in my God. You know, having faith in my destiny that I will meet someone, and just putting it into God's hands."

Yet, this fellow also notes that he has had "some painful rejections," and notes "loneliness, rejection, (and) self-pity" as the chief factors reducing his self-esteem and happiness. In response, he marshals several cogent identitymaintenance strategies, both conceptual and interactive.

The former revolve along two methods this man uses to see the situation differently. First, he expresses the rationalization that "its not me, its only one aspect of me." Next, he stresses unfair cultural differences in the perception of single people:

"Its just an area of my life or a part of my personality that they are questioning or drawing attention to... Its not that they're knocking me down totally."

"Everywhere in our society we see the, uh, 
pervasiveness of couples. You know, the relationship. ..Uh, in the 1700's, people like Immanuel Kant had almost no sex life at all, and no relationships. It was almost ...it was a...it was a sign of status, among men anyway, to be single, because you could devote yourself to your life, to your work."

The latter, interactional strategies utilized by this man neatly complement the first of these more subjective methods and the crusader beliefs stated above. Consider the following comments:

"I need to believe, as people have said to me when I go to them about talking about my rejections, and, its just that they aren't interested in me. Its not that they are condemning me. They're not personally criticizing me, its just, for whatever reason, they're not interested at this point in their lives. They might not be interested in a relationship... Or maybe just, there's just something about me that they don't feel comfortable with - and that's OK. It doesn't mean that they are judging me or condemning me."

"Positive feedback...I seek it out. I ask people sometimes to say something good about me."

All in all, this individual exemplifies a healthy array of identity-maintenance strategies, both conceptual and interactional, that enable him to effectively deal with passing, potentially disconfirming rejections. Moreover, his predominantly future-directed beliefs in this role are difficult to ultimately disconfirm in present experience, and his multiple involvements in numerous activities enable him to get his mind off the loneliness of the single role. In short, he has no reason to consider rejections as totally disconfirming, nor to switch between types of belief in this 
role.

For an intermediate example, recall the comments of a 28-year-old female who tries to focus on the present because "I've never thought of good things coming later." Unhappy over living with her mother, being let down by her few friends, her parents' divorce, and a compulsive disorder, she emphasizes the stoic, "make the most of life" variety of egocentric belief in relation to her single status, because her past experiences have not been fruitful.

After encountering several attractive and pleasant men on a holiday, however, her hopes were raised despite herself. Yet, as these men were married, while they expressed some interest, she was ultimately rejected. The conflicting positive and negative elements of this interaction appear as a tension between stoic and transcendental beliefs in her anguished comments of self-interaction:

"It wasn't bothering me for a good year or so. But, like, lately since I've met up with some guys that I hit it off with, now I... I feel like I really need that in my life. And yet, I don't want to...I'm mad at myself for wanting that because I feel like I'm setting myself up for a fall."

Indeed, at another point in the interview this respondent becomes quite emotional when wondering about always being "alone," and states that "I think I have met the right person in a few cases but its just been bad timing." Both of these comments indicate that this individual, focusing as 
strongly as she does on the present, is now having difficulty maintaining her stoic beliefs in favor of transcendental ones. of course, her interactions with these men played a large part in this result.

Basically, this respondent is utilizing a conceptual strategy emphasizing what is good about the present, and considering unpleasant matters out of her control. However, due to her relatively unpleasant life experiences in the past, when an initially positive interaction gives her hope, it is highly meaningful and she unwittingly wants it to continue. Yet, she has also been hurt in the past by this, and refuses to consciously look ahead despite the fact that a general transcendental outlook has been suggested to her. ${ }^{83}$ This puts her face to face with her loneliness in another rejection, regardless of the various egocentric beliefs she utilizes to save face. ${ }^{84}$ Moreover, as her mother is virtually her only social support, this makes things relatively hard. In short, here is a good example of an individual utilizing a poorly chosen conceptual strategy with relatively little interactional backup. ${ }^{85}$ The tension and relative unhappiness shows as her identity-maintenance strategies are breaking down.

Finally, consider the examples of individuals whose identity-maintenance strategies have completely broken down in relation to a particular typical belief. In addition to the 
young student and the separated woman in the previous section, both of whom were undeniably left by their partners and quickly made the switch between types, consider the following respondent. This 36-year-old divorced woman has very few social activities - even relative to the woman above. ${ }^{86}$ She does not work, her children are not with her, her family is far away, and her relationships have largely been unsuccessful. As such, she places an inordinate amount of emphasis on personal relationships.

A function of her admittedly low self-esteem, she expresses this emphasis in four ways: (1) her only egocentric statement that she equates being single with being "alone;" (2) her extremely transcendental view that someone would "save" her from being single; (3) her favored self-image as a "lady;" and (4) in her overwhelming empathetic emphasis on being in a relationship with her "soul mate."

This respondent underwent an unfortunate and disconfirming turn of events, however, in a sexual encounter with her former boyfriend or "soul mate" while she was involved with another man:

"That did, um, bring about big, big conflict. Something that I had to handle right away and, uh, something that I found myself... I found myself very confused. Um, because I thought that, uh, I thought that...because I had run away from the man that I truly love into another man's arms, I thought that I had loved the second man, where in actuality, um, he was just there for convenience...My morals, um, I um, were brought right down to the ground. Um, I have always tried to 
perceive myself to be a lady. And I really felt, um, excuse the language, but I did feel like a slut."

As a result of this encounter, the resultant breakup of her current relationship, and her subsequent furious dismissal of overtures from her former boyfriend, extreme behavior followed: she attempted suicide. In her words, "depression is something that is so overpowering, it...it takes over your beliefs and, uh, your...just your fundamental desire to live." Central to this was her fear of loneliness, and, upon reflection, of angry rejection by her "soul mate." She states:

"I was very confused. I was very mixed up. I was very, I felt very alone, and, uh, if you've ever had the feeling of being alone within a crowd, and, not being able to talk with anyone - especially your best friend um, that...that makes you feel very lousy. Because you, uh, you sit there and you wonder, you know "What the hell is it all worth?" You know, you can't talk with anyone especially the person that you want so much to listen, you want them to listen to... And you're afraid that, uh, they're going to turn their backs on you, and, that would hurt me even more."

Basically, this respondent's strong fear was that her empathetic view of her former boyfriend would almost certainly be rudely disconfirmed if she called him again following both her sexual behavior, and her angry dismissal of his overtures. Moreover, the strength of this empathetic belief in him would not let her, at least at the time in question, consider transcendental beliefs as to another man in her future. Finally, her cherished role as lady was, in her eyes, in 
tatters. Emotionally naked, she made an immediate switch in all respects to perhaps the most self-directed and present oriented outlook possible when she egocentrically turned her anger towards herself. ${ }^{87}$

From the above three examples can be seen the sharp difference between individuals who undergo potentially disconfirming events with well-developed conceptual and interactional identity maintenance strategies, and those that do so with inappropriate or no such mechanisms. In the former case there is no need to shift between types of belief in relation to one's happiness. In the second example, the tension between types is readily apparent where the individual seeks by sheer force of will to stick to an inappropriate strategy. Finally, the potentially devastating effects of disconfirmation of one's central identity with no available conceptual or interactional strategies is shown by the third example. These illustrate the importance of this component of the hypothesis.

\section{(c) Frequency:}

In addition to the major factors of perceived disconfirmation and breakdown of identity-maintenance strategies, another factor hypothesized as relevant to changing between types is the number or frequency of disconfirmations experienced by an individual over time. Basically, the more disconfirmations, the more likely will 
identity-maintenance strategies fail, and the more likely will be that person to make a change between types of belief regulating his/her happiness in a particular role.

of course, the concept of repeated negative interactions accumulating over time in one's level of unhappiness has already been discussed (infra, p.123-127). In that section it was noted that numerous such interactions over a period of time resulted in one being much less happy. For example, one respondent sums it up in the comment that:

"If you're getting constant negative feedback you're going to have very low self-esteem. I think that's a natural outcome." (female, age 28 ).

In addition, however, it must be noted that repeated evaluative interactions, particularly negative ones, increase the chances of an individual changing his/her typical conception of happiness. Of course, this makes logical sense. Identity-maintenance strategies that may hold up under one or a few negative interactions may not have the strength to hold up under a more sustained attack. The present discussion will focus on negative interactions, as they appear in the data as the examples most directly relevant to this portion of the hypothesis.

However, due to the fact that it has been noted above that positive, confirming interactions may also lead to a change between types, it cannot be logically discounted that repeated interactions of this variety also improve the chances 
of a change between typical beliefs. It is at least suggestive.

A negatively-induced change in typical outlooks is hinted at by the following comments:

"If you get, or you're having a lot of negative things happen to you, or you're having a lot of negative feedback, that definitely can affect your mood or the way you perceive things." (female, age 22).

"I would say I carry the negative, uh, comments with me and overanalyze it." (female, age 28).

"If you've got a, you know, you've got a string of bad things happening, or, you know, a lot of criticisms against what you've been doing, then you're probably going to get depressed about it and probably not put as much effort into it, you know, just get down on yourself." (male, age 21).

The first comment suggests changes in typical perceptual belief, the second intensive self-interaction, and the latter a shift from a crusader to an egocentric outlook in the face of constant criticism.

Aside from these suggestive general comments, however, there is clear evidence in the data illustrating this relationship with regard to the single role. Consider, for example, the comments of the 28-year-old female in the previous section (infra, p.194-95). Having never had a steady boyfriend, she notes both her repeated negative experiences and her resultant dislike of the transcendental outlook:

"It doesn't seem to work out for me."

"You're always told "Maybe you haven't met the right person," but I think I have met the right person in a few 
cases but its just been bad timing...I just have this feeling as far as relationships.... 'm always going to have bad timing 'cause I..its not like I've met a lot of the right people. There's, you know, there's been a few people that I think would be the right person, but they're...they're already committed to somebody else or, its just the timing's wrong."

"I'm afraid to kind of...have any hope for that. I try not to think about it."

This respondent has had repeated negative interactions in relation to a formerly more transcendental outlook with regard to the single role. Not surprisingly, her present beliefs lean much more heavily towards the stoic "make the best of it" variety of the egocentric.

Interestingly enough, however, while at the time of the interview she expressed largely egocentric beliefs of a stoic nature, she also notes that during extensive positive but ultimately unsuccessful interactions over a two-week vacation with two male friends, hope began to blossom for a relationship. This resulted in the internal confusion between her stoic and more repressed transcendental outlooks, outlined in the previous section. Finally, of course, when discovering that these men were married, she merely reinterpreted the whole event in light of her past, and reasserted her stoic beliefs.

This example shows both that repeated negative interactions result in an individual downplaying or rejecting one type of belief, and that repeated positive interactions 
with certain others may result in its return to prominence even over the active opposition of the person. Finally, it also illustrates how, when the ultimate disconfirmation came, past history and belief enabled a swift interpretive change back to the egocentric.

Another interesting example with regard to the single role involves a comparison between two observational subjects engaged in similar behavior, but expressing their typical outlooks with regard thereto as a result of repeated confirmations, in one case, and numerous disconfirmations, on the other.

The former of these is a 27-year-old male professional who expresses largely egocentric beliefs with regard to his present sexual enjoyment in the singles scene, and crusader beliefs with regard to the "hunt" - whether long or shortterm. He has experienced very few rejections in this role, and is characterized by his friends as a "gigolo." Notwithstanding this behavior, however, he also expresses confidently transcendental beliefs about "the right one coming along," and notes that he doesn't want to spend the rest of his life in the single's scene. Considering his present success, he has no reason to doubt his belief in this as an eventuality in his life. ${ }^{88}$

Contrasting sharply with this person is a 34 -year-old woman who engages in extensive sexual behavior in the present 
as she holds out no hope for the "right one" appearing in the future. Having gone through a husband's death, many rejections, and experiences of being used, she has decided to give up hope, focus on the present and enjoy herself. ${ }^{89}$ She now rejects dating as something that merely "raises expectations and dashes them, " preferring to pick up men in bars for impersonal sex. In her words: "I'm just out to have fun and good sex because every time I hope or let myself believe any more I get hurt."

Here can be seen a more thoroughgoing egocentric belief arising not out of confirmation, as in the former example, but out of repeated and painful disconfirmations that have resulted in a conscious effort to remove transcendental beliefs with regard to all aspects of her conception of happiness in the single role.

Thus, the foregoing has illustrated the obvious conclusion that repeated evaluative interactions that disconfirm one's typical conception of happiness with regard to particular role-specific aspects, or confirms another type in relation thereto, are more likely to result in a change between types.

\section{(d) Intensity:}

Another factor relevant to whether or not an interaction is disconfirming of one's present conception of happiness is its relative intensity. This refers to the 
relative intended emotional strength behind the disconfirming comments or actions central to the interaction itself. It comprises factors such as whether unpleasant comments or actions are expressed quietly and politely, as opposed to loudly and violently. Basically, the more intense are the comments or actions, the more likely will disconfirmation take place, and a shift between types occur.

Of course, many people have had the experience of not paying heed to polite negative comments of another until that person gets openly angry. The researcher has himself noted such behavior in his experiences during a previous relationship.

The best illustrations of this factor in the data, however, come from much more intense and unpleasant interactions. For example, one respondent notes that he was date-raped at the age of eighteen. He notes that while, prior to this he engaged in transcendental "daydreaming a lot, putting a lot of hope into the future," afterwards he egocentrically blamed himself, exhibited "depression, " and had "suicidal tendencies." As he states:

"Um, its a hard word, um, to describe, um, the effect of, um, any kind of sexual assault. Um, negation of... I would say negation of self, not negation of identity. So it goes even one step further inside." (male, age 25).

This respondent made a rapid shift from a transcendental to a very self-absorbed and unhappy egocentric 
outlook as a result of the very intense interaction of rape. He required psychiatric help and counseling over a five-year period before coming out of this unhappy state.

Similarly, consider the shift in types illustrated by the previously noted separated woman undergoing rejection by her husband of eight years. Formerly empathetic, doing for him rather than for herself, she is extremely hurt by his intense rejection of her offers of forgiveness and crusading desire to "make it work" (i.e. slamming the door). It does not take her long to start talking transcendentally about her "prince charming" in the future.

These examples are both in sharp contrast to more polite and peaceful disconfirmations, such as the subject who was rejected after asking another to dance. It is almost trite to say that this rejection likely did not carry the weight for her, nor have the long-term effect on her typical outlook, that these more intense interactions did for those above. Not only could it likely be interpreted away, the fact that this subject remained at the singles dance after this rejection could be interpreted as meaning that her typical beliefs about meeting a man were not ultimately disconfirmed by this polite encounter.

Similarly, a 33-year-old male notes that he feels better about rejections when they are polite:

"People have said to me, when I go to them about 
talking about my rejections,... its just they aren't interested in me. Its not that they are condemning me. They're not personally criticizing me. Its just, for whatever reason, they're not interested at this point in their lives. They might not be interested in a relationship... Or maybe, just there's something about me that they don't feel comfortable with - and that's OK. It doesn't mean that they are judging me or condemning me."

Indeed, the rationalization enclosed within such polite rejections may in itself help him keep his present crusader/transcendental outlook on happiness in the single role.

Thus, it has been illustrated that intense interactions carry more weight in the context of disconfirmation, and are more likely to lead to a change in typical belief with regard to happiness than those of a more quiet, polite variety. ${ }^{90}$

\section{(e) Significance of Interaction Partner:}

This final factor with regard to mechanisms of change between typical beliefs about happiness has been discussed previously (infra, p.101-105). As such, it will not be extensively reviewed at this point. Essentially, this factor refers to the proposition that the more significant or authoritative one perceives one's interaction partner to be in a potentially disconfirming encounter, the more likely is disconfirmation to occur.

of course, this is due to the simple fact that less 
significant or authoritative others may be summarily dismissed as not knowing what they are talking about, both in general, and in relation to knowledge about oneself. As one respondent put it:

"If a stranger were to come up to me and say something, I would say "Well, what do you know? You don't know me from a hole in the ground." (female, age 28).

As well, such a relationship has already been illustrated in the example of the young university student whose cherished girlfriend had left him, resulting in a rapid change from egocentric to transcendental beliefs with regard to his happiness. It is also illustrated with regard to the separated woman whose husband had undeniably rejected her, in her rapid shift to transcendental beliefs. Finally, it is expressed well in the extreme behavior of the divorced woman who attempted a shift through suicide. In her words:

"It makes a very big difference, um, because people that are close to me are the people that really know me, and if they say something, uh, in a negative manner, uh, it... it hurts because these people know me, and 9 times out of 10, these people know me better than I know me." (female, age 36).

Little else needs be said about this straightforward matter.

This concludes the discussion of the third cluster of hypotheses with regard to mechanisms of change. As has been noted, individuals will change their typical conception of happiness, whether with regard to a role or an aspect of a 
role, both upon perceived present confirmation of one's future-directed beliefs, or upon disconfirmation of one's typical beliefs in interaction. This requires both pérception of an event as potentially disconfirming and a breakdown of the identity-maintenance strategies marshalled against it. Finally, the relevance of factors such as frequency, intensity, and significance of interaction partners cannot be overlooked. There is thus evidence in these data to convincingly illustrate the third group of hypotheses.

\section{(4) Conclusion:}

The foregoing analysis is exceedingly complex; yet, not so much so as the subject matter: human social individuals. Reviewing these three general clusters of hypotheses has revealed the strengths and deficiencies of both the research design and the initial theoretical model.

First, with regard to the research design, it is likely that the choice of the single role was a good one. It is abundantly clear that individuals themselves associated personal relationships, and the lack thereof, very closely with personal happiness. Indeed, interview respondents, who make up the bulk of the sample, spoke a great deal about this, even though the questions regarding the single life did not come until near the end of the interview.

Indeed, aside from the small sample size and the lack 
of immediate quantitative data, (which is partially offset by other empirical data discussed in chapter two and herein in relation to the typology), this effort has generated interesting conclusions which may point towards further research as to their ultimate generalizability.

Second, with regard to the initial theoretical model, several other conclusions can be made. First, the above-noted prevalence of comments regarding the single role and personal relationships suggest that this is indeed a master status for many individuals in our society. The relative unhappiness of single individuals, particularly among older respondents, the evaluative comments made by several individuals regarding such single individuals as "Iosers" or "dirty old men," the broad motivational function of transcendental beliefs, and the other evidence cited in chapter three all point to the moral significance of one's status regarding personal relationships cutting across an individual's other roles. This can also be seen reflected in the extreme behavior of some of the respondents.

Next, while no blatantly disconfirming evidence has been found in relation to any of three initial clusters of hypotheses, it also becomes clear from the data that these, as initially formulated, are far too simplistic in several respects. For example, it was not initially recognized that positive, confirming interactions could precipitate an 
individual changing between typical conceptions of happiness. This was reserved only for disconfirmations. Nor was it recognized that significance of interaction partner contained the element of authority as well as familiarity. Indeed, the variety of sub-types among egocentric beliefs alone shows the light that empirical investigation can shed on bare theory.

Yet, perhaps the most important elaboration gleaned from this investigation is that individuals utilize more than one typical belief per role at a particular time in relation to different conceptualized aspects thereof. The rigid model, as initially conceived, did not take into consideration that the single role and personal relationships embody many different aspects, on both the temporal and self/other dimensions, that individuals may address separately, even if hypothetically, through typical beliefs.

Third, while, for methodological reasons, not explicitly focusing on roles other than the presence or absence of a personal relationship, it is clear that individuals have made typical statements which, when general, apply to happiness in several roles at once (e.g. "I kind of just live for each moment 'cause I have control over it now"). Others suggest that they utilize different typical beliefs for different roles. Consider the following as representative:

"If its me, uh, in my career, my academics, then I'm thinking of myself. Um, I don't really care how other people do...Um, as far as friends are concerned, um, I 
think of them, um, to a point when it becomes, when I feel, rightly or wrongly, that they are not thinking of me. Um, then things get a little more egocentric." (female, age 26).

Fourth, keeping in mind the earlier conclusions that happiness is additive across both time and roles, this suggests that it is possible to interpret any of these typical statements, even if in apparent conflict, as referring to one or several roles, or various aspects thereof.

Finally, assuming the above to be correct, it may be asserted, reinterpreting the comments at the end of chapter two, that one's happiness will ultimately consist of adapting the most favorable mix of typical beliefs to the various aspects of the roles that one occupies in order to maximize positive interactions, interpretations, and, thereby, positive accumulative evaluations of oneself.

In closing, much more research needs to be done on the model of happiness suggested by this study. Its conclusions, while firmly grounded in the data at hand, are merely preliminary when applied to the larger picture. Still, it does provide at least a plausible explanation of how we experience what we feel. 


\section{Chapter 5: Summary and Conclusions.}

The preceding four chapters have set out in detail a comprehensive theory of happiness from a sociological perspective. This has been examined by qualitative study of social individuals occupying the culturally strategic single role - individuals very much involved in the pursuit of happiness. The purpose of this final chapter is to summarize the basic findings of this investigation and to explore its implications for future research.

\section{(1) Summary:}

It will be recalled that the theory as set out was divided into three segments for ease of discussion and analysis. First, attention was drawn to what was termed the "general interactional model" of happiness. There, attention was given to the perceptual and evaluative beliefs that individuals hold in relation to their selves in the cultural context of social interaction. By simultaneously integrating a model of the self based on horizontal (I/me), vertical (roles) and moral dimensions with the contents of these beliefs in various inter and intrapersonal interactions, the various hypotheses in this section were illustrated in light of the data.

For example, it was found that positive, confirming 
social interactions lead to happiness; negative, disconfirming ones the opposite. Next, various factors were found to impinge on whether an individual interpreted an interaction in a happy or an unhappy manner. These included (i) perceptual beliefs; (ii) evaluative beliefs; (iii) the contents of the individuals' self-interaction; (iv) utilization of various "identity maintenance strategies"; (v) relative significance of interaction partner(s); (vi) the presence or absence of helpful social support; and (vii) the relative importance of one's interactional role. Finally, it was illustrated that positive and negative interactions accumulate - both over time and across roles - in an individual's general level of happiness .

Secondly, attention was drawn to the typology of perceptual and evaluative beliefs in relation to happiness. It will be recalled that this typology, delineated along the temporal and self/other dimensions, consists of four ideal types: (i) the "transcendental" (future reference/individual focus); (ii) the "egocentric" (present reference/individual focus); (iii) the "crusader" (future reference/ "other" focus); and (iv) the "empathetic" (present reference/ "other" focus).

It was suggested that individuals hold different rolespecific varieties of these four types of belief with regard to the various roles they occupy, both to experience and 
manage their levels of happiness/unhappiness therein. Upon empirical investigation of individuals experiencing the single role, this was modified to also include various conceptualized aspects of the same role. Ultimately, this research suggests that one's happiness consists, at bottom, of utilizing the most favorable mix of role-specific varieties of these beliefs to both experience and manage interactions in one's various extant roles.

Third, attention was drawn to what have been termed "mechanisms of change." These apply in situations where an individual becomes disillusioned with his/her typical conception of happiness in one or more roles and seeks a new perspective. It was illustrated that individuals will do this when (i) perceived disconfirmation of one's present conception, or confirmation of a desired conception, occurs in interaction and (ii) "identity-maintenance strategies" for maintaining belief have broken down. Also found relevant to this shift are contributing factors such as (iii) frequency; (iv) intensity; and (v) whether or not disconfirmation (or confirmation) takes place in interaction with significant or authoritative others.

\section{(2) Research Implications:}

The above, then, are the general outlines of the theory, of happiness illustrated in this study. It remains, however, to consider its wider implications for future 
research. In this regard, several interrelated matters must be addressed: (a) topics to investigate; (b) possible sources of data; and (c) theoretical development. Each of these matters will be addressed in turn.

\section{(a) Topics to Investigate}

First, it was clear from the respondents in this study that individuals do not only utilize typical beliefs with regard to the single role, but have expressed them in relation to other roles as well. Indeed, a variety of typical statements have been made with regard to diverse roles in people's lives. Accordingly, it would be interesting to investigate the prevalence of, and relative concentration between, typical beliefs regarding happiness/unhappiness in important roles such as career, ${ }^{1}$ recreation, ${ }^{2}$ personal health, ${ }^{3}$ and bringing up children. ${ }^{4}$ A little thought enables one to see the possibility of these beliefs in each one of these examples. Such further investigations will not only flesh out the present theoretical model, they may also point to important limitations not apparent in the present preliminary study.

In addition, the oft-noted split between experiencing happiness and managing unhappiness in light of these typical beliefs points to interesting prospects. For example, the authors on sex addiction and codependency make reference, in diverse and unconnected references, to all four typical 
beliefs. Individuals experiencing such compulsive disorders, utilize such beliefs in an "unhealthy" way to manage their low self-esteem and unhappiness. Several examples will illustrate:

"While I was in my addiction I had the belief that all I had to do was meet the right person and everything would be different. " ${ }^{5}$ (transcendental).

"The only life that seemed normal to me was the life of searching for one more sexual high after another. I believed that I was living a lifestyle that other people were missing out on; they just weren't as high as I was. " 6 (egocentric).

"The trouble is, you've never experienced having what you wanted before. You've only known what it was like not to have it, and to work like crazy to try and get it. You're used to the yearning and the suspense, which creates a lot of heart-pounding excitement... ..because not having what you want is much more stimulating than having it." ${ }^{7}$ (crusader).

"Most of the people I've worked with in family groups have been obsessed with people they care about. When I asked them what they were feeling, they told me what the other person was feeling. When I asked what they did, they told me what the other person had done. Their entire focus was on someone or something other than themselves. Some of them had spent years of their lives doing this - worrying about, reacting to, and trying to control other human beings. They were shells, sometimes almost invisible shells of people."8 (empathetic).

What becomes apparent from these examples is that these beliefs can have both healthy and unhealthy varieties the latter becoming prevalent when those with low self-esteem turn management of unhappiness into a way of life. It would be most instructive to see systematic research on this topic, perhaps a qualitative study of various twelve-step recovery groups, which themselves utilize various typical beliefs in 
their "programs." 9

Finally, and of particular interest to the author, would be a study of the utilization of typical beliefs by victims of violent crime $^{10}$ in managing their unhappiness in relation to such an emotional blow. This is particularly interesting given the moral blamelessness, lack of personal power, and cross-pollenizing effect of such events on all a person's roles.

Conceptually, at least, it is possible to discern all four types of belief among victims in the experience and management of their unhappiness: transcendental (e.g. "I'Il see her again"); egocentric ("It's not in my power to bring her back"); crusader ("I've got to fight to make sure this doesn't happen again"); and empathetic ("No one but another victim knows how I feel"). It would be most instructive to gather empirical data on this topic.

\section{(b) Possible Sources of Data}

In addition to the sources of new data suggested above, it may also be interesting to point out further possibilities in investigating the cultural bases of these beliefs. For example, this study on typical beliefs in relation to the single role would be well supplemented by a content analysis of the lyrics of popular songs, many of which deal with the topic of love and relationships. Similarly, content analysis of popular novels and television programs, in 
addition to films, ${ }^{11}$ could shed a great deal of light on the cultural prevalence of these beliefs in many different roles. Moreover, if a time dimension were added, it would be possible to explore the changes, if any, in the distribution, varieties, and extent of typical beliefs with regard to various roles in society, and, by implication, corresponding changes in happiness.

\section{(c) Theoretical Development}

It is clear that the theory presented here has developed when confronted with empirical data. The inclusion of authority as a dimension of significance, the realization that confirmation of a desired belief can precipitate a change between types, the four additional sub-varieties of egocentric belief, and, particularly, the realization that different beliefs may be held at the same time with regard to different conceptualized aspects of the same role, all bear this out. It is hoped that further empirical research along the lines set out above will add further refinements to this theory.

At this point, however, it is timely to note four areas in which this theory may have interesting wider implications for theory and research.

First, it goes without saying that the present research on the management function of typical beliefs contributes to the understanding of emotion management as discussed by theorists such as Hochschild and Thoits. It will 
be interesting to see the directions in which future studies in this area are taken by this work.

Second, in relation to the concept of the self, the idea that this entity is composed of horizontal (I/me), vertical (a hierarchy of internalized role designations), and moral dimensions invites further empirical investigations on this controversial and central topic in sociological social psychology. ${ }^{12}$

Third, the implications for the development of role theory are considerable. By asserting that one's acculturated perceptual beliefs unconsciously structure the form of each hierarchically arranged role, while ones conscious evaluative beliefs, in tandem with the I/me interactants in one's role set, constitute the content, this theory adds to an understanding of how the self, beliefs, and social structure are interrelated. Further research on this topic is warranted.

Finally, it may be interesting to reverse the dominant direction in much of this study and inquire whether, if happiness and emotion are so intricately related, and individuals commonly speak of being happy or unhappy in relation to other emotions, why some specific emotions in our cultural vocabulary may not be seen as subcategories, varieties or combinations of the particular typical beliefs set out herein. For example, hope may be largely transcendental; fear, shame, and despair egocentric; ambition, 
crusader; and sympathy empathetic. It will be interesting to see whether further research bears out this notion, or whether the model, as presented here, is limited to happiness itself. In conclusion, much has been illustrated by the present efforts, both in relation to emotion and the age-old question of happiness itself. However, this preliminary effort, while providing tentative answers, raises many questions of its own. It is hoped that future research along the lines set out above can shed further light on these important issues. 


\section{Notes to Chapter one:}

1.Rene Descartes, Meditations on First Philosophy, p.131-200 in The Philosophical Works of Descartes, : Vol. 1, translated by E.S. Haldane and G.R.T. Ross. (Cambridge, Cambridge University Press, 1973). p.150. Actually, Descartes did not use these exact words. Rather, this is the popularized version of his sentence: "I am, I exist, is necessarily true each time that I pronounce it, or that I mentally conceive it."

The author is aware that Descartes recognized the implied question here, and answered: "I am a thing that thinks." However, the Meditations do not go far beyond this unsatisfying answer, and instead become bogged down in metaphysics, epistemology, and proofs for the existence of God.

2.For example, he has written that: "..the body is the source of endless trouble to us... it fills us full of loves, lusts, and fears and fancies of all kinds, and endless foolery, and...takes away the power of thinking at all." Plato, Phaedo, in The Dialogues of Plato, ed. by B. Jowett. p.66. Another philosopher who comes to mind here is Thomas Hobbes.

3.For example, he has stated: "Reason is, and ought only to be the slave of the passions." David Hume, A Treatise of Human Nature. (Vol. 2) (London, J.M. Dent and Sons Ltd., 1974). p.127.

4. Chesire Calhoun and Robert C. Solomon, eds., What is an Emotion?: Classic Readings in Philosophical Psychology. (New York, Oxford University Press, 1984).

5.Ibid, p.7-8. Note, however, that Calhoun and Solomon consider these categories to be ideal types, and that "this constitutes an overview of the primary emphases of different theories of emotion." For example, while David Hume espoused a primarily sensation theory of emotion, he tempered this with evaluative and cognitive components.

6. Pure sensation and physiological theories are inherently reductionistic in nature. They focus on individual physiological perception or arousal only, and leave out any room for social factors such as beliefs, interaction, identity and the social self, to name but a few. 
Secondly, the extensive use of causal analysis in these theories is itself problematic. It is interesting, for example, to contrast Hume's famous critique of causal analysis in the Treatise of Human Nature with Descartes' rigidly causal theory of emotion in his passions of the soul. (extracted at p.55-70 in Calhoun and Solomon, Supra). Furthermore, Calhoun and Solomon have noted that these theories can only adequately explain emotions related to present events, not future directed emotions such as hope or backward looking sentiments like nostalgia. (See their distinction, at p.10, between "occurrent" and "dispositional" emotions - the latter of which cannot be explained by sensation and physiological theories).

Third, such theories leave little room for conscious involvement or cognition in the experience of emotion. Rather, there is merely a reflexive response to a given situation which is said to. create the physiological changes later perceived. This view, which was elaborated by William James (see extract, p.127-41 of Calhoun and Solomon, Supra), was later put in doubt by experimental work by walter B. Cannon (see extract, p.142-51 of Calhoun and Solomon, Supra).

As for behavioral theories of emotion, it might be said that these err in the opposite direction. Where sensation and physiological theories place too much emphasis on the subjective feel of emotions, behavioral theories, particularly more radical ones, leave this factor out altogether in favor of observable, measurable behavior. (See Calhoun and Solomon, p.11;15). In such positivist theories, again, there is little room for social factors or individual creativity - merely the concession that "some" emotional behaviors may be learned and culture dependent, while the rest are innate. (See Calhoun and Solomon, p.12). This reductionist "black box" focus on innate "emotions" causing or being expressed in behavior, or, in more recent versions, as "dispositions" to certain types of behavior (p.15), again leaves scant room for beliefs, cognitions and the social self as components of emotion. Indeed, some theorists in this vein have gone so far as to identify emotion with behavior itself. (e.g. see the extract from Gilbert Ryle's Concept of Mind, p.254-63 in Calhoun and Solomon, Supra).

7. Note here the similarity of these theories and W.I. Thomas' famous dictum that "If men define situations as real, they are real in their consequences." See:

W.I. Thomas and D.S. Thomas, The Child in America. (New York, Alfred A. Knopf, 1928). at p.572. 
8.Although these headings merely identify certain broad theoretical similarities, and theorists in various groups mentioned often share more than this classification would suggest.

9.Arlie Russell Hochschild, The Managed Heart. (Berkeley, University of California Press Ltd., 1983) p.210。

Arlie Russell Hochschild, Ideology and Emotion Management: A Perspective and Path For Future Research, p.117-142 in (Theodore D. Kemper, ed.) Research Agendas in the Sociology of Emotions. (New York, State University of New York Press, 1990).p.119.

By "interactional" theory, Hochschild means a theory that does not view emotion as merely a biological process (as do the "organismic" theories she identifies with Charles Darwin, William James and the early Sigmund Freud). Nor a totally "social constructionist" theory which leaves biology out altogether in favor of social influences. Rather, Hochschild views emotion as a "biologically given sense" in which, due to the "plasticity" of our inborn natures, social and cognitive factors play a much larger part. (See (1983) pages 204-7, 210, 219-20 and 222; and (1990) pages 119-20 respectively).

Note that early interactionists such as Cooley, Thomas and Mead also emphasized the "plasticity" of our inborn nature. See:

Bernard N. Meltzer, John W. Petras and Larry T. Reynolds, Symbolic Interactionism: Genesis, Varieties and Criticism. (Boston, Routledge and Kegan Paul Ltd., 1975). p.12; 15; and 23 .

10.Ibid, Hochschild (1990), p.118-19.

11.Ibid, Hochschild (1983), p.56-75.

12.Ibid, Hochschild (1983), p.33. The former concept obviously owes much to Goffman's idea of the presenting self.
13. See Hochschild
(1983) ,
p. 33;
(1990)
p.121.

14.Peggy A. Thoits, Emotional Deviance: Research Agendas, p.180-203 in (Theodore D. Kemper, ed.) Research Agendas in the Sociology of Emotions. (New York, state University of New York Press, 1990).

15. Ibid, p.191-2. 
16. Ibid, p.192-3.

17. Ibid, p.193. "The five most effective methods in the students' perceptions were (in descending order of perceived effectiveness): seeking support, seeing the situation differently, catharsis, hiding feelings, and taking direct action. In short, actions and thoughts that focused on the situation itself or on the expressive component of emotion were most frequently used and perceived as effective." (p.1934).

18. Candace Clark, Emotions and Micropolitics in Everyday Life: Some Patterns and Paradoxes of "Place." p.30533 in (Theodore D. Kemper, ed.) Research Agendas in the Sociology of Emotions. (New York, State University of New York Press, 1990).

19. Ibid. See Clark's note 3 on p. 328 where she states: "Following Thoits, I define emotion as an awareness of some combination, but not necessarily all, of the following elements: (1) external situational cues, (2) changes in physiological sensations, (3) expressive gestures, and (4) a cultural label."

20.Ibid, p.307. The former relates to a specific encounter; the latter to the sum of all interactions.

21.Ibid, p.309. This will become important later in the discussion of happiness and constructing a model thereof. 22. Ibid, p.314. strategies:

23.Ibid, p.316. Clark elaborates five distinct

(i) "Expressing negative emotions to another or withholding positive emotions to induce the other's fear, shame, or to put the other "down." (p.317-20).

(ii) "Expressing positive emotions to another, or withholding negative emotions, to induce the other's liking or solidarity feelings." (p.320-1).

(iii) "Controlling the other's level of emotional arousal while remaining cool oneself to "displace" the other." (p.3213) .

(iv) "Eliciting the other's feeling of loyalty and obligation." (p.323-5).

(v) "Patronizing the other, by expressing positive emotions (e.q. sympathy to a superior) that mark one's superiority." $(\mathrm{p} .325-7)$. 
24.Randall Collins, Stratification, Emotional Energy, and the Transient Emotions. p.27-57 in (Theodore D. Kemper, ed.) Research Agendas in the Sociology of Emotions. (New York, State University of New York Press, 1990).

25.Ibid, p.31-5. Here, Colling refers to common activities with a common focus and coordination.

26.Ibid, p.34-7. Here, Collins refers to situations where power and status divide interactants and roles into "order givers" and "order takers."

27.Ibid, p.37-9. Here, Collins refers to situations which involve membership, inclusion vs. exclusion, centrality or marginality in a group, etc.

28. For example, in interaction rituals, Collins argues that the common focus and coordination results in cognitions becoming charged up with emotional energy, thereby producing a common positive mood. (p.31-5). In power rituals, on the other hand, order-givers gain emotional energy as a result of their dominance, while order-takers suffer a reduction.(p.347). Finally, with regard to status rituals, Collins postulates that an individual's level of emotional energy will be high or low, depending on how integrated into a membership group he/she is at the time. (p.37-9).

29.Ibid, p.39. These interaction ritual chains cumulate to constitute the macro structure of stratification, which then affects future rituals as social structure.

30. Michael Hammond, Affective Maximization: A New Macro-Theory in the Sociology of Emotions. p.58-81 in (Theodore D. Kemper, ed.) Research Agendas in the Sociology of Emotions. (New York, State University of New York Press, 1990)。

31.Ibid, p.58-60. Hammond calls the pursuit of strength and security in such arousal "affective maximization," which, he asserts, is a "compelling motivational principle." (p.60). This sounds echoes of Epicurus and Bentham's utilitarian calculus.

$$
32 \text {. Ibid, p. } 60 \text {. }
$$

33. For example, Hammond argues that as economic and technical development increased historically, leaving those at the low end of the stratification system with a lesser share of the economic surplus, belief systems came into play 
postulating the future as the source of a superior level of affective maximization, either in this life or the next. (p.72). According to Hammond, humans cognitively shape their worlds to achieve this goal, even in the face of negative facts. (p.60).

34. Steven L. Gordon, Social Structural Effects on Emotions. p.145-79 in (Theodore D. Kemper, ed.) Research Agendas in the Sociology of Emotions. (New York, State University of New York Press, 1990).

35. Theodore D. Kemper, Introduction: Themes and Variations in the Sociology of Emotions, p.3-23 in (Theodore D. Kemper, ed.) Research Agendas in the Sociology of Emotions. (New York, State University of New York Press, 1990). See p.8 where Kemper discusseg Gordon's theory.

36.Gordon, p.148.

37. Ibid, p.150.

38.Ibid, p.150;153. Note that these cumulative properties of social relationships are based on past and contemplated future interactions. Also note that Gordon's inclusion of a physiological substrate marks his as an "interactionist" theory of emotion, in Hochschild's sense.

39.Ibid, p.151. There, Gordon writes: "In emotion differentiation, societies and subgroups distinguish in their language and social behavior among many types of emotion. Forms of anger can be culturally identified as annoyance, irritation, rage, fury, bitterness, jealousy, or vengeance, for example, each leading to different social interaction patterns."

40.Ibid, p.151. Gordon states that: "Through socialization, individuals learn to feel, attend to, express, and recognize the particular emotions identified in their society."

41.Ibid, p.151. As for management, Gordon states: "the management of sentiments is the regulation of both expression and feeling according to norms of appropriateness."

42.Thomas J. Scheff, Socialization of Emotions: Pride and Shame as Causal Agents., p.281-304 in (Theodore D. Kemper, ed.) Research Agendas in the Sociology of Emotions. (New York, State University of New York Press, 1990)。(1) 
Thomas J. Scheff, Microsociology: Discourse, Emotion, and Social Structure. (Chicago, University of Chicago Press, 1990) . (2)

43. Scheff (1990-1), p.283. Here, Scheff is-taking a page from Cooley's "looking glass self."

44. Ibid, p.283-84.

45.Scheff notes (1990-1, p.286-89), however, that shame is usually unacknowledged in negative interactions, and rarely experienced as such. Rather, it is frequently hidden, even from those experiencing it, in two forms: (1) overt "undifferentiated" shame where codewords label shame as something else (e.g. "awkward"); and (2) "bypassed" shame, characterized by covert symptoms such as repetitive, obsessive thought. Both types of shame, he feels, are so prevalent that they may enormously penetrate many situations in which individuals experience critical evaluation from others. Moreover, he feels that pride and shame may be crucial in the overall socialization of emotions. (p.295).

46. Supra, note 35, p. 8 . Scheff is not suggesting that this is only a one-way process. At other points in his paper he lays great emphasis, for example, on the socialization of emotions.

47. Theodore D. Kemper, Social Relations and Emotions: A Structural Approach. p.207-37 in (Theodore D. Kemper, ed.) Research Agendas in the Sociology of Emotions. (New York, State University of New York Press, 1990).

Theodore D. Kemper, A Social Interactional Theory of Emotions. (New York, Wiley, 1978)。

48. Kemper (1990), p.217.

49.Supra, note 35, p.11. A similarity with Collins can be seen here, as he also stressed these two factors. It might also be noted that Kemper considers both Collins and Hammond to be positivists, in addition to the next theorist that will be discussed.

50. Kemper (1990), p.223;231. Kemper feels that power and status, however conceived, are the prime determinants of emotion.

51.Ibid, p.223-4. 
52.Lynn Smith-Lovin, Emotion as the Confirmation and Disconfirmation of Identity: An Affect Control Model., p.238270 in (Theodore D. Kemper, ed.) Research Agendas in the Sociology of Emotions. (New York, State University of New York Press, 1990).

Lynn Smith-Lovin, An Affect Control View of Cognition and Emotion., p.143-170 in (Judith A. Howard and Peter L. Callero, eds.) The Self-Society Dynamic: Cognition, Emotion, and Action. (New York, Cambridge University Press, 1991).

53.Smith-Lovin (1990), p.239. Smith-Lovin does not imply that individuals choose their identities, but that they subjectively favor certain socially constructed identities.

54. Ibid, p. 240 .

55. Ibid, p.241. A computer program called INTERACT runs these equations. It is described in detail by David $R$. Heise, the co-founder of this theory, in Affect Control Model: Technical Appendix., p.271-80 in (Theodore D. Kemper, ed.) Research Agendas in the Sociology of Emotions. (New York, State University of New York Press, 1990).

The author does not agree with the implicit positivist assumption in the above model that it is possible to quantify all subjective aspects of emotional experience and thereby achieve accurate predictions. This does away with individual creativity, turns the "I" into an afterthought, and is overly reactive in nature.

56.Smith-Lovin (1990), at p.245. Smith-Lovin writes at p.244 that: ". emotions provide signals about how well events are maintaining social meanings...emotions are the "code" for representing the degree and kind of confirmation or disconfirmation of identities that is occurring. .emotion words describe feelings that characterize the combination of a fundamental EPA profile (that is, the person's original identity in a situation) and the transient profile produced by an event." (emphasis added).

57. These are theorists with a strong anti-positivist stance whom have been heavily influenced by phenomenological philosophers such as Heidegger, Scheler and Sartre.

58.Norman K. Denzin, on Understanding Emotion: The Interpretive-Cultural Agenda., p.85-116 in (Theodore D. Kemper, ed.) Research Agendas in the Sociology of Emotions. (New York, State University of New York Press, 1990). Denzin is alone in this category among recent 
theorists of emotion. Yet, it is quite apparent that many of the early interactionists were more directly influenced by phenomenological thought, and, indirectly through them, so were some of the other theorists previously discussed.

$$
\text { 59.Ibid, p.88. See also: }
$$

Norman K. Denzin (1982) "A Note on Emotionality, Self and Interaction." American Journal of Sociology 89 (2) p.402-9, at p.404, where Denzin defines emotions as "..temporally embodied self-feelings which arise from emotional social acts persons direct to self or have directed toward them by others."

60.Denzin (1982), at p.405. He writes (p.406): "The phenomenological stream describes the inner side of interaction that occurs when the person interacts with himself and with another in a social situation. In the phenomenological stream the person takes his own attitude toward self, (A-A), toward the other, (A-B), and turns the imagined attitude of the other towards himself, (B-A). The interactional stream references the co-present, face to face interaction that occurs between two parties in a concrete or an imagined situation. Emotional self interaction involves person A initiating a line of action toward B that calls out in $B$ a significant emotional gesture that is present in $A^{\prime} \mathbf{s}$ action and thought. Person A turns this emotional gesture inward, judging and interpreting the meaning of $B^{\prime} s$ actions in light of $A^{\prime} s$ own incipient emotional attitude (A-A, A-B, B-A). This interpretation becomes part of $A^{\prime}$ 's emotional selffeelings and is then incorporated into A's next gesture or statement to B. Thus, A's self-feeling becomes part of an emotional social act that enters B's inner phenomenological stream and becomes part of B's emotional social act (toward both $\mathrm{B}$ and A)." (emphasis in original). structure:

61.Denzin (1990), p.88. He then gives this a four-fold

(i) "The physical body;

(ii) The body felt from within the person;

(iii) The body as it acts and is seen by others; and

(iv) The body as it expresses the self for the person."

62. Norman K. Denzin (1985) "Emotion as Lived Experience." Symbolic Interaction. $8(2): 223-40$. , at p.228-30. 
63. Ibid, p.230. Denzin states here that feelings of the lived body, while augmented by groups of sensible feelings, "..cannot be reduced to sensible feelings for they are feelings of the lived body as a totality. They are not located in a particular part or section of the subject's body, but are given in the total extension of the body as a unitary field of experience... In this respect the meanings of events to the person are given in lived feelings."

64.Ibid, p.230-32. According to Denzin, "intentional value feelings" attempt to isolate the core meanings an instance of emotionality has for the actor, past, present or future. They transcend specific interactions, are part of the individual's interpretive framework, and exist as orientations toward the world - which may be culture bound. See also Denzin (1990), at p.89.

65. Ibid, p.232-34. "Feelings of the self and the moral person" are also interpretive, and may have their genesis in cultural values outside of emotional experience. However, unlike "intentional value feelings," these are centered ". .in the self of the subject; although they are interiorizations of these broader interpretive schemes. They are lodged in the inner stream of consciousness. They do not have to move through or be given in or by the lived body, in sensible feelings or intentional value feelings. They are, however, closely attached to the latter. Self feelings make the selfhood of the subject an object of emotional consciousness. The person draws his focus of attention into and onto himself as a distant object in his field of experience. $n$ (emphasis added). See also Denzin (1990), at p.89.

Essentially, these involve long-term moral evaluations that the person directs toward him/herself as a moral being in his/her own world and the world of others. (p.232). By subjecting oneself to the inner and outer moral codes of the everyday lifeworld, one thereby gains self-dignity and selfrespect. (p.233).

66. See above, note 6 . Also see the comments at p.4-6 (infra).

67.Jean-Paul Sartre, The Emotions. (Extracted at p.244-50 of Calhoun and Solomon, Supra). p.247.

68.Jack Kapica, "Study Finds Religion Fount of Happiness." Globe and Mail, Wednesday, August 12, 1992, p.A6.

This article details a current study by University of western Ontario sociologists Ted Hewitt and Gail Frankel. They found that, in a preliminary sample of 299 students, those 
with "a significant commitment to their faith" are healthier, are more satisfied with life, can deal better with stress and have shorter hospital stays than those who do not practice any religion. "Mental and physical health improved with the intensity of faith, with those in the non-religious:category reporting the least happiness and those in the fundamentalistevangelical group reporting the greatest sense of well-being." This was despite the fact that all of the students had about the same level of stress in their lives. Overall, the researchers refer to these as "statistically significant differences" and plan a full-scale study of the general Canadian population.

69. Calhoun and Solomon note at p.21 that these two types of theory often overlap: "Almost all the evaluative theories are similarly cognitive."

70. Calhoun and Solomon note that some evaluative thinkers such as Franz Brentano and Max Scheler compare proand con- emotional attitudes with positive and negative value judgments. (p.8). Others, such as Sartre and Solomon, feel that emotions are, or resemble, unspoken value judgments or beliefs. (p.16). Last in this category are theorists such as Brentano who add that emotions are "simply pleasant or unpleasant sensations of pro- and con- attitudes upon which we formulate our value beliefs." (p.16).

$$
\begin{aligned}
& \text { 71. Ibid, p.16. } \\
& \text { 72.Ibid, p.16. }
\end{aligned}
$$

73.Robert C. Solomon, Emotions and Choice., p.305-326 in (Chesire Calhoun and Robert C. Solomon, eds.) what is an Emotion?: Classic Readings in Philosophical Psychology. (New York, Oxford University Press, 1984). p.317.

74. Sociologists are not alone among social scientists in exhibiting interest in the relationship between beliefs and emotion. See, for example, the following anthropological study:

Catherine Lutz, Unnatural Emotions: Everyday Sentiments on a Micronesian Atoll and Their Challenge to Western Theory. (Chicago, University of Chicago Press, 1988).

In this book, Lutz describes the emotional life of a people residing on Ifaluk Atoll in Micronesia - an emotional iffe based on very different cultural beliefs, and understood in entirely different ways, than in western industrial 
societies.

$$
\begin{aligned}
& \text { 75. Hammond, p. } 56 ; 60 ; 72 . \\
& \text { 76. Collins, p. } 34 ; 40 ; 42 . \\
& \text { 77.Denzin (1985), p.231-33. } \\
& \text { 78. Hochschild (1990), p.124-7 ("Ideology and }
\end{aligned}
$$
emotion management").

79. Gordon, p.150. Note also Gordon's comment on the culture-specific emotion of "accidie" (p.157-8). ". a medieval emotion resulting from laziness in fulfilling one's religious duties. The emotion blended boredom with gloom and fear over losing God's grace, and thus depended upon certain religious beliefs and obligations being accepted."

$$
\begin{aligned}
& \text { 80.Thoits (1990), p.184. } \\
& \text { 81.Smith-Lovin (1990), p.242. } \\
& \text { 82.Scheff (1990-1), p.283. } \\
& \text { 83.Clark, p.316. }
\end{aligned}
$$

84. Kemper (1990), p.219;224; 231-2. Although he argues that cultural beliefs merely mediate and interpret power and status dimensions for the purpose of individual emotions.

85. None of this should be especially surprising. Long ago W.I. Thomas noted the "as if" nature of human social interaction (see Meltzer, Petras and Reynolds, p.26-7) - the "definition of the situation" that many of the above authors have alluded to. If something is defined as real, it is real in its consequences - and those consequences can surely include emotion.

Similarly, George Herbert Mead's theory of the past notes that the past is an important component of the present, and, indeed, structures and conditions the experiences found therein. It is the contention here that this component includes beliefs in relation to emotion as well. See:

David R. Maines, Noreen M. Sugrue, and Michael A. Katovich. (1983). "The Sociological Import of G.H. Mead's Theory of the Past." American Sociological Review 48: 161-173. p.162. 
86.Thomas Kuhn, The Structure of Scientific Revolutions. (2nd ed.) (Chicago, University of Chicago Press, 1970). Kuhn writes at p.113 that: "What a man sees depends both upon what he looks at and also what his previous visualconceptual experience has taught him to see. In the absence of such training there can only be, in William James' phrase "a bloomin' buzzin confusion." (emphasis added).

\section{Also see:}

Scott Greer, The Logic of Social Inquiry. (2nd ed.) (New Brunswick, N.J., Transaction Publishers, 1989). Where, at p.32 he notes that a fact is merely "a complex of sense data organized with respect to a prior frame of reference."

Kathleen Carley, Growing Up: The Development and Acquisition of Social Knowledge. p.75-102 in (Judith A. Howard and Peter L. Callero, eds.) The Self-Society Dynamic: Cognition, Emotion, and Action. (New York, Cambridge University Press, 1991). At p.78 Carley points to a wealth of research showing that assumed social knowledge is necessary in order for the individual to establish his or her frame of reference, make decisions, interpret communications, and perform tasks. "Without social knowledge the members of the group would have no common basis that would admit discussion, let alone agreement."

87. Chesire Calhoun, Cognitive Emotions? p.327-342 in (Chesire Calhoun and Robert C. Solomon, eds.) What is an Emotion?: Classic Readings in Philosophical Psychology. (New York, Oxford University Press, 1984). p.342.

88. If a "fact" is indeed "a complex of sense data organized with respect to a prior frame of reference," as Greer and Kuhn argue, then, to that extent beliefs determine what one can perceive. First, if an emotion is a sense, as Hochschild would have one believe, then in the process of perception, as in the other senses, belief, or socialized groups of perceptual cognitions, must play a part in organizing and giving meaning to the otherwise undifferentiated impressions as they are conveyed to the self. If, on the other hand, emotion is an evaluation or a hasty judgement, as various philosophers have noted, the basis of evaluation or grounds for judgement are logically necessary before emotion can proceed.

It is interesting to note that Hochschild has added a new twist to this discussion with her study of ideology and work roles among married couples. See: 
Arlie Russell Hochschild, The Second Shift: Working Parents and the Revolution at Home. (New York, Viking-Penguin, 1989) > Hochschild notes that it sometimes happens that a husband is socialized to hold an "egalitarian" gender ideology which is in conflict with his feelings. (1990), p.127-9. She explains this with her concept of "cautionary tales" "important episodes from a person's past that carry meaning for the future." (e.g. the husband being jealous of his wife's job because he had been neglected by a workaholic mother in his childhood. Here, one observes a socialized "feeling rule" (egalitarianism) conflicting with an ill-defined or unadmitted belief (being neglected in favor of his wife's job). This in itself produces tension and heightened feeling which may or may not be manageable.

$$
\text { 89.Smith-Lovin (1990), p.253-54. }
$$

90.Vernon Pratt, The Philosophy of the Social Sciences. (London, Methuen and Co. Ltd., 1978). p.64.

Pratt discusses as an example of the latter type the Azande concept of causality. This tribal people perceives supernatural forces as the cause of observable events. Observable happenings (e.g. a failed harvest) merely serve to confirm these beliefs. Such a system of beliefs is structured to remove the possibility of empirical disconfirmation.

91.Meltzer, Petras and Reynolds, p.26.

92.I. Festinger, H. Riecken and S. Schachter, When Prophecy Fails (New York, Harper and Row, 1964).

Here it is argued that cognitions that "do not fit together" produce discomfort in individuals, who then attempt, by various methods, to either find grounds for upholding the belief (e.g. obtaining new information, reducing the importance of the belief, seeking social support), or to change one of the conflicting beliefs.

93. Peter L. Berger and Thomas Luckmann, The Social Construction of Reality: A Treatise on the Sociology of Knowledge. (Garden City, N.Y., Doubleday and Company, Inc., 1967) . p.147-156.

Here, Berger and Luckmann discuss "routine vs. crisis" methods for maintaining beliefs in order to guarantee a "measure of symmetry" between objective and subjective reality. 
94.Harold Garfinkel, Studies in Ethnomethodology. (Englewood Cliffs, N.J., Prentice-Hall, 1967)。

Garfinkel noted that when people are pushed into situations that make them recognize the arbitrariness of their taken-for-granted reality and routines, one finds them engaging in almost infinite regressions of justifying their interpretations.

95. Thoits (1990), at p.184, writes: "When transient sentiments in response to a described event deviate from fundamental expectations...the event is disconfirming. Disconfirming events are affectively motivating; they cause tension. Because affective expectations are not confirmed, a new understanding of the event must be constructed."

96.Smith-Lovin (1990), p.242 notes that events may produce "transient impressions" different from one's fundamental understandings of what people and behaviors are like. Such a "disconfirmation" produces an emotional response as, for her: "Emotions are the "code" for representing the degree and kind of confirmation or disconfirmation of identities that is occurring." (p.244). She also suggests (p.246) that disconfirmation of identity occurs when individuals differ in their definitions of the situation (i.e. different beliefs, expectations, identities), or when they come from different subcultures with different meanings for identities and behaviors. Finally, she suggests (p.248) that disconfirmation may occur simply when there is role conflict.

97. Emile Durkheim, The Division of Labour in Society. (New York, The Free Press, 1984).

98. Perhaps this can be seen in Durkheim's comment at p.120 that: "..there is a constantly decreasing number of beliefs and collective sentiments that are both sufficiently collective and strong enough to assume a religious character. This means that the average intensity of the common consciousness is itself weakening."

Recently, empirical support has been found for these well worn ideas. See:

Kathleen Carley, Growing Up: The Development and Acquisition of Social Knowledge. p.75-102 in (Judith A. Howard and Peter L. Callero, eds.) The Self-Society Dynamic: Cognition, Emotion, and Action. (New York, Cambridge University Press. 1991).

(p.92-3) that the less homogeneous the society the more 
social knowledge children develop that is not shared by the parents.

See also:

Louis A. Zurcher, Jr., The Mutable Self.

(Beverly Hills, CA, Sage, 1977).

Michael R. Wood and Louis A. Zurcher, Jr., The Development of a Postmodern Self: A Computer-Assisted Comparative Analysis of Personal Documents. (New York, Greenwood Press, 1988)。

Ralph H. Turner, "The Real Self: From Institution to Impulse" (1976) American Journal of Sociology 81: 989-1016.

All of these authors assert that contemporary structural instability has produced societywide changes in the content of selves and identities. They stress that a self dependent on identification with social structures (and their attendant beliefs) is not functional or adaptive when a society's institutions are unstable or lack legitimacy. This is seen as the basis for the increase in individualism and spontaneity in personality surveys between the 1950's and 1970's.

99.William James, Principles of Psychology.

(New York, Henry Holt, 1890). p.294.

100.Meltzer, Petras and Reynolds, p.31., referring to Mead, state: "While the mind emerges out of social interaction, its high level of development among humans depends upon a condition that represents a synthesis of their biological, psychological and sociological nature. This process, "the turning back of the experience of the individual upon himself," is reflexiveness."

$$
\begin{aligned}
& \text { 101.Ibid, p.32. } \\
& \text { 102.Ibid, p.41. } \\
& \text { 103. Ibid, p.41. See also: }
\end{aligned}
$$

George Herbert Mead. (1912). "The Mechanism of Social Consciousness." Journal of Philosophy 9: 401-6, at p.405, where Mead writes:

"The "I" or the ego is identical with the analytic or synthetic processes of cognition, which in conflicting situations reconstructs out of the "protoplasmic" states of consciousness both the empirical self (the "me") and the world 
of object. The objective world is a mental construct and is defined in terms of the "I" or the ego. It is a man's reply to his own talk. Such a me is not then an early formation which is then projected and ejected into the bodies of other people to give them the breath of human life. It is rather an importation from the field of social objects into an amorphous, unorganized field of what we call inner experience. Through the organization of this object, the self, this material is itself organized and brought under the control of the individual in the form of so-called self-consciousness."

104.Meltzer, Petras and Reynolds, p.61-2, note that Blumer saw the "I" as the impulsive, undifferentiated phase of the self, while the "me" was viewed as representing the generalized "other" incorporated within the individual comprising the organized set of attitudes and definitions prevalent within the group. For Blumer, then: "Every act begins in the form of an "I" and, generally, ends in the form of a "me." For the "I" constitutes initiation of the act prior to its coming under the control of the definitions or expectations of others (the "me"). The "I," thus, provides propulsion, while the "me" provides direction, to the act." (emphasis added).

105.Ibid, p.62. Meltzer, Petras and Reynolds write that, for Kuhn: "..behavior is socially determined - by the actor's definitions, particularly self definitions. Thus, the self becomes a me exclusively, and conduct is held to be wholly predictable (in principle) on the basis of internalized prescriptions and proscriptions. If we know the actor's reference groups, according to Kuhn, we can predict his/her self attitudes; and, if we know these, we can predict his/her behavior. In short, antecedent conditions determine the human being's self; and his/her self determines his/her conduct. This view, of course, conveniently disposes of such "nonempirical" concepts as the "I" and impulses." (emphasis added).

106.J. David Lewis. (1979). "A Social Behaviorist Interpretation of the Meadian "I." American Journal of Sociology 85: 261-285. See p.269.

Lewis characterizes Blumer (and others like him) as taking a "remedialist" position (p.264;274), while Kuhn and his followers are seen as proposing a "residual" interpretation. (p.264-5; 274). See also p.265-6 where Lewis argues that both of the above views misrepresent Mead's thought in important ways. 
107. Lewis (1979), p.269. This also harkens back to Denzin's idea of the phenomenological stream.

$$
\text { 108. Ibid, p.269. }
$$

109. This view is somewhat closer to Blumer's position than Kuhn's. Yet, unlike the quasi-causal "impulsive tendency" found there to account for the unpredictability of actions (see Lewis, p.273-4), here there is rational and social consideration going on inside the self prior to action. As Lewis writes (p.270): "By imagining the effects one's own gesture will have upon the other, one can consciously control the response of both self and other."

110.Erving Goffman, The Presentation of Self in Everyday Life. (New York, Doubleday, 1959).

111.M. Scott and S. Lyman. (1968). "Accounts." American Sociological Review 33: 46-62. Scott and Lyman define an account (p.46) as: "a linguistic device employed whenever an action is subjected to valuative inquiry ...verbally bridging the gap between action and expectation... By an account, then, we mean a statement made by a social actor to explain unanticipated or untoward behavior."

112.J. Hewitt and R. Stokes. (1978). "Disclaimers" p.308-19 in (J. Manis and B. Meltzer, eds.) Symbolic Interactionism, (3rd ed.) (Boston, Allyn and Brown, Inc.).

Hewitt and Stokes provide the following definition at p.310-11: "A disclaimer is a verbal device employed to ward off and defeat in advance doubts and negative typifications which may result from intended conduct. Disclaimers seek to define forthcoming conduct as not relevant to the kind of identity-challenge or re-typification for which it might ordinarily serve as a basis. Examples abound and serve to make the abstract concrete: "I know this sounds stupid, but..." (emphasis added).

\section{Supra, note 18.}

114.Sheldon Stryker (1987) Identity Theory: Developments and Extensions. p.89-104 in (Krysia Yardley and Terry Honess, eds.) Self and Identity: Psychosocial Perspectives. (Chichester,U.K.: Wiley, 1987).

Sheldon Stryker, Exploring the Relevance of Social Cognition for the Relationship of Self and Society: Linking the Cognitive Perspective and Identity Theory. p.19-41 in (Judith A. Howard and Peter L. Callero, eds.) The Self-Society 
Dynamic: Cognition, Emotion, and Action. (New York, Cambridge University Press, 1991).

See also:

Richard T. Serpe, The Cerebral Self: Thinking and Planning About Identity-Relevant Activity.p.55-73 in (Judith A. Howard and Peter L. Callero, eds.) The Self-Society Dynamic: Cognition, Emotion, and Action. (New York, Cambridge University Press, 1991). p.58-60.

Peter J. Burke, Attitudes, Behavior, and the Self.p.189-208 in (Judith A. Howard and Peter L. Callero, eds.) The SelfSociety Dynamic: Cognition, Emotion, and Action. (New York, Cambridge University Press, 1991). p.189-90.

115.Judith A. Howard, Introduction: The Self-Society Dynamic p.1-17 in (Judith A. Howard and Peter L. Callero, eds.) The self-Society Dynamic: Cognition, Emotion, and Action. (New York, Cambridge University Press, 1991)。 p.3-4.

116.Perhaps the term "role set" would also be appropriate here. See: Robert $\mathrm{K}$. Merton, Social Theory and Social Structure. (Revised edition). (New York, The Free Press, 1957). p.369.

117.Denzin (1985), p.232. He also notes (1985) p.407, that a "circuit of selfness" attaches an individual to the world. In that connection, emotionality, meaning, and other individuals are intricately linked. This field of experience situates the self in others' phenomenological and interactional streams, and it is at the confluence of these two streams of experience that one's emotional self-feelings are found.

$$
\text { 118.Denzin (1985), p.232. }
$$

119.Denzin (1985), p.232-3 distinguishes two different levels of the self: the "surface" and the "deep." What he calls the "surface self" is what is seen in public, presented to others through the interactional stream, and managed through emotion management rules. In contrast, the "deep" internal moral self is discovered through self and moral feelings that involve a conception of the self as a distinct moral object and subject in the world.

120.Denzin (1985), p.232-3 adds that: "Moral selfconsciousness or value-awareness is at the core of the person at this deep level. The moral feelings of the morally self- 
reflective subject involve a respect for the moral codes of the everyday lifeworld. This moral law embodies the core features of human nature including such matters as honor, respect, freedom, dignity, love, shame, the ritual, the sacred, the civil, and personal responsibility as embodied in the moral code of the person and society. By subjecting himself to this moral code the subject gains self-dignity and self-respect. This internalized self-respect which comes from the inner and outer moral codes of the world of daily interactional life, constitutes the inner meanings of the moral person." (emphasis added).

121. Many recent emotion theorists have implicitly backed up Denzin's idea of the self containing a moral element by arguing that individuals act in ways that confirm positive evaluations of self and minimize negative ones. This can be seen, for example, in Hammond's pursuit of affective maximization (Hammond, p.59-60) and Thoits' conception of emotion management (Thoits, p.182; 184; 192). It is also implicit in Kemper's notion of power and status motivating and causing emotional outcomes (Kemper (1990), p.221-3); SmithLovin's "affect-control model" (Smith-Lovin (1990), p.242); Clark's examples of "micropolitical strategies" that individuals use to maintain "place" (Clark, p.316-27); and, perhaps most explicitly, in Scheff's model of pride and shame. Other authors, while not addressing emotion per se, have also noted the moral component of the self. See:

Morris Rosenberg, Conceiving the Self. (New York, Basic Books, Inc., 1979). p.42-5.

Michael L. Schwalbe, Social Structure and the Moral self. p.281-303 in (Judith A. Howard and Peter L. Callero, eds.) The Self-Society Dynamic: Cognition, Emotion, and Action. (New York, Cambridge University Press, 1991). p.288-9. 
Notes to Chaptex Two:

1.For example, one may also be considered happy when experiencing the joyful emotion of love; unhappy when feeling angry, envious, ashamed, scared, or lonely. As such, the study of happiness may provide important clues to the study of other, subsidiary emotions.

2.Aristotle, Nicomachean Ethics, in (W.D. Ross, ed.) The Works of Aristotle. 1177a, 11-17.

3.See, for example:

V.J. McGill, The Idea of Happiness.

(New York, Frederick A. Praeger, 1967). Where Aristotle's treatment of happiness is used as the "framework" against which other theories are examined.

Elizabeth Telfer, Happiness.

(London, The MacMillan Press Ltd., 1980). Where Telfer critically examines Aristotle's treatment of the subject, and, while not totally agreeing with him, states that his "is a quite reasonable policy to adopt in pursuing happiness." (p.135)。

Robin Barrow, Happiness.

(Oxford, Maretin Robertson \& Company Ltd.; 1980). Barrow devotes an entire chapter to reviewing and criticizing Aristotle's account.

$$
\text { 4.McGill, p.17-19. }
$$

5. In contrast to the unidimensional stoics and epicureans, for example, where the former overemphasized a restriction of desires; the latter indulging them in the right proportion.

6. The author is not unaware of a different interpretation of Aristotle's "virtue" in this passage, namely, as the highest "function" of the human animal: contemplation. However, this interpretation leads back to the same conclusion, as contemplation of any sort necessarily involves reference to belief. 
7.Aristotle's comment reminds one of how Thomas Kuhn (supra) stresses the many different rational ways science has looked at the same natural phenomena over the centuries - most which have later been characterized as "wrong" when a new paradigm came along. When this is considered alongside Robert Solomon's claim (supra) that emotions are "hasty judgements" made without adequate knowledge, and since we can never (on Kuhn's reasoning) reach the one final "correct" answer, then one is hard pressed (given these assumptions) to find any significant difference between what has been traditionally dichotomized as "reason" and "emotion." Instead, it would make more sense to postulate a unified cognitive realm embracing both of these traditional opposites.

One difference, however, may be suggested. Both "reason" and "emotion" are useful to us, but in different ways. Whereas reason, as exemplified by science, is primarily useful to us in manipulating and understanding our objective world, emotion is useful in understanding and perceiving ourselves in relation thereto.

here. See:

8.Abraham Maslow's hierarchy of needs comes to mind

Abraham H. Maslow, Motivation and Personality.

(New York, Harper and Row, 1970).

In this seminal work, Maslow divided needs into a hierarchy in which, so long as each type of lower-order need is satisfied, individuals will move up to express higher ones. Maslow's hierarchy, from lower to higher, includes: physiological needs, safety needs, the need to belong and to love, esteem needs, and, ultimately, self-actualization needs.

9.Telfer, p.1-9. At p.8 Telfer states: "I lay down necessary conditions for happiness as follows: a happy man does not want anything major in his life to be otherwise; he is pleased with, that is wants (to keep), what he has got; there is nothing major which he has not got and which he wants (to get)."

10. Bertrand Russell, The Conquest of Happiness. (London, Unwin Hyman Ltd., 1989). p.13. Russell writes here that: "In discussing this problem, I shall confine my attention to those who are not subject to any extreme cause of outward misery. I shall assume a sufficient income to secure food and shelter, sufficient health to make ordinary bodily activities possible. I shall not consider the great catastrophes, such as loss of all one's children, or public disgrace. There are things to be said about such matters, and 
they are important things, but they belong to a different order from the things that I wish to say. My purpose is to suggest a cure for the ordinary day to day unhappiness from which most people in civilised countries suffer..."

11.Barrow, p.68-9 takes issue with this view, denying that factors such as health, wealth, and pleasure are logically necessary to happiness. He notes that "one could be rich, healthy, loved, etc., and yet be unhappy." On the other hand, he writes: "A man might be poor, yet happy; he might be sick, yet happy; he might be friendless, yet happy; he might be unpleasant, yet happy; he might even have retired to bed to pass dried peas from one saucepan to another, yet be happy. We may think some or all of those instances exceedingly unlikely; we may be at a loss, ourselves, to understand how others could be happy under such or other circumstances, since we certainly could not be; we may find it hard to credit: but the fact remains that such things are conceivable, in a way that it is not conceivable that a bachelor should be married."

Aside from pointing out this logical point, however, Barrow refers to empirical studies at pages.10,12 and-13 that show these variables are indeed related to happiness.

12. One must keep in mind Calhoun's "cognitive sets" and Hochschild's "cautionary tales" affecting perception here, cognitively, but not necessarily consciously, conflicting with surface evaluative beliefs in the experience of emotion.

In addition, see the following studies in "selfschemata" which, according to Serpe (Supra, ch. 1, note 114), demonstrate "that individuals process schema-relevant information more rapidly, and in ways that are consistent with their self-structures. In other words, individuals process information about self selectively and assimilate that information differentially into their self-schemata." These studies include:

J.W. Alba \& L. Hasher. (1983). "Is Memory Schematic?" Psychological Bulletin 93: 203-231.

C.M. Judd \& J.A. Kulik. (1980). "Schematic Effects of Social Attitudes on Information Processing and Recall." Journal of Personality and Social Psychology 38: 569-578.

H. Markus (1977). "Self-Schemata and Processing Information About the Self." Journal of Personality and Social Psychology $35: 63-78$.

H. Markus \& K. Sentis (1982). The Self in Social Information Processing, p.41-70 in (J. Suls, ed.) Psychological 
Perspectives on the Self. (Hillsdale, N.J., Erlbaum, 1982).

H. Markus \& J. Smith (1981). The Influence of Self-schemata on the Perception of Others, p.233-262 in ( $N$. Cantor \& $J$. Kihlstrom, eds.) Personality, Cognition, and Social Interaction. (Hillsdale, N.J., Erlbaum, 1981).

W.B. Swann (1983). Self-Verification: Bringing Social Reality into Harmony With the Self, p.33-66 in (J. Suls \& A.G. Greenwald, eds.) Psychological Perspectives on the Self (Vol 2) (Hillsdale, N.J., Erlbaum, 1983).

W.B. Swann \& S.J. Read (1981). "Self-Verification Processes: How We Sustain our Self-Conceptions. "Journal of Experimental Social Psychology 17: 351-372.

13.Francis L.K. Hsu, Americans and Chinese: Reflections on Two Cultures and Their People. (New York, Doubleday Natural History Press, 1972). This author found some evidence that cultural and moral beliefs affect emotionality. In a comparative study of a sample of Chinese and a sample of Americans, Hsu found that the Americans experience a greater intensity of misery and joy, while the Chinese subjects enjoyed a more constant, mild equilibrium. He hypothesizes that this difference may be accounted for by the difference between the individual-centred upbringing of the Americans and the social-centred culture of the Chinese.

14.Mary Owen Cameron, Identity and the Shoplifter., p.315-17 in (E. Rubington and M. Weinberg, eds.) Deviance: The Interactionist Perspective. (5th ed.) (New York, MacMillan Publishing Co., 1987).

\section{Hochschild (1983), p.219. \\ Hochschild (1990), p.119.}

16. This does not mean to say that a person so completely deprived could not feel undifferentiated confusion or physical pain. It just asserts that more specifically defined emotional states would be beyond his or her comprehension - at least until some learning and development of the self takes place.

\section{See ahead, notes 34 and 38 .}

Clark implicitly recognizes this as well by her comment that: "I define emotion as an awareness of some combination, but not necessarily all of the following elements: (1) external situational cues, (2) changes in 
physiological sensations, (3) expressive gestures, and (4) a cultural label." See Clark, p.328, note 3.

18.Meltzer, Petras and Reynolds, p.37-9. See also Maines, Sugrue and Katovich (Ch. 1 , note 85) at p.161-3.

19.George H. Mead. (1923). "Scientific Method and the Moral Sciences." International Journal of Ethics 33: 224-47. at p.247.

20.Meltzer, Petras and Reynolds, p.34.

Note also the following two studies claiming that "satisfaction is additive":

- Institute for Social Research Newsletter

(University of Michigan, 2:2, Summer 1974) at p.4 where it is stated that: "the more satisfaction in any of a dozen or so domains, the greater the overall feeling of contentment." It is also claimed that certain of these domains, such as health, marriage, job and income "carry a little more weight than others."

-J.P. Robinson and P.R. Shaver, Measures of Social Psychological Attitudes (Ann Arbor, Michigan, Institute for Social Research, 1978).

21.Collins (Supra,Ch.1, note 24 ) at p.41-2; 46-7. The concept of "interaction ritual chains" is inherently accumulative.

22.Gordon (Supra, Ch.1, note 34) at p.150, states: "Sociologists understand that emotion is determined not only by present conditions, but also by cumulative properties of a social relationship based on past interactions, and by anticipations of future contacts."

23.Clark (Supra, Ch.1, note 18) at p.307 implies accumulation when she distinguishes "place" as "momentary" and "self Concept" as "enduring."

$$
\begin{aligned}
& \text { 24.Hochschild (1990), p.122-4; 126-9. } \\
& 25 . \text { Kemper (1990), p. } 224 . \\
& \text { 26.Gordon, p.164-9. } \\
& \text { 27.Scheff (1990-1), p.295-301. }
\end{aligned}
$$


28.Denzin (1990), p.91; 94; 103. Denzin particularly stresses films in socializing emotions and giving meaning to emotional interactions.

29.Burke (Supra, Ch.1, note 114) at p.189-90 notes that, according to identity theory, "an identity is the internal component of a role-identity, whereas a role is the external component."

See also: Stryker (supra), and

George J. McCall \& J.L. Simmons, Identities and Interactions (Revised ed.) (New York, The Free Press, 1978). These authors also "empathize the importance of the internal hierarchical organization of the self in terms of role identities: the characters that an individual constructs for him/herself as an occupant of particular social positions. Role-identities are organized according to their relative prominence for the self. This prominence hierarchy of role-identities in turn merges with immediate contextual circumstances to create a relatively flexible situational self."

Judith A. Howard, From Changing Selves Toward Changing Society, p.209-237 in (Judith A. Howard and Peter L. Callero, eds.) The Self-Society Dynamic: Cognition, Emotion, and Action. (New York, Cambridge University Press, 1991). at p. 210 .

30.For example, Hochschild, Thoits and Clark (supra, Ch.1). This definition is also compatible with Goffman's "presentation of self." Indeed, his concept of "performance teams" may include a "team of one person" (1959, p.85) which, I suspect, would involve the subvocal interaction of various I/me components in an individual's internalized role-set prior to action by the "I" - all with the aim of producing the most favorable presentation of self in a particular structurallylocated interaction.

example:

31.Numerous authors point to this idea. See, for

Viktor Gecas, The Self-Concept as a Basis for a Theory of Motivation, p.171-187 in (Judith A. Howard and Peter L. Callero, eds.) The Self-Society Dynamic: Cognition, Emotion, and Action. (New York, Cambridge University Press, 1991).

Gecas, at p.174 states that "by virtue of having a self-concept the individual is motivated to maintain and enhance it." He then divides this motivation into three: self- 
esteem, self-efficacy, and authenticity, and discusses theoretical and empirical grounds for this assertion (174-78). Particularly interesting from a sociological standpoint is authenticity. Gecas writes that this motive "emphasizes beliefs about what is real and what is false as perceived by the individual and used as a basis for self-assessment. Authenticity is a function of commitment to systems of meaning in society, particularly to various identities embedded in systems of values and beliefs. Individuals are motivated to avoid the negative end of the authenticity continuum, characterized by feelings of meaninglessness, selfestrangement, and anomie."

Burke (Supra, Ch.1, note 114) at p.194-5 discusses his findings that "people tend to select activities whose meanings are congruent with their self-meanings."

Rosenberg (Supra, Ch.1, note 121) at p.53-62 discusses the empirical support for what he calls the "self-esteem" and the "self-consistency" motives. He also notes (p.59) that "without some picture of what he is like, the individual is virtually immobilized."

Howard (Supra, note 29) at p.213 refers to studies demonstrating "overwhelming" evidence for the "ubiquity of the motivation for self-verification, the desire to verify preexisting self-conceptions."



34.Denzin (1990), p.94. Note that Denzin has also referred to happiness (1985, p.230) as a feeling of the lived body. It is here agreed that happiness can take this form in temporally distinct situations, or when one is "happy about" something. However, the author feels that Denzin misses the deeper meaning of happiness in the longer term, which fundamentally involves feelings of the self and the moral person.

Indeed, Barrow notes (p.50) Lloyd Thomas' delineation of four main uses of the word "happy." These are: "(1) use of the term to refer to a feeling, typically of fairly short duration; (2) use of the term in expressions such as 'I am feeling happy about my job' where feelings are not (or not primarily) involved at all; (3) a behavioristic use, most common with the adverbial form, which implies something like 'with relish' or 'gleefully'..; and (4) use of the term to 
refer to a relatively long period, as in the comment 'he had a happy life." Later, after an analysis of the concept, he responds to the objection that he has merely described contentment, by calling this "mere playing with words." (p.79). "The truth is surely that one may be 'wildly happy', meaning something like 'happy and delirious with joy', or 'contentedly happy', but in either case one is happy." (p.80). The definition utilized in this study attempts to take into account both ends of this emotional continuum.

$$
\text { 35.Smith-Lovin (1990), p.245. See also: }
$$

Lynn Smith-Lovin, An Affect Control View of Cognition and Emotion, p.143-169 in (Judith A. Howard \& Peter L. Callero, eds.) The Self-Society Dynamic: Cognition, Emotion, and Action. (New York, Cambridge University Press, 1991).

Smith-Lovin states at p.165 that "Currently, the Achilles heel of the affect control approach is the lack of empirical research validating the model."

While she discusses (p.151) validation studies of behavioral predictions explaining one-third to one-half of subjects' estimates of the likelihood of events, she adds (p.165) that "the theory's predictions about emotional response and about cognitive outcomes have not been tested yet."

$$
\text { 36.Clark, p.309. }
$$

37. This definition is termed "tentative" as, by using this as a framework, (often referred to as "cumulative moral identity"), what happiness consists of will be elaborated in greater detail in the following pages.

A number of authors have pointed to the correlation between self-esteem (positive self-evaluation) and happiness. See, for example:

John P. Robinson and Philip R. Shaver, Measures of Social Psychological Attitudes. (Ann Arbor, Michigan: Institute for Social Research, 1978).

J.G. Bachman, Youth in Transition, Volume II: The Impact of Family Background and Intelligence on Tenth-Grade Boys. (Ann Arbor, Michigan: Survey Research Centre, Institute for Social Research, 1970.

R.G. Landry and E.M. Pardew "Self-Concept Enhancement of Preschool Children." (Paper presented at the Annual Meeting of the American Educational Research Association, New Orleans, 
February 1973). Landry found that for children given a "self concept enhancement program" there are "very significant increases on the factor scales of happiness, sociability and sharing."

As for the outcome of positive interactions producing happiness, see:

Louis A. Zurcher (1982), "The Staging of Emotion: A Dramaturgical Analysis" Symbolic Interaction 5(1) 1-22, at p.16 where the elation of football players who have just won a championship game is described.

I differ with Zurcher, however, on the degree of emphasis to place on the dramaturgical staging of emotion relative to emotion in general. Zurcher states (p.2) that "the situation often calls for a series of versatile emotional presentations, often in a programmed order." He goes on (p.3) to add that "dramaturgy is..helpful for revealing how emotional expression is socially influenced within the immediate situation of groups of people who have assembled in accordance with institutional patterns." My point is not to deny the utility of dramaturgy in situations where several individuals, all occupying the same basic role, have assembled for a common, scripted purpose (e.g. football fans and players, military reservists). It is to note that such a focus leaves out many smaller scale situations of emotional significance where individuals occupy different roles, share different beliefs, and pursue differing purposes in a relatively unprogrammed and unstructured order.

Moreover, I would assert that in both types of situations above, the cues and prompts for emotion are not just staged, but are functions of an individual's perceptual and normative beliefs regarding emotion, oneself, and one's ego-extensions (such as one's favored team) in a particular social setting. This wider view enables one to grasp an understanding of the whole continuum of emotional experience, not just one end of the spectrum.

38. Lest this matter create confusion, and it be asserted that happiness is only an emotion in the short term, and a rational evaluation of one's life called "contentment" over longer periods, my argument is that the cognitive processes involved in both are parallel. To arbitrarily draw a line between short-term "happiness" and long-term "contentment" may leave out too much relevant to this investigation when (a) the use of the word "happiness" as a significant symbol in our language is found in both interpretive and evaluative senses; (b) philosophers in varying cultures and time periods have utilized both senses in their 
investigations; (c) only the degree of physiological arousal is greater in the short term; and (d) short-term emotional interactions add up over time to this long-term evaluation of one's life. It is thus likely that the whole will be comprised of, and later affect, some elements of its parts i.e. emotion, as they are closely interrelated.

Other authors have exhibited confusion over this issue

as well. Barrow (p.75-6) notes that while "happiness is generally presumed to be an emotion..it seems far from obvious that it should be so classified." He then states the alternative view that one cannot experience an emotion "without interpreting a limited aspect of one's experience" or an "object" in a certain way. While he states that happiness has no such "object" (restricting "objects" to interactional externals) he fails to consider reflexivity and the human ability to take oneself as an object over any time period (where we are not limited by the temporal boundaries of the interaction). As for his second objection - that one can be unconsciously happy - this is taken care of by the device of background "cognitive sets" previously discussed. His timid conclusion, and his statement that distinguishing happiness and contentment is "mere playing with words, "further attests to his uncertainty on this point. He concludes: ". happiness is not entirely like other emotions and therefore either should not be classified as one or, alternatively, should be recognized as an emotion unique among emotions." I, for the reasons set out, prefer the latter view.

39.This, of course, does not deny the happiness felt by an individual as the result of a positive interaction or long-term satisfaction with several areas of his/her life. It merely states that such happiness is either transitory or partial when there are other matters about which the individual is ambivalent, dissatisfied or unhappy.

40. Barrow, p.73-4. "The essence of happiness lies in having a favourable attitude towards whatever relationship one happens to have to one's circumstances...seeing the world as one would like it to be. To be happy is to have a sense of enmeshment with one's world."

41.Telfer, p.8. Since an individual is held infra to be comprised of factors including "others" and "objects" with which one identifies, this can be extended to include one's "life as a whole."

42. Particularly since Barrow stresses the relationship between self-esteem and happiness at p.10, 12, and 102 . 
43. Barrow is quite radical when it comes to beliefs and happiness. For example, he writes at p.74 that: "It should by now be evident that a man might be misinformed about something or self-deceived and yet be happy. Indeed, sometimes he may be happy precisely because he is deceived or deluded. The man whose happiness would be shattered were he to realize that his wife is having an affair with another man, is not perhaps to be envied, but he may be happy, and, if he is, it is his delusion that allows it."

44.Telfer, p.9.

45.Ibid, p.1-9, where Telfer discusses necessary conditions for happiness.

46.Ralph H. Turner and Victoria Billings, The Social Contexts of Self-Feeling, p.103-122 in (Judith A. Howard \& Peter L. Callero, eds.) The Self-Society Dynamic: Cognition. Emotion, and Action. (New York, Cambridge University Press, 1991).

At p.115 these authors discuss the results of a study where they asked respondents to describe interactions which expressed their "real selves" and others which did not. They found that "True-self experiences are most distinctively associated with a mood of relaxation, competence, fulfillment, or belonging. Spurious-self experiences are associated especially with feelings of being phony or out of place, ashamed, angry, or helpless or hurt." They also found that prior self-conception was the factor cited most frequently by respondents in determining the meaning to be assigned to the interaction (roughly half), with beliefs and social structural roles less so. (p.114). play here.

47. Denzin's "intentional value feelings" come into

It is to be noted that only recently has the idea that cognitive discrepancies are sources of discomfort received empirical verification. See: Hazel Markus \& Robert B. Zajonc, The Cognitive Perspective in Social Psychology, p.137-230 in (Gardner Lindzey \& Elliot Aronson, eds.) The Handbook of Social Psychology (3rd ed.) (New York, Random House, 1985).

See also:

Rosenberg (1979), ch. 4, where he describes a study of the effects of "contextual dissonance" on self-esteem.

Secondly, and in addition, note that Howard (Supra) at 
p.213 cites studies by Swann, among others, showing the ubiquitous motivation for self-verification. She notes that "individuals create self-confirmatory opportunity structures through selective interaction and selective comparison processes, selecting self-confirmatory feedback, and selective interpretation. These processes work in tandem with a positivity bias; most people have positive self-conceptions and wish to verify these self-conceptions. When these two motivations conflict, the desire for self-verification is apparently likely to prevail."

Morris Rosenberg, Self Processes and Emotional Experiences, p.123-142 in (Judith A. Howard and Peter L. Callero, eds.) The Self-Society Dynamic: Cognition, Emotion, and Action. (New York, Cambridge University Press, 1991) at p.132 concurs, noting that "the main way to control one's emotions is to control one's thoughts... This is the strategy of selectivity, the motivated choice from among various options." He then goes on (p.132-8) to discuss the evidence for this in terms of selective attention, perspectival selectivity, selective interpretation, and self-deception.

48. It is not always necessary for this social support to come from within the interaction frame as described here. A person can always approach various significant others later to cushion the shock of potentially disconfirming interactions.

Note that the following authors have found evidence that social support minimizes the adverse effects of stress and strain:

S. Cohen \& T.A. Wills (1985), "Stress, Social Support, and the Buffering Hypothesis" Psychological Bulletin 98: 310-357.

R.C. Kessler \& J.D. McLeod, Social Support and Mental Health in Community Samples, p.219-240 in (S. Cohen \& S.L. Syme, eds.) Social Support and Health. (New York, Academic Press, 1985).

R.J. Turner, Direct, Indirect, and Moderating Effects of Social Support on Psychological Distress and Associated Conditions. In (H.B. Kaplan, ed.) Psychological Stress: Trends in Theory and Research. (New York, Academic Press, 1983).

49.Rosenberg (1991), at p.139 notes that "the use of certain mental self-manipulation devices, it has been found, is more likely to be associated with superior than with inferior emotional satisfaction and adjustment." He then gives various examples, including: 
Shelley E. Taylor \& Jonathan D. Brown (1988), "Illusion and Well-Being: A Social Psychological Perspective on Mental Health." Psychological Bulletin 103: 193-210. These authors provide much evidence to show that people who have "illusions" about their own worth, their ability to control events, and their expectations about events are more likely to be characterized by various indicators of mental health, such as "the ability to care about others, the ability to be happy and contented, and the ability to engage in productive and creative work." (p.193).

Ruut Veenhoven, Conditions of Happiness.

(Boston, D. Reidel, 1984). Veenhoven found that happy subjects are more likely than unhappy ones to use certain defensive strategies, leading him to consider what he calls "the comforts of self-deceit." (p.295).

P.M. Lewinsohn, w. Mischel, w. Chaplin, \& R. Barton (1980), "Social Competence and Depression: The Role of Illusory SelfPerceptions." Journal of Abnormal Psychology 89: 203-212. These authors found that individuals who fail to engage in self-deception, i.e. people who see themselves as they really are, are those most likely to be diagnosed as clinically depressed.

Howard Tennen \& Sharon Herzberger (1987), "Depression, SelfEsteem, and the Absence of Self-Protective Attributional Biases." Journal of Personality and Social Psychology 52: 7280. These authors discovered that depressives and individuals with low self-esteem are less likely than others to make selfserving attributions.

50.The latter includes such diverse elements as Hochschild's "feeling rules," conceptual escape routes, Denzin's "intentional value feelings," Rosenberg's discussion of "selectivity" and "self-deception," and Clark's "micropolitical strategies."

51. These may include, but are not necessarily limited to, those strategies that Rosenberg (1991) refers to as "selectivity." At p.132-38 he divides the selectivity strategy into three headings, each of which has several specific type of strategy. (1) Selective attention (e.g. selective exposure, direct control of mental content); (2) perspectival selectivity (e.g. altering time perspectives and/or one's comparison reference groups; minimization); and (3) selective interpretation (e.g. selective attribution, selective comprehension, selective credulity, and selective attribution 
of authenticity).

$$
\text { See also Rosenberg (1979), p.260-76. }
$$

52. It would appear that many of these terms utilized by various theorists are interchangeable. For example, Hochschild's emotion management shares much in common with Rosenberg's "selectivity"; while her "deep acting" corresponds approximately to his idea of "self-deception."

point.

53. See note 49 for empirical studies relevant to this

54.Diana Scully and Joseph Marolla, "Rapists Vocabulary of Motives," p.340-35I in (E. Rubington and M.Weinberg, eds.) Deviance: The Interactionist Perspective. (5th ed.). (New York, MacMillan Publishing Co.,1987).

In this article, Scully and Marolla portray individuals in somewhat of a similar position straining to see themselves differently by stating socially based "excuses" and "justifications." In a prison social environment openly hostile to them (and which is merely a harsher reflection of our society at large) these researchers found most sex offenders extremely willing to talk in order to glean for themselves any sort of acceptance. To paraphrase one type of response: "It was a mistake. Its over now and I can do nothing but regret it and be sorry. But I'm a nice guy really. You can't judge my whole life because of one mistake."

55.William B. Swann, Jr., Self-Verification: Bringing Social Reality into Harmony with the Self, p.33-66 in (J. Suls \& A.G. Greenwold, eds.) Psychological Perspectives on the Self (Vol. 2) (Hillsdale, N.J., Erlbaum, 1983).

William B. Swann, Jr., (1987) "Identity Negotiation: Where Two Roads Meet" Journal of Personality and Social Psychology. 53: 1038-1051.

These two above studies show the strength of the motivation for self-verification is such that most of those with negative self-images actually seek out what is negative in an interactional situation in order to maintain a consistent image over enhanced self esteem.

Roy F. Baumeister \& Dianne M. Tice (1985) "Self-Esteem and Responses to Success and Failure" Journal of Personality 53: $450-467$.

These authors conducted experiments on subjects with 
varying levels of self-esteem. They discovered that subjects with high self esteem remained interested in a task more often if they met with initial success. Subjects with low selfesteem lost interest after initial success, but would try, after failure, in order to become "adequate."

The apparent contradiction between these studies and the rapists profiled in the preceding note may be more apparent than real. Individuals with simple low self-esteem who fail at a relatively unimportant task may still view themselves in the morally acceptable light of the "victim"

- the bottom rung on the ladder of adequate self-esteem - and opt for consistency. The rapists, on the other hand, as a result of their past behavior, prison location, and deviant "master status" cutting across roles have a much more difficult time in convincingly playing this minimum role, whether to themselves or to others. As such, they will struggle harder to achieve acceptability over consistency, as the latter would lead to an unacceptable self-evaluation.

56.R.F. Baumeister, J.P. Shapiro, and D.M. Tice, "Two Kinds of Identity Crisis" Journal of Personality 53: 407-24. These authors would refer to the situation described as an "identity deficit." (p.408).

57. A good example would be a man torn between his love for his family and his love for his wife, in a situation where these significant others despise each other.

58. Baumeister and Tice (Supra, note 56) p.408 would refer to this situation as an "identity conflict."

59. See ahead, note 108.

60.G.H. Von Wright, The Varieties of Goodness.

(London, Routledge and Kegan Paul, 1963). At p.93 Von Wright sets out three traditional ideals of happiness: Aristotle's view that happiness is to be found in action; Epicurus' ideal under which "true happiness" derives, above all, from having things that please; and the utilitarian perspective which views happiness as something like present contentment, i.e. "an equilibrium between needs and wants on the one hand and satisfaction on the other." In what follows, it will be seen that this classification is somewhat incomplete, and that each of the ideals described can fit into one of the cells of the typology. 
61. It was decided not to include past-orientations as a dimension of the typology as, according to Mead, these are merely elements of the emergent present, i.e. those "living in the past" are really emphasizing a meaningful present reconstruction of past events, as well as their present self and accumulation of happiness. It is felt that this will not add much to the discussion that has not already been said, especially since there are few, if any, beliefs about happiness, in the sense that follows, that may be so categorized. Indeed, "living in the past" may be culturally frowned upon as a way of living our lives (e.g. the advice to a rejected lover to "get on with your life"; the admonition that "you can't change the past" etc.).

Moreover, and following from the above, such emotional orientations, active as they are in the present, may be easily assimilated into the four existing categories of belief (see ahead). For example, the present pleasure one feels when recalling a past encounter is typically egocentric; hoping that one's past lover will return and save one from loneliness is quintessentially transcendental; actively attempting to get him/her back is a fine example of the crusader; "while stressing one's "eternal emotional bond" with that person reeks of the empathetic.

62. Benedict Spinoza, Ethics. (V, Prop.xLI)。 By no means does Spinoza endorse this view. He immediately follows these words with the affirmation that "Blessedness is not the reward of virtue, but virtue itself."

Similarly Bertrand Russell, (Supra, note 10, p.25) attacks this common view: "The habit of looking to the future and thinking that the whole meaning of the present lies in what it will bring forth is a pernicious one. There can be no value in the whole unless there is value in the parts. Life is not to be conceived on the analogy of a melodrama in which the hero and the heroine go through incredible misfortunes for which they are compensated for a happy ending."

63.McGill (Supra), at p.70, notes that St. Augustine, in The City of God, denied that happiness was possible in this lifetime as, by defining happiness as complete and perfect, it implied the possession of the infinite - God.

64. For a discussion of the concept of "vocabularies of motive," of which "accounts" and "disclaimers" are subcategories, see:

C. Wright Mills. (1940). "Situated actions and Vocabularies of Motives," American Sociological Review, 5: 904-13. 
Laurie Taylor. (1979). "Vocabularies, Rhetorics and Grammar: Problems in the Sociology of Motivation." p.145-61 in D. Downes and P. Rock (eds.) Deviant Interpretations.

(New York, Harper and Row).

65.McGill,p.84 states that St.Thomas Aquinas, (Summa Theologica, A1) makes this comment. However, it is also noted that while Aquinas held that happiness on earth is but an imperfect image of and preparation for happiness in heaven, he "is far from maintaining that hope for future happiness... is the whole of our earthly happiness." (i.e. Aquinas felt happiness to be possible on earth).

66. Maines, Sugrue and Katovich (Supra).

67.Meltzer, Petras and Reynolds, p.41.

68. Hammond, p.72. However, Hammond's work is merely suggestive in this regard as he traces the root of such differentiation to a reductionist, individual "need" for affective maximization.

69. Paula Nurius, Possible Selves and Social Support: Social Cognitive Resources for Coping and Striving, p.239-258 in (Judith A. Howard \& Peter L. Callero, eds.) The SelfSociety Dynamic: Cognition, Emotion, and Action. (New York, Cambridge University Press, 1991).

At p.242 Nurius states that: "..self-conceptions are not just repositories of the past and catalogues of the present, however active the role of self in constructing and maintaining these representations. Self-conceptions also carry both positive and negative beliefs about what could come to pass in the future and about what is possible. These possible selves are thus the future-oriented components of the selfconcept; they personalize and give enduring cognitive form to one's goals, motives, and hopes and fears for the future." It is here asserted that these "possible selves" are heavily implicated in the transcendental and crusader types of belief about happiness as described herein.

70.Roger O'Toole, The Precipitous Path: Studies in Political Sects. (Toronto, Peter Martin Associates Ltd., 1977). Discusses, for example, an isolated Marxist sect in the Toronto area. One party member is here quoted as saying (p.72): "I've been in the party for twenty years, and I've held on to the party ideas - and, God knows, its been a hard job at times to hang on to them with the pressures of work and life - and I've been tempted just to let it all go... But I'd come here (to Socialist Labour Party Headquarters) and talk to 
the other Socialist Labour Party fellows, and do you know that was a real help in meeting all the problems."

See also:

D. Blazer and E. Palmore "Religion and Aging in a Longitudinal Panel" Gerontologist (February 1976). These authors report a significant relationship between religious ritual (rather than faith) and happiness. See p.82;84.

And also the following three studies which provide evidence that social support "buffers and minimizes adverse effects of stress and strain.":

S. Cohen \& T.A. Wills, (1985) "Stress, Social Support, and the Buffering Hypothesis" Psychological Bulletin 98: 310-357.

R.C. Kessler \& J.D. MCLeod, "Social Support and Mental Health in Community Samples," p.219-240 in (S. Cohen \& S.L. Syme, eds.) Social Support and Health. (New York, Academic Press, 1985).

R.J. Turner, "Direct, Indirect, and Moderating Effects of Social Support on Psychological Distress and Associated Conditions," in (H.B. Kaplan. ed.) Psychological Stress: Trends in Theory and Research. (New York, Academic Press, 1983).

71. Epictetus, The Discourses and Manual, translated by P.E. Matheson. (Oxford, Oxford University Press, 1916). This quotation is, of course, the famous opening passage of Epictetus' Manual.

72. For example, in Twelve-Step recovery programs like Alcoholics Anonymous, the first step seems very stoic i.e. admitting one's powerlessness over an external. This, as well as the hope that one can achieve recovery "one day at a time," is reinforced through the social support the individual encounters in frequent meetings, talking to sponsors, and the perception that other people like themselves have become happier.

73. Jean-Paul Sartre, No Exit, in No Exit and Three Other Plays. (New York, Vintage Books, 1955). p.47.

74. Benedict Spinoza, Ethics, V. Prop.XLII.

75.E.W. Desmond, "A Pencil in the Hand of God."

Time (Can. ed.) 134 (23) December 4, 1989. p.14. 
76. It is important to note that this is the case where an individual has a present object to focus on in this sense. Others, without such a wide interpretation of "others" as stated by Mother Teresa, may merely hold role-specific empathetic beliefs (e.g. mother and child, husband and wife). If, in these latter instances, one does not have a social role to link to one's empathetic belief (e.g. one is single without children), this does not forestall one from conceiving of that belief in action when the role appears, nor, for that matter, adding to the richness of one's transcendental beliefs in managing the present. This will appear more clearly in the section discussing the qualitative data.

77.Alan w. Watts, The Meaning of Happiness.

(New York, Harper Colophon Books, 1979). Watts" conception of happiness is perhaps the most broadly-based example of the empathetic category. Describing happiness as "total acceptance" (p.180), Watts states (p.46) that "spirituality is a deep sense of inner freedom based on the realization that one's self is in complete union and harmony with life, with God, with the self of the universe or whatever that principle may be called."

Other authors who may be characterized as empathetic, at least in part, include Bertrand Russell (note 10, p.191), and, to a lesser extent, Robin Barrow - the latter referring to happiness as "a sense of enmeshment with one's world." (p.74).

78.McGill notes this at p. 341 in a review of modern self actualization theory, where he writes: "unselfishness, properly understood, is the expansion of the self to include a concern for others. Selfishness is the narrowing and freezing of the self by fear and frustration, whereas unselfishness is growth and expansion of the range of interests."

Similarly, Bertrand Russell (Supra, note 10, p.191) writes: "The whole antithesis between self and the rest of the world, which is implied in the doctrine of self-denial, disappears as soon as we have any genuine interest in persons or things outside ourselves."

Watts writes (p.174) that: "Those who search for happiness do not find it because they do not understand that the object of their search is the seeker. We say that they are happy who have "found themselves" for the secret of happiness lies in the ancient saying, "Become what you are." We must speak in paradox because we think we are divided from life and, to be happy, must unite ourselves with it. But we are already united, and all our doings are its doings. Life lives us; we do not live life. Yet in fact there is no "us" apart 
from life that life can so live. It is not that we are passive tools of life, as fatalists believe, for we could only be passive tools if we were something other than life. When you imagine yourself to be divided from and at war with life, you imagine yourself to be its passive tool and so are unhappy..." Finally, the similarities between these views and those of Mead, Lewis and Denzin regarding the self cannot be denied.

79. This does not deny that in some cases such "dogooders" actually restrict those they want to help. However, this is not the point. What matters to the individual is whether he/she believes that the other person(s) are being helped, and, if the other interactants do nothing to contradict this belief, then the effect on the actor's happiness remains the same. One need only recall the Thomas dictum here.

80.For total adherents of such beliefs, a "reward in heaven" would be an afterthought, since happiness is, for them, a by-product of involvement in their activities. For such purists, the "reward" would likely consist of an opportunity to pursue more of the same.

81. Supra, note 75, p.16.

82. Examples of, and departures from, this pure type of belief with regard to lovers and single individuals will be reviewed in Chapter 4.

83.John Stuart Mill, Autobiography. (London, Oxford University Press, 1924).p.120. As can be seen in this quotation, Mill in his later years moved away from the Benthamite/hedonistic/utilitarian conception of happiness espoused in Utilitarianism.

84.Although this latter aspect may not be as pronounced as in truly empathetic beliefs. Indeed, here it is often more a question of predominant as opposed to total focus on other.

85.C.E. Sears, Days of Delusion - A strange Bit of History. (New York, Houghton Mifflin Co., 1924). Discusses a group approximating this type well with regard to temporal orientation: the Millerites. This millennial religious sect, based on the teachings of one William Miller, was active in the years 1818-1845. It held the belief that the "second coming" would occur in the year 1843, and "unselfishly" lived their lives accordingly - proselytizing and often doing things 
like giving away their property "as the time approached" to demonstrate their conviction (although this latter component of the "crusader" type is less clear-cut here).

Also keep in mind Nurius' concept of "possible selves" in relation to this type of belief. (Note 69, Supra).

86.Ibid. The Millerites' beliefs were disconfirmed several times, and, although initially rationalized as "errors in calculation," successive disconfirmations led to the eventual disbanding of the group in 1845 .

87. Lesak Kolokowski, The Alienation of Reason: A History of Positivist Thought. (New York, Doubleday Anchor Books, 1969). p.162. This is Kolokowski's uncomplimentary paraphrase of James' epistemological position, where James took his radical-empirical, quasi-utilitarian calculus and applied it to the theory of knowledge, thereby resulting in an extremely relativist position. In the present study, it is contended that these pragmatic comments apply to emotions like happiness as well. See, for example, James' works like the Will to Believe, where such views are obvious.

$$
\begin{aligned}
& \text { 88.Meltzer, Petras and Reynolds, p.19. } \\
& \text { 89.Ibid, p.30. }
\end{aligned}
$$

Also note that Burke (1991) Supra, at p.194-5 discusses the results of his research that "indeed, people do tend to select activities whose meanings are congruent with their self-meanings."

90.This recognizes that the event or interaction must actually be perceived as giving rise to a disconfirmation by the individual. Thus, it may be that certain unarticulated beliefs would protect one individual from perceiving a disconfirmation, while another person, without such beliefs, and exposed to the same event, would be profoundly affected.

91. This disconfirmation can be either of the individual's perceived moral identity in light of his/her beliefs, or the beliefs themselves.

In a disconfirmation, there is asserted to be "cognitive dissonance" (to use Festinger, Riecken and Schachter's terminology) between the "I, "the "me" (including beliefs and perceptual cognitive sets), and the imagined attitude of other toward self. This occurs when a symbolic objectivation in the interactional stream enters the individual's phenomenological stream above in a contradictory manner, such that the past component of his/her present 
reality and/or identity is perceived to be wrong.

Stryker (1991) supra, at p.30 notes that "only recently has the postulate..that cognitive discrepancies are sources of discomfort that give rise to efforts to remove the discomfort, received empirical verification." Indeed Swann $(1983,1987)$ supra, among others, have demonstrated the "ubiquity of the motivation for self-verification."

Turner and Billings (1991) supra, at p.115 add that, in their study of "true" and "spurious" self-experiences, "true-self experiences are most distinctively associated with a mood of relaxation, competence, fulfilment, or belonging. Spurious-self experiences are associated especially with feelings of being phony or out of place, ashamed, angry, or helpless or hurt."

Rosenberg (1979) supra, discusses the empirical support for viewing "self-consistency" as a motivation (p.57$62)$; notes $(p .102 ; 125)$ his research showing that self-esteem is lower in a dissonant context (i.e. desegregated schools in Baltimore); and discusses the contexts where the esteemprotecting mechanism of "selectivity" fails (p.277-78).

Also, and in addition, it must be noted that all of the above-noted conceptual escape routes, identity strategies, micropolitics and social support must break down for a disconfirmation to truly occur.

92. This refers to whether or not the disconfirmation is an isolated incident, or something that occurs in a similar fashion, on an ongoing basis, over a period of time. It is suggested that the more frequent the disconfirmations in a given time period, the more unhappy the individual, and the more likely he/she will be to practice identity-maintenance strategies or seek a new, positive identity. Consider the techniques of identity reconstruction utilized by Synanon, an intensive drug treatment program in the U.S., where frequently repeated disconfirmations are the established norm in breaking down deviant identities and constructing new ones. See:

Rita Volkman and Donald R. Cressey, Drug Rehabilitation, p.156-173 in (M.S. Weinberg, E. Rubington, and S.K. Hammersmith, eds.) The Solution of Social problems: Five Perspectives. (Second Edition) (New York, Oxford University Press, 1981). 
93. This refers to the strength of the disconfirmation. For example, whether unpleasant, disconfirming comments in an interaction are spoken quietly and politely, as opposed to loudly and violently. It is suggested that the latter situation would usually have a more pronounced emotional effect, and likely lead to more intensive utilization of identity maintenence strategies.

94.For example, a rejection in intimate interaction with one's wife, who also knows a great deal about oneself, would likely be more disconfirming than a rejection by a less valued stranger in a bar.

95.This is not necessarily an exhaustive list, but merely intended to be illustrative.

96.For example, the failure of the Millerites' prediction of the second coming.

97.M. Cernetic, "Fallen Idol Prays For Redemption." Globe and Mail, May 20, 1991. p.1. Here is noted that, following revelations that televangelist Jimmy Swaggart had dealings with a prostitute, he lost $69 \%$ of his viewers, and $3 / 4$ of the seminarians dropped out of "Jimmy Swaggart Bible College."

It must be noted, however, that an individual may also perceive himself as hypocritical in light of his/her own beliefs $\underline{e . g}$. the priest who has had an ongoing affair with a nun.

98.For example, the old socialist in a declining party. (see O'Toole, Supra).

99.For example, Hochschild's flight attendants are taught to see difficult drunks as "just like a child."

100.For example, the unhappy person who picks up one of the popular "self-help" books at the drugstore.

101.For example, the lawyer who enters the profession with ideals, but eventually becomes disillusioned with the extent of pettiness he perceives in the world.

102.For example, the loss of a loved one, literally part of oneself, whether through violence, accident or disease, leading the empathetic to become stoic. This also applies to situations like rape and assault (the denial of personhood and laying of blame on the victim) and adultery (part of oneself becoming a lie - either as victim or 
perpetrator).

103. For example, a wealthy missionary, or a son whose parents and girlfriend despise each other.

104.For example, the tension in stoicism between a radical assertion of freewill and an equally radical determinism.

105. For example, the seventeenth century woman accused of witchcraft by her husband.

106.For example, the athlete who trained for months for a championship game, but lost. See Zurcher (1982) supra.

107.See Thoits (1990) and Rosenberg (1979, 1991) (Supra) for other examples that can be considered "identity maintenence strategies" as discussed here.

108.Louis A. Zurcher, Jr., The Mutable Self. (Beverly Hills, C.A., Sage Publications, 1977).

Louis A. Zurcher \& Michael R. Wood, The Development of a Postmodern Self: A Computer-Assisted Comparative analysis of Personal Documents. (New York, Greenwood Press, 1988).

Ralph H. Turner (1976) "The Real Self: From Institution to Impulse." American Journal of Sociology. 81: 989-1016.

The above-noted authors argue that current structural instability has produced changes across society in the content of selves and identities. The former argues that instability in the self is due to various forms of societal change, including: (1) the successful rationalization and secularization of industrial society; (2) the decline of the sense of historical continuity associated with secularization and modernization; (3) the overripe development of rationalistic Western culture; (4) accelerated social change; (5) the increasing importance of consumption as opposed to production values and orientations; and (6) symbolic overload due to a rapid increase of cultural imagery. See also Howard (supra) p.215.

109. I derive this from the two following authors:

Everett C. Hughes, "Dilemmas and Contradictions of Status," American Journal of Sociology, I (March, 1945) 353-359.

Howard S. Becker, outsiders: Studies in the sociology of 
Deviance. (Glencoe, The Free Press, 1963).

These men pioneered the idea of deviance as a "master status" cutting across and negatively coloring all of an individual's societal roles and identities.

Being effectively labeled as deviant may indeed count as such an all-embracing moral disconfirmation of self.

110. See the first section of chapter three for a full discussion of the overwhelming importance of this role, which may indeed constitute a master status within our society.

111.Peter L. Callero, Toward a Sociology of Cognition, p.43-54 in (Judith A. Howard \& Peter L. Callero, eds.) The Self-Society Dynamic: Cognition, Emotion, and Action. (New York, Cambridge University Press, 1991). Indeed, Callero argues ( $p .49-51)$ for a view of roles as simultaneously "social objects" and "perspectives" that he refers to as "role thinking." Once a role becomes an objective social object in the community, it also becomes a symbolic social tool that the self-interacting individual can utilize for a variety of purposes, such as in defining self. (p.50). Callero argues that "since cognition is a covert form of interaction among various roles, thought is necessarily role-based. In other words, cognition in the form of self-conscious covert interaction is not possible outside of role use."

112. See note 31 , supra, where are discussed various theoretical and empirical works based on the idea that, by virtue of having a social self-concept, the individual is motivated to protect and enhance it.

113. Unfortunately, these also appear to do most to insulate one's self-image in actions of great moral turpitude. For example, members of a "christian" order in Newfoundland were recently investigated for molesting young orphan boys. It is possible that the "forgiveness" aspect of christian beliefs may have been perverted here into a license to indulge themselves - so long as they asked God for forgiveness later. When this is coupled with the power that these men had over their charges, their relative isolation from a potentially disapproving outside society, their previous perceived status as unselfish caregivers, their duty to provide "discipline", and the non-judgemental social support of their fellow culprits, it is likely that many of these men managed their self-image quite well. Such a subculture, characterized by territorial, normative, and rhetorical techniques of identity (and emotion) management likely enabled them to be quite happy in their criminal exploits. 
It is cases such as this that cause me to agree with the words of Barrow (supra), who has written at p.71: "..there are good reasons for objecting to people finding happiness in certain cases, but that is a different matter from there being good reasons for denying that somebody could be happy in those cases. There seems to be a confusion that consists in moving from the true belief that happiness is some kind of good to the conclusion that it cannot be associated with evil. But the fact is that repugnant causes may give rise to a good state of mind."

114.As for societies approaching Durkheim's "organic solidarity", where the more complex social structure is reflected in more complex and differentiated selves, current research indicates that, despite the risk of role conflict, multiple role involvements are more conducive to happiness. Nurius (1991) supra, at p.247 points to the following theoretical and empirical studies suggesting that: "the greater the number of identities held, the stronger one's sense of meaningful, guided existence and thus of psychological health and security."

S. Marks, (1977) "Multiple Roles and Role Strain: Some Notes on Human Energy, Time, and Commitment" American Sociological Review 42 : $921-936$.

S.D. Sieber, (1974) "Toward a Theory of Role Accumulation" American Sociological Review 39: 567-578.

L.Verbrugge, (1983) "Multiple Roles and Physical Health of Women and Men" Journal of Health and Social Behavior 24: 1630 .

P.A. Thoits, (1983) "Multiple Identities and Psychological Well-Being: A Reformulation and Test of the Social Isolation Hypothesis" American Sociological Review 48: 174-187.

M.K. Potts, The Effects of Role Multiplicity on Health Status, Illness Rates, and Illness Behavior in Men and Women: A Test of the Scarcity and Expansion Hypothesis. (Unpublished doctoral dissertation, Purdue University, West Lafayette, IN., 1987).

In addition, see the following article suggesting that the "more complex one's system of "self-aspects," the less extreme are one's swings in affect and self-appraisal, the less deflatable is one's self-esteem, and the less vulnerable one is to the myopia, uncertainty, and spillover effects of negative input or emotion." (Referred to in Nurius,252-3): 
P.W. Linville, (1987) "Self-Complexity as a Cognitive Buffer Against Stress-Related Illness and Depression." Journal of Personality and Social Paychology 52: 663-676. 


\section{Notes to Chapter Three:}

1.This is not to say that the comments of these individuals regarding past or anticipated relationships will be irrelevant - indeed these may shed important light on both their attitudes to their present reality and experience of happiness/unhappiness.

Moreover, there have been included, to round out the sample, two respondents who, at the time of study, were either involved in a relationship, or resuming one. In these cases, the questioning was adjusted to ask them of their attitudes and beliefs at those times when they were single.

2.Barrow (supra), P.5.

3. Ibid, p.13. The studies referred to by Barrow are:

John P. Robinson \& Phillip R. Shaver, Measures of Social Psychological Attitudes. (Ann Arbor, Michigan: Institute For Social Research, 1978). This volume incorporates, according to Barrow, "most, if not all, of the attitudinal studies of happiness and related concepts."

A study cited in Institute For Social Research Newsletter (University of Michigan, 2, no.2, Summer 1974). p.3.

following:

A further study that may be of interest here is the

Robert S. Weiss, Attachment in Adult Life, p.171-184 in (C. Murray Parkes and J. Stevenson-Hinde, eds.) The Place of Attachment in Human Behavior. (New York, Basic Books Inc., 1982).

Weiss studied a group of individuals whose marriages had recently ended, and who then joined a group for single parents. He found that, despite the fact that they gained support from the group, they continued to complain of loneliness. No measure of friendship was sufficient to make up for the loss of close attachment and emotional intimacy which they had experienced in marriage.

4.Barrow, p.104 takes this quotation directly from p.3 of the second study cited above. 
5.Carl J. Couch, Social Processes and Social Relationships: A Formal Approach. (New York, General Hall, Inc., 1989). p.177. Couch also agrees with Barrow's observations above regarding the centrality of personal relationships to happiness. He goes on to say at p.177 that: "One of the obvious qualities of romantic relationships is that they are both highly pleasurable and painful. Those in the throes of a robust, pleasant romantic relationship are ecstatic; they are on top of the world. Those in the midst of a breakup of a robust romantic relationship sink to the depths of depression."

This cultural emphasis on relationships can also be seen in relation to sex in the comments by Carnes cited below. It can also be seen in the comments of Sue Klavans Simring and Steven S. Simring that, in their work with families as practising psychotherapists and university professors during the last twenty years, "In the minds of many adults, a happy marriage has become virtually synonymous with Ultimate Happiness." See:

Sue Klavans Simring and Steven S. Simring, The Compatibility Quotient. (New York, Fawcett Columbine, 1990). p.4.

\section{Anthony storr, solitude.}

(London, Collins Publishing Group, 1988) . p.1-2.

This eminent British psychiatrist adds that "Gellner goes on to affirm that the realm of personal relations has become "the area of our most pressing concern." Our anxieties in this field are compounded by the decline of religious belief. Religion not only provided rules of conduct regarding personal relationships, but also offered a more predictable, stable alternative. Relationships with spouse, children, or neighbors might be difficult, unfulfilling, or unstable; but, so long as one continued to believe in Him, the same could not be said of one's relationship with God."

For more detail on Gellner's views see:

Ernest Gellner, The Psychoanalytic Movement. (London, 1985).

7.Ibid, p.5-6. Storr goes on to make several more interesting comments in this regard:

- "Object-relations theorists believe that, from the beginning of life, human beings are seeking relationships, not merely instinctual satisfaction. They think of neurosis as representing a failure to make satisfying human relationships rather than as a matter of inhibited or underdeveloped sexual 
drives." (p.7).

- "This concentration upon interpersonal relationships ...is not characteristic of all forms of analytical practice: but it does link together a number of psycho-analystg and psychotherapists who may originally have been trained in different schools, but who share two fundamental convictions. The first is that neurotic problems are something to do with early failures in the relation between the child and its parents: the second, that health and happiness entirely depend upon the maintenance of intimate personal relationships." (p.8) (emphasis added).

- "If we call an adult dependent, we imply that he is immature. But if he has no intimate attachments, we conclude that there is something wrong with him. In Western society. extreme detachment from ties with others is usually equated with mental illness. Chronic schizophrenics sometimes lead lives in which relationships with others play virtually no part at all. The capacity to form attachments on equal terms is considered evidence of emotional maturity. It is the absence of this capacity which is pathological. Whether there may be other criteria of emotional maturity, like the capacity to be alone, is seldom taken into account." (p.11).

8.Philip Blumstein, The Production of Selves in Personal Relationships p.305-322 in (Judith A. Howard \& Peter L. Callero, eds.) The Self-Society Dynamic: Cognition, Emotion, and Action. (New York, Cambridge University Press, 1991). p.313.

$$
\begin{aligned}
& \text { 9.Ibid, p.313-14. } \\
& \text { 10.Ibid, p.314. }
\end{aligned}
$$

11. Patrick J. Carnes, Don't Call it Love.

(New York, Bantam Books, 1991). p.77-78. Carnes describes in detail at p.75-80 how our "addictive culture" contributes to and reinforces such extreme behaviors among sex addicts with low self-esteem.

One example of the cultural influence on sex as a coping mechanism is stated at p.78: "More subtle is when sexual excitement becomes a solution. In a recent study, alcoholism researchers found that in the average episode of Dallas characters had a combined total of thirteen drinks to cope with anxiety. What the researchers did not count was the use of sex to cope with crisis and fear. When J.R. Ewing's empire is on the brink of disaster, he finds a woman he has some control over and has sex with her. At the conclusion of the sexual episode he does something "dastardly" that puts distance between himself and the woman. J.R. can smile once 
again, for he has regrouped psychologically to face the crisis."

With regard to the aforementioned cultural elements regarding appearance and female self-esteem, see also:

Edwin M. Schur, "Women and Appearance Norms," p.57-61 in (E. Rubington and M.S. Weinberg, eds.) Deviance: The Interactionist Perspective. (Fifth Edition). (New York, MacMillan Publishing Company, 1987).

12.For a discussion of the concept of a "deviant master status" see:

Everett C. Hughes, "Dilemmas and Contradictions of Status," American Journal of Sociology, I (March, 1945), 353-359.

Howard S. Becker, Outsiders: Studies in the Sociology of Deviance. (Glencoe, The Free Press, 1963).

Becker, at p.33 states that: "Apprehension for one deviant act exposes a person to the likelihood that he will be regarded as deviant or undesirable in other respects... The status of deviant (depending on the kind of deviance) is this kind of master status. One receives the status as a result of breaking a rule, and the identification proves to be more important than most others. One will be identified as a deviant first, before other identifications are made."

Single individuals, who break a rule or norm by not having intimate personal relationships, can be seen as a subculture when alone, but exhibit wider subcultural development insofar as they involve mutual association and participation in singles groups and organizations. See:

Joel Best and David F. Luckenbill (1980), "The Social Organization of Deviants," Social Problems, 28 (1) p.14-31.

Insofar as such single individuals are perceived to be, or labelled "deviant" as they age, this will involve the acquisition of a deviant "master status" cutting across roles and identities. (e.g. "dirty old man"). Indeed, in some social circles today, and even more so in the past, being divorced carries a social stigma that cut across a woman's other roles. Finally, while some single individuals may not be publicly labelled as deviant by others, it may be that they have such low self-esteem, and/or such a lack of affective integration into social groups, that they place a very high emphasis on romantic relationships: feeling "worthless" being 
single. Such self-labelling probably has much the same "cross pollenizing" effect on one's happiness in various roles as does the externally imposed "master status discussed above.

(model).

$$
\text { 13. Storr, p.11. }
$$$$
\text { 14.Smith-Lovin (1990), p.258-59. }
$$

15. See Chapter 2, p.25-35 (definitions) and 35-43

16. While it may be initially objected that it is methodologically impossible to test this hypothesis while looking only at the single role, it became clear from the data that respondents, in discussing happiness, often referred to their other roles as well. It is these additional comments that will be used to examine this hypothesis.

17. It would be an interesting exercise, for example, to compile "role mosaics" of the different types of belief that particular individuals utilize in the experience and management of happiness in relation to the various roles comprising their social identity.

18.I would agree with Barrow (p.81) that happiness/unhappiness are logical contradictories instead of contraries, such that a movement away from one necessarily involves movement toward the other. As such, they are merely different points on the same continuum, and logically differ from contraries such as love and hate (i.e. you can cease hating somebody, but this does not necessarily mean that you are coming to love them).

19. Of course, such a belief is really a double-edged sword in relation to happiness. While managing the unhappiness of the culturally undervalued single role, it simultaneously perceptually reinforces the evaluative idea that one cannot be truly happy unless one is in a relationship.

20. Notice both the perceptual and evaluative aspects of such beliefs in this type of interaction. If one is successful in a one night stand, one perceives enjoyment and evaluates oneself positively (e.g. as "attractive," "charming," etc.).

21. The distinguishing characteristic between this and the more individual-directed orientations found in transcendental and egocentric beliefs is the individual's active, goal-directed perspective. Thus, where a pure 
transcendental belief focuses on that "magical day" when the passive individual will be "saved" from his or her present. personal plight, and the egocentric stresses the individual'g present positive or negative personal experiences, those holding crusader beliefs make it a goal to meet that special somebody, and derive their present level of happiness/unhappiness not so much from its achievement (which would characterize the transcendental) but as a by-product of the active striving that they do on the way. As such, their focus of attention is not as much on themselves as it is on their outside goal.

22. It also helps expand on the details of transcendental beliefs, as to what adherents expect to find when they experience that "magic day."

23. See chapter 2, p.56-61, especially p.57-58.

24. While the researcher's identity as observer was not initially known to some of these respondents, it is felt that to have revealed it in an area as sensitive as personal relationships would have added a measure of bias to the data (after all, most individuals like to present their "best face," and would not likely have "opened up" in the same way had they perceived (wrongly) that I'was not one of them). Moreover, the two anonymous respondents involved in dates with the researcher eventually were told of the general nature my research, and one had expressed interest in conducting an interview. Finally, I must add, on a more personal note, that I would have taken these same actions, with these same individuals, if I had not been involved in this research. As such, any assertion that these people were emotionally "used" to secure research data is unfounded.

25.John Lofland, Analyzing Social Settings: A Guide to Qualitative Observation and Analysis. (Belmont, CA., Wadsworth Publishing Company, 1971). I based my introduction to these interviews largely on that described by Lofland at p.86-7 in this text.

See :

26. From which may be implied consent to participate.

Bruce I. Berg, Qualitative Research Methods for the Social Sciences. (Boston, Allyn and Bacon, 1989). p.138.

27. Howard S. Becker, Sociological Work: Method and Substance. (Chicago, Aldine Publishing Company, 1970). At p.59 Becker writes: "The field worker can sometimes take advantage 
of his presence in the situation to produce evidence based on his own experiences...also, if we actually engage in the same activities as the people we study, (we can) make use of our responses to the events, tasks, and troubles of that style of life."

28.John I. Kitsuse, "Societal Reaction to Deviant Behavior," p.13-20 in (E. Rubington and M.S. Weinberg, eds.) Deviance: The Interactionist Perspective. (Fifth Edition). (New York, MacMillan Publishing Company, 1987). In this wellknown study of societal reactions to homosexual behavior, Kitsuse admitted that "The sample was neither random nor representative of any specified population, and the generalizability of the interview materials is limited." Kitsuse chose instead, as do $I$, to use the interview data as illustrative of a general theoretical conception, commenting on any problems as they arise.

29. It is felt that while young people are traditionally associated with the single life, to focus solely on young university students would not give as wide a scope to the conclusions of this study. After all, considering the historically high divorce rate alone, the attitudes and beliefs of single people at other ages must be taken into consideration.

30.By a margin of 16 to 11 .

31. This would tend to reflect the ratio in the general population, where there are slightly more females.

32.Lofland (supra) notes (p.93-4) that unknown participant observers have been used in numerous published qualitative studies. Some of these include:

-Sheri Cavan, Liquor License: An Ethnography of Bar Behavior. (Chicago, Aldine Publishing Co., 1966)。

- Lyn H. Lofland, In the presence of Strangers: A Study of Behavior in Public settings. (Working Paper No.19 of the Center for Research on Social Organization, University of Michigan, 1966).

-Mark Krain, "On Staying Loose: Task Avoidance in the U.S. Army Reserve." (Manuscript, University of Michigan, 1967).

-Julius A. Roth, Timetables: Structuring the Passage of Time in Hospital Treatment and Other Careers. (Indianapolis, BobbsMerrill Co., 1963). 
-Fred Davis, "The Cabdriver and His Fare: Facets of a Fleeting Relationship," American Journal of Sociology, 65: 158-165 (September, 1959).

-Ralph H. Turner, "The Navy Disbursing Officer as a Bureaucrat,"

American Sociological Review, 12: 342-348 (June, 1947)。

-Melville Dalton, Men Who Manage: Fusions of Feeling and Theory in Administration. (New York, John Wiley, 1959).

-Jerry Jacobs, "Symbolic Bureaucracy: A Case Study of a Social Welfare Agency," Social Forces, 47: 413-422 (June, 1969)。

-John Irwin, "Surfing: The History of a Deviant Scene." (Manuscript, San Francisco State College, 1970).

33. And individuals "put on the spot." would likely give self-serving answers that would protect and appear to enhance their self-esteem.

This problem comes up with the interviews as well. However, the fact that the researcher has previously established friendships with many of the interviewees, it is felt, allows for a level of honesty and critical understanding that transcends most of the self-serving statements they may make.

Moreover, the covert nature of the participant observation also acts as a methodological counterweight to any such tendency in the interviews.

34. Indeed, both respondents with whom I dated were eventually told of the nature of my research. One hopefully asked "Am I going to be in your thesis?" and expressed interest in doing an interview. While the second declined to give an interview, she was informed of my area of study.

35. See supra, note 26.

36. Indeed, even if ethical problems persist from the collection of the data, these confidentiality safeguards ensure that there will be no ultimate harm done. 


\section{Notes to Chapter Four:}

1.It is also implicit in this hypothesis that "effectiveness," the third component of Smith-Lovin's affectcontrol model of emotion, is a component of one's positive assessment of self. After all, one cannot evaluate oneself, or have others make totally positive evaluations, unless one perceives oneself to be, and presents oneself as, effective. As such, this is a necessary moral and evaluative element in one's interactional self-image.

2.Recall that, even for individuals with very low self-esteem, the morally blameless self-image of victim is still almost always available.

3.This seems to correspond to the findings of the empirical studies cited in chapter two. See, for example, the studies by Swann, and that of Baumeister and Tice.

4. Of course, if one holds a negative role identity, it's disconfirmation will consist of a positive interaction as outlined above.

In contrast, interactions confirming negative roleidentities do not produce such strong transitory emotions of unhappiness as there is internal consistency, external agreement, and, usually, a well-worn conceptual escape route in place (e.g. viewing oneself as a victim). Such individuals may be generally unhappy, but it is nothing new to them. It is only when the management function of these escape routes are torn away (e.g. Scully and Marolla's rapists) that one sees more desperate unhappiness in confirmatory negative interactions.

It is thus chiefly when one views, or tries to view oneself in a positive way in a particular role, that a disconfirming, negative interaction produces a significant intensification of the experience of unhappiness.

5. Of course, this is due to the fact that there is empirical difficulty in finding individuals' personal accounts of "objectively" negative interactions that are not perceived as such (i.e. where the individual's subvocal perceptual beliefs do not enable him/her to see a situation or interaction as negatively reflecting on him/herself). Due to this unconscious "first line of defence," it is only when the individual consciously recognizes a situation or interaction as disconfirming that we may realistically obtain his/her 
accounts of "identity maintenance strategies."

It may be that future experimental work may shed some light on this aspect of identity maintenance. It is a limitation of the type of data utilized in this study, however, to make any more than logical conclusions in this regard. To do other would be empirically irresponsible.

Finally, note that the discussion of conscious "identity maintenance strategies" will be taken up in relation to the components of the following hypothesis.

and 5 (supra).

6. Keeping in mind the qualifying comments in notes 4

7.Although there may be relevance to the emotions that one would feel otherwise.

8. The following are comments regarding the meaning of happiness to respondents:

A 23-year-old female, relates her happiness to "doing something that I felt good about myself."

A 19 -year-old female university student equates happiness with "liking yourself."

A 21-year-old male student notes that "feeling good about myself" is an important component of happiness.

A 33-year-old male, similarly, equated happiness to "self-acceptance," as does a 36-year old woman.

A 28-year old woman adds "If you are happy with what you are doing, and, I think, if you know what you are doing is right - you're doing good things - that makes you happy...you have to feel good about yourself to be happy."

A 25 -year old student relates happiness to "high selfesteem" and "putting some of my social anti-discriminatory attitudes now more into working - putting into my work, on the one hand, and trying to put some of it out into the public. So it all is connected."

Finally, a 26-year-old student refers to happiness as "essentially a state of being at peace with yourself, your identity, and with how you fit in, how your life is going."

In all of these comments runs the common thread of a positive evaluation of self, to which evaluative criteria are a necessary component.

9. While these may include conceptual escape routes and other "identity maintenance strategies," the full discussion of these matters will be left to the following section.

As well, it will become readily apparent that some of these approaches approximate types of perceptual/evaluative beliefs as set out in the typology. This is no accident. However, a full discussion of these beliefs will not be 
undertaken until the first group of hypotheses relating to the general interactional model have been dealt with.

10. Of course, not all "personal problems" take days or weeks to work out, and this respondent is obviously referring to more extreme examples. Nevertheless, the principle of selfinteraction or "reflection" remains the same in less serious situations.

11. Of course, if their beliefs do not enable the initial perception of a negative assessment, and this is not brought to one's attention by others, then one does not need to resort to active identity-maintenance strategies, as one's involuntary perception has already taken care of matters.

12. For example, these may include such diverse elements as "conceptual escape routes" embedded in one's system of beliefs, "emotion management, " "selectivity" and self-presentational "micropolitical strategies."

seeking out social support for one's interpretation of self also figures in here, although this matter will be discussed in relation to the next component of the third hypothesis.

\section{See chapter 2, notes 49-52.}

14. This list is merely a cross-section of the numerous subjective identity-maintenance strategies found in the data. other examples have included: religious rationalization of misfortunes as having a reason; focusing on the idea that belief does not necessarily equal knowledge; dismissing others" views as "speculation;" holding "abstract" interpretive beliefs that invariably fit a situation; asserting that "nobody's perfect;" rationalizing an excuse; learning to perceive oneself differently through therapy; minimizing the significance of an event or one's interaction partner; adopting a stoic attitude; denial; occupying one's mind with activity; writing in one's diary; accentuating the positive; focusing on worse times in one's past; emphasizing what one has learned; postulating a better future; rationalizing negative feedback as "not personal;" adjusting one's expectations; pointing to cultural differences; and playing the victim.

15. These examples are also intended to be merely illustrative, not exhaustive. Other interactional strategies shown by the data include questioning; seeking out positive feedback; demonstrating that one is superior to criticism; laughing at another's expense; "putting down" others; and 
adopting an apologetic stance.

16.For example, a young male university student who takes pride in his work states: "I guess the strangers may be the worst because, like, you know, they're seeing, you know, they don't know you...there's no personal things about it so I guess its more the truth."

A female civil servant states that it would "probably be easier to take from strangers 'cause, um, you figure they're giving you an objective answer, whereas family you might tend to think they...they're...its more of a personal opinion. Its not very objective."

17. See Chapter 2, note 47, where Howard speaks of the motivation for self-verification operating in tandem with a positivity bias. However, she also cites empirical support for the proposition that, where these conflict, the desire for self-verification is likely to prevail.

18. See Chapter 2 , note 48 , where are listed empirical studies showing that social support minimizes the adverse effects of stress and strain.

19. Rather than discuss this matter under that heading, it was felt that this, as a separate component of the hypothesis, deserves a separate review. It is merely important to note that seeking out social support may also fall under "identity maintenance strategies."

20.The following will not emphasize breakups and divorces, as these have already been discussed to a large extent in respect of respondents' comments immediately above.

21. Indeed, after reviewing the following comments on subject-matter, consider that it may be that roles incorporate, in addition to specific structural rights and duties as traditionally outlined, both subject matter and role-sets - each of which are subsumed under the larger category of the generalized other. As such, perceptual beliefs regarding subject-matter provides the form, while evaluative beliefs and the role-set provides the content of the role. Of course, some roles may contain larger role-sets than others (e.g. the role of child, in most cases, only admits of two parents, while the role of employee may contain many coworkers and superordinates). This opens the possibility that not only is there an internalized hierarchy of subject matter (or form) between roles, but also a content hierarchy of roleothers within most roles (e.g. one's respected boss may be more important than one's boorish fellow employees, but 
neither are more important than one's parents).

22. While some individuals say that they would rather get criticism from their friends and relatives, this is more indicative of the trust that they have in these individuals to be fair and constructive in their comments than it is of a preference for malicious comments from these sources.

23. It is here suggested that perceptual and evaluative beliefs may vary from role to role, although this is not necessarily always the case. In any event, they are associated with the social roles internalized in the self.

24. See note 21 above for further elaboration on this this complex matter. Remember that subject matter was there closely associated with perceptual beliefs structuring the form of a role, while evaluative beliefs were more closely associated with role-sets comprising the content of each role. Each of these, when taken together, comprise the generalized other or "me" which is considered in self-interaction prior to the individual's "I" response.

25. Indeed, while the final respondent's comments go on to state that, for her, positive comments "go in one ear and out the other," it must be remembered what was shown with regard to the first and second hypotheses. Both the evaluative component of the comments and the internal self-image of the individual must correspond or unpleasant internal confusion is the result. The data there discussed, as well as other empirical studies, have demonstrated the prevalence of the self-consistency motive when an individual has low selfesteem. Since the hypothesis under discussion is built on the foundation of these earlier ones, and it is apparent that this individual, who has had a long history of low self-esteem, largely filters out positive comments to maintain consistency, there is here no contradiction. This individual's perceptual and evaluative beliefs do not allow her to easily perceive and/or internalize positive comments so that they can accumulate.

26.The role specific accumulation of happiness/unhappiness will be more explicitly dealt with in the following discussion of the fifth and final hypothesis.

27. Of course, should the negative evaluation of an individual in a particular role assume the properties of a deviant "master status," this "cross-pollinates" most, if not all, of ones internalized and interactional roles, essentially resulting in a much broader accumulative negative effect on 
happiness.

28. This respondent goes on to downplay happiness through possessions and emphasizes the happiness of getting an "A" on a paper. Ultimately, five roles are discussed by this respondent: son, hunter, boyfriend, level of wealth, and being a student - each with its corresponding evaluation in relation to his overall happiness.

29. This is also implied when individuals "count their blessings" and positively compare themselves to other people as discussed earlier.

30. For example, many of the base-line individuals are involved in outside activities such as academics, sports, writing, coaching, hunting, student politics, advocacy, support groups, volunteering, and so on. This is in sharp contrast with the limited outside involvements of these latter two respondents. One collects welfare and engages in little meaningful activity outside of personal relationships, while the other's time is taken up almost completely by the demands of her job and small children.

31. Ruth Benedict, Patterns of Culture.

(Boston, Houghton Mifflin Co., 1959). Benedict utilizes broad culturally specific terms to sensitize westerners to other cultures by relying on longstanding western archetypes/ prototypes. As Benedict utilizes "Appollonian" and "Dionysian" to characterize Zuni and Kwakiutl cultures, I use hedonism, stoicism, etc., to illustrate egocentric styles.

32 . See chapter 2 , note 69 , where the relationship
between Nurius" concept of "possible selves" and transcendental beliefs is suggested.

33. Sam and Jessica will appear again in these pages, the former with regard to the egocentric and crusader types; the latter with regard to the egocentric and the empathetic. Both differentiate these types on whether or not they are referring to the present or the future; themselves or another in regard to the single role.

34. It is true that Rose, an older separated woman with small children expressed similar brave sentiments about the desirability of having a man and being alone. However, I would suggest that this is more a function of her sense of relief in being free of an unhealthy relationship (e.g. her statement that the separation is like "a burden being lifted") as well as of her "presentation of self." Indeed, at points she notes 
how the marriage damaged her self-esteem, questions her desirability to men, talks of how she doesn't want to spend old age alone, and points out that her low self-esteem catches up with her at night. She also expresses her eventual desire to meet her "prince charming," despite her claim that happiness must come from within.

35.Except, perhaps, the "lonely" sub-type of egocentric beliefs.

36. Charlotte Davis Kasl, Women, Sex, and Addiction. (New York, Ticknor and Fields, 1989). This author, a well known authority on sex addiction and codependency, notes at p.166 the following transcendental responses as typical of either of these disorders, which are characterized by low self-esteem:

- "The only relief I had from the miserable way I was feeling was to fantasize a wonderful person who would make it all better."

- "While I was in my addiction I had the belief that all I had to do was meet the right person and everything would be different. I had no idea that my troubles were about my own fears."

- "I became addicted to romantic novels and kept thinking something like that would happen to me."

37. See Ch2, note 108, in which Zurcher's studies of the individualistic "postmodern self" are cited. One reason stated for this individualism is that individuals find it increasingly difficult to identify with an uncertain social structural order.

38. Patrick J. Carnes, Don't Call it Love: Recovery From Sexual Addiction. (New York, Bantam Books, 1991).

39. The emphasis here is on the background of our individualistic culture, not temporal orientation. All the same, traditional religion does carry some egocentric elements (e.g. forgiveness of ones sins upon present confession and repentance).

40. Carnes notes at p.75-77 that: "our culture seeks entertainment and escapism rather than searching for meaning," and that it is inherently selfish in being "exploitive of others." 
41. It is also interesting to note that this "hedonistic" variety of egocentric belief, when taken to extremes, often shows up in those individuals of low selfesteem characterized by the compulsive disorder of "sex addiction." Patrick J. Carnes, a well known researcher on this topic, notes that "For sex addicts, sexual obsession becomes the organizing principle of daily life. Everything revolves around it." He notes the following words of respondents he calls "Peter" and "Don" as representative:

"Food was something I would think about only periodically. Sleep became passe'. I would rush from work on Friday afternoon and change clothes and pick up a bag of costumes, I called them - sleazy Levi's, torn shirts, things like that - and jump in the car and rush to the city. Then check into a bathhouse and be there all weekend long and get maybe six hours sleep the whole weekend. Catnaps in the bathhouse at times when they weren't very busy between $6: 00$ and $9: 00$ in the morning. I'd rush back home Monday morning at 6:00, jump in the shower and shave and put on a suit and go off to work. I would do that week after week after week. During the week I would frequently rush out on Tuesday night or Thursday night because I couldn't stand not doing it. It was all this rushing, rushing, rushing."(p.26).

"I came to live totally alone, in constant fantasy of one type or another about all sexual things. At one point I realized that the regular world of people, work, families, school, and caring about these things seemed completely foreign to me. The only life that seemed normal to me was the life of searching for one more sexual high after another. I believed that I was living a life-style that other people were missing out on; they just weren't as high as I was." (p.57).

42. It must also be noted that this individual had, at the time of the interview, a boyfriend.

43. A well known variant of this view in our culture is expressed by the "serenity prayer."

44. Anthony Storr, Solitude.

(London, Collins Publishing Group, 1989). This eminent psychiatrist notes at p.11 that "In Western society, extreme detachment from ties with others is usually equated with mental illness... The capacity to form attachments on equal terms is considered evidence of emotional maturity." He also writes at p.5-6 that "The majority of psycho-analysts, social 
workers, and other members of the so-called "helping professions" consider that intimate personal relationships are the chief source of human happiness. Conversely, it is widely assumed that those who do not enjoy the satisfactions provided by such relationships are neurotic, immature, or in some other way abnormal. Today, the thrust of most forms of psychotherapy, whether with individuals or groups, is directed toward understanding what has gone wrong with the patient's relationships with significant persons in his or her past, in order that the patient can be helped toward making more fruitful and fulfilling human relationships in the future."

Under such circumstances, considering the weight of both cultural and professional-institutional opinion, can it be any wonder that solitary individuals frequently feel abnormal when "lonely?"

45. See chapter 2 , note 69 , where the relationship between Nurius' concept of "possible selves" and crusader beliefs about happiness was noted.

46. See ahead to the discussion of problematic and mixed beliefs, as well as to the discussion of individuals holding a variety of typical beliefs with regard to different conceptualized aspects of the same role.

47. The author is aware that this statement was already used in relation to the general motivating power of transcendental beliefs. However, it is clear that this statement also has a crusader component in relation to the single role. Specifically, the idea of the "perfect girl" is transcendental, while the activity of searching, and any positive emotions accompanying it, relates more clearly to the crusader.

48. It is important to note that while Couch characterizes sensual play as "primarily" a present centered activity, he does not rule out intentions and goals for the long or short-term future in this activity - the hallmark of crusader beliefs.

49. Crusader beliefs often appear among those individuals characterized by the compulsive disorders of sex addiction and codependency. For example, therapist Robin Norwood notes a typical example of deep-seated crusader beliefs in a codependent patient she had been treating. This woman had gone through several unsuccessful relationships as a result of trying to "change" difficult partners. Now, well on the way to recovery, and involved with a stable, loving partner, she is unhappy. Norwood advised her: 
"The trouble is, you've never experienced having what you wanted before. You've only known what it was like not to have it, and to work like crazy to try and get it. You're used to the yearning and the suspense, which creates a lot of heart-pounding excitement... because not having what you want is much more stimulating than having it."

The patient agreed. See:

Robin Norwood, Women Who Love Too Much. (New York, Pocket Books, 1985).

With regard to sex addiction, crusader beliefs play a similar role. Carnes notes that these become "primary coping strategies" :

"Sexual preoccupation becomes an "analgesic fix" for the sex addict. Obsession and fantasy become a primary coping strategy. planning, searching, intriguing, and looking for opportunity become a way to get through each day... The conquest is everything." (Carnes 1991: 21-2; 47).

Interestingly, Carnes also notes that for those that characterize themselves as "love addicts" or "romance junkies," (i.e. those that spend an "inordinate amount of time" preparing for sexual episodes, and become "lost in endless intrigues and obsessions") the fantasy of striving is often more satisfying than the actual sexual experience. (1991:44-5).

Thus, it would seem that crusader beliefs appear both to produce and manage happiness/unhappiness among those single individuals characterized by the compulsive disorders of sex addiction and codependency.

50. It will be noted, however, that some respondents discussing such belie:s do so in the "as if" sense (i.e. they speak about what they feel a relationship should or would be like if they were presently involved in one).

Due to the fact that single individuals were selected as the topic of study, it was not possible to get much data on actual attitudes to present relationships. Yet, such beliefs, which are as much the result of past relationships as they are of cultural conditioning, indicate how they would think if presently involved in the way they desire. 
51.Rosenberg (1979) Supra, notes at p.35-6 that "The self does not have fixed and rigid boundaries. It can take into itself more and more objects and individuals, more and more external things whose fate then becomes wrapped up in its own." He identifies three defining characteristics of this phenomenon of "ego-extension": (i) "the subjective experience of "me" or "mine" associated with a person, institution or object (e.g. my wife); (ii) "the presence of the emotions of pride or shame" in that thing; and (iii) "the phenomenon of introjection..."the adoption of externals (persons or objects) into the self, so as to have a sense of oneness with them and to feel personally affected by what happens to them." When an external object is introjected, the fate of the object and of the self are experienced as inextricably intertwined."

Of course, the ultimate experience of this type is the traditional mystical idea of union with God or the universe. For a discussion of: such emotional experiences see the following:

\section{-Plotinus, The Enneads.}

-June Callwood, Emotions.

(Toronto, Doubleday Canada Ltd., 1986). Callwood notes at p.67 that "The merging of self and God in oneness is revered as a private experience by Buddhists and interpreted by Christians and Jews as holiness and social obligation."

-Anthony Storr, Solitude.

(London, Collins Publishing Group, 1989). See pages 17-18; 368; and 186-9; where this eminent British psychiatrist describes, quotes, or refers to the mystical experiences of many notable individuals such as Walt Whitman, Arthur Koestler, Edmund Gosse, A.L. Rowse, C.S. Lewis, Bernard Berenson, Admiral Byrd, William James, and C.P. Snow. He refers to these as an "oceanic feeling."

storr goes on to state at p.188 that: "The sense of perfect harmony with the universe, of perfect harmony with another person, and of perfect harmony within the self are intimately connected; indeed, I believe them to be essentially the same phenomena. The triggers of these experiences are of many different kinds...nature, art, religion, sexual love, childbirth, knowledge, creative work, (and) certain forms of exercise... (are) the most common... Experiences of this kind can also occur spontaneously in solitude without the aid of any external stimulus."

52.Sigmund Freud, Civilization and its Discontents, Standard Edition, edited by James Strachey, 24 volumes, XXI (London, 1961). Freud writes at p.66 that "At the height of 
being in love the boundary between ego and object threatens to melt away. Against alil the evidence of his senses, a man who is in love declares that "I" and "you" are one and is prepared to behave as if it were a fact."

53. Philip Blumstein, The Production of Selves in Personal Relationships, p. 305-318 in (Judith A Howard and Peter L. Callero, eds.) The Self-Society Dynamic: Cognition, Emotion, and Action. (New York, Cambridge University Press, 1991). at p.318.

54. The author must confess that he was once involved in a relationship where great significance was placed on similar events as evidence that the parties were "meant to be." (e.g. picking up the phone to call each other at the same moment and reaching each other without a ring).

55.Plato, The Symposium. Plato uses the character of Aristophanes, the comic playwright, to propose the myth that humans were originally created by the gods connected to each other as hermaphrodites. The gods became angry at these original beings' arrogance and power, so they bisected the race into two sexes. The result was that each half-being felt compelled to find a partner who would restore its former wholeness.

56.Paul Tillich. Love, power and Justice. Tillich writes that the joy experienced in finding "the loved one" is in truth self-fulfillment. "The absolutely strange cannot enter into a communion... That which is absolutely strange to me cannot add to my self-fulfillment; it can only destroy me if it touches the sphere of my being. Therefore love cannot be described as the union of the strange but as the reunion of the estranged...Love manifests its greatest power where it overcomes the greatest separation. And the greatest separation is the separation of self from self."

57. Rose downplays the importance of having a man in her life right now as she has difficulties to deal with, and that it would be "unfair" to the other person. Yet, her insecurity comes out clearly when she wonders if she is still attractive to men; talks of the "low self-esteem" she is enduring because of her separation; notes that she does not want to spend old age alone; discusses how her low self-esteem catches up with her at night; and dreams of meeting her "prince charming."

58. Melody Beattie, Codependent No More. (San Francisco, Harper and Row, 1987). 
59. This may also have something to do with more limited social integration into extensive role involvements as compared, say, to Jessica.

60.The following theorists have argued that, despite the risk of role-conflict, the greater the number of roleidentities held, the stronger will be a person's sense of a meaningful, guided existence, as well as of psychological health and security:

-S. Marks (1977) "Multiple Roles and Role Strain: Some Notes on Human Energy, Time, and Commitment." American Sociological Review

$42: 921-936$.

-S.D. Sieber (1974) "Toward a Theory of Role Accumulation." American Sociological Review 39: 567-578.

In addition, the following researchers have recently found empirical support for this "identity-accumulation" hypothesis:

-P.A. Thoits (1983) "Multiple Identities and Psychological Well-Being: A Reformulation and Test of the Social Isolation Hypothesis." American Sociological Review 48: $174-187$.

-L. Verbrugge (1983) "Multiple Roles and Physical Health of Women and Men." Journal of Health and Social Behavior 24: $16-30$.

-M.K. Potts (1987) The Effects of Role Multiplicity on Health status, Illness Rates, and Illness Behavior in Men and Women: A Test of the Scarcity and Expansion hypothesis. (Unpublished doctoral dissertation, Purdue University, West Lafayette, IN.) Potts replicated this finding, but also discovered that, in addition to the number of identities, the types of identities (how personally meaningful, how socially valued) and the structural factors associated with them (e.g. access to and support for role opportunities such as employment) differed significantly by gender and confused the identities-health relationship.

61.This, of course, is an example of variation in degree as discussed with regard to other types of belief. Yet, unlike transcendental and clearly crusader beliefs where the variation tends to take place mostly along the temporal dimension, empathetic beliefs, which emphasize the present, tend to show more variation along the self/other dimension. 
That is why this matter has been discussed separately here.

62. Couch, (supra) stresses the empathetic nature of lovemaking at p.185 where he states: "Lovemaking is largely a present-centered activity. Pasts inform the activity and projected futures structure it, but to achieve high levels of mutual arousal, each must focus primarily on the immediate ongoing responses of the other."

63. Consider, for example, the many elderly people who do not live very long after the death of their spouse.

Couch also cites at p.190 observations by well-known therapists Masters and Johnson showing that a "powerful sense of emotional well-being comes when each partner knows that at times of greatest vulnerability the other can be relied on to provide warmth, comfort and protection." See:

William H. Masters and Virginia E. Johnson, in association with Robert J. Levin The Pleasure Bond. (Boston, Little, Brown., 1974). p.56.

64. While a number of respondents have noted that they have at times "dwelled on the past" - and thereby engaged in an activity seemingly outside of the typology as set out - it must be remembered that this is a present activity whereby the past is internally reconstructed to give positive or negative meaning to the present. As such, when Mead's theory of the past is considered, these statements may be interpreted as egocentric or empathetic when so structuring present emotions, and crusading or transcendental when they refer to something again to be attained or received, as the case may be.

65. Of course, it has been asserted all along that individuals may hold different typical beliefs with regard to different roles, and, without extensively delving into the matter for reasons of economy, the data bear this out. Consider as representative these two comments of a female graduate student:

"I am one, in the position that I'm in now, living my life for some kind of future as far as my career is concerned. But I also live for the present when I can go out and have a good time.."

"It really depends on what the situation is. If its...if its me in my career, my academics, then I'm thinking of myself. Um, I don't really care how other people do...Um, as far as friends are concerned, um, 
I...I think of them, um, to a point when it becomes, when I feel, rightly or wrongly, that they are not thinking of me. Um, then things get a little more egocentric." (Her usage).

From these two comments can be gleaned that this woman holds largely transcendental beliefs with regard to her academics (due to the self/future focus), hedonistically egocentric beliefs with regard to recreational activities (due to the self/present focus), and predominantly empathetic beliefs with regard to reciprocal friendship (due to the other/present focus). Yet, she points to this changing to "egocentric" (her own usage) when the friendship is not reciprocal.

Overall, each respondent was asked of their predominant temporal orientation, and whether they worried more about their selves or others. To a one, they all gave qualified responses that can be interpreted either on the basis of differing typical beliefs for differing roles, or the same typical beliefs across several roles. This interpretation is in full agreement with the theoretical statements set out in chapter 2 .

66. Personal development, even when stated as a goal, cannot be seen as a crusader belief due to the fact that the goal is not an external, but oneself.

67. Of course, the similarity to the transcendental religious notion of divine retribution cannot be ignored here.

As well, to the extent that "what goes around" involves present personal gratification, it may also be seen in an egocentric light.

68.For example, it is not far from this statement to the idea that "it happened to teach me a lesson" or "it was to make me grow as a person."

69. This individual refers to "having a good time in the present" while putting more emphasis, in the longer term, on obtaining or achieving outside goals such as a "good relationship" and a "good job."

70.This respondent is especially prone to making empathetic statements. Elsewhere she states: "When a friend of mine is hurting, I hurt too."

71. This respondent also shows that he exhibited crusading beliefs in relation to meeting women in his bitter comments over the breakup of a recent relationship: "It took 
me like, you know, three years of university to find someone that I liked that much.."

72. Of course, when any man refers to his girlfriend as a "keeper" - thus signifying a possession - it should be questioned as to how far these minority empathetic beliefs consciously pervade, among other things.

73. This respondent's prior empathetic beliefs about her marriage are brought out in her painful statement: "It was a big blow to have someone that I trusted and was devoted to and loyal to for eight years just up and leave me for another woman."

74. Note her concern that to get involved with someone at this point would be immoral - implicitly giving herself a pat on the back.

75. Note the respondent's express exclusion of the crusader stance in finding Mr. Right. Also note that she is attempting to buttress her happiness in being alone by comparing the search for any man to fill the void to her previous unhappiness with her husband. She is also implicitly referring to the free aspect of her newfound singlehood here in her "I would rather" comment.

76. This latter type is utilized to prevent his hopes being repeatedly raised and dashed by those of his sexual conquests with whom he would like to pursue a relationship, and to diminish the significance of the others.

77. The importance of perceptual beliefs is important here. See p.87-91 (infra) for a general discussion of these beliefs in relation to happiness. In general, as well, it must be noted that if an individual's beliefs do not enable him/her to perceive a disconfirmation, and this is not brought home to $\mathrm{him} / \mathrm{her}$ in interaction, then no disconfirmation can occur.

This also recognizes that identity-maintenance strategies, which incorporate perceptual and evaluative beliefs, enable individuals to avoid seeing events as disconfirming in favor of a more palatable interpretation. See the following section in this regard.

78. Remember the expanded conception of self in the crusader and especially the empathetic types here.

79. While this woman's situation was there discussed to illustrate her utilization of different types of belief in the present in relation to different aspects of the single role, 
no contradiction is implied by looking at her comments in relation to the disconfirming events of her separation.

80. That is to say, no identity-maintenance strategies, whether conceptual or interactional, can prevent her from recognizing the full scope of what has happened.

81. This is implied in (a) her level of upset over having "someone that I trusted and was devoted to and loyal to for eight years just up and leave me for another woman" intimate interactions over that period of time, positive or negative, cannot help but form a large part of her generalized other - and (b) in her empathetic comments over what qualities she is hoping to find when she is involved with the next man in her life.

82. Remember, as well, that individuals may hold several typical beliefs with regard to different aspects of the same role. As such, it may be that disconfirmation may only result in a change between types with regard to a particular aspect of a role.

83. She states at one point that "You're always told "maybe you haven't met the right person." At many points in the interview she dismisses such an outlook.

84. She expresses the "downplayer" and the "self-worth" varieties of egocentric beliefs throughout the interview. Neither of these are particularly well-suited to dealing with loneliness relative to the transcendental.

85.It is interesting to note that the stoics in ancient times were notorious for committing suicide when their rigorous system became too hard to bear in relation to difficult life situations.

86.For example, while the former respondent works full-time and is involved in a social club, this respondent hasn't worked for some time, is on welfare, has a daughter that she rarely sees due to distance and custody arrangements, and has had several unsuccessful relationships.

87. This, of course, depending on her thoughts, may also be interpreted not so much as a change from the empathetic, but a total expansion across roles with a corresponding change in the intended "other" dimension thereof, from losing herself in a man to losing herself in the unknown.

The follow-up to these events was that her ex- 
boyfriend, or "soul mate," came to the hospital upon hearing of her actions, and they reconciled. Immediately, she again began expressing empathetic beliefs about their relationship.

88. Indeed, in previous conversations with the researcher, this subject noted that, for him, it was a recurring problem to have some of his "conquests" seek a longer-term relationship, when he had no such desire.

89. For example, one boyfriend told her that he was gay because he couldn't face telling her that he couldn't stand her old mother and her kids. This pattern of her potential boyfriends rejecting her family has repeated itself on other occasions as well.

90. Of course, the significance of interaction partner and the number of roles cut across by some of these more intense interactions are also at play here. 


\section{Notes to Chapter Five:}

1.For example, one may exhibit egocentric beliefs with regard to one's success, or lack thereof, in one's career, transcendental beliefs regarding advancement (e.g. "all will be well when I get my promotion"), crusader beliefs regarding targets (e.g. "it's not the having, its the fight to get it"), and empathetic beliefs in discussions among co-workers regarding similar experiences.

It may also be interesting to look at differences in prevalence of typical beliefs between various careers (e.g. it could be that those in the "helping professions" exhibit more empathetic beliefs while those in business show more of a crusader makeup). Of course, such ideas need empirical investigation.

2 . One could hold egocentric beliefs with regard to one's enjoyment of recreational activities; transcendental with regard to upcoming activities in comparison with the present; crusader with regard to things like winning a game or a championship; and empathetic regarding one's understanding of another's experiences.

3.For example, one could hold egocentric beliefs regarding one's experience of (hedonistic) or lack of (stoic) health; transcendental beliefs that "all will be well when I am better; " crusader beliefs in one's fight to beat a disease; and empathetic beliefs in relation to family, friends, and other patients who have undergone the same experience.

4.For example, parents may exhibit transcendental beliefs regarding vacations without small children (e.g. "I can hardly wait. It will be so nice and quiet - no kids for a whole week"); egocentric beliefs regarding the pleasure of playing with one's offspring; crusader beliefs regarding the goal of "giving the kids a proper upbringing;" and, of course, the empathetic beliefs of all parents regarding their children as part of themselves.

5. Charlotte Davis Kasl, Women, Sex, and Addiction. (New York, Ticknor and Fields, 1989). p.166. This well known authority on sex addiction and codependency notes this transcendental response as typical of either disorder, characterized by low self-esteem. Two further examples:

"The only relief I had from the miserable way I was 
feeling was to fantasize a wonderful person who would make it all better."

"I became addicted to romantic novels and kept thinking something like that would happen to me."

6.Patrick J. Carnes, Don't Call it Love: Recovery From Sexual Addiction. (New York, Bantam Books, 1991). p.57.

It is also interesting to note the egocentric subtype of stoicism found in the first step of all twelve-step recovery programs - the admission that "I have no power over ."

7. Robin Norwood, Women Who Love Too Much. (New York, Pocket Books, 1985).

While the above comments of Norwood refer to codependency, Carnes has also noted them in relation to sex addiction. As he states at p.21-2 and 47: "Sexual preoccupation becomes an "analgesic fix" for the sex addict. Obsession and fantasy become a primary coping strategy. Planning, searching, intriguing, and looking for opportunity become a way to get through each day...The conquest is everything."

8. Melody Beattie, Codependent No More.

(San Francisco, Harper and Row, 1987). p.53.

9.For example, the stoic variety of egocentric belief is found in the first step, while other types can be found throughout the other steps, inspirational readings, and discussions among members and their sponsors. such victims.

10.This would include families and close friends of

11.Norman K. Denzin, On Understanding Emotion: The Interpretive-Cultural Agenda p.85-116 in (Theodore D. Kemper, ed.) Research Agendas in the Sociology of Emotions. (New York, State University of New York Press, 1990). Denzin is a leading advocate of studying film in relation to emotion.

12. In addition to the studies by Stryker and Denzin, to name a few, who, taken together, articulate a similar position. 


\section{Appendix I:}

\section{Interview Schedule}

\section{(a) Introduction/ demographic profile:}

1. First Name.

2. Sex.

3. Age.

4. Occupation.

5. Educational level.

6. Class (self-reported).

7. Marital status (including whether respondent is currently "seeing someone").

8. Whether respondent has any children.

9. Health.

\section{(b) Concomitant Conditions:}

10. Are you presently satisfied or dissatisfied with your level of Income? Why or why not?

11. Are you presently satisfied or dissatisfied with your material possessions? Why or why not?

12. Do you feel that you've enjoyed relative good fortune in your life?

13. Have you experienced any personal tragedies? 


\section{(c) Beliefs and Values:}

14. Describe your fundamental beliefs.

15. Describe your fundamental values.

16. Would you consider these your philosophy of life? (If no, what is your philosophy of life?)

17. How did you arrive at these views?

18. Could you imagine anything challenging these? (If no, what if the situation arose....? )

19.Do you feel that, in your opinion, you live up to these ideals? Why or why not?

\section{(d) Self-Image:}

20. How do you view yourself as a person? (At present, in the past, and in the future).

21. How would you evaluate your life? (i.e. what criteria do you use?)

22. Do you like yourself? Why or why not?

23. Would you characterize yourself as a person with high, low, or medium self-esteem?

24. How would other people view you?

(e) Interaction Effects/Identity-Maintenance:

25. Would you characterize yourself as meek, assertive, or aggressive? Why?

26. How do you respond to negative feedback from other people? 
27. Does who they are make a difference to you? (e.g. friends and family, as opposed to strangers and acquaintances).

27. Do you ever challenge them?

28. Do you sometimes rationalize their comments away?

29. Do you ever manipulate the situation to your advantage? (e.g. making them feel guilty for their behavior).

30. How do you respond to positive feedback from other people?

31. Do these responses regarding positive and negative feedback relate to your values as stated earlier? If so, how? 32. Do these responses relate to your beliefs? If so, how?

33. What do you feel are the long-run effects of repeated positive or negative feedback?

34. How do you handle bad luck?

35. How do you handle personal misfortunes or tragedies?

$$
\text { (f) Typology (general): }
$$

36. Are you a person that tends to dwell on the past, focus on the present, or puts a lot of hope into the future?

37. In what ways? In what respects? Why?

38. Would you say that you worry more about yourself or more about others?

39. In what areas? In what respects?

$$
\text { (g) Roles: }
$$

40. What is the most important role(s) in your life?

41. How well, in your opinion, do you perform it? 


\section{(h) Typology (singles and relationships):}

42. How do you like being single?

43. How do you conceive of yourself in your role as:a single person? (e.g. as "free" or as a "loser").

44. How do you conceive of the chance of meeting someone?

45. Is meeting someone important to how you feel about yourself?

46. What do you think a relationship should be like?

\section{(i) Happiness:}

47. Would you consider yourself a happy person? Why or why not?

48. What, in your opinion, is happiness?

49. Do you think it is achieved or received?

50. Does this have anything to do with your values and beliefs?

51. Is your happiness flexible over time? (e.g. is there a base-line, such that events may bring you down, but the "other eggs in the basket" help you bounce back; or, are you more of a "rollercoaster," tending to extremes of happiness and despair in relation to events?).

\section{(j) Conclusion:}

52. Is there anything else that you would like to add? 


\section{APPENDIX II: \\ Demographic Profile of Respondents}

(a) Interview Subjects:

Sex Age Education Class Marital Status Children occupation

$\begin{array}{lllllll}\text { M } & 21 & \text { univ-yr3 } & \text { up-m } & \text { single } & \text { no } & \text { student } \\ \text { F } & 19 & \text { univ-yr1 } & \text { mid } & \text { single } & \text { no } & \text { student } \\ \text { M } & 21 & \text { univ-yr3 } & \text { mid } & \text { single } & \text { no } & \text { student } \\ \text { F } & 21 & \text { univ-yr2 } & \text { up-m } & \text { single } & \text { no } & \text { student } \\ \text { M } & 21 & \text { univ-yr3 } & \text { up-m } & \text { single } & \text { no } & \text { student } \\ \text { F } & 28 & \text { c-coll } & \text { mid } & \text { single } & \text { no } & \text { clerical } \\ \text { M(bi) } 33 & \text { univ-yr2 } & \text { wkng } & \text { single } & \text { no } & \text { student } \\ \text { F } & 22 & \text { univ-yr4 } & \text { wkng } & \text { involved } & \text { no } & \text { student } \\ \text { F } & 36 & \text { high Sch } & \text { wkng } & \text { divorced/ } & \text { yes } & \text { unemployed } \\ & & & & \text { involved } & & \text { separated } \\ \text { F } & 28 & \text { c-coll } & \text { 1-m } & \text { yes } & \text { education } \\ \text { M(bi) } 25 & \text { univ }+ & \text { mid } & \text { single } & \text { no } & \text { grad st. } \\ \text { F } & 26 & \text { univ }+ & \text { wkng } & \text { single } & \text { no } & \text { grad st. }\end{array}$

(b) Observational Subjects:

Sex Age Education Class Marital Status Children occupation

$\begin{array}{lllllll}\text { M } & 30 & \text { univ }+ & \text { mid } & \text { single } & \text { no } & \text { grad st. } \\ \text { F } & 29 & \text { c-coll } & \text { up-m } & \text { divorced } & \text { yes } & \text { clerical } \\ \text { F } & 37 & \text { c-coll } & \text { wkng } & \text { single } & \text { no } & \text { education }\end{array}$




$\begin{array}{lllllll}\text { M } & 27 & \text { univ }+ & \text { up-m } & \text { single } & \text { no } & \text { journalism } \\ \text { F } & 34 & \text { univ } & \text { wkng } & \text { widow } & \text { yes } & \text { service } \\ \text { M } & 32 * & \text { univ-yrl } & \text { mid } & \text { single } & \text { no } & \text { student } \\ \text { M } & 56 * & \text { jr. high } & \text { wkng } & \text { divorced } & \text { yes } & \text { retired }\end{array}$

Relatively Brief Interactions:

$\begin{array}{lllllll}\text { F } & 21 * & \text { univ-yr3 } & \text { mid } & \text { single } & \text { no } & \text { student } \\ \text { F } & 35 * & \text { unknown } & 1-\mathrm{m} & \text { divorced } & \text { yes } & \text { clerical } \\ \text { F } & 35 * & \text { unknown } & 1-\mathrm{m} & \text { divorced } & \text { yes } & \text { unknown } \\ \text { F } & 23 * & \text { univ-yr? } & \text { mid } & \text { single } & \text { no } & \text { student } \\ \text { M } & 21 * & \text { univ-yr? } & \text { mid } & \text { single } & \text { no } & \text { student } \\ \text { F } & 35 * & \text { unknown } & 1-\mathrm{m} & \text { divorced } & ? & \text { unknown } \\ \text { M } & 45 * & \text { unknown } & 1-\mathrm{m} & \text { divorced } & ? & \text { business } \\ \text { F } & 60 * & \text { unknown } & \text { mid } & \text { divorced? } & ? & \text { unknown }\end{array}$

* Indicates estimated age of subject. 


\section{Bibliography}

J.W. Alba \& L. Hasher (1983) "Is Memory Schematic?" " Psychological Bulletin 93: 203-231.

Aristotle, Nicomachean Ethics, in The Works of Aristotle. (W.D. Ross, ed).

J.G. Bachman, Youth in Transition, Volume II: The Impact of Family Background and Intelligence on Tenth-Grade Boys. (Ann Arbor, Michigan: Survey Research Centre, Institute For Social Research, 1970).

Robin Barrow, Happiness.

(Oxford, Maretin Robertson \& Company Ltd., 1980).

R.F. Baumeister and D.M. Tice (1985), "Self-Esteem and Responses to Success and Failure." Journal of Personality 53: $450-467$.

R.F. Baumeister, J.P. Shapiro, and D.M. Tice (1985), "Two Kinds of Identity Crisis." Journal of Personality 53: 407-24.

Melody Beattie, Codependent No More.

(San Francisco, Harper and Row, 1987).

Howard S. Becker, outsiders: Studies in the Sociology of Deviance. (Glencoe, The Free Press, 1963).

Howard S. Becker, Sociological Work: Method and Substance.

(Chicago, Aldine Publishing Company, 1970).

Ruth Benedict, Patterns of Culture.

(Boston, Houghton Mifflin Co., 1959).

Bruce L. Berg, Qualitative Research Methods For the Social Sciences. (Boston, Allyn and Bacon, 1989).

Peter L. Berger and Thomas Luckmann, The Social Construction of Reality: A Treatise on the Sociology of Knowledge.

(Garden City, N.Y., Doubleday and Company, Inc., 1967).

Joel Best and David F. Luckenbill (1980), "The Social Organization of Deviants," Social Problems 28(1) p.14-31. 
D. Blazer and E. Palmore, "Religion and Aging in a Longitudinal Panel" Gerontologist (February 1976).

Philip Blumstein, The production of Selves in Personal Relationships p.305-322 in (Judith A. Howard and Peter $L$. Callero, eds.) The Self-Society Dynamic: Cognition, Emotion, and Action. (New York, Cambridge University Press, 1991).

Franz Brentano, on the Origin of our knowledge of Right and Wrong, extract p.203-14 in (Chesire Calhoun and Robert C. Solomon, eds.) What is an Emotion?: Classic Readings in Philosophical Psychology. (New York, Oxford University Press, 1984).

Peter J. Burke, Attitudes, Behavior, and the Self, p.189-208 in (Judith A. Howard and Peter L. Callero, eds.) The SelfSociety Dynamic: Cognition, Emotion, and Action. (New York, Cambridge University Press, 1991).

Chesire Calhoun, Cognitive Emotions? p.327-342 in (Chesire Calhoun and Robert C. Solomon, eds.) What is an Emotion?: Classic Readings in Philosophical Psychology.

(New York, Oxford University Press, 1984).

Chesire Calhoun and Robert C. Solomon, eds., what is an Emotion?: Classic Readings in Philosophical Psychology.

(New York, Oxford University Press, 1984).

Peter L. Callero, Toward a Sociology of Cognition, p.43-54 in (Judith A. Howard and Peter L. Callero, eds.) The Self-Society Dynamic: Cognition, Emotion, and Action. (New York, Cambridge University Press, 1991).

June Callwood, Emotions.

(Toronto, Doubleday Canada Ltd., 1986).

Mary Owen Cameron, Identity and the Shoplifter. p.315-17 in (E. Rubington and M, Weinberg, eds.) Deviance: The Interactionist Perspective. (Fifth Edition) (New York, MacMillan Publishing Co., 1987).

Walter B. Cannon, A Critical Examination of the James-Lange Theory of Emotions. p.142-151 in (Chesire Calhoun and Robert C. Solomon, eds.) what is an Emotion?: Classic Readings in Philosophical Psychology.

(New York, Oxford University Press, 1984). 
Kathleen Carley, Growing Up: The Development and Acquisition of Social knowledge. p.75-102 in (Judith A. Howard and Peter L. Callero, eds.) The Self-Society Dynamic: Cognition, Emotion, and Action. (New York, Cambridge University Press, 1991).

Patrick J. Carnes, Don't Call it Love: Recovery From Sexual Addiction. (New York, Bantam Books, 1991).

Sheri Cavan, Liquor License: An Ethnography of Bar Behavior. (Chicago, Aldine Publishing Co., 1966).

M. Cernetic, "Fallen Idol Prays For Redemption." Globe and Mail, May 20, 1991. p.1.

Candace Clark, Emotions and Micropolitics in Everyday Life: Some Patterns and Paradoxes of "Place." p.305-333 in (Theodore D. Kemper, ed.) Research Agendas in the Sociology of Emotions. (New York, State University of New York Press, 1990).

S. Cohen and T.A. Wills (1985), "Stress, Social Support, and the Buffering Hypothesis." Psychological Bulletin 98: 310-357.

Randall Collins, Stratification, Emotional Energy, and the Transient Emotions. p.27-57 in (Theodore D. Kemper, ed.) Research Agendas in the Sociology of Emotions.

(New York, State University of New York Press, 1990).

Carl J. Couch, Social processes and Social Relationships: A Formal Approach. (New York, General Hall, Inc., 1989).

Melville Dalton, Men Who Manage: Fusions of Feeling and Theory in Administration. (New York, John Wiley, 1959).

Fred Davis, "The Cabdriver and His Fare: Facets of a Fleeting Relationship" American Journal of Sociology 65: 158-165 (September 1959).

Norman K. Denzin. (1982). "A Note on Emotionality, Self and Interaction." American Journal of Sociology $89(2): 402-9$.

Norman K. Denzin. (1985) . "Emotion as Lived Experience." Symbolic Interaction. 8(2): 223-40.

Norman K. Denzin, on Understanding Emotion: The InterpretiveCultural Agenda. p.85-116 in (Theodore D. Kemper, ed.) Research Agendas in the Sociology of Emotions.

(New York, State University of New York Press, 1990). 
Rene Descartes, Meditations on First Philosophy p.131-200 in The Philosophical Works of Descartes, Vol. 1, translated by E.S. Haldane and G.R.T. Ross. (Cambridge, Cambridge University Press, 1973).

Rene Descartes, The Passions of the Soul, extract p.53-70 in (Chesire Calhoun and Robert C. Solomon, eds.) what is an Emotion?: Classic Readings in Philosophical Psychology. (New York, Oxford University Press, 1984).

E.W. Desmond, "A Pencil in the Hand of God." Time (Canadian edition) 134(23) December 4, 1989, p.14.

Emile Durkheim, The Division of Labour in Society. (New York, The Free Press, 1984).

Epictetus, The Discourses and Manual, translated by P.E. Matheson. (Oxford, Oxford University Press, 1916).

I. Festinger, H. Riecken and S. Schachter, When Prophecy Fails. (New York, Harper and Row, 1964).

G. Fine and S. Kleinman. (1983). "Network and Meaning: An Interactionist Approach to structure" Symbolic Interaction $6: 97-110$.

Sigmund Freud, Civilization and its Discontents, standard Edition, edited by James strachey, 24 volumes, XXI (London, 1961).

Harold Garfinkel, Studies in Ethnomethodology. (Englewood Cliffs, N.J., Prentice-Hall, 1967).

Viktor Gecas, The Self-Concept as a Basis for a Theory of Motivation, p.171-187 in (Judith A. Howard and Peter L. Callero, eds.) The Self-Society Dynamic: Cognition, Emotion, and Action. (New York, Cambridge University Press, 1991).

Ernest Gellner, The Psychoanalytic Movement. (London, 1985).

Erving Goffman, The Presentation of Self in Everyday Life. (New York, Doubleday, 1959).

Erving Goffmann, Role Distance, p.85-152 in Encounters: Two Studies in the Sociology of Interaction. (Indianapolis, The Bobbs-Merrill Co. Inc., 1961). 
Steven L. Gordon, Social Structural Effects on Emotions p.145179 in (Theodore D. Kemper, ed.) Research Agendas in the Sociology of Emotions. (New York, State University of New York Press, 1990).

Scott Greer, The Logic of Social Inquiry (2nd ed.)

(New Brunswick, N.J., Transaction Publishers, 1989).

Michael Hammond, Affective Maximization: A New Macro-Theory in the Sociology of Emotions p.58-81 in (Theodore D. Kemper, ed.) Research Agendas in the Sociology of Emotions.

(New York, State University of New York Press, 1990).

David R. Heise, Affect Control Model: Technical Appendix p.271-280 in (Theodore D. Kemper, ed.) Research Agendas in the Sociology of Emotions. (New York, State University of New York Press, 1990).

J. Hewitt and R. Stokes. (1978). "Disclaimers" p.308-19 in (J. Manis and B. Meltzer, eds.) Symbolic Interactionism (3rd ed.) (Boston, Allyn and Brown, Inc., 1978).

Arlie Russell Hochschild, The Managed Heart.

(Berkely, University of California Press Ltd., 1983).

Arlie Russell Hochschild, The Second Shift: Working Parents and the Revolution at Home. (New York, Viking-Penguin, 1989).

Arlie Russell Hochschild, Ideology and Emotion Management: A Perspective and Path For Future Research p.117-142 in (Theodore D. Kemper, ed.) Research Agendas in the Sociology of Emotions. (New York, State University of New York Press, 1990).

Judith A. Howard, Introduction: The Self-Society Dynamic, p.117 in (Judith A. howard and Peter L. Callero, eds.) The SelfSociety Dynamic: Cognition, Emotion, and Action. (New York, Cambridge University Press, 1991).

Judith A. Howard, From Changing Selves Toward Changing Society, p.209-237 in (Judith A. Howard and Peter L. Callero, eds.) The Self-Society Dynamic: Cognition, Emotion, and Action. (New York, Cambridge University Press, 1991).

Francis L.K. Hsu, Americans and Chinese: Reflections on Two Cultures and Their People. (New York, Doubleday Natural History Press, 1972).

Everett C. Hughes, "Dilemmas and Contradictions of Status" American Journal of Sociology L (March 1945), 353-359. 
David Hume, A Treatise of Human Nature (Vol. 2)

(London, J.M. Dent and Sons Ltd., 1974).

Institute For Social Research Newsletter.

(University of Michigan, 2:2, Summer 1974, p.4.

John Irwin, "Surfing: The History of a Deviant Scene."

(Manuscript, San Francisco State College, 1970).

Jerry Jacobs, "Symbolic Bureaucracy: A Case Study of a Social Welfare Agency" Social Forces 47: 413-422 (June 1969).

William James, Principles of Psychology.

(New York, Henry Holt, 1890).

C.M. Judd and J.A. Kulik (1980) "Schematic Effects of Social Attitudes on Information Processing and Recall," Journal of Personality and Social Psychology 38: 569-578.

Jack Kapica, "Study Finds Religion Fount of Happiness." Globe and Mail, Wednesday, August 12, 1992, p.A6.

Charlotte Davis Kasl, women, Sex, and Addiction. (New York, Ticknor and Fields, 1989).

Theodore D. Kemper, A Social Interactional Theory of Emotions. (New York, Wiley, 1978).

Theodore D. Kemper, (ed.) Research Agendas in the Sociology of Emotions. (New York, State University of New York Press, 1990).

Theodore D. Kemper, Social Relations and Emotions: A Structural Approach p.207-237 in (Theodore D. Kemper, ed.) Research Agendas in the Sociology of Emotions. (New York, State University of New York Press, 1990).

Theodore D. Kemper, Introduction: Themes and Variations in the Sociology of Emotions p.3-23 in (Theodore D. Kemper, ed.) Research Agendas in the Sociology of Emotions. (New York, State University of New York Press, 1990).

R.C. Kessler and J.D. Mcleod, Social Support and Mental Health in Community Samples, p.219-240 in (S. Cohen and S.L. Syme, eds.) Social Support and Health. (New York, Academic Press, 1985). 
John I. Kitsuse, Societal Reaction to Deviant Behavior, p.1320 in (E. Rubington and M.S. Weinberg, eds.) Deviance: The Interactionist Perspective. (Fifth Edition) (New York, MacMillan Publishing Company, 1987).

Lesak Kolokowski, The Alienation of Reason: A History of Positivist Thought. (New York, Doubleday Anchor Books, 1969).

Mark Krain, "On Staying Loose: Task Avoidance in the U.S. Army Reserve." (Manuscript, University of Michigan, 1967).

Thomas S. Kuhn, The Structure of Scientific Revolutions. (2nd ed.) (Chicago, University of Chicago Press, 1970).

R.G. Landry and E.M. Pardew, "Self-Concept Enhancement of Preschool Children." (Paper presented at the Annual Meeting of the American Educational Research Association, New Orleans, February, 1973).

P.M. Lewinsohn, W. Mischel, W. Chaplin, \& R. Barton (1980), "Social Competence and Depression: The Role of Illusory SelfPerceptions." Journal of Abnormal Psychology 89: 203-212.

J. David Lewis. (1979). "A Social Behaviorist Interpretation of the Meadian "I" American Journal of Sociology 85:261-285.

P.W. Linville (1987), "Self-Complexity as a Cognitive Buffer Against Stress-Related Illness and Depression" Journal of Personality and Social Psychology 52: 663-676.

John Lofland, Analyzing Social Settings: A Guide to oualitative Observation and Analysis. (Belmont, CA., Wadsworth Publishing Company, 1971).

Lyn $H$. Lofland, In the presence of Strangers: A Study of Behavior in Public settings. (Working Paper No.19 of the Center for Research on Social Organization, University of Michigan, 1966).

Catherine Lutz, Unnatural Emotions: Everyday Sentiments on a Micronesian Atoll and Their Challenge to Western Theory.

(Chicago, University of Chicago Press, 1988).

David R. Maines, Noreen M. Sugrue and Michael A. Katovich. (1983). "The Sociological Import of G.H. Mead's Theory of the Past." American Sociological Review 48:161-173. 
S. Marks (1977), "Multiple Roles and Role Strain: Some Notes on Human Energy, Time, and Commitment" American Sociological Review 42 : $921-936$.

H. Markus (1977) "Self-Schemata and Processing Information About the Self." Journal of Personality and Social Psychology 35: $63-78$.

H. Markus and $K$. Sentis, The Self in Social Information Processing, $\mathrm{p} .41-70$ in (J. Suls, ed.) Psychological Perspectives on the Self. (Hillsdale, NJ., Erlbaum, 1982).

H. Markus and J. Smith, The Influence of Self-Schemata on the Perception of others, p.233-262 in (N. Cantor and $J$. Kihlstrom, eds.) Personality, Cognition, and social Interaction. (Hillsdale, NJ., Erlbaum, 1981).

H. Markus and R.B. Zajonc, The Cognitive Perspective in Social Psychology, p.137-230 in (Gardner Lindzey and Elliot Aronson, eds.) The Handbook of Social Psychology (Third Edition) (New York, Random House, 1985).

William H. Masters and Virginia E. Johnson, in association with Robert J. Levin, The Pleasure Bond. (Boston, Little, Brown., 1974).

George J. McCall and J.L. Simmons, Identities and Interactions (Revised Edition) (New York, The Free Press, 1978).

V.J. McGill, The Idea of Happiness.

(New York, Frederick A. Praeger, 1967).

George Herbert Mead. (1912). "The Mechanism of Social Consciousness." Journal of Philosophy 9:401-6.

George Herbert Mead. (1923). "Scientific Method and the Moral Sciences." International Journal of Ethics 33:224-47.

Bernard N. Meltzer, John W. Petras and Larry T. Reynolds, Symbolic Interactionism: Genesis, Varieties and Criticism.

(Boston, Routledge and Kegan Paul Ltd., 1975).

Robert K. Merton, Social Theory and Social structure. (Revised Edition) (New York, The Free Press, 1957).

John Stuart Mill, Autobiography.

(London, Oxford University Press, 1924). 
C. Wright Mills. (1940). "Situated Actions and Vocabularies of Motives" American Sociological Review 5:904-13.

Robin Norwood, Women Who Love Too Much.

(New York, Pocket Books, 1985).

Paula Nurius, Possible Selves and Social Support: Social Cognitive Resources for Coping and Striving, p.239-258 in (Judith A. Howard and Peter I. Callero, eds.) The Self-Society Dynamic: Cognition, Emotion, and Action. (New York, Cambridge University Press, 1991).

Roger O'Toole, The Precipitous Path: Studies in Political Sects.

(Toronto, Peter Martin Associates Ltd.,1977).

Plato, Phaedo, in The Dialogues of Plato.

(B. Jowett, ed.).

Plato, Symposium, in The Dialogues of Plato.

(B. Jowett, ed.).

Plotinus, The Enneads.

M.K. Potts, The Effects of Role Multiplicity on Health status, Illness Rates, and Illness Behavior in Men and Women: A Test of the Scarcity and Expansion Hypothesis. (Unpublished doctoral dissertation, Purdue University, West Lafayette, IN., 1987).

Vernon Pratt, The Philosophy of the Social sciences. (London, Methuen and Co. Ltd., 1978).

J.P. Robinson and P.R. Shaver, Measures of Social Psychological Attitudes. (Ann Arbor, Michigan, Institute For Social Research, 1978).

Morris Rosenberg, Conceiving the Self.

(New York, Basic Books, Inc., 1979).

Morris Rosenberg, Self-Processes and Emotional Experiences, p.123-142 in (Judith A. Howard and Peter L. Callero, eds.) The Self-Society Dynamic: Cognition, Emotion, and Action. (New York, Cambridge University Press, 1991).

Julius A. Roth, Timetables: Structuring the Passage of Time in Hospital Treatment and other Careers. (Indianapolis, BobbsMerrill Co., 1963). 
Bertrand Russell, The Conquest of Happiness.

(London, Unwin Hyman Ltd., 1989).

Gilbert Ryle, Concept of Mind, extract p.252-263 in (Chesire Calhoun and Robert C. Solomon, eds.) What is an Emotion?: Classic Readings in Philosophical Psychology.

(New York, Oxford University Press, 1984).

Jean-Paul Sartre, The Emotions, extract p.244-50 in (Chesire Calhoun and Robert C. Solomon, eds.) What is an Emotion?: Classic Readings in Philosophical Psychology.

(New York, Oxford University Press, 1984).

Jean-Paul Sartre, No Exit in No Exit and Three Other Plays. (New York, Vintage Books, 1955).

Thomas J. Scheff, Microsociology: Discourse, Emotion, and Social Structure. (Chicago, University of Chicago Press, 1990).

Thomas J. Scheff, Socialization of Emotions: Pride and Shame as Causal Agents p.281-304 in (Theodore D. Kemper, ed.) Research Agendas in the Sociology of Emotions. (New York, State University of New York Press, 1990).

Max Scheler, Formalism in Ethics and Non-Formal Ethics of Values extract p.215-28 in (Chesire Calhoun and Robert C. Solomon, eds.) What is an Emotion?: Classic Readings in Philosophical Psychology. (New York, Oxford University Press, 1984).

Edwin M. Schur, Women and Appearance Norms, p.57-61 in (E. Rubington and M.S. Weinberg, eds.) Deviance: The Interactionist Perspective. (Fifth Edition) (New York, MacMillan Publishing Company, 1987).

Michael L. Schwalbe, Social structure and the Moral self, p.281-303 in (Judith A. Howard and Peter L. Callero, eds.) The Self-Society Dynamic: Cognition, Emotion, and Action. (New York, Cambridge University Press, 1991).

M. Scott and S. Lyman, "Accounts."

American Sociological Review 33:46-62.

Diana Scully and Joseph Marolla, Rapists Vocabulary of Motives, p.340-351 in (E. Rubington and M. Weinberg, eds.) Deviance: The Interactionist Perspective. (5th ed.)

(New York, MacMillan Publishing Co., 1987). 
C.E. Sears, Days of Delusion - A Strange Bit of History.

(New York, Houghton Mifflin Co., 1924).

Richard T. Serpe, The Cerebral Self: Thinking and Planning About Identity-Relevant Activity. p.55-73 in (Judith A. Howard and Peter L. Callero, eds.) The Self-Society Dynamic: Cognition, Emotion, and Action. (New York, Cambridge University Press, 1991).

S.D. Sieber (1974), "Toward a Theory of Role Accumulation" American Sociological Review 39: 567-578.

Sue Klavans Simring and steven S. Simring, The Compatibility Quotient. (New York, Fawcett Columbine, 1990).

Lynn Smith-Lovin, Emotion as the Confirmation and Disconfirmation of Identity: An Affect Control Model p.238-270 in (Theodore D. Kemper, ed.) Research Agendas in the Sociology of Emotions.

(New York, State University of New York Press, 1990).

Lynn Smith-Lovin, An Affect Control View of Cognition and Emotion p.143-70 in (Judith A. Howard and Peter L. Callero, eds.) The Self-society Dynamic: Cognition, Emotion, and Action.

(New York, Cambridge University Press, 1991).

Robert C. Solomon, Emotions and Choice p.305-26 in (Chesire Calhoun and Robert C. Solomon, eds.) what is an Emotion?: Classic Readings in Philosophical Psychology.

(New York, Oxford University Press, 1984).

Benedict Spinoza, Ethics extract p.71-92 in (Chesire Calhoun and Robert C. Solomon, eds.) What is an Emotion?: Classic Readings in Philosophical Psychology.

(New York, Oxford University Press, 1984).

Anthony Storr, Solitude.

(London, Collins Publishing Group, 1988).

Sheldon Stryker (1987) Identity Theory: Developments and Extensions p.89-104 in (Krysia Yardley and Terry Honess, eds.) Self and Identity: Psychosocial Perspectives. (Chichester, U.K.: Wiley, 1987). 
Sheldon Stryker, Exploring the Relevance of Social Cognition for the Relationship of Self and Society: Linking the Cognitive Perspective and Identity Theory. p.19-41 in (Judith A. Howard and Peter L. Callero, eds.) The Self-Society Dynamic: Cognition, Emotion, and Action. (New York, Cambridge University Press, 1991).

W.B. Swann, Self-Verification: Bringing Social Reality into Harmony With the Self, p.33-66 in (J. Suls and A.G. Greenwald, eds.) Psychological perspectives on the self (Vol. 2) (Hillsdale, NJ., Erlbaum, 1983).

W.B. Swann and S.J. Reid (1981), "Self-Verification Processes: How We Sustain our Self-Conceptions." Journal of Experimental Social Psychology 17: 351-372.

Laurie Taylor, Vocabularies, Rhetorics and Grammar: Problems in the Sociology of Motivation p.145-61 in (D. Downes and P. Rock, eds.) Deviant Interpretations.

(New York, Harper and Row, 1979).

Shelley E. Taylor and Jonathan D. Brown (1988), "Illusion and Well-Being: A Social Psychological Perspective on Mental Health."

Psychological Bulletin 103: 193-210.

Elizabeth Telfer, Happiness.

(London, The MacMillan Press Ltd.,1980).

Howard Tennen and Sharon Herzberger (1987), "Depression, SelfEsteem, and the Absence of Self-Protective Attributional Biases."

Journal of Personality and Social Psychology 52: 72-80.

P.A. Thoits (1983), "Multiple Identities and Psychological Well-Being: A Reformulation and Test of the Social Isolation Hypothesis" American Sociological Review 48: 174-187.

Peggy A. Thoits, Emotional Deviance: Research Agendas p.180203 in (Theodore D. Kemper, ed.) Research Agendas in the Sociology of Emotions. (New York, State University of New York Press, 1990).

W.I. Thomas and D.S. Thomas, The Child in America.

(New York, Alfred A. Knopf, 1928).

Paul Tillich, Love, Power and Justice. 
Ralph H. Turner, "The Navy Disbursing Officer as a Bureaucrat" American Sociological Review 12: 342-348 (June 1947).

Ralph $\mathrm{H}$. Turner, "The Real Self: From Institution to Impulse," (1976) American Journal of Sociology 81: 989-1016.

Ralph H. Turner and Victoria Billings, The Social Contexts of Self-Feeling, p.103-122 in (Judith A. Howard and Peter L. Callero, eds.) The Self-Society Dynamic: Cognition, Emotion, and Action. (New York, Cambridge University Press, 1991).

R.J. Turner, Direct, Indirect, and Moderating Effects of Social Support on Psychological Distress and Associated Conditions. in (H.B. Kaplan, ed.) Psychological stress: Trends in Theory and Research. (New York, Academic Press, 1983).

Ruut Veenhoven, Conditions of Happiness.

(Boston, D. Reidel, 1984).

L. Verbrugge (1983), "Multiple Roles and Physical Health of Women and Men" Journal of Health and Social Behavior 24: 1630 .

Rita Volkman and Donald R. Cressey, Drug Rehabilitation, p.156-173 in (M.S. Weinberg, E. Rubington, and S.K. Hammersmith, eds.) The Solution of Social Problems: Five Perspectives. (Second Edition) (New York, Oxford University Press, 1981).

Alan W. Watts, The Meaning of Happiness.

(New York, Harper Colophon Books, 1979).

Robert $S$. Weiss, Attachment in Adult Life, p.171-184 in (C. Murray Parkes and J. Stevenson-Hinde, eds.) The Place of Attachment in Human Behavior. (New York, Basic Books Inc., 1982).

G.H. Von Wright, The Varieties of Goodness.

(London, Routledge and Kegan Paul, 1963).

Michael R. Wood and Louis A. Zurcher, Jr., The Development of a Postmodern Self: A Computer-Assisted Comparative Analysis of Personal Documents. (New York, Greenwood Press, 1988).

Louis A. Zurcher, Jr., The Mutable Self.

(Beverly Hills, CA., Sage, 1977).

Louis A. Zurcher (1982), "The staging of Emotion: A Dramaturgical Analysis." Symbolic Interaction 5(1), 1-22. 